\title{
WestVirginiaUniversity
}

THE RESEARCH REPOSITORY @ WVU

Graduate Theses, Dissertations, and Problem Reports

2021

\section{Implications of Fraud Detection Decisions}

\author{
Marie Rice \\ West Virginia University, mmr0016@mix.wvu.edu
}

Follow this and additional works at: https://researchrepository.wvu.edu/etd

Part of the Accounting Commons

\section{Recommended Citation}

Rice, Marie, "Implications of Fraud Detection Decisions" (2021). Graduate Theses, Dissertations, and Problem Reports. 8314.

https://researchrepository.wvu.edu/etd/8314

This Dissertation is protected by copyright and/or related rights. It has been brought to you by the The Research Repository @ WVU with permission from the rights-holder(s). You are free to use this Dissertation in any way that is permitted by the copyright and related rights legislation that applies to your use. For other uses you must obtain permission from the rights-holder(s) directly, unless additional rights are indicated by a Creative Commons license in the record and/ or on the work itself. This Dissertation has been accepted for inclusion in WVU Graduate Theses, Dissertations, and Problem Reports collection by an authorized administrator of The Research Repository @ WVU.

For more information, please contact researchrepository@mail.wvu.edu. 


\title{
Implications of Fraud Detection Decisions
}

\author{
Marie Rice \\ Dissertation submitted \\ to the John Chambers College of Business and Economics \\ at West Virginia University \\ in partial fulfillment of the requirements for the degree of \\ Doctor of Philosophy in \\ Business Administration - Accounting \\ D. Kip Holderness, Jr., Ph. D., Chair \\ Richard B. Dull, Ph. D. \\ A. Scott Fleming, Ph. D. \\ Lisa M. Dilks, Ph. D. \\ Department of Accounting \\ Morgantown, West Virginia \\ 2021
}

Keywords: Occupational fraud, emotion regulation, punishment, management controls Copyright 2021 Marie Rice 


\section{Abstract \\ Implications of Fraud Detection Decisions}

\section{Marie Rice}

This dissertation is comprised of three studies that examine the implications of fraud detection decisions. The first study examines whether auditors' mindfulness practices influence their ability to accurately detect fraud risk factors. The second study evaluates whether organization type influences whether and how perpetrators are punished. The third study evaluates whether management's decision to increase controls when fraud occurs has unintended negative consequences for other employees. Together, these studies contribute to accounting literature related to fraud detection.

Study one evaluates the effects of mindfulness practices (i.e. emotion regulation) on auditors' ability to identify and accurately recall fraud risk factors in audit evidence. Emotion regulation strategies have differing effects on cognitive load that may impact auditors' ability to identify fraud risk factors and recall details about fraud risk factors. Auditors use prompts to further enhance their ability to identify fraud risks. This study finds that emotion regulation strategy does not affect the ability to identify fraud risk factors or the ability to recall fraud risk factors. However, this study highlights variance in the effectiveness of prompts, which are relied upon in audit process as a tool to increase focus but have also been shown to increase cognitive load in psychology literature. For example, Amazon Mechanical Turk participants who are prompted to be mindful of discrepancies within financial information less accurately identify such discrepancies (i.e. fraud risk factors) as compared to those who do not receive a prompt. Students, on the other hand, are more likely to identify fraud risk factors when prompted to do so. Suggestions for future research are provided to expand on this finding.

In study two, we use the ACFE survey data to examine the impact of fraud severity and the perpetrator's status and organization type on the victim organization's decisions in pursuing an outcome against the principal perpetrator. We find that as fraud severity increases, the severity of the outcome pursued against the principal perpetrator increases as well. Supporting status characteristics theory, we also show that victim organizations pursue less severe outcomes against a perpetrator with a high status as compared to a perpetrator with a low status when the duration of the fraud is short. As the fraud duration increases, however, victim organizations pursue equally severe outcomes against all perpetrators. Lastly, governmental, not-for-profit, and privately held organizations are more likely to pursue no outcome than to terminate the principal perpetrator, as compared to publicly traded organizations. Further, governmental and not-for-profit organizations are more likely to terminate and criminally prosecute than just terminate the principal perpetrator.

In study three, we examine potential unintended consequences when fraud, such as employee theft, is detected. Management teams often increase or modify formal controls when fraud, such as employee theft, is detected. However, doing so may have unintended consequences for the perpetrator's coworkers. For example, affective event theory explains that when employees believe that the response is unfair, they become counterproductive, reducing the firm's overall productivity. We test whether theft by a coworker reduces non-offending employee productivity using a two-period experiment with groups of two employees and one manager. Employees can steal each period and, if theft is detected in period one, managers can increase detection for all employees in period two. We find that two out of three managers increase inspections for all employees, even without incentive to do so. Further, we find that employees' affect intensity and ability to be influenced by others are related to their levels of productivity and likelihood of taking in period 1 but not taking in period 2 . 


\section{Dedication}

I dedicate this dissertation to my family, "framily," and friends who endeavored to take this journey with me. I am especially grateful to my mother, husband, children, and grandchildren for their love, support, and willingness to uproot their lives and take this adventure. Together we persevered, met every challenge that came our way, celebrated as our family grew, and found our way through to a new chapter in our lives. This dissertation represents a period in our lives that has shaped our path forward. I love you all and am truly appreciative of your support. As we all move forward, I hope that you look back on this time with a grateful heart, as I do. On to new adventures! 


\section{Acknowledgements}

I gratefully acknowledge the time, attention, advice, and counsel I received from the faculty at West Virginia University, my co-authors, external advisors, and fellow PhD students.

This dissertation is a culmination of the advice, counsel and support I received from the WVU faculty, particularly Dr. Kip Holderness, Jr. , Dr. Rick Dull, Dr. Scott Fleming, Dr. Richard Riley, Jr. and Dr. Lisa Dilks. As my chair, Kip spent countless hours providing feedback on various projects, some of which are included in this dissertation, as well as counsel on the academic profession. His specific guidance always helped me improve and learn. Similarly, Rick's time, counsel, and advice has been invaluable. I am so grateful for the opportunities he gave me to use my strengths, while guiding me through the research process. Reflecting on the helpful guidance and advice I received over the past few years reminds me of the quips Scott and Dr. Riley always have ready, whether it be "Simplify it," or "If you can't draw it, you don't understand it," their comments and advice have always helped me improve my research. Dr. Dilks inspires and challenges me with her enthusiasm, positive outlook and helpful, specific feedback. I have so enjoyed learning from her and receiving her advice and counsel through these years. Several other WVU faculty members have inspired and advised me during my tenure and I'm grateful for the guidance and support I have received; it is truly a wonderful place to learn and grow! Let's Go Mountaineers!

I would be remiss if I did not acknowledge my former colleagues at Gonzaga University, particularly Dr. Matt Hoag, Dr. Dan Law, Dr. Paul Buller, Dr. Andrew Brajcich, and Dr. Sara Kern, who inspired me to pursue a PhD, and supported me before and during the process. I especially thank Dr. Gary Weber, my mentor and esteemed advisor, for his time and guidance over the years. I truly would not have taken this journey had it not been for all of them! Thank you for motivating me to pursue my dream!

I sincerely thank all whom I have mentioned here and the countless others who have influenced my journey. There aren’t enough pages to truly thank you all properly. 
CHAPTER ONE -INTRODUCTION. 1

CHAPTER TWO - CURSE OF THE POKER FACE: THE EFFECTS OF MINDFULNESS ON AUDITORS' ABILITY TO IDENTIFY FRAUD RISK FACTORS ............................................. 6

ABSTRACT ........................................................................................................................................................................

INTRODUCTION

BACKGROUND AND HYPOTHESIS DEVELOPMENT .....................................................................................11

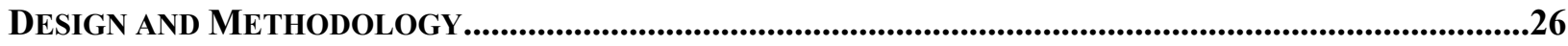

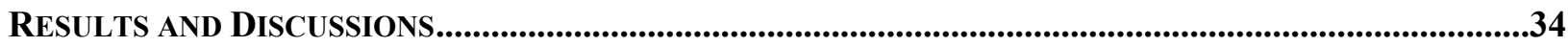

CONTRIBUTIONS, LIMITATIONS, AND SUGGESTIONS FOR FUTURE RESEARCH....................................56

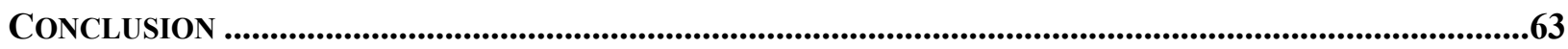

FIGURES AND TABLES .......................................................................................................................................65

APPENDIX A: FRAUd FIRM SOURCE MATERIALS......................................................................................95

APPENDIX B: EXPERIMENTAL DeSIGn, EXPERT PANel PROCESS ......................................................104

APPENDIX C: FINAL LIST OF DISCREPANCIES AND ADDITIONAL TESTS SELECTED.............................105

APPENDIX D: EXPERIMENTAL DESIGN.........................................................................................................106

APPENDIX E: INSTRUCTIONS FOR PARTICIPANTS ........................................................................................108

Appendix F: Experimental Materials, Seen by All Participants after Assignment ........110

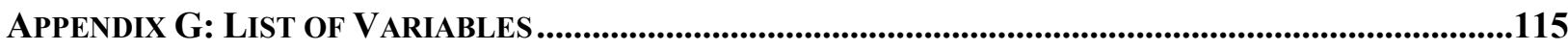

CHAPTER THREE - THE FRAUD GOES ON: THE EFFECTS OF FRAUD DURATION, VICTIM ORGANIZATION TYPE AND PERPETRATOR STATUS ON PUNISHMENT ...............................117

ABSTRACT .....................................................................................................................................................................118

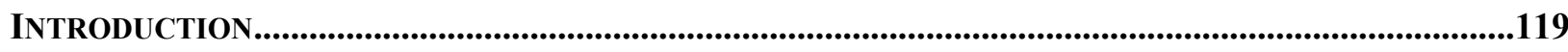

THEORETICAL BACKGROUND AND HYPOTHESIS DEVELOPMENT....................................................122

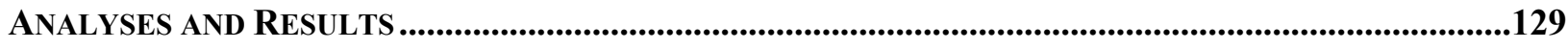

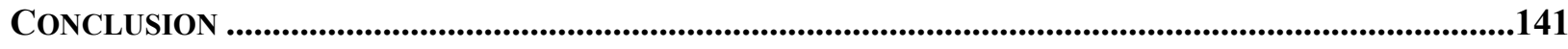

FIGURES AND TABLES ....................................................................................................................................144 


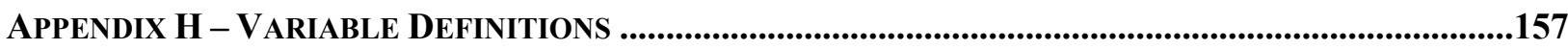

CHAPTER FOUR - SPILLOVER EFFECTS OF MANAGEMENT'S RESPONSE TO FRAUD ....... 160

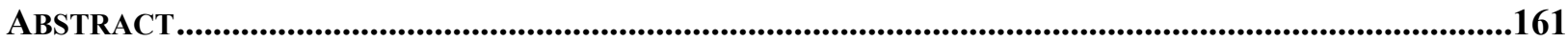

INTRODUCTION

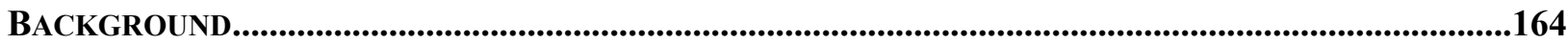

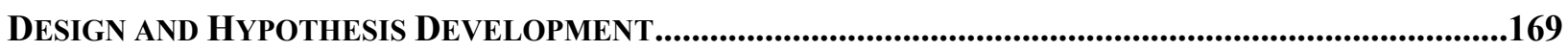

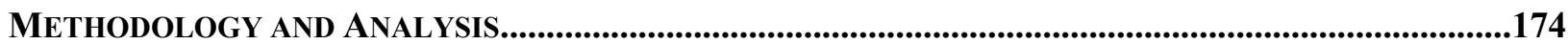

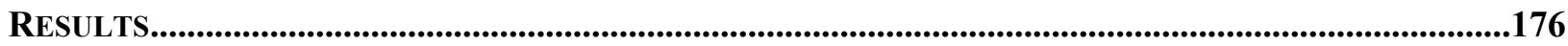

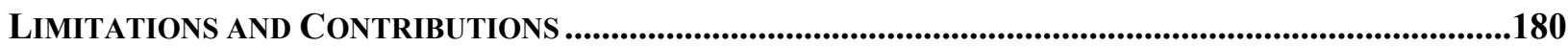

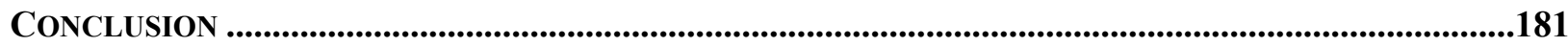

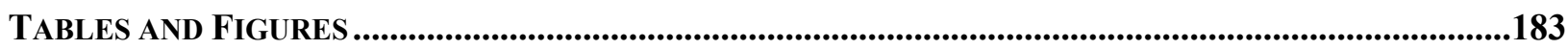

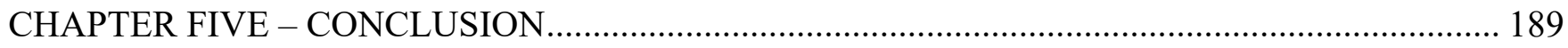

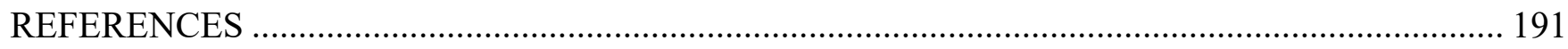




\section{CHAPTER ONE -INTRODUCTION}

Occupational fraud has a significant effect on organizations and contributes to approximately thirty percent of business failures in the United States annually (Lipman and McGraw 1998; Snyder and Blair 1989; Marasi, Bennet, and Budden 2018), generating a nontrivial impact to the economy. Thirty-three percent of retail, manufacturing, and service employees surveyed self-reported stealing from their employer (Clark and Hollinger 1983). To combat occupational fraud, organizations decide how to train auditors to detect fraud, whether to punish the perpetrator, and/or whether to increase the likelihood of detecting other perpetrators' frauds in the future. Whether organizations detect fraud and how they address fraud is an important empirical question because of the organizational and economic implications. This dissertation examines these decisions in experimental or archival studies.

Auditors work in high stress, high client interaction environments and often face contentious situations (Bergner, Peffer, and Ramsay 2016) that lead to high turnover intention (Parker and Kohlmeyer 2005). To deal with this environment, auditors engage in self-preservation and self-regulatory mechanisms to manage their emotional reactions. However, the coping mechanism they employ impacts their ability to recall details (Gross 2002). In study one, I conduct a $3 \times 2$ experimental design, manipulating the type of emotion regulation strategy an auditor may deploy and whether the participant is prompted to focus on inconsistencies in audit evidence, proxies for potential fraud risk factors. I measure the number of fraud risk factors identified ("Quantity"), as proxied by inconsistencies in information between pieces of audit evidence, and the accuracy with which fraud risk factors are described (“Accuracy”). Results show that emotion regulation strategy does not affect the ability to identify fraud risk factors or accurately recall fraud risk factors identified, regardless of whether there are prompts to identify such factors. 
However, participants within different sample pools react to the study's manipulations in different ways. For example, Amazon Mechanical Turk ("mTurkers") participants identify more fraud risk factors (proxied by discrepancies within financial documents) when they are not prompted to do so, as compared to when they are prompted to do so while graduate students (“Grads") more accurately identify fraud risks when they are prompted to do so. This finding is interesting and adds to a body of audit literature that finds that prompts are effective tools to increase focus (e.g. Brazel, Jones, and Prawitt 2014; Hammersley, Carpenter, and Bamber 2010). It further highlights findings in psychology literature that prompts increase cognitive load and may have unintended consequences. These differences may be due to cognitive processing or construct relevance. However, graduate students are less familiar with mindfulness and may redirect their cognitive load toward the experimental task instead of the emotion regulation strategy to which they were assigned. This study contributes to audit literature by highlighting potential boundary conditions with the use of prompts and offering recommendations for future research.

When fraud is detected, organizations choose whether and how to punish perpetrators involved in fraud schemes. Prior literature shows that punishment severity is correlated with crime severity (Wolfgang, Figlio, Tracy, and Singer1985) and differs by the victims' and perpetrators' characteristics (Albonetti 1998; Wheeler et al. 1988; Hagan and Parker 1985). In study two, we examine the impact of fraud severity, the perpetrator's status, and the organization type on the victim organization's decision to pursue an outcome against the principal perpetrator. To our knowledge, no prior study has examined these interactions in an occupational fraud setting. We find that as fraud severity increases, the severity of the outcome pursued against the principal perpetrator increases as well. However, victim organizations pursue less severe outcomes against high status perpetrators, as compared to low status perpetrators in fraud cases with a short duration. 
As the fraud duration increases, however, victim organizations pursue equally severe outcomes against all perpetrators. Lastly, governmental, not-for-profit, and privately held organizations are more likely to pursue no outcome against principal perpetrators as compared to publicly traded organizations. However, governmental, and not-for-profit organizations are more likely to terminate and criminally prosecute the principal perpetrators, pursuing harsher outcomes. We conclude that fraud outcome is determined not only by the severity of the fraud act, but also by the status of the perpetrator who committed the fraud and the type of the victim organization. This study contributes to fraud literature by providing a multivariate analysis of fraud punishments and adds to literature on executive fraud.

After fraud is detected and the perpetrator is punished, organizations often make changes to prevent recurrence, but these changes have a spillover effect on the perpetrator's coworkers. For example, managers may use formal controls, such as inspections of employees' work, to increase workplace conformity (Bedford, Malmi, and Sandelin 2016) and to punish workplace deviance (Parilla, Hollinger, and Clark 1988), like employee theft. However, increased controls may negatively impact employees who are not engaged in wrongdoing and may perceive the inspections to be an unfair punitive or threatening action against them (Chenhall, Hall, and Smith 2010; Penney and Spector 2005).

Counterproductive workplace behavior occurs when employees seek retribution against the organization for the perceived unfair treatment. Contrarily, if management chooses to not punish fraud by increasing controls, employees who do not commit fraud may later engage in fraud. In study three, we examine the effects of managers' use of formal controls to increase detection of fraud in future periods on employee productivity. To evaluate coworker productivity and management's response to fraud, we conduct a two-round experiment with groups of four 
participants, including one manager and two employees. Both roles, manager, and employee, are explained to all participants. In each round, employees choose how many hours of their 40-hour work week to contribute toward company productivity and whether they will take $\$ 0.50$ from the investment fund. In round one, managers inspect one employee's decisions. If the manager observes an employee take from the investment fund, they may choose to increase inspections in round two from one employee to two employees. We find that two out of every three managers will increase controls for all employees when fraud is detected, even when not incented to do so. Further, we find that participants' affect intensity and ability to be influenced by others are related to their productivity and whether they will take from the investment fund in period 1 . However, this finding does not hold in period 2. This study contributes to managerial controls and fraud literature by evaluating the effects of management's decisions in response to fraud on the perpetrator's coworkers.

Addressing and managing fraud is an important component of organizational risk management as fraud can result in both economic and human capital damage. This dissertation examines three stages of fraud risk management: detecting fraud, issuing punishment to the perpetrator, and managing the effects of changes to the environment after fraud is detected using three separate studies. A conceptual model is shown in Figure 1.

$$
\text { --Insert Figure 1- }
$$

This dissertation provides suggestions for future research to further explore these concepts. 


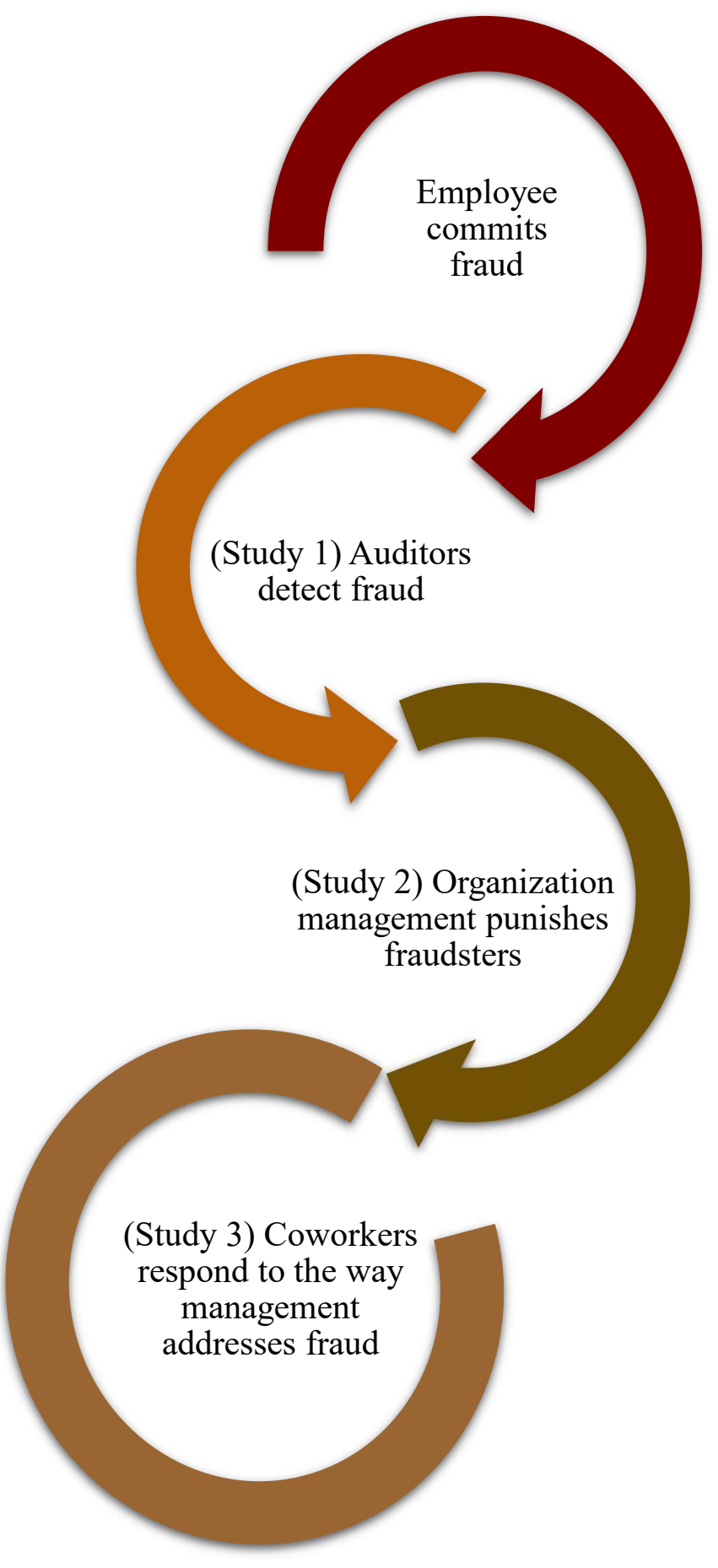




\title{
CHAPTER TWO - CURSE OF THE POKER FACE: THE EFFECTS OF MINDFULNESS ON AUDITORS’'ABILITY TO IDENTIFY FRAUD RISK FACTORS
}

\author{
Marie M. Rice \\ John Chambers College of Business, West Virginia University \\ mmr0016@mix.wvu.edu
}

\begin{abstract}
Author Note
Submitted in partial fulfillment of Ms. Rice's requirements for the degree of Doctor of Philosophy in Accounting at West Virginia University. The corresponding author may be reached atmmr0016@mix.wvu.edu.
\end{abstract}




\begin{abstract}
The present study evaluates the effects of mindfulness practices (e.g. emotion regulation) on auditors' ability to identify and accurately recall fraud risk factors in audit evidence. Auditors work in a contentious environment and use coping mechanisms, such as mindfulness, to deal with the negative effects. Mindfulness practices are a fast-growing trend and include emotion regulation. Emotion regulation strategies have differing effects on cognitive load that may impact auditors' ability to identify fraud risk factors and recall details about fraud risk factors. Auditors use prompts to further enhance their ability to identify fraud risks. While I find that emotion regulation strategy does not affect the ability to identify fraud risk factors or the ability to accurately recall fraud risk factors, this study contributes to audit literature by showing that prompts have varying effects for participant proxies used in audit research. Amazon Mechanical Turk ("mTurk") participants are more accurate when not prompted than when they are given a prompt, but graduate students are more accurate when prompted than not. Overall, the two groups are similarly accurate in their identification of fraud risk factors. These sample groups also differ in the amount of time spent on the study, familiarity with mindfulness, and years of experience. Future studies should examine these attributes and their effect on the usefulness of prompts in an audit setting.
\end{abstract}

Keywords: mindfulness, emotion regulation, audit, fraud 


\section{INTRODUCTION}

Auditors work in high stress, high workload (Persellin, Schmidt, Vandervelde, and Wilkins 2014), high client interaction environments and often face contentious situations (Bergner, Peffer, and Ramsay 2016) that lead to burnout (Herda and Lavelle 2012), low organizational commitment, and high turnover intention (Parker and Kohlmeyer 2005; Greenhaus, Collins, Singh, and Parasuraman 1997). During the COVID-19 pandemic, these challenges have been further increased by the necessity to work from home while caring for family members (NF1 2021; Antonova, Schlosser, Pandey, and Kumari 2021; Conversano et al. 2020; Katella 2020; Saricali, Satici, Satici, Gocet-Tekin, and Griffiths 2020). The pressures auditors face may result in premature workpaper signoff (Herda, Cannon, and Young 2018 a,b), unauthorized reduced sample sizes, or underreported time (Sweeney and Pierce 2006). To combat the effects of the pressures and to reduce stress (Anderson 2020), auditors engage in self-preservation and self-regulatory mechanisms to manage their own reactions in social interactions with each other, supervisors, and clients to facilitate successful interpersonal relationships. Such coping mechanisms improve work relationships and enable auditors to accomplish organizational goals (Jeung, Kim, and Chang 2018), including providing quality audit services.

Recent trends in public accounting and large corporations (e.g. Aetna, Google, Amazon, SAP, and Thomson Reuters) highlight the importance of mindfulness as such a coping mechanism. Mindfulness has been shown to improve focus (Fisher 2020), decision-making, and mental clarity (Brooks 2020; KPMG 2015). Mindfulness is the act of intentionally quieting one's mind to observe the present moment and environment, and to self-regulate one's responses to these observations (Bishop et al. 2004). Practicing mindfulness is a metacognitive process (Bishop et al. 2004) that increases focus, attention, the ability to regulate emotions and respond flexibly, and decreases 
reactivity (Davis and Hayes 2011). The ability to be mindful is a trait-level attribute that can be increased through state-level interventions and practices (Chang and Stone 2019; ), such as meditation and self-regulation. Mindfulness practices are a fast-growing trend and there are over 3.7 million related videos on YouTube (YouTube 2020) and devices like smartphones enable access to mindfulness tools. These applications and tools have become even more important during the COVID-19 pandemic, when mental health and wellness have been taxed. Albeit a popular trend, many individuals do not understand that the benefits of mindfulness, including decentered awareness of the present moment and increased attention to detail, are affected by the emotion regulation strategies deployed by individuals.

For instance, auditors may develop a "poker face" to ensure their physical reaction to stress or confrontation does not betray their actual, felt emotions (Butler, Wilhelm, and Gross 2006) in the workplace. Cambridge dictionary defines a poker face as "an expression on someone's face that does not show what they are thinking or feeling" (Cambridge 2020). While having a poker face can be very useful in the workplace (Waldron and Krone 1991), suppressing expressed emotion in this way also has unintended negative effects on the individual's working memory, including recall, and attention to detail (Gross 2002). For example, auditors' use of emotion suppression may reduce their ability to accurately identify fraud risk factors. Auditors may therefore benefit from an alternative emotion regulation strategy, cognitive reappraisal. The goal of cognitive reappraisal is to reframe negative situations into positives and its benefits include increased memory capacity and reduced felt negative emotions in conflict situations.

Prior industrial/organizational psychology and social psychology literature has studied the effects of emotion regulation on working memory and attention to detail (e.g. Good et al. 2016; Fiol and O'Connor 2003). Herda, et al. (2018 a,b) applies these concepts in the accounting realm by 
evaluating the effects of mindfulness on auditors' decision-making. Specifically, Herda, et al. (2018 a,b) find that auditors are less likely to engage in premature workpaper signoffs when they are prompted to be mindful of external financial statement users and that supervisors' prompts to be mindful reduce audit quality threatening behavior. This study extends Herda, et al. $(2018 \mathrm{a}, \mathrm{b})$ by prompting participants to consider discrepancies in financial information while they engage in an emotion regulation strategy ("ERS"), a specific mindfulness practice. Thus, while the prompt used in this study is like the one used in Herda, et al. $(2018 \mathrm{a}, \mathrm{b})$, the construct of mindfulness is more narrowly defined. Specifically, I conduct a $3 \times 2$ experiment, manipulating type of emotion regulation strategy and whether the participant is prompted, to assess the effect of ERS on auditors' ability to identify fraud risk factors present in financial statement information. I find that ERS does not affect the ability to identify fraud risk factors, as proxied by inconsistencies in information between pieces of audit evidence, or the accuracy of the fraud risk factor (i.e. recall quality). However, these findings may be confounded by the level of cognitive processing participants use during the task.

Audit practice attempts to address the conflict between the affect-inducing environment auditors face and the level of cognitive processing (Petty and Caciopo 1986) required for their tasks by using prompts, such as checklists, and instructions to focus auditors' attention to certain risks. Prior literature has shown that such prompts increase auditors' ability to identify inconsistencies between financial reporting documents (e.g. Hobson, Mayew, Peecher, and Venkatachalam2017; Brazel, et al. 2014; Trotman and Wright 2012; Asare and Wright 2004). However, prompts also invoke cognitive processing and can increase cognitive load (Block, Hancock, and Zakay 2010). Therefore, while prompts are helpful, their use may have unintended consequences. Participants in this study respond to prompts in differing manners. Specifically, prompted graduate student 
participants more accurately identify fraud risk factors (i.e. discrepancies in financial information) than those who are not prompted, but mTurkers are less accurate in identifying fraud risk factors when prompted than when not prompted. These differences may be due to the level of cognitive processing participants exhibit during the experiment, or participants' variance in familiarity with mindfulness. On average, the two participant groups are similarly accurate in the identification of fraud risk factors.

My study contributes to audit literature related to auditors' evaluation of audit evidence, particularly when primed, and audit firm management by offering additional considerations for the use and effectiveness of prompts as a tool for fraud detection with different subpopulations of accounting professionals. This finding is particularly timely, given an upcoming article in Auditing: A Journal of Practice and Theory on the use of non-professionals as audit judgment and decisionmaking research subjects (Leiby, Rennekamp, and Trotman 2021). My study provides further research opportunities that contribute to the growing body of psychosocial literature related to mindfulness and emotion regulation, such as when and how mindfulness influences client negotiations, audit team brainstorming sessions, or other interpersonal interactions within the accounting setting. Finally, my study highlights the importance of evaluating the operationalizations of promoted benefits in audit practice, as opposed to accepting them at face value. Are they really walking the talk?

\section{BACKGROUND AND HYPOTHESIS DEVELOPMENT}

The concept of mindfulness stems from Buddhist traditions, which include šamatha and vipašyanâ, calming oneself and thinking clearly, respectively (Dunne 2011). Mindfulness is defined as "a state of consciousness characterized by receptive attention to and awareness of present events and experiences, without evaluation, judgment and cognitive filters" (Glomb, Duffy, Bono, and 
Yang 2011, p.119). It is premised on the belief that awareness of the present moment and attention to the details occurring therein improve ability to assess the situation and manage one's response to it. Prior literature has examined mindfulness as either an extension of (Shapiro and Schwartz 2000) or an antecedent to (Brown, Ryan, and Creswell 2007a) self-regulation theory. Mindfulness extends self-regulation by adding conscious awareness and intentional choice (Shapiro and Schwartz 2000) to self-observation, judgment about one's behavior as compared to situational norms, and affective reaction (Bandura 1991). Mindful examination also precedes self-regulatory behavior choice and may be viewed as a separate, but related construct from self-regulation (Mackenzie and Baumeister 2015). However, it differs from self-control and self-awareness, which are also related to selfregulation, in that it discourages preservation of the "self" and identity by permitting all stimuli in the present moment to be brought into the conscious mind without judgment (Brown, Ryan, and Creswell 2007a). It also differs from situational awareness, which emphasizes evaluating and prioritizing situational details to form cognitive patterns and predictions about future events (Endsley 1995).

The goals of mindfulness include decentering oneself from the present moment to focus attention (Hulsheger, Walkowoiak, and Thommes 2018) and allow for an objective analysis of the current situation; reducing automaticity of thoughts (Glomb et al. 2011); increasing awareness of one's emotional and physiological responses to situational stimuli (Glomb et al. 2011; Hulsheger et al. 2018); and improving mental, emotional, and physical health (Chang and Stone 2019; Chambers, Gullone, and Allen 2009). It emphasizes monitoring distractions, disengaging from them, and focusing attention on a specific target (Dunne 2011). Unlike emotional intelligence, the awareness and management of one's own and other's affective responses, mindfulness requires intentional behavior modification (Jimenez-Picon et al. 2021). Mindful focusing allows for the intentional 
redirect of attention from one thing to another (Bishop et al. 2004). The benefits of mindfulness have been validated in psychology, neurology, and industrial/organizational psychology literature and have positive impacts on organizational outcomes (Sutcliffe, Vogus, and Dane 2016) and individual competence (Brown and Ryan 2003).

\section{Mindfulness Practices}

Mindfulness is a trait-level attribute, but individuals can increase mindfulness via state-level experiences, interventions, and practices (Chang and Stone 2019; ) like meditating and learning to self-regulate emotional and physiological responses in line with situational stimuli (Grandey 2000). Learning to self-regulate improves overall emotional competency, which further increases selfawareness (Matthews, Zeidner, and Roberts 2004). Self-regulation refers to aligning one's reactions with standards or expectations (Baumeister and Vohs 2016) and is key to mindfulness (Hulsheger et al. 2018) and interpersonal interaction (Rime 2007). Self-regulating one's attention enables the prioritization of goal-relevant over goal-irrelevant stimuli (Ochsner and Gross 2005) while selfregulating one's emotional and physiological responses to situations enables self-control (Bandura 1991), conscientiousness, and adaptability (Goleman 2001). Self-regulation also increases selfefficacy (Bandura 1991) and can lead to increased performance and competence (Baumeister and Vohs 2016; Sutcliffe, Vogus, and Dane 2016).

\section{Mindfulness has Gained Popularity in Recent Years}

Mindfulness has been encouraged in popular press and has gained popularity in Australia, Canada, China, New Zealand, Western Europe, and the United States in recent time, with higher prevalence in western cultures (Selva 2019). Information on mindfulness and mindfulness practices and interventions are widely available. There are over 3.7 million mindfulness videos on YouTube (YouTube 2020) and devices like smartphones enable access to mindfulness tools. Mental health 
and wellness have become an increasingly publicized topic, and has been highlighted in the media, particularly during the COVID-19 pandemic (Katella 2020). Mental health professionals and researchers have promoted the use of mindfulness practices as a way to mitigate the isolation, despair, and other mental health issues many have faced during this time (Antonova, Schlosser, Pandey and Kumari 2021; Katella 2020; Saricali, Satici, Satici, Gocet-Teken, and Griffiths 2020).

Mindfulness practices are a useful skill in the workplace where display rules and organizational norms dictate when and how individuals in certain roles should respond to situations (Gandey 2000; Waldron and Krone 1991). This is particularly true in industries with high stress (Eby et al. 2019) and client interaction (Grandey 2000), along with the necessity to multi-task (Chang and Stone 2019), like auditing. Indeed, three of the Big 4 accounting firms joined with several large investment and law firms to form the City Mental Health Alliance, which promotes mental health and mindfulness in the workplace. Mindfulness is encouraged by the Big 4 public accounting firms as a means to enhance overall well-being (PwC 2020); to reduce stress and increase cognition (KPMG 2015); and to improve focus (Fisher 2020), decision-making, and mental clarity (Brooks 2020; KPMG 2015). Mindfulness has been examined in conjunction with accounting practices (Chang and Stone 2019) and accounting outcomes, such as audit quality (Herda, et al. 2018 a,b). Chang and Stone (2019) explain that mindfulness may facilitate deeper cognitive processing, increased awareness, reduced framing effects, and increased skepticism. Herda, et al. (2018 a,b) find that mindfulness improves audit quality by reducing pre-mature workpaper signoffs and the benefits of mindfulness can be attained simply through supervisor prompts.

However, anecdotal evidence from the accounting profession indicates that mindfulness may not be widely accepted within the profession. A senior manager with a Big 4 firm explained 
that, although the firm posts information about mindfulness on its site, execution of the program is sporadic. For example, the firm had a webinar on mindfulness and mindfulness practices, but "it was unprompted, and we were not told beforehand" (B1 2021). This comment aligns with Chang and Stone's (2019) finding that accounting firms may promote mindfulness on their websites but do little more to ensure its effectiveness or integration into firm culture. When mindfulness is enacted within firms, the promotion of mindfulness by accounting firms is often operationalized as a wellness benefit for stress reduction and is targeted toward new employees (NF1 2021). These initiatives are more successful when firm leaders support the program. Bono, Foldes, Vinson, and Muros (2007) explain that top-down initiatives are essential when implementing emotion regulation programs in the workplace.

In one large firm, the mindfulness program was inspired by an executive leader who meditates and engages in mindfulness practices (NF1 2021, NF2 2021, NF3 2021). The program at this firm includes national support through the human resources function, as well as support and promotion within each region; approximately one-third of firm employees participate in the program (NF3). The firm also provides access to a mobile application to enable participation by all employees. Employees report increased confidence in client negotiations and presentations, along with reduced anxiety and stress, and overall mood improvement (NF1 2021, NF2 2021). Employees further state that the mindfulness program is a "differentiator for retention" (NF1 2021). Firm management explains that "The largest take away is awareness...a sign that it's getting integrated into the culture" (NF3 2021). Smaller firm principals, consultants, and trainers similarly report leading mindfulness initiatives to improve objectivity and focus, facilitate client negotiations, reduce angst, and increase belief in having "enough time, money, space, whatever..." (F1 2021). Thus, while accounting professionals report positive outcomes from practicing mindfulness, and 
the COVID-19 pandemic has highlighted the need for such programs, accounting firms have not fully embraced the trend.

\section{Mindful Self-Regulation reduces Contention}

Mindful self-regulation is an alternative mechanism to surface acting, which is common in emotion labor industries with high client interactions. Employees engage in surface acting by forcing themselves to display expected physiological and emotional responses during interactions with each other, customers, and supervisors, that may be contrary to what they feel (Grandey 2000). Surface acting increases the burden of processing cognitive and affective information while attempting to control one's behavioral and emotive responses, causing a depletion of working memory (Schmeichel 2007; Unsworth and Spillers 2010). Surface acting is cognitively and emotionally taxing and is negatively associated with stress (Grandey 2003) and burnout (Mo and Shi 2017).

The audit profession is prone to burnout and turnover (Cannon and Herda 2016; Herda 2012; Herda and Lavelle 2012) and it is important for auditors to learn coping skills, like mindful emotion regulation, to help them deal with their contentious environment. Mindful self-regulation enables individuals to deal with others who may be contentious or difficult without lashing out or becoming stressed (Goleman 2001), distancing themselves from the event. Mindful self-regulation yields only a small to medium effect on cognition (Chang and Stone 2019). Cognitive load theory explains that individuals have a capacity for simultaneous cognitive processing (Bannert 2002). As cognitive load increases, individuals have a harder time recalling information and accessing working memory. Higher cognitive load impedes performance and affects judgments (Fraser et al. 2012; Block, et al. 2010). Mindful self-regulation both decreases the negative effects from contention and stress and 
allows the individual to use their cognitive resources in other ways; accounting firms would benefit from encouraging auditors to practice mindful self-regulation.

Emotion regulation is a deliberative, effortful cognitive process (Ochsner and Gross 2005) that can be defined as "the set of processes whereby people seek to redirect the spontaneous flow of their emotions" (Koole 2009, p.6). Emotion regulation is studied as a self-control mechanism for cognitive processes (Koole 2009; Schmeichel 2007; Grecucci, Giorgetta, Van't Wout, Bonini, and Sanfey 2013) and as a temporal process (Koole 2009; Gross 2001). Emotion regulation helps reduce implicit automaticity and improves the explicit control over one's thoughts and attention, and the subsequent response (Gyurak, Gross, and Etkin 2011). Prior literature in this vein explores neocortical activity that occurs when an individual regulates emotion and finds that the orbitofrontal and prefrontal cortex are activated along with the limbic system, indicating simultaneous cognitive and affective activity in reward centers of the brain (Grecucci et al. 2013; Sripada et al. 2013; Goleman 2001). The temporal nature of selecting an emotion regulation strategy results in varying levels of emotion regulation effort (Koole 2009), and neocortical activity and depletion may vary by emotion regulation strategy (“ERS"; Gross 2002).

Emotion regulation strategies are selected based on their temporal execution and the individual's intent and preferences. The modal/process model of emotion regulation focuses on five key points in the process: situation selection, situation modification, attentional deployment, cognitive change, and response modulation (Gross 2001). Emotion regulation may occur early or late in the temporal chain via emotion regulation strategies. For example, an auditor preparing for a client meeting may consider several possible responses from the client to anticipate and plan their reactions to those responses. A later response modulation strategy may include amplifying positive emotions while visiting with clients to reduce discomfort. For example, an auditor may focus on 
the positive aspects of the client's business and how the audit process may benefit those successes. The temporal nature and method by which each strategy is executed results in different consequences in different situations (Sheppes et al. 2014).

\section{Effects of Mindfulness Practices Vary by Emotion Regulation Strategy}

The effects of mindfulness vary based on the ERS employed and can have unintended consequences, depending on the situation. This paper focuses on two specific goal-oriented strategies, emotion suppression and cognitive reappraisal. Goal-oriented strategies are influenced by the individual's beliefs about situational norms and the types and amount of emotionally charged information present in the situation (Koole 2009). They exist on a continuum, from those that seek emotion exaggeration to emotion adjustment techniques to eliminating emotion response. Goaloriented strategies occur throughout the emotion regulation process and focus on self-control of attention, information intake, and physiological response (Koole 2009). The effects of goal-oriented strategies persist over time, with adjustment techniques having the longest duration (Brockman et al. 2017; Halperin and Gross 2011). Emotion suppression and cognitive reappraisal are both downregulation strategies that seek to reduce negative emotions; however, they do so in different ways.

The benefits of mindfulness also vary based on the emotion regulation strategy deployed. This paper examines emotion suppression and cognitive reappraisal. Emotion suppression inhibits expressed emotion, which leads to increased cognitive load, decreased positive affect, and memory deficits. It is characterized by a lack of emotion expression, otherwise known as a poker face. Thompson, Medvec, Seiden, and Kopelman (2001) explain, "social psychologists argue that expression of positive emotion, in contrast to a poker face, can be an advantage" (p.155) in the workplace. Cognitive reappraisal reframes negative situations as positive, which leads to early cognitive activation, and increased memory, and greater felt positive emotions than negative 
emotions, which persist over time. The differences in cognitive processing between emotion regulation strategies likely translate into higher ability to recall a greater number of details from reading materials and to recall them more accurately when using cognitive reappraisal than when suppressing emotion. Auditors' recall and attention to detail are essential when they are reviewing financial reporting documents, particularly when assessing fraud risks or identifying fraud risk factors.

\section{Emotion suppression}

When an individual believes that emotions are uncontrollable or excessive, they are likely to select a strategy that avoids or inhibits emotion, such as emotion suppression (Trincas, Bilotta, and Mancini 2016). For example, when auditors believe they must please an angry client to keep the account, they may suppress their emotions to get through a meeting with that client. Emotion suppression is a well-researched (see Koole 2009) response modulation strategy that seeks to reduce behavioral signals that betray felt emotion (Gross 2013). Like surface acting where individuals' mask their felt emotions, it is reflected in a "poker face," but does not reduce the effects of felt emotions (Butler, Wilhelm, and Gross 2006) or psychophysiological responses (Koole 2009; Gross 2013). Suppressing negative emotion can lead to more positive or fewer negative interactions (Waldron and Krone 1991) and a willingness to negotiate. Le and Impett (2013) find that suppressing negative emotion while making sacrifices (i.e. giving up one's self interests) leads to perceived emotional authenticity, which improves interpersonal relations. Likewise, suppressing

positive emotion ensures compliance with behavioral expectations, such as not laughing during meetings.

However, emotion suppression invokes cognitive processing in both the neocortical region and the limbic system (Grecucci, Pappaianni, Siugzdaite, Theuninck, and Job 2015; Gross 2013; 
Ohira et al. 2006), which increases cognitive load. Cognitive processing time, working memory, including recall, and attention to detail are negatively affected by emotion suppression (Gross, Richards, and John 2006; Gross 2013; Goldin McRae, Ramel, and Gross 2008; Bonano, Papa, Lalande, Westphal, and Coifman 2004). Additionally, increased sympathetic cardiovascular activity occurs with emotion suppression (Gross and Levenson 1997; Gross, Richards, and John 2006 ). The negative effects of emotion suppression persist over time and individuals who engage in emotion suppression self-report increased negative affect (Koole 2009) and a higher level of negative, as opposed to positive, felt emotions (Gross 2013). Emotion suppression of negative affect also reduces job satisfaction and increases intention to quit (Cote and Morgan 2002). Those who suppress emotions subsequently negatively change their behavior toward coworkers with whom they interacted while suppressing emotion, and report liking and trusting the individual less after emotion suppression (Waldron and Krone 1991). In an audit context, this may manifest in more contentious relationships within audit teams, or between auditors and clients. For example, auditors ask probing questions of their clients to gain an understanding of the organization's ethical climate, processes and systems, and any changes that have occurred since the prior audit engagement, which may become contentious. During these interactions, auditors are expected to remain objective, and some may suppress their emotions to maintain a poker face during heated conversations. Doing so, however, may impair auditors' ability to focus during the meeting or reduce the information auditors recall from such encounters.

\section{Cognitive Reappraisal}

Cognitive reappraisal is a cognitive change strategy, which occurs after the individual appraises a current situation (Gross 2001). Cognitive change strategies seek to modify appraisal of situational information to alter its emotional significance (Gross and Samson 2007). Its goal is to 
reduce negative affect by replacing negative felt emotion with positive felt emotion by recontextualizing the situation (Gross 2013; Koole 2009). It is particularly helpful in mitigating the effects of stress from situations that are beyond the individual's control (Troy, Shallcross, and Mauss 2013). For example, auditors who feel overburdened by their workload may perceive that they lack control to reduce the burden. Instead of focusing on their stress, cognitive reappraisal provides a way to focus on the positive aspects of the workload (e.g. clients who seek out and appreciate the firm's work, job security, the governance role provided by the auditor to the investing community and regulators, etc.). Similarly, an auditor who perceives that a client's management team is unethical or dishonest may reframe the situation by focusing on the transparency their work provides within the financial reporting process and to the client's governing board and external stakeholders.

McRae, Jacobs, Ray, John, and Gross (2012) explain that the ability to reappraise is improved with practice, and reappraisal ability is positively related to how often one practices reappraisal, improved memory capacity, and overall well-being. This is likely because the increase in felt positive emotions over felt negative emotions persists over time. Halperin and Gross (2011) find that the positive effects of reappraisal, including holding on to hope and intent to provide aid to enemies, lasted over five months in a wartime conflict.

The benefits of reappraisal also include reduced cognitive load on the limbic system and early activation of the neocortical region, which enables the moderation of emotion and increased cognitive activity (Goldin, et al. 2008) that exceeds activity levels associated with natural emotional response (Sripada et al. 2013). Fulford, Feldman, Tabak, McGillicuddy, and Johnson (2013) find that reappraisal leads to cognitive flexibility, improved emotion regulation and problem solving. Although cognitive reappraisal has long-term positive benefits and aids memory and recall, auditors 
are encouraged to have a skeptical mindset while evaluating fraud risks (Charron and Lowe 2008; Vinten, Payne, and Ramsay 2005), and are discouraged from considering non-fraud alternative explanations. Specifically, they are discouraged from "viewing the world with rose-colored glasses" and are instead incentivized to think critically and exhibit stoicism. While prior studies of cognitive reappraisal in the workplace are limited, results have shown that it acts as a coping strategy for workplace bullying (Wilkins 2014) and reduces negative response when provoked to anger (Mauss, Cook, Cheng, and Gross 2007). The ability to reduce contention in the workplace is particularly important to auditors who work with each other and both serve and evaluate their clients. Minimizing anger in these settings facilitates effective relationships.

Cognitive reappraisal emphasizes change of thought while emotion suppression relies on modifying physiological response (Gross 2006). Therefore, cognitive reappraisal attempts to change felt emotion while emotion suppression seeks to modify expressed emotion, yielding different effects in the ability to be aware of one's surroundings and attention to detail. Increased cognition coupled with the long-term positive effects of prosocial behavior can be very beneficial to workplace interactions. Therefore, auditors who engage in emotion suppression may experience cognitive overload from the burden of managing the situation and hiding their felt emotions, while those who reframe the situation as positive may cope with the situation using problem-solving skills, without adding to their cognitive load. I hypothesize that auditors who exercise cognitive reappraisal are likely to identify more fraud risk factors and to accurately recall fraud risk factors more accurately, than those who engage in emotion suppression. I develop hypotheses $1 \mathrm{a}$ and $1 \mathrm{~b}$ from this line of inquiry:

Hla: Cognitive reappraisal leads to identification of more fraud risk factors in financial information than emotion suppression. 
$H 1 b$ : Cognitive reappraisal leads to more accurate identification of fraud risk factors in financial information than emotion suppression.

\section{Prompts to Identify Discrepancies within Financial Information Moderate the Effect of Emotion Regulation Strategy on the Accurate Identification of Fraud Risk Factors}

The effects of mindful attention to detail when an individual engages in cognitive reappraisal or emotion regulation are likely moderated by prompts and primes. Prompts induce cognitive processing (Block, et al. 2010), adding to an individual's cognitive load. The cognitive load induced by prompting auditors to be attentive to discrepancies within the financial information they review impedes the cognitive capacity of those engaging in emotion suppression but has little effect on cognitive capacity when one engages in cognitive reappraisal. Contrarily, prompts improve focus (Brazel et al. 2014) and prompting auditors to be mindful of discrepancies that exist in financial information may mitigate the negative effects of the additional cognitive load from emotion suppression. Therefore, prompts may either cause cognitive overload or improve auditors' ability to focus when they suppress emotions. Cognitive reappraisal does not impede cognitive load; thus, prompting an auditor to be mindful of discrepancies that may exist in financial information likely enhances their ability to accurately identify fraud risk factors. The differing effects of ERS on the accuracy with which fraud risk factors are identified are likely moderated by whether an auditor is prompted to consider discrepancies within financial information or not.

Extensive audit literature has examined the effects of priming and prompts on audit risk assessments and subsequent audit-related decisions. Auditors prompted to consider explicit information or to evaluate inconsistencies in audit evidence are more likely to identify errors or fraud. For example, Hobson et al. (2017) show that auditors are less likely to identify cognitive dissonance markers in transcripts of calls between chief executive officers and investment analysts 
in fraud firms than in non-fraud firms, except when prompted with a definition of cognitive dissonance. Auditors are also unlikely to identify inconsistencies between non-financial measures and financial reports, unless prompted to do so (Brazel et al. 2014). Similarly, Simon (2012) finds that auditors who are prompted to link management's goals to audit evidence identify more relevant fraud risks and select audit procedures that are more correlated to the identified risks. Bowlin (2011) finds that auditors are only likely to allocate audit resources to low-dollar, high-strategic risk accounts when prompted to consider management's response to the allocation of audit resources. Likewise, Herda, et al. (2018 a,b) find that auditors who receive prompts from supervisor coaching are more likely to consider the effect of their work on financial statement users and to subsequently reduce premature workpaper signoffs.

Conversely, Hammersley, Bamber, and Carpenter (2010) show that priming results in effective fraud risk assessments when auditors are reviewing summary information, but not specific information, which shows the moderating effect of document type on priming and prompts. Therefore, while prompts are frequently used in audit practice, they have both positive implications by focusing attention and can lead to negative, unintended consequences. Thus, the effects of prompting auditors to be mindful of discrepancies that exist within financial information while they are engaging in emotion regulation strategies likely impacts their ability to accurately identify fraud risk factors, as proxied by discrepancies within financial information.

I hypothesize:

H2a: Prompted auditors identify more fraud risk factors in financial information than nonprompted auditors. 
H2b: Auditors who are prompted to be mindful of discrepancies within financial information will identify more fraud risk factors when they practice cognitive reappraisal, as compared to when they suppress emotions.

$H 2 c$ : Prompted auditors more accurately identify fraud risk factors in financial information than non-prompted auditors.

H2d: Auditors who are prompted to be mindful of discrepancies within financial information more accurately identify fraud risk factors when they practice cognitive reappraisal, as compared to when they suppress emotions.

The effects of emotion regulation strategies on the detection of fraud risk factors interacts with prompts such that when prompted to be mindful of discrepancies that may exist in financial information, auditors who engage in cognitive reappraisal likely improve their performance by more accurately identifying fraud risk factors, as compared to auditors who suppress their emotions. Therefore, the effect of prompts moderates the relationship between emotion regulation strategy and the ability to accurately identify fraud risk factors. However, the relationship between ERS and the ability to accurately identify fraud risk factors does not only occur through prompts. This leads to a clarifying hypothesis:

H3: The effect of prompting moderates, but does not mediate, the relationship between ERS type (cognitive reappraisal/emotion suppression) and the ability to accurately recall fraud risk factors identified.

Prior research shows that, when prompted by checklists or specific client information, auditors are likely to increase audit procedures to address identified risks related to the prompt, but not overall (Hammersley et al. 2010; Asare and Wright 2004). Therefore, I further hypothesize that 
additional procedures recommended by auditors to address the fraud risk factors identified will be related to discrepancies in the financial information they identify:

H4: Additional audit procedures identified will be related to the prompt to identify

inconsistencies between the documents but will not include other potential fraud risks.

Figure 2 represents a theoretic model for this study.

--Insert Figure 2--

\section{DESIGN AND METHODOLOGY}

This paper examines the effects of mindfulness practices on auditors' recall and attention to detail in an experimental design with samples of Amazon Mechanical Turk ("mTurk") workers ${ }^{1}$ and accounting and finance students.

\section{Development of Experimental Materials}

I follow extant accounting studies related to auditors' attention to fraud risk factors when examining inconsistencies between types of financial reporting evidence (see also Hobson et al. 2017; Brazel et al. 2014; Trotman and Wright 2012; Asare and Wright 2004). Experimental packets include information that auditors and investment analysts routinely collect in the course of their work, including audio files and transcripts from earnings call question and answer sessions and the

\footnotetext{
${ }^{1}$ The proposal for this study included the use of Prolifics panel participants. However, Prolifics was only able to provide 3 participants who met the study's criteria. Similarly, Qualtrics and Amazon panels did not provide a sufficient number of participants to achieve power in this study (36 and 27, respectively). Leiby et al. (2021) explain that this is a common issue with audit judgement and decision-making research, and recommend that researchers use professional auditors to validate experimental materials but use "non-expert participants" (p.33), such as mTurkers and students, to ensure full studies achieve sufficient power. Conversely, they recommend that researchers consider running small, focused experiments initially to verify that the experiment applies to the audit setting and then to run the full study with non-expert participants (see Kadous, Proell, Rich and Zhou 2019). This study uses professional auditors to develop experimental materials and accounting and finance students, including Master of Business Administration and Master of Accountancy students, who are familiar with the experimental tasks, to validate the study's results.
} 
quarterly financial reports discussed during an earnings call. Earnings calls are divided into two subparts: a scripted session of remarks prepared and delivered by company management and a question and answer session between presenting management and investment analysts and others. During prepared remarks, management relays the financial results for the company during the current financial reporting period, as well as year-to-date. The subsequent question and answer ("Q\&A") session between company management and investment analysts and others is a candid discussion based on questions from those who call in to a queue moderated by an outside investment relations firm. Prior literature has shown that the Q\&A sessions in earnings calls are more informative than the prepared remarks (Mayew, Sethuraman, and Venkatachalam 2020; Matsumoto, Pronk and Roelofsen 2011; Kimbrough and Louis 2011) and management's responses in these question and answer sessions reveal cognitive dissonance markers when management is relaying information that they know to be untruthful (Hobson, Mayew and Venkatachalam 2012).

Fraud firms exhibit a higher number of inconsistencies between financial and non-financial measures than non-fraud firms (Brazel et al. 2009); therefore, the experimental materials are related to a fraud firm and a non-fraud competitor. The fraud firm was subject to a Securities and Exchange Commission Audit and Accounting Enforcement (“AAER") covering the period presented. However, the case brought by the $\mathrm{SEC}^{2}$ against the firm did not include charges of fraud under Rule 10b-5. Rather, the SEC charged the firm with violations of the books and records provisions, including failure to maintain adequate controls. The selection of this firm was intentional as accounting professionals may be familiar with companies charged under SEC Rule 10b-5.

\footnotetext{
${ }^{2}$ These methods differ from prior studies that first archivally establish relationships between the proxied fraud risk factor by applying the Dechow f-score to similar materials (Hobson et al. 2011) or measuring the effect of the difference between financial and non-financial measures on fraud risk (Brazel et al. 2009).
} 
I use an expert panel of Manager/Sr. Manager-level public accountants in Big 4 and national firms ("Panel participants") to facilitate the development of the financial documents evaluated by participants, as described in Appendix A. As part of the process, the expert panel listed discrepancies they noted between the information within each firm. Feedback from panel participants revealed that the experiment took more time to complete than expected (approximately 45 minutes to 1 hour) and that it elicited deep thinking (Petty and Caciopo 1986) and metacognitive processing (Roelle, Nowitzki, and Berthold 2017). One panel member was also able to identify the fraud firm during this process.

The list of discrepancies noted by the expert panel was compared to the findings noted in the AAER for the fraud firm, and a list of words that may be predictive of fraud cases (see Purda and Skillicorn 2015). Following Berry and Mielke (1988), I measure the level of agreement between raters and with the SEC AAER for each discrepancy noted. Where agreement was moderate to high (Cohen's kappa $>0.600$ ), the discrepancy was included in the experimental materials. The final list included an equal number of actual discrepancies and erroneously identified discrepancies between the earnings call question and answer session and the financial statement excerpts, for each firm. In addition, the expert panel identified potential substantive tests they may employ to reduce the identified risks.

To reduce experimental burden, a second phase of design was implemented using only materials related to the fraud firm (see Appendix B), as fraud firms exhibit a higher number of discrepancies than non-fraud firms (Brazel et al. 2009). Phase II participants are solicited using Amazon Mechanical Turk ${ }^{3}$ (“mTurk”) via their screening platform, Cloud Research. In this phase,

${ }^{3}$ Controls within Cloud Research were deployed to ensure participants were familiar with the experimental task and experienced study participants. Specifically, mTurkers have participated in at least 500 studies, had 
I explain mindfulness by having participants read an article on the benefits of mindfulness that describes mindfulness practices related to self-regulation and seek participants' feedback on the experimental tasks, as described in Appendix B. Phase II panel participants were asked to select discrepancies noted between the financial information for the fraud firm from a drop down of the final list identified and agreed to by the expert panel. mTurk participants in Phase II strongly agreed on the discrepancies in the information provided within the group and with the SEC AAER $($ Cohen's kappa $=0.909)$. Feedback from Phase II participants revealed that the experiment took approximately 35-40 minutes to complete, which was longer than desired. Therefore, a summary of the article provided to the expert panel ${ }^{4}$ and Phase II participants was included in the final experimental materials. Final experimental materials are available in Appendix $\mathrm{F}^{5}$.

\section{Independent Variables}

In the final experimental materials, I randomly assign participants to an ERS condition [IV1ERS], including emotion suppression (“Suppress"), cognitive reappraisal (“Reframe”) or a control group ("Control") ${ }^{6}$. Random assignment adds control by dispersing those with varying levels of

an approval rating of at least $80 \%$, earned at least a bachelor's degree, worked in an office in the Finance or Business Service industries, were currently employed full-time, and work at least 36 hours per week.

${ }^{4}$ I follow experimental research in psychology, which shows that merely instructing participants to engage in emotion suppression or cognitive reappraisal yields significant differences between the conditions (e.g. Sripada et al. 2014; Goldin et al. 2008; Richards and Gross 2000).

${ }^{5}$ The proposal for this study included the use of participants' self-reported heart rate variability ("HRV") throughout the study via screenshot from the participant's personal heart rate monitoring application as a means to confirm participants' engagement with the assigned emotion regulation strategy condition (i.e. a secondary manipulation check). This process was included in Phase II, however, participants uploaded various files that did not show their HRV. Therefore, the lack of control in this setting negates the use of HRV as a manipulation check. Per the WVU IRB, removing HRV from the study also reduces the data privacy requirements, enabling the use of Qualtrics for data collection, instead of REDCap.

${ }^{6}$ I choose emotion suppression because of its relevance to the audit profession and its correlation with negative, or skeptical, mindsets, which are encouraged in auditing. In the psychology literature, emotion suppression and cognitive reappraisal are often compared in studies on emotion regulation (see Gross 2001, 2013). 
trait-level ERS preference between groups. Participants in each group are provided information related to the mindfulness practice they are assigned to and given instructions on how to exercise the practice. For example, participants in the Suppress group are told to refrain from showing emotion, while those in the Reframe group are try to feel less negative about the information presented, and those in the control group are told to thoughtfully consider the information presented (see Appendix F).

As a manipulation check, participants are asked to identify the mindfulness practice they utilized during the activity ("ManCk1"). Upon completion of the manipulation check, participants are reminded of the mindfulness practice they are assigned to and are told that they are to read information about a company and answer related questions. Following Brazel et al. (2014), I prompt one-half of the participants to identify inconsistencies between documents related to quarterly financial reporting for a public company [IV2- Prompt]. Following participants' evaluation of the experimental materials, participants complete a second manipulation check (“ManCk2”). Table 1 lists the conditions assigned and the corresponding cell sizes.

--Insert Table 1--

\section{Dependent Variables}

After reviewing the company's earnings call and financial information, I ask participants to rate the likelihood that company management is engaging in financial misreporting on a scale of 1 to 100 [DV1- financial reporting fraud]. I also ask each participant to identify the discrepancies they noted in the financial information from the final list developed during the design of the experimental materials, and then to select the fraud risk factors they identified, if any. I measure the ability to identify fraud risk factors as a count of the fraud risk factors selected from the final list of fraud risks that exist in the SEC's AAER, as provided by the expert panel [DV2- Quantity]. 
I further measure ability to accuracy with which participants identify inconsistencies that exist within the company documents [DV3- Accuracy] as the number of correctly identified fraud risk factors less the number of incorrectly identified fraud risk factors. That is [(\#correct $+\#$ of avoided incorrect answers) - \# incorrect], thus accuracy can range from -8 to 8 (e.g. 4 accurately identified correct answers +4 accurately avoided incorrect answers -0 incorrect answers $=8$ ). Evaluating financial information in this way is a metacognitive process that requires deep thought and concentration. Roelle et al. (2016) explain that cognitive processes, such as emotion regulation and prompts, influence metacognitive processes by either setting the stage for elaboration, or by overloading cognitive capacity.

I further ask participants to identify additional substantive tests [DV4- Test] they might employ to mitigate the risks identified. Four options are provided from the list developed by the expert panel, two of which are related to the discrepancies between the documents (i.e. recalculation of the allowance for doubtful accounts and allocation of revenue by product type), one of which may be extrapolated from the materials (i.e. tests of internal controls), and one of which is not related to the experimental materials provided (i.e. goodwill impairment test). I measure whether the participant identified additional tests, and if so, whether the tests identified correlate with the fraud risks the participant noted.

Additionally, I measure the duration of time participants spend on the study as a secondary mechanism to validate their ERS engagement. Emotion suppression adds to cognitive load and decreases working memory while cognitive reappraisal increases it. Therefore, I evaluate participants' cognitive processing times as evidence of the execution of their assigned ERS. I expect participants assigned to the suppress condition to spend more time processing the experimental materials than those in the reframe or control conditions, as emotion suppression increases cognitive 
load. I further expect that participants who are prompted to be mindful of discrepancies within financial information will spend more time on the experimental materials than those who are not prompted, as prompts also induce cognitive processing. Therefore, participants who are assigned to the suppress condition and are also prompted will likely spend the most time on the study, as compared to those who are assigned to the reframe or control conditions and/or are not prompted. Further, participants who are in the reframe or control conditions and are not prompted to be mindful of discrepancies within financial information will likely spend the least amount of time on the study.

In closing, I collect process measures related to the individual's frequency practicing mindfulness and emotion regulation, and the likelihood that their current employer encourages mindfulness. I further ask participants to self-report the difficulty they encountered cognitively processing the experimental materials (i.e. focusing, stopping, and thinking, remembering details). Finally, I ask participants to provide their sex at birth, highest level of education, number of people in their current place of employment, position within their current firm, and number of years they have worked full-time.

\section{Sample Selection}

A $3 \times 2$ study requires a minimum of 120 participants to achieve power; therefore, I follow Leiby et al. (2021) and use online participants to acquire enough subjects to reach power. I obtain mTurk participants via Cloud Research ${ }^{7}(n=54)^{8}$, deploying controls to ensure participants represent financial professionals familiar with the experimental tasks. ${ }^{9}$ The study is described as

\footnotetext{
${ }^{7}$ Prolifics ( $\mathrm{n}=3$ ), Amazon Mechanical Turk ( $\left.\mathrm{n}=27\right)$, and Qualtrics $(\mathrm{n}=36)$ panels (see Leiby et al. 2021; Peer, Brandimorte, Samat, and Acquisti 2017) were considered as sample sources but were unable to provide a sufficient number of participants to achieve power.

${ }^{8}$ The study yielded a $55.4 \%$ abandonment rate.

${ }^{9}$ Controls include: exclusion from participation in prior studies related to the current study (e.g. participation in design of the experimental materials); mTurk approval ratings of at least $80 \%$; college education (i.e.
} 
"Mindfulness and Financial Information" ${ }^{10}$ Leiby et al. (2021) and Buchheit, Doxey, Pollard, and Stinson (2018) explain that the use of controls in this way helps validate participant attributes and provides greater assurance over data quality, in the absence of a controlled environment. Prior studies have shown that mTurkers are a more representative sample of the general population than student samples. However, extant literature is unclear on whether mTurkers provide quality responses in longer studies. For example, Bellingtier and Neupert (2017) find mTurkers to be an acceptable population for daily diary studies, which require multiple contacts between participants and experimenters over several days. Conversely, Aguinis, Villamor, and Ramani (2021) and Goodman, Cryder, and Cheema (2013) explain that mTurkers are less attentive than other participants, particularly with longer experimental tasks, and often abandon studies with such $\operatorname{tasks}^{11}$.

To validate the study results in the audit setting and increase the number of study participants, I further recruit undergraduate accounting students $(\mathrm{n}=30)$, and graduate students enrolled in Master of Business Administration and Master of Accountancy programs at a large Mid-Atlantic university

bachelor's degree or higher); experience with investments; U.S. citizen; employed as an office worker, finance professional, business service professional, or office worker; work at least 36 hours per week; block duplicate IP addresses; block suspicious geocodes (i.e. non-matching to IP location); and block low quality participants.

${ }^{10}$ There is a growing body of literature related to the effects of mindfulness on financial information analysis and decision-making (see Engels, Kumar and Philip 2020; Charoensukmongkul and Aumeboonsuke 2018, 2016; Ng 2018, Stone 2011, Gonzalez and Byron 2010; Shefrin 2008). Chambers, Gullone, and Allen (2009) explain that when mindfulness is practiced, it becomes automatic and requires less cognition to perform. Thus, those familiar with mindfulness and financial information analysis are more likely to provide quality responses in this study.

${ }^{11}$ To offset these risks, I compensate mTurkers in two parts. Each mTurker receives nominal compensation of $\$ 0.25$ for participating in the study and those who provide quality response receive a bonus of $\$ 3.75$. Therefore, mTurkers are extrinsically motivated to complete the study. 
$(n=48)^{12}$. Accounting students are likely more familiar with the audit processes and exhibit greater cognitive processing of the experimental materials.

\section{RESULTS AND DisCUSSIONS}

As described above, I expect that participants assigned to the cognitive reappraisal condition will identify more fraud risk factors and more accurately identify fraud risk factors than participants assigned to the control or emotion suppression conditions. Further, I expect prompting participants to be mindful of discrepancies that may exist in financial information has a positive main effect on the ability to accurately identify fraud risk factors and moderates the relationship between emotion regulation strategy and the ability to accurately recall fraud risk factors.

\section{Exploratory Data Analysis}

Data were analyzed using IBM SPSS version 27 and PROCESS by Andrew Hayes. Analysis of the descriptive statistics for continuous variables show 11 outliers in study duration. Four of these outliers included durations more than 83 minutes and seven had durations less than 5 minutes. The data is left-skewed and kurtotic, particularly in the ERS=Control condition. As such, additional data analysis was completed. Univariate and multivariate analyses show that these outliers do not affect the dependent variables ${ }^{13}$ or the models of interest. However, considering these results, median duration time to complete the study is used for supplemental analysis of participants' cognitive processes.

${ }^{12}$ Student participants were either compensated with a $\$ 10$ Amazon gift card or a combination of extra credit and a $\$ 5$ Amazon gift card. Student participants were compensated regardless of the quality of their response. There was no statistically significant difference in results provided within student samples between compensation arrangements.

${ }^{13}$ Analyses were run including and excluding outliers. No statistically significantly differences were noted in the results. 
Univariate and multivariate analyses were performed on all other variables. Sex at birth revealed that there are 2.58 times more males than females in the study. ${ }^{14}$ The number of males exceeds females in each condition. No other data anomalies were identified, and data were consistent across conditions. Overall descriptive statistics are in Tables 2 through 5.

--Insert Tables 2, 3, 4, and 5--

Bivariate correlations were examined for all variables using Spearman (non-parametric) and Pearson (parametric) coefficients. Spearman correlations for ordinal variables show that the identification of fraud risk factors is positively related to the accurate identification of fraud risk factors $(r h o=0.575, p<0.01)$, the number of additional tests selected to address fraud risk factors $(r h o=0.353, p<0.01)$, and the duration of time participants spend on the study $(r h o=0.280, p<0.01)$. Spearman correlations also show that the number of financial statements analyzed on a quarterly basis is negatively related to participants' difficulty remembering details about the financial information they reviewed $(r h o=-0.176, p<0.05)$. Conversely, how much time participants spend on the study is positively related to related to the number of financial statements they analyze on a quarterly basis $(r h o=0.182, p<0.01)$ and the number of additional tests participants select to address the fraud risks they identify $(r h o=0.313, p<0.01)$.

Pearson correlations for linear relationships show that the accurate identification of fraud risk factors is negatively related to difficulty focusing on the task $(r=-0.191, p<0.05)$. Participants' self-reported difficulty focusing on the experimental task $(r=-0.184, p<0.05)$ and difficulty remembering facts about the information reviewed $(r=-0.256, p<0.05)$ are negatively related to

${ }^{14}$ Anderson, Reilly, Gorrell, Schaumberg, and Anderson (2016) find the gender differences in emotion regulation are most related to shame and the length of time needed to recover from negative emotions. This study asks participants to modify both positive and negative emotion. Therefore, no gender effect is expected. 
how frequently they practice mindfulness. Participants' difficulty remembering facts is also negatively related to how frequently they practice emotion regulation $(r=-0.189, p<0.05)$. Finally, participants' frequency of practicing mindfulness $(r=0.220, p<0.05)$ and emotion regulation $(r=$ $0.269, p<0.01)$ are positively related to the likelihood that their current employer encourages mindfulness and the frequency of practicing mindfulness is positively related to the frequency of practicing emotion regulation $(r=0.664, p<0.01)$.

Table 6 provides the Pearson (Lower) and Spearman (Upper) correlation coefficients of interest. These relationships show that the data support the benefits of mindfulness and the impact of practicing mindfulness on cognitive load (Grecucci, Pappaianni, Siuzdaite, and Theuninck 2015). --Insert Table 6--

However, the benefits of mindfulness and the related cognitive load may differ based on whether and how often participants practice mindfulness. Block, et al. (2010) explain that familiarity with constructs decreases participants' cognitive load and improves performance. As previously described, this study finds that the frequency of practicing mindfulness is positively correlated with the accurate identification of fraud risk factors and differs between samples. In this study, mTurk ("mTurkers") participants ( $\mathrm{M}=5.26)$ and Undergraduate students ("Undergrads") $(\mathrm{M}=5.00)$ are more likely to practice mindfulness than Graduate ("Grads") students ( $\mathrm{M}=3.02)$. mTurk participants $(\mathrm{M}=4.83)$ and Undergrads $(\mathrm{M}=4.41)$ are also more likely to practice emotion regulation strategies than Graduate students $(\mathrm{M}=3.23)$. Undergrads $(\mathrm{n}=19)$ are also more likely to report high school graduation as their highest level of education than Grads $(\mathrm{n}=6)$ or mTurkers $(n=4)$ and mTurkers report having a higher average number of years of full-time work experience $(\mathrm{M}=5.77)$, as compared to Grads $(\mathrm{M}=0.43)$ or Undergrads $(\mathrm{M}=0.76)$. The differences between sample groups may affect participants' ability to manage the cognitive processes of emotion 
regulation and prompts while engaging in the metacognitive experimental task in this study. Descriptive statistics between samples are available in Tables 7 through 9. --Insert Tables 7, 8, and 9; Figures 3, 4, and 5--

Given these results, the differences noted between samples were evaluated for statistical significance. Based on preliminary analyses of the descriptive statistics, chi square test of association by sample, and analyses of variance, differences were noted between samples in the frequency of practicing mindfulness or emotion regulation. Familiarity with mindfulness and emotion regulation or financial statement analysis should improve automaticity, reducing the cognitive load such activities impose on the participant, freeing the individual to allocate greater cognition toward prompts and the experimental tasks. Therefore, I evaluate whether participants' familiarity with mindfulness or emotion regulation or financial statement analysis significantly affects participants' ability to accurately identify fraud risk factors.

Frequency practicing mindfulness or emotion regulation. Using a multivariate analysis of covariance (MANCOVA) model, I assess whether differences in familiarity with mindfulness or emotion regulation between sample source ("samples") are statistically significant. ${ }^{15}$ Preliminary assumption checking revealed that data was normally distributed, as assessed by Shapiro-Wilk test $(p>0.05)$; there were no univariate or multivariate outliers, as assessed by boxplot and Mahalanobis distance $(p>0.001)$, respectively; there were linear relationships, as assessed by scatterplot; no multicollinearity $(r=0.664, p<0.01)$, and homogeneity of variance-covariance, as assessed by Box's $M$ test $(p=0.693)$. The differences between samples on the combined dependent variables was statistically significant, $F(3,109)=4.137, p=0.001 ;$ Pillai's Trace $=0.203$; partial $\eta 2=0.101$.

\footnotetext{
${ }^{15}$ The model included controls for number of financial statements analyzed, education, gender, position with current firm, and years of experience.
} 
mTurkers and Undergrads are statistically significantly more likely to practice mindfulness and emotional regulation than Grads $\left(\mathrm{M}_{\mathrm{mTurk}}=5.26, \mathrm{SD}=1.29 ; \mathrm{M}_{\text {Undergrads }}=5.00, \mathrm{SD}=1.81 ;\right.$ and $\mathrm{M}_{\text {Grads }}=$ $3.02, \mathrm{SD}=2.45$, respectively) and are more likely to practice emotion regulation than Grads $\left(\mathrm{M}_{\mathrm{m} T u r k}=4.83, \mathrm{SD}=1.51 ; \mathrm{M}_{\text {Undergrads }}=4.30, \mathrm{SD}=1.59 ;\right.$ and $\mathrm{M}_{\text {Grads }}=3.23, \mathrm{SD}=1.88$, respectively $)$. Follow-up univariate ANOVAs showed that both practicing mindfulness $[F(2,111)=11.160, p<$ 0.001; partial $\eta 2=0.167]$ and emotion regulation $[F(2,111)=6.612, p=0.002$; partial $\eta 2=0.106]$ were statistically significantly different between the sample groups, using a Bonferroni adjusted $\alpha$ level of 0.025 .

Bonferroni post-hoc tests show that mTurkers practice statistically significantly higher mindfulness, on average, than Grads ( $\left.\mathrm{M}_{\text {Diff }}=2.24, \mathrm{SE}=0.44, \mathrm{p}<0.001\right)$. Likewise, Undergrads practice mindfulness at a marginally significantly higher average rate than $\operatorname{Grads}\left(\mathrm{M}_{\text {Diff }}=1.98\right.$, $\mathrm{SE}=0.45, p<0.001)$. However, the difference in practicing mindfulness did not statistically significantly differ between Undergrads and mTurkers $(p=1.000)$. Bonferroni post-hoc tests also show that $\mathrm{mTurkers}\left(\mathrm{M}_{\text {Diff }}=1.60, \mathrm{SE}=0.35, p<0.001\right)$ and Undergrads $\left(\mathrm{M}_{\text {Diff }}=1.17, \mathrm{SE}=0.41, p<\right.$ 0.001) practice statistically significantly higher emotion regulation, on average, than Grads. However, the difference in practicing emotion regulation did not statistically significantly differ between Undergrads and mTurkers $(p=0.91)$.

\section{--Insert Table 10--}

These results indicate that mTurk and undergraduate student participants are more familiar with mindfulness and emotion regulation than graduate student participants. Participants' frequency of practicing mindfulness and emotion regulation reduces the amount of cognitive load they spend regulating their emotion during the study and frees their cognitive capacity for the experimental tasks. Therefore, I evaluate whether the differences in mTurker and Undergrad frequency of 
practicing mindfulness or emotion regulation influence their ability to identify fraud risk factors or their ability to accurately identify fraud risk factors, as compared to Grads.

Financial statement analysis. I test whether the number of financial statements participants analyze each quarter significantly differs between samples and whether such experience affects participants' ability to accurately identify fraud risk factors. Chi square tests of association show that Undergrads are less likely to analyze one to nine (36.67\%) financial statements quarterly than mTurkers (51.85\%) or Grads (52.08\%), but are more likely to analyze 10 to 24 financial statements per quarter $(43.33 \%)$ than mTurkers $(29.63 \%)$ or Grads $(29.17 \%), \chi^{2}=17.518, p=0.025$. Additionally, the difference in years' work experience between mTurk subjects $(\mathrm{M}=5.77)$ and Undergrads $(\mathrm{M}=0.76)$ or Grads $(\mathrm{M}=0.43)$ is statistically significant, $\chi 2=17.518, p=0.025$.

To assess the effects of emotion regulation strategy and prompts on the ability to accurately recall fraud risk factors (i.e. Accuracy), I run a between-subjects analysis of covariance (ANCOVA $)^{16}$. Using an alpha level of 0.05 to evaluate homogeneity assumptions, Levene's homogeneity of variance test was not statistically significant for both dependent variables $(p>0.01)$. Results indicate that the interaction effect of Prompt * Sample statistically significantly affects ability to accurately identify fraud risk factors, $F(2,86)=2.620, p=0.079$, partial $\mathrm{y}^{2}=0.057$. Specifically, mTurk participants were statistically significantly more accurate in identifying fraud risk factors when not prompted $(\mathrm{M}=5.19, \mathrm{SD}=1.77)$ than when prompted $(\mathrm{M}=4.56, \mathrm{SD}=2.16$, $p=0.062)$. The ERS x Sample interaction was not statistically significant, however, $F(2,86)=0.061$, $p=0.988$, partial $\mathrm{y}^{2}=0.004$. In addition, Education $[F(1,86)=4.686, p=0.033]$ and the number of

\footnotetext{
${ }^{16}$ The model included controls for number of financial statements analyzed, education, gender, position with current firm, and years of experience.
} 
financial statements analyzed per quarter $F(1,86)=8.387, p=0.005$, had statistically significant effects on the ability to accurately recall fraud risk factors.

\section{--Insert Table 11--}

In addition to the differences between samples noted previously, I evaluate whether differences exist between samples that may also impact participants' cognitive load. Specifically, I examine whether differences' in the amount of time participants spend on the study significantly statistically differ between samples.

Duration and Cognitive Processing. As discussed earlier, eleven outliers were identified in the amount of time spent on the study. Although the outliers did not have a statistically significant effect on the variables of interest in this study, duration also serves as a proxy for cognitive processing used (Gross 2013; Goldin et al. 2008). Therefore, I evaluate median duration in time between samples and condition ${ }^{17}$ to assess whether participants' cognitive processing differed between emotion regulation condition or sample. The effects of ERS, prompt, and sample on duration time are also compared, removing outliers.

Examination of median duration in minutes shows that mTurkers exhibit greater cognitive processing when not prompted across ERS conditions (Suppress $=22.60 ;$ Control $=17.87$, Reappraisal $=16.24)$ as compared to when they are prompted (Suppress $=18.71$; Control $=7.50$, Reappraisal=13.00). Contrarily, graduate students exhibit greater cognitive processing when prompted $($ Suppress $=40.98 ;$ Control $=28.65$, Reappraisal $=22.33)$ than when not prompted $($ Suppress $=25.65 ;$ Control $=28.23$, Reappraisal $=21.68)$. Further, graduate students exhibited the

${ }^{17}$ Median duration to complete the study was highest when participants suppressed emotion (Median= 22.70) and lowest when participants reframed the situation (Median=18.13), showing that the ERS manipulation was effective. However, results within each sample varied. 
highest cognitive processing and mTurkers exhibited the lowest amount of cognitive processing when prompted across ERS conditions, as proxied by duration in minutes (see Table 13). Undergraduates exhibit varying cognitive processing times across conditions, such that they endure greater processing times when prompted in the Reappraisal condition (Median=22.33) than when not prompted (Median=21.68) but lower processing time in the Suppress condition when prompted $($ Median $=22.27)$ than when not prompted $($ Median= 25.81; see Table 13). These results indicate that mTurkers allocate fewer cognitive resources to the study and perform a less thorough evaluation of the experimental materials, as compared to graduate students. The differences may be related to the influence of affective information on the samples, such as the fact that mTurkers are more familiar with mindfulness (Mean=5.26) than graduate students (Mean=3.02) or may simply be reflective of a lack of attention.

--Insert Tables 12-13; Figure 6--

Univariate analysis of variance was also performed to assess whether the mean duration is statistically significantly different between sample, ERS, and/or prompt. Residual analysis was performed to test for the assumptions of the ANOVA. Outliers were removed and the data was assessed by inspection of a boxplot; normality was assessed using Shapiro-Wilk's normality test for each cell of the design and homogeneity of variances was assessed by Levene's test. Residuals were normally distributed $(\mathrm{p}>.05)$ and there was homogeneity of variances $(p=0.621)$. All pairwise comparisons were run where reported $95 \%$ confidence intervals and p-values are Bonferroniadjusted. Although the median durations between samples were not statistically significantly different, the unweighted marginal means of duration for mTurkers, undergraduate students and graduate students were $18.80(\mathrm{SE}=1.464), 22.86(\mathrm{SE}=2.540)$ and $33.99(\mathrm{SE}=4.489)$, respectively. The mean difference between mTurkers $(18.80,95 \%$ CI $[15.85,21.74])$ and graduate students 
$(33.99,95 \%$ CI $[24.95,43.03])$ of -15.20 is statistically significantly different, $p=0.002$. Therefore, it appears that graduate students exhibited greater cognitive effort on the experimental task, which may contribute to differences noted. However, there was no effect of emotion regulation strategy or prompt on duration in minutes.

--Insert Table 14 and Figure 6--

These results indicate that differences between samples in this study are different enough to potentially skew the results. To prevent the introduction of bias into the coefficients, tests of hypotheses are performed within each sample, as opposed to across samples ${ }^{18,19}$.

\section{Tests of Hypotheses - mTurk}

\section{The effects of ERS (H1a) and Prompts on Fraud Risk Identification (H2a and H2b)}

To evaluate whether differences in participants' frequency of practicing mindfulness or emotion regulation affect their ability to identify fraud risk factors, depending on whether prompts affect their ability to identify fraud risk factors, I test H1a, H2a, and H2b using a cumulative odds ordinal logistic regression with proportional odds to determine the effect of emotion regulation strategy on the ability to identify fraud risk factors ${ }^{20}$. There were proportional odds, as assessed by a full likelihood ratio test comparing the fitted model to a model with varying location parameters,

${ }^{18}$ Testing the hypotheses within each sample reduces cell sizes and lowers power below acceptable levels. Additional observations are necessary to achieve power and derive reliable results.

${ }^{19}$ Using small sample sizes within each participant pool ("sample source") biases against finding significant results as the cell sizes are too small to achieve power. Therefore, it is likely that trends within the data may not be statistically significant, but may be worthy of future study.

${ }^{20}$ The model was also run including controls for 1) frequency of mindfulness practices, frequency of emotion regulation practice, whether the participants' current firm encourages mindfulness, or 2) participant characteristics (i.e. years of experience, experience analyzing financial statements, education level, current job position, gender). However, the model fit was poor as many cell sizes were below 5 . As such, a separate chi square test of association was conducted to address these attributes to the error term in this model. No significant relationships existed. 
$\chi^{2}(15)=7.353, p=0.947$. The Pearson goodness-of-fit test indicated that the model was a good fit to the observed data, $\chi^{2}(15)=6.584, p=0.968$, but 5 cells $(16.7 \%)$ had frequencies lower than five. The final model statistically significantly predicted the dependent variable over and above the intercept-only model, $\chi^{2}(5)=13.596, \mathrm{p}=0.018$, Pseudo $R^{2}=0.235$.

Results show that there is a statistically significant two-way interaction between mTurkers assigned to the control emotion regulation strategy and prompts to be mindful of discrepancies within financial information [Wald $(1)=7.083, b=3.650, S E=1.372, p=0.008$ ], as compared to those in the reframe condition ${ }^{21}$. While $\mathrm{H} 2 \mathrm{c}$ does not include the control ERS, the finding highlights the effect of prompts when participants do not engage in emotion regulation. Further, there is also a significant main effect of prompting mTurkers to be mindful of discrepancies within financial information (Yes vs. No) on the ability to identify fraud risk factors [Wald (1) $=7.044, b=-2.952$, $S E=1.112, p=0.008]$. However, the effect is in the opposite direction of that hypothesized in H2a. That is, mTurkers are more likely to find $0(n=3)$ or $1(n=13)$ fraud risk factors than $2(n=5), 3(n=4)$ or $4(n=3)$ fraud risk factors when prompted than when not prompted $(n=1,6,10,5$, and 4 , respectively). Thus, mTurk participants are less likely to identify fraud risk factors when they are prompted to identify discrepancies within financial information than when they are not prompted to do so.

This finding is contrary to expectations as prompts should improve performance by increasing participants' focus. It is possible that mTurkers are less influenced by prompts than student participants. This finding is interesting as mTurkers' familiarity with mindfulness and emotion regulation implies that they have greater cognitive capacity to allocate toward prompts and

${ }^{21}$ The control condition was also used as a referent category. Results did not change. 
the experimental task than those unfamiliar with mindfulness and emotion regulation. Contrarily, mTurkers may simply be less attentive than student participants and prompts may not be sufficient to attract their attention. Aguinis, Villamor, and Ramani (2020) explain that mTurkers are less engaged than student participants in longer experiments, such as those that invoke metacognitive processes. This finding is interesting as mTurkers represent the general population and may be more like new entrants to the audit profession than graduate students. Audit practitioners are directing their mindfulness programs toward new practitioners (NF1 2021), who may already be familiar with mindfulness practices.

Results show that there is also a main effect of the control condition emotion regulation strategy [Wald $(1)=-5.804, b=-2.454, S E=1.019, p=0.0016$ ] on the ability to identify fraud risk factors. Further, mTurkers who reframe their negative thoughts as positive thoughts are more likely to identify $0,1,2$, or 3 fraud risk factors than mTurkers who suppress their emotions during the study; however, these results are not statistically significant, partially supporting H1a.

--Insert Table 15; Figures 7-

The effects of ERS (H1b) and Prompts on Accurate Identification of Fraud Risks (H2a and H2b)

I test hypotheses $\mathrm{H} 1 \mathrm{~b}, \mathrm{H} 2 \mathrm{c}$ and $\mathrm{H} 2 \mathrm{~d}$ within the mTurk sample to assess the effects of emotion regulation strategy and prompts on the ability to accurately recall details about fraud risk factors (i.e. Accuracy). I run a $3 \times 2^{22}$ between-subjects analysis of covariance (ANCOVA), controlling for participants' frequency practicing mindfulness or emotion regulation, and the

\footnotetext{
${ }^{22}$ Participant's evaluation of the likelihood that the firm was engaging in financial misreporting was initially
} included in the model, but the model violated the assumption of sphericity, and was modified accordingly. 
likelihood that the participant's current firm encourages mindfulness ${ }^{23}$. Using an alpha level of 0.05 to evaluate homogeneity assumptions, Levene's homogeneity of variance test is not statistically significant for both dependent variables $(p>0.01)$. Results indicate that the interaction effect of Prompt * ERS does not statistically significantly affects ability to accurately identify fraud risk factors $F(2,35)=0.057, p=0.945$, partial $\mathrm{\eta}^{2}=0.108$, refuting H2d. Additionally, mTurk participants assigned to the control condition who were not prompted were statistically significantly more accurate in identifying fraud risk factors when not prompted $(\mathrm{M}=5.19, \mathrm{SD}=1.77)$ than when prompted $(\mathrm{M}=4.56, \mathrm{SD}=2.16, p=0.083)$. The main effect for prompts $(\mathrm{H} 2 \mathrm{c})$ on the accurate identification of fraud risk factors is not statistically significant. Results suggest that the ability to accurately recall fraud risk factors identified $(\mathrm{H} 2 \mathrm{~d})$ is not affected by the interaction between the control emotion regulation condition and prompts; however, the main effect of accurately identifying fraud risk factors is not statistically significantly predicted by emotion regulation strategy with mTurk participants.

--Insert Table 16; Figure 8-

\section{Moderating Effect of Prompts (H3)}

To evaluate whether prompts moderate the relationship between ERS and the ability to accurately identify fraud risk factors, I examine the interaction between ERS and Prompt. A chisquare test for association is conducted between additional tests selected to address fraud risk factors identified and the prompts given to auditors. All expected cell frequencies were greater than five. There is no statistically significant association between additional test selected, $\chi^{2}(5,48)=$ $1.225, p=0.312$ (see Table 16). Likewise, the type of test selected is not statistically significantly

${ }^{23}$ The model controlled for gender, education level, position, and years of experience. 
related to prompts. Thus, while Hammersley et al. (2010) find that auditors identify additional procedures related to prompts, participants in this study did not correlate such procedures to discrepancies within the financial information in the experimental materials. It is also possible that mTurk participants did not feel that the discrepancies identified warranted further testing.

\section{Additional Substantive Testing Related to Prompts (H4)}

A chi-square test for association is conducted between additional tests selected to address fraud risk factors identified and the prompts given to auditors. All expected cell frequencies were greater than five. There is no statistically significant association between additional test selected and the number of fraud risks identified, $\chi^{2}(1) 0.126, p>0.10$. Likewise, the type of test selected is not statistically significantly related to prompts to identify discrepancies within financial information. Thus, while Hammersley et al. (2010) find that auditors identify additional procedures related to prompts, participants in this study did not correlate such procedures to discrepancies within the financial information in the experimental materials. It is also possible that study participants did not feel that the discrepancies identified warranted further testing. As such, participant's self-report that management is involved in financial misreporting is evaluated in supplemental analyses. These results indicate that mTurk participants do not correlate the fraud risks they identify with additional substantive tests.

In summary, mTurkers more accurately identify fraud risk factors when they are not prompted, as compared to when they are prompted. Thus, while the main effect of prompt is significant in the test of $\mathrm{H} 2 \mathrm{a}$, the direction of the finding is the opposite of that expected. Possible explanations for this finding may be that mTurkers 1) were able to reduce their cognitive capacity used on the emotion regulation manipulation and allocate cognitive resources to the task, or 2) prompted mTurkers experienced cognitive overload because of the prompt and experience the 
unintended consequences of being prompted, or 3) mTurk participants were inattentive during the study and the prompt manipulation was ineffective for them. While this study does not provide sufficient data to further examine these explanations, future research may examine the finding further.

\section{Tests of Hypotheses - Undergrads}

\section{The effects of ERS (H1a) and Prompts on Fraud Risk Identification (H2a and H2b)}

To evaluate whether differences in participants' frequency of practicing mindfulness or emotion regulation affect their ability to identify fraud risk factors, depending on whether prompts affect their ability to identify fraud risk factors, I test H1a, H2a, and H2b using a cumulative odds ordinal logistic regression with proportional odds to determine the effect of emotion regulation strategy on the ability to identify fraud risk factors. ${ }^{24}$ However, there were marginal proportional odds, as assessed by a full likelihood ratio test comparing the fitted model to a model with varying location parameters, $\chi^{2}(15)=24.214, p=0.062$. Similarly, the Pearson goodness-of-fit test indicated that the model is a moderately good fit to the observed data, $\chi^{2}(15)=22.961, p=0.085$, but 12 cells $(40.0 \%)$ had frequencies lower than five. The final model is not statistically significantly predictive of the dependent variable over and above the intercept-only model, $\chi^{2}(5)=4.686, p=0.455$, Pseudo $R^{2}=0.158$

Therefore, a multinomial logistic model is run to test hypotheses H1a, H2a and H2b. The Likelihood ratio test indicated that the model is not a good fit to the observed data, $\chi^{2}(8)=11.478$,

\footnotetext{
${ }^{24}$ The model was also run including controls for 1) frequency of mindfulness practices, frequency of emotion regulation practice, whether the participants' current firm encourages mindfulness, or 2) participant characteristics (i.e. years of experience, experience analyzing financial statements, education level, current job position, gender). However, the model fit was poor as many cell sizes were below 5 . As such, a separate chi square test of association was conducted to address these attributes to the error term in this model. No significant relationships existed.
} 
$p=0.176$. The final model statistically significantly predicted the dependent variable over and above the intercept-only model, $\chi^{2}(32)=47.117, p=0.041$, Pseudo $R^{2}=0.873$. Using zero as a reference category, results show that there is no statistically significant difference in whether undergraduate student participants identify $1,2,3$, or 4 fraud risk factors, as compared to identifying zero fraud risk factors, regardless of which emotion regulation (H1a) or prompt (H2a) condition they are assigned to. Similarly, the interaction between emotion regulation strategy and prompt to be mindful of discrepancies within financial information $(\mathrm{H} 2 \mathrm{~b})$ did not statistically significantly predict whether undergraduate students identified 1,2,3 or 4 fraud risk factors as compared to identifying zero fraud risk factors.

However, there is a main effect of the frequency with which undergraduate students practice emotion regulation and the likelihood that they would identify two fraud risk factors. Specifically, the when emotion regulation frequency increases by 1 unit, the probability of choosing two fraud risk factors is 2.951 times higher than the selecting zero fraud risk factors. While this finding is interesting, multinomial results are difficult to generalize because of their specificity and the fact that emotion regulation is correlated with identifying two as opposed to zero fraud risk factors does not provide context about undergraduate students' behavior.

--Insert Table 17; Figure 9-

\section{The effects of ERS (H1b) and Prompts on the Accurate Identification of Fraud Risks (H2c and H2d)}

I test hypotheses $\mathrm{H} 1 \mathrm{~b}, \mathrm{H} 2 \mathrm{c}$ and $\mathrm{H} 2 \mathrm{~d}$ within the Undergrad sample to assess the effects of emotion regulation strategy and prompts on the ability to accurately recall details about fraud risk 
factors (i.e. Accuracy), I run a $3 \times 2^{25}$ between-subjects analysis of covariance (ANCOVA), controlling for participants' frequency practicing mindfulness or emotion regulation, and the likelihood that the participant's current firm encourages mindfulness ${ }^{26}$. Using an alpha level of 0.05 to evaluate homogeneity assumptions, Levene's homogeneity of variance test is not statistically significant for both dependent variables $(p>0.01)$. Results indicate that there is no main effect of emotion regulation strategy $(\mathrm{H} 1 \mathrm{~b})$ or prompt $(\mathrm{H} 2 \mathrm{c})$ to be mindful of discrepancies within financial information on the ability to accurately identify fraud risk factors. Similarly, there is no interaction effect between emotion regulation strategy and prompt on the ability to accurately identify fraud risk factors, refuting $\mathrm{H} 2 \mathrm{~d}$.

These results indicate that the ability to accurately identify fraud risk factors is not predicted by emotion regulation strategies or prompts with Undergrad participants.

--Insert Table 18; Figure 10-

\section{Moderating Effect of Prompts (H3)}

To evaluate whether prompts moderate the relationship between ERS and the ability to accurately identify fraud risk factors, I examine the interaction between ERS and Prompt. Given that the interaction between ERS and prompt is not statistically significant, it is unsurprising that prompts do not either moderate or mediate the relationship between ERS and the ability to accurately identify fraud risk factors.

\footnotetext{
${ }^{25}$ Participant's evaluation of the likelihood that the firm was engaging in financial misreporting was initially included in the model, but the model violated the assumption of sphericity, and was modified accordingly. ${ }^{26}$ A separate model also controlled for gender, education level, position, and years of experience. Results did not statistically significantly differ.
} 


\section{Additional Substantive Testing Related to Prompts (H4)}

A chi-square test for association is conducted between additional tests selected to address fraud risk factors identified and the prompts given to auditors. All expected cell frequencies were greater than five. There is a statistically significant association between Undergrads identifying a fraud risk factor in the allowance for doubtful accounts and selecting an additional test selected to recalculate the allowance for doubtful accounts, $\chi^{2}(1)=8.571, p=0.003$. This finding is important as Undergrads were the only sample group to identify the need to perform additional tests related to an important fraud risk in the materials provided. These results indicate that Undergrads correlate some fraud risks with additional tests to address the risks, partially supporting H4 for Undergrads.

\section{Tests of Hypotheses - Grads}

\section{The effects of ERS (H1a) and Prompts on Fraud Risk Identification (H2a and H2b)}

To evaluate whether differences in participants' frequency of practicing mindfulness or emotion regulation affect their ability to identify fraud risk factors, depending on whether prompts affect their ability to identify fraud risk factors, I test $\mathrm{H} 1 \mathrm{a}, \mathrm{H} 2 \mathrm{a}$, and $\mathrm{H} 2 \mathrm{~b}$ using a cumulative odds ordinal logistic regression with proportional odds to determine the effect of emotion regulation strategy on the ability to identify fraud risk factors. There were proportional odds, as assessed by a full likelihood ratio test comparing the fitted model to a model with varying location parameters, $\chi^{2}(15)=16.950, p=0.322$. The Pearson goodness-of-fit test indicated that the model was a good fit to the observed data, $\chi 2(15)=14.008, p=0.520$, but 5 cells $(16.7 \%)$ had frequencies lower than five. The final model did not statistically significantly predict the dependent variable over and above the intercept-only model, $\chi 2(5)=8.524, p=0.130$, Pseudo $R^{2}=0.171$. As such, results show that there is no statistically significant effect of emotion regulation strategy (H1a) or prompt (H2a) on the ability to identify fraud risk factors. Similarly, there is no interaction effect between emotion regulation 
strategy and prompt (H2b). However, the model does not fit the data well and only explains 17.,1\% of the variance in graduate students' ability to identify fraud risk factors.

To improve the model, controls for mindfulness frequency, frequency practicing emotion regulation and the likelihood that the participant's current firm encourages mindfulness practices. However, the assumption of parallel lines was violated in this model. Therefore, a multinomial logistic regression was run to assess the effects of emotion regulation strategy and prompts on the ability to identify fraud risk factors. There was no statistically significant difference in the likelihood that graduate students would select 1,2, 3, or 4 fraud risk factors, as compared to zero fraud risk factors.

--Insert Table 19; Figure 11-

\section{The effects of ERS (H1b) and Prompts on the Accurate Identification of Fraud Risks (H2c and H2d)}

I test hypotheses $\mathrm{H} 1 \mathrm{~b}, \mathrm{H} 2 \mathrm{c}$ and $\mathrm{H} 2 \mathrm{~d}$ within the Grads sample to assess the effects of emotion regulation strategy and prompts on the ability to accurately recall details about fraud risk factors (i.e. Accuracy), I run a $3 \times 2^{27}$ between-subjects analysis of covariance (ANCOVA), controlling for participants' frequency practicing mindfulness or emotion regulation, and the likelihood that the participant's current firm encourages mindfulness ${ }^{28}$. Using an alpha level of 0.05 to evaluate homogeneity assumptions, Levene's homogeneity of variance test is not statistically significant for both dependent variables $(p>0.01)$. Results indicate that the main effects for emotion regulation strategy (H1b) and prompting participants to be mindful of discrepancies within financial

\footnotetext{
${ }^{27}$ Participant's evaluation of the likelihood that the firm was engaging in financial misreporting was initially included in the model, but the model violated the assumption of sphericity, and was modified accordingly.

${ }^{28}$ A separate model also controlled for gender, education level, position, and years of experience. Results did not statistically significantly differ.
} 
information $(\mathrm{H} 2 \mathrm{c})$ on the accurate identification of fraud risk factors were not statistically significant. Results further show that the interaction between emotion regulation strategy and prompts $(\mathrm{H} 2 \mathrm{~d})$ is also not statistically significant.

--Insert Table 20; Figure 12-

However, this model likely suffers from low power as a visual inspection of a plot of fraud risks identified by emotion regulation condition shows that graduate students in the suppress condition exhibit variability in the number of fraud risk factors they identify. However, the shape of the distribution for the fraud risk factors graduate student participants identify in the control and reframe conditions is curvilinear. This finding has potential implications for audit firms implementing mindfulness programs as there may be a point at which the emotion regulation strategy is less salient than the effects of emotion suppression when auditors are also prompted. Further, participants assigned to the suppress/prompt $=\mathrm{N}$ condition were less likely to identify 1,3 , or 4 fraud risk factors, as compared to Grads in the reframe condition. Also, Grads in the suppress/prompt $=\mathrm{N}$ condition identify 3 or 4 fraud risk factors in alignment with theoretical expectations for emotion regulation strategy. That is, those in the suppress condition are least likely to identify 3 or 4 fraud risk factors, and those in the reframe condition are most likely to identify a higher number of fraud risk factors. Similarly, Grads who are prompted are more likely to identify $1,2,3$, or 4 fraud risk factors and less likely to identify 0 fraud risk factors than those who are not prompted. However, Grads in the reframe condition who are prompted are less accurate in their identification of fraud risk factors than those in the control or suppress conditions, contradicting the impact of cognitive load theory on emotion regulation. Although these findings are not statistically significant, the data trends are interesting as they support the impact of emotion suppression on cognitive load by showing that when participants engage in emotion suppression, the number of 
fraud risk factors they identify is lower than other emotion regulation strategies, but that the difference is mitigated when participants are prompted to focus on indicia of fraud risk.

\section{Moderating Effect of Prompts (H3)}

To evaluate whether prompts moderate the relationship between ERS and the ability to accurately identify fraud risk factors, I examine the interaction between ERS and Prompt. The interaction effect of ERS x prompt does not have a statistically significant effect on the accurate identification of fraud risk factors. Therefore, prompts do not moderate or mediate (refuting H3) the relationship between ERS and the ability to accurately identify fraud risk factors.

\section{Additional Substantive Testing Related to Prompts (H4)}

A chi-square test for association is conducted between additional tests selected to address fraud risk factors identified and the prompts given to auditors. All expected cell frequencies were greater than five. There is no statistically significant association between additional test selected and the number of fraud risks identified, $\chi^{2}(1) 0.823, p>0.10$. Likewise, the type of test selected is not statistically significantly related to prompts to identify discrepancies within financial information (i.e. all odds ratios were less than 1). Thus, while Hammersley et al. (2010) find that auditors identify additional procedures related to prompts, participants in this study did not correlate such procedures to discrepancies within the financial information in the experimental materials. It is also possible that study participants did not feel that the discrepancies identified warranted further testing. As such, participant's self-report that management is involved in financial misreporting is evaluated in supplemental analyses. These results indicate that Grad participants do not correlate the fraud risks they identify with additional substantive tests. 


\section{Between Sample Analysis}

Conducting within-sample analysis produces interesting results related to prompts. However, the sample sizes are so small with such analysis that power is not achieved, and results may only be utilized as guidance for future research. To expand on the opportunities for future research, I conduct a comparative analysis of the descriptive statistics between participant samples to highlight data trends.

For example, as described previously, participants in this study are either prompted to be mindful of discrepancies within financial information or not. While prompts are commonly used in audit practice to hone auditors' focus to specific matters (Hobson et al. 2017, Brazel et al. 2014; Hammersley et al. 2010), they also induce cognitive processing and may impair cognitive load (Roelle et al. 2015; Block et al.2010). This study finds that Amazon Mechanical Turk workers in the prompt-Yes condition are less accurate in identifying fraud risk factors than those who are not prompted. Student participants, however, more accurately identify fraud risk factors when prompted than when not prompted (see Figure 14). Similarly, Figure 15 shows that participants who both told to suppress their emotions and are prompted to be mindful of discrepancies within financial information are more likely to vary in the number of fraud risk factors they identify. That is, while the number of identified fraud risk factors form a curvilinear shape in all the other conditions in this study (i.e. Suppress/No Prompt, Reframe/Yes Prompt, Reframe/No Prompt, Control/Yes Prompt, Control/No Prompt), the shape of the distribution of identified fraud factors in the Suppress/Yes Prompt condition approximates a bimodal distribution. While these results are not statistically significant, future studies should examine when and how prompts affect audit professionals and non-professional audit research participants. 


\section{Supplemental Analyses}

In addition to the variables of interest, I collect process measures related to participants' perceptions about the financial information evaluated during the study. For example, participants' belief that the company may have engaged in financial misreporting may impact the number of additional substantive tests they select to address the fraud risk factors. Alternatively, the number of fraud risk factors identified may influence participants' perception of whether the company is engaged in financial misreporting or not.

Financial Misreporting. Examining whether participants believed company management of the firm described in the experimental materials committed financial misreporting likely impacts the identification of fraud risk factors. That is, if a participant believed the company is engaging in fraudulent financial reporting, they may be more likely to identify a higher number of fraud risk factors in the company's financial information than if they do not believe the company is engaging in such activities. In this study, participants assigned to the Suppress condition may still feel negative affect but are told to contain such feelings. These negative feelings may influence participants' beliefs in whether the company is engaging in financial misreporting. Conversely, participants in the Reframe condition are told to replace negative affect with positive affect. Therefore, they may be less likely to perceive that the company is engaging in misconduct. I examine whether such differences exist between these conditions and between sample source, based on the differences in mTurkers and student participants noted previously.

A one-way ANOVA is conducted to examine the effects of sample, ERS, and prompts on the likelihood management is engaging in financial misreporting ("FRF"). Residual analysis is performed to test for the assumptions of the ANOVA. Outliers were assessed by inspection of a boxplot; normality is assessed using Shapiro-Wilk's normality test for each cell of the design and 
homogeneity of variances is assessed by Levene's test. There were no outliers, residuals were normally distributed $(p>.05)$ and there is homogeneity of variances $(p=0.287)$.

The main effect of sample on the likelihood that financial misreporting is occurring is statistically significant, $F(2,129)=3.069, p=0.050$, partial $\eta 2=0.052$. No other relationships were statistically significant. All pairwise comparisons were run where reported $95 \%$ confidence intervals and p-values are Bonferroni-adjusted. The unweighted marginal means of financial misreporting scores for mTurkers, undergraduate students and graduate students were 44.854 (SE $=3.052), 50.00(\mathrm{SE}=4.142)$ and $55.68(\mathrm{SE}=3.13)$, respectively. The mean difference between

mTurkers $(44.85,95 \%$ CI $[38.81,50.90])$ and graduate students $(55.68,95 \%$ CI $[49.48,61.88])$ of -10.83 is statistically significantly different, $p=0.05$. That is, mTurkers are less likely to believe that the company is engaging in fraudulent financial reporting than graduate students. However, the difference is not affected by emotion regulation strategy or whether the participant is prompted. This finding indicates that, although participants' ability to identify fraud risk factors does not differ (H1a), even when they are prompted to consider such factors (H2a), there are differences in how mTurkers and graduate students interpret the experimental materials. These differences may relate to the participants' attentiveness and allocation of their cognitive resources in this study.

--Insert Table 23 and Figures 13-14--

\section{CONTRIBUTIONS, LimitaTIONS, AND SUGgESTIONS FOR FUTURE RESEARCH}

My study contributes to audit literature by highlighting potential boundary conditions with the effectiveness of prompts. This study includes several limitations and provides suggestions for future research. In addition, the effects of cognitive processing, construct familiarity, or experience may impact the effectiveness of prompts. 


\section{Sampling}

While the present study yielded small sample sizes and misaligned participants, the findings gave rise to additional research questions. Experimental research suffers from participants' selfselection bias, therefore, future studies in mindfulness in accounting may seek mixed methods designs to include survey or firm-sourced secondary data. Suggestions for alternative study designs and future research are provided in the following section.

\section{Increasing Mundane Realism May Increase the Salience of Mindfulness Practices}

This study only includes one participant, but emotion regulation strategies are most often deployed when individuals interact, and such interactions may have a stronger effect on emotion regulation in future studies (see Curtis, Dennis, and McNamara 2017; Burgoon et al. 2002). Interpersonal emotion regulation is dynamic and more likely relevant to accounting (Zaki and Williams 2013). Emotions elicited in social interactions are qualitatively different from individual decisions (Grecucci et al. 2013). For example, individual decision-making does not involve social contexts of fairness, equity, cooperation, and socially driven emotions (Grecucci et al.2013), which trigger emotional response. The level of emotional response is impacted by others' responses to an individual's emotional reaction and each party's emotional competence (Goleman 2001). Auditors are more likely to engage in emotion suppression when facing difficult client interactions than just when prompted.

Analysis of the effect of prompts on the ability to identify fraud risk factors shows that participants in the Suppress condition behave differently than those in the Control or Reframe conditions in this study. Specifically, while the number of fraud risk factors in the prompt $=$ Yes condition has a curvilinear shape in the Reframe and Control ERS conditions, the distribution varies in the Suppress condition as shown in figure 16. 
Auditors may suppress their emotions during difficult client meetings to maintain a poker face. Therefore, future studies may evaluate the effects of emotion suppression or cognitive reappraisal when dyads of auditors or auditors and auditees interact, and whether these effects differ by the dyad's composition (Wong, Tschan, Messerli, and Semmer 2013).

\section{Alternative Mindfulness Practices May Have a Stronger Effect on Fraud Risk Detection}

To achieve ecological validity, this study only evaluates specific components of mindfulness. Mindfulness includes both physiological and emotion self-regulation practices. Physiological regulation includes moderating breathing and heart rate with a goal of reducing emotion-betraying psychophysiological reactions (Mauss and Robinson 2010). Shapiro and Schwartz (2000) find that conscious attention to breathing results in even, deeper breaths and intentional regulation of heart rate leads to rhythmic regularity, but shallow breathing. Prior literature shows that heart rate is negatively related to emotion regulation, while heart rate variability is positively related to emotion regulation (Mason, Scrimm, Zaccoletti, Tornatra, and Goetz 2018; Denson, Grisham, and Moulds 2011). Further, heart rate variability is positively related to multiple-text comprehension (Mason et al. 2018).

Accounting firms emphasize the use of meditation as a mindfulness practice. Meditation includes the regulation of breathing and heart rate. The present study does not evaluate the physiological attributes of mindfulness, which may have a stronger effect on fraud risk detection than mere primes. Future research should also consider the effects of mindful meditation on fraud risk detection. Further, auditors' ERS may be assessed via physiological measurements, such as skin conduction or functional electroencephalograph images (Troy et al. 2013). Other studies may also evaluate the effects of ERS on cognitive dissonance markers (Hobson et al. 2017) in auditee commentary or earnings call transcripts. 
In addition, this study only evaluates the effect of two out of six emotion regulation strategies on auditors' ability to recall details about fraud risk factors at one point in time. Additional studies may examine the effects of other ERS on audit processes or may measure ERS in different ways. Other emotion regulation strategies, such as emotion exaggeration/amplification, may be more beneficial than suppression (Koole 2009) or may decrease working memory (Schmeichel 2007) to the same degree as emotion suppression. Future studies may evaluate the effects of emotion exaggeration or other emotion regulation strategies on audit quality-threats. Likewise, emotional modification strategies, such as surface acting, may have differing effects on auditors' ability to identify fraud risk factors. Extensions of this study may include mindfulness or emotion regulation practices over a longer period with student populations to both increase the salience of the constructs and capitalize on subjects' knowledge of the audit process.

Mindfulness is both a state-level and trait-level attribute. Prior research shows that increases to trait-level mindfulness increases state-level mindfulness (Chang and Stone 2019: Kiken et al. 2015); however, I only manipulate mindfulness at a single point in time. This singularity also negates the implications of the temporal nature of emotion regulation (Gross 2013), which explains that emotion regulation is a process during which each goal-activated strategy is deployed. For example, emotion suppression occurs while an individual cognitively processes an event; however, cognitive reappraisal occurs before an event occurs. Future studies may also examine the temporal or longitudinal effects of mindfulness on fraud risk detection.

\section{When and Why Does the Effect of Prompts Differ?}

Prompts may produce unintended consequences with certain participant pools or when participants experience high cognitive load when evaluating fraud risk factors. This study finds that prompts to identify discrepancies within financial information yield differing effects of 
participants' ability to accurately recall fraud risk factors. However, the data does not lend itself to further inquiry as to why such difference exists because the difference is noted between samples. For example, mTurkers' attention or cognitive processing may be less than other groups in this study. Alternatively, graduate students may have experienced excessive cognitive load because of their lack of familiarity with mindfulness, or they may have allocated their cognitive resources to the experimental task instead of using some of it for the emotion regulation strategy to which they were assigned. Future research may examine whether and how participant characteristics affect the usefulness of prompts, or whether boundary conditions limit the cognitive processing induced by prompts. Prompts likely induce greater cognitive processing when they are fully understood, and individuals can elaborate information subsequently received. As such, future studies may examine whether bias, affect, or self-regulation (as discussed in this study) impact the effectiveness of prompts.

\section{Does Construct or Audit Process Familiarity Have a Greater Effect on Sample Selection?}

The present study finds variance in the effectiveness of prompts between samples of proxies for auditors (i.e. mTurkers and graduate students) ${ }^{29}$. mTurkers in this study are more familiar with the constructs of interest (i.e. mindfulness and emotion regulation) and are more likely to engage with them. As such, I find that mTurkers' cognitive processing times align with emotion regulation theory (e.g. greater processing times for emotion suppression than reappraisal). However, graduate students' cognitive processing does not follow suit. It is possible that the metacognitive processing exhibited during the experimental task increases cognitive load to the point that the cognitive effects

\footnotetext{
${ }^{29}$ mTurker and graduate student participants in this study are demographically similar, with the exception of number of years' tenure in their current profession. However, their results in this study are often statistically significantly different, thus comparing and contrasting these groups offers additional research opportunities.
} 
of emotion regulation is reduced for graduate students. That is, graduate students are so focused on the task that the emotion regulation strategy to which they are assigned is not utilized during the study.

These differences yield additional methodological research questions regarding the impact of construct familiarity on selecting the appropriate sample for audit research. In light of Leiby et al.'s (2021) forthcoming publication related to the use of proxies for audit judgment and decisionmaking research, future studies should examine whether merely soliciting participants from the various online sources is appropriate, given both the research question and study design. For instance, audit practitioners use prompts from early in their tenure, often before they graduate with an undergraduate degree. However, the prompts may not be as effective for new employees, who are more like the general population than those with experience. While Leiby et al. (2021) emphasize the importance of considering the research question with sample selection and the use of non-professional participants to achieve power, their study is silent regarding experimental design. Future research may examine the balance needed between experimental task and research question in sample selection in an audit setting.

\section{Antecedents to Mindful Emotion Regulation May Influence Results}

While this study manipulates mindful emotion regulation and measures its effect on fraud detection, antecedents to mindful self-regulation may modify the relationship. Therefore, future studies may consider examining the effect participant characteristics have on mindful selfregulation, such as gender or affect. For example, Nolen-Hoeksema (2012) finds that women are more likely to ruminate on their emotions and dissect them while men use external coping mechanisms, such as alcohol, to regulate their emotions. This finding supports Zlomke and Hahn's (2008) prior finding that women not only ruminate on their issues more frequently than men but 
are also more likely to consider multiple perspectives and are less likely to blame others for their problems. McRae, Ochsner, Mauss, Gabrieli, and Gross (2008) explain that these differences are likely because men engage in lower levels of cognitive processing than women when regulating emotion, and women are more likely to use positive affect when engaging in cognitive reappraisal. In this study, there is a higher number of men than women across conditions and samples. Therefore, the results may be affected by gender bias. Future studies should examine whether gender affects emotion regulation strategy in an audit context.

In addition to gender, trait-level affect may influence one's ability to regulate emotions and/or the emotion regulation strategy employed. For example, emotion suppression is positively correlated with negative affect, while cognitive reappraisal is positively correlated with positive affect. While my study randomly assigns participants, who experience positive and negative affect into each condition, future studies may evaluate the effects of positive or negative affect on ERS selection.

\section{Extension to Other Subjects Within Fraud Detection Population}

The present study evaluates the effect of auditors' emotional regulation strategy on fraud detection. However, auditors are only one group of individuals involved in the detection of fraud. For example, in addition to literature on auditors' role in fraud detection, a large and growing body of literature examines linguistic and numeracy clues in financial reports that may lead informed investors to detect fraud (Chen, Wu, Chen, $\mathrm{Li}$, and Chen 2017). Informed investors act as an external governance mechanism for firms (Dyck, Morse, and Zingales 2010) by participating in corporate earnings calls (Cen, Chen, Dasgupta, Ragunathan 2021; Haag, Hofmann, Paulus, Schwaiger, and Sellhorn 2020) and evaluating firm financial information. This involvement in the financial reporting process facilitates a familiarity with financial statement analysis, the 
experimental task in this study. Therefore, future research may examine whether the results in this study may differ based on who detects fraud (e.g. informed investors, corporate accountants, internal or external auditors, third parties, etc.).

\section{CONCLUSION}

The present study examines the effects of emotion regulation strategy, a mindfulness practice, and prompts on auditors' ability to identify fraud risk factors and recall the fraud risk factors identified. Mindfulness is a fast-growing trend that is promoted by large accounting firms and corporations as a mechanism for improving focus and decision-making and reducing stress. Accounting practitioners who practice mindfulness report feeling more confident in client negotiations and presentations (NF2 2021) and feeling less stressed (F1 2021). Although accounting firms promote the use of mindfulness, particularly with new employees, and mindfulness has been shown to improve audit quality (Herda, et al. 2018b), such practices have not been widely adopted. Where mindfulness has been adopted, firms provide general guidance on the benefits of practicing mindfulness but fail to explain that different mindfulness practice may yield differing results.

For example, emotion self-regulation may be performed in various ways, including suppressing emotion or engaging in cognitive reappraisal of the situation. Emotion suppression adds to cognitive load, taxing the individual's ability to perform well. Cognitive reappraisal, however, does not affect cognitive load and improves one's positive affect. Therefore, this study examines whether engaging in emotion suppression or cognitive reappraisal affect auditor's ability to identify fraud risk factors or accurately recall fraud risk factors in an experimental design.

Results show that while emotion regulation strategy (i.e. emotion suppression or cognitive reappraisal) does not affect auditors' ability to identify fraud risk factors or accurately recall fraud risk factors, the effect of prompts differs between participant. Specifically, participants who are 
more representative of the general population (i.e. mTurkers) and are prompted, less accurately identify fraud risk factors than those who are not prompted to do so. This effect may be due to the allocation of cognitive resources used by mTurkers in the study, or the impact of cognitive overload on graduate student participants due to their lack of familiarity with mindfulness. While this study does not provide sufficient measures to ascertain why such differences exist, it provides several suggestions for future research to examine this research question. 


\section{Figures AND TABLES}

Figure 2 Theoretic Model of the Effect of Mindfulness on Fraud Detection

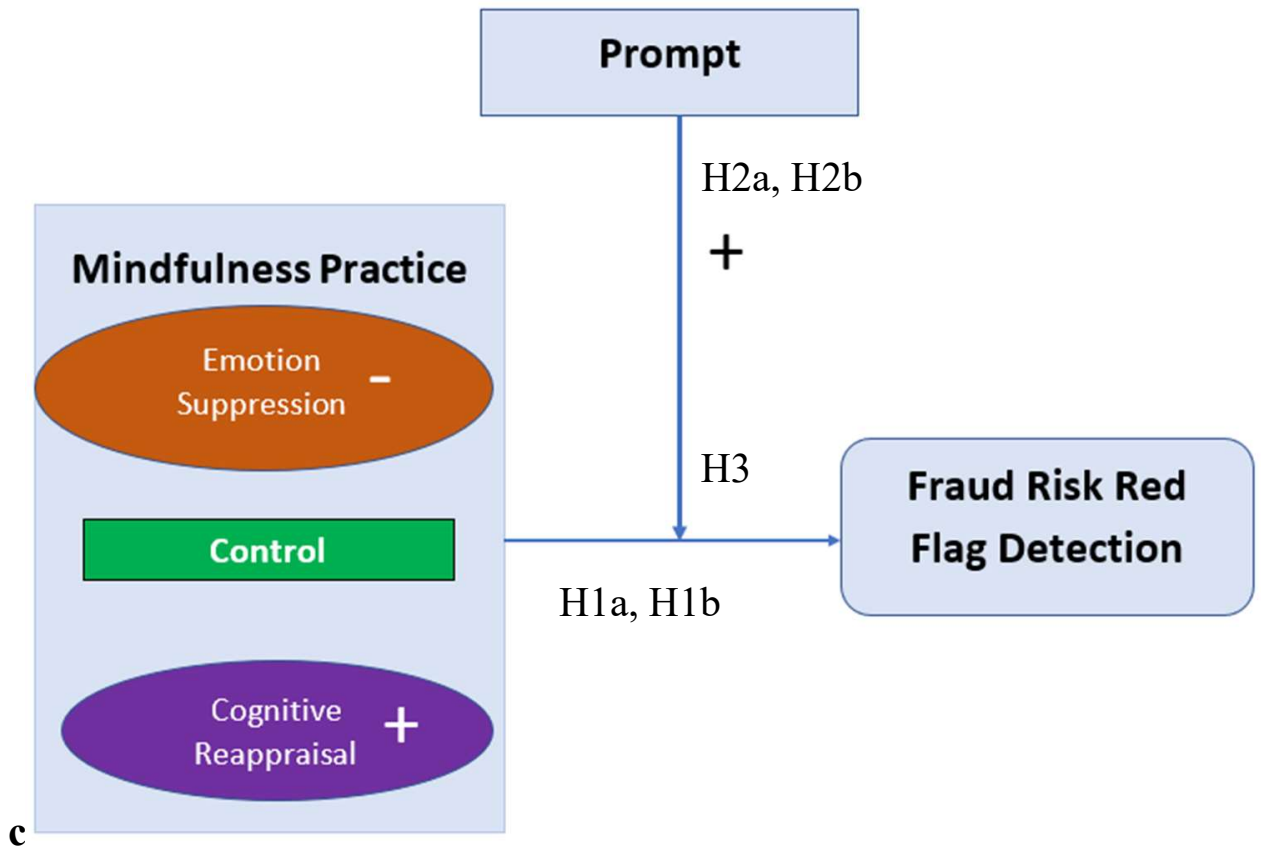

Figure 3 Frequency of Practicing Mindfulness by Sample

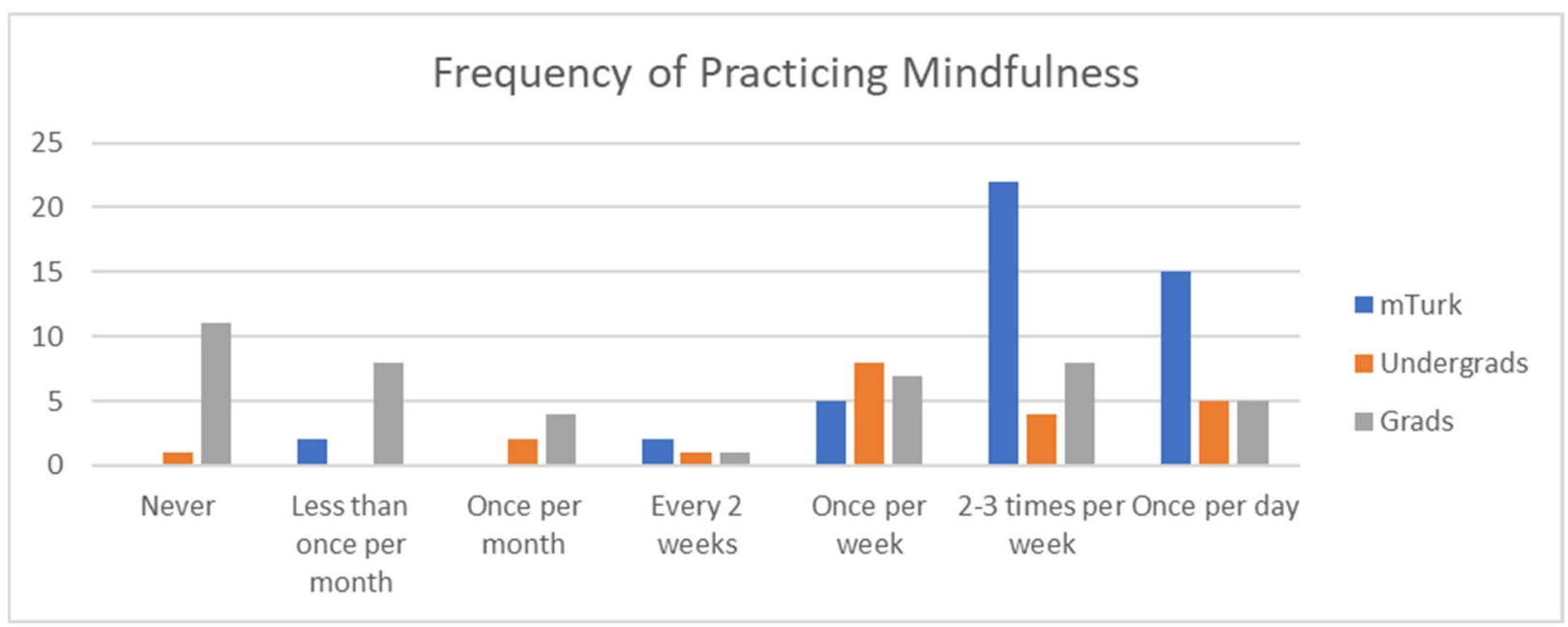


Figure 4 Level of Education by Sample

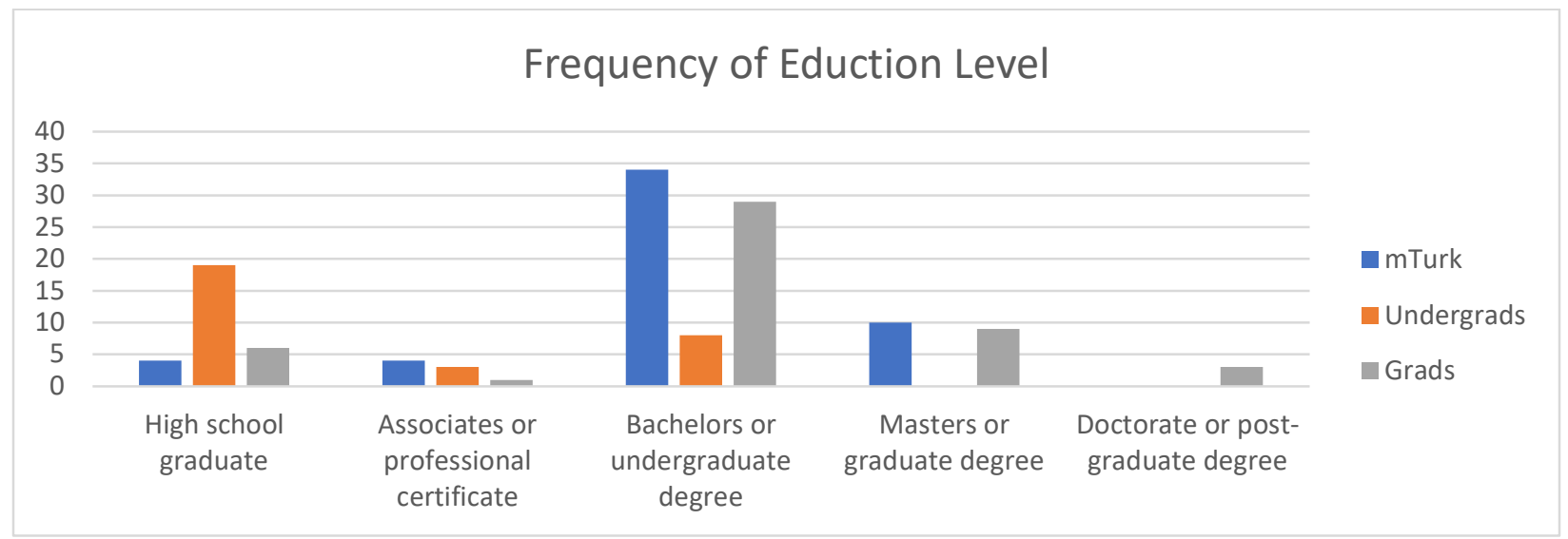

Figure 5 Mean Years of Experience by Sample

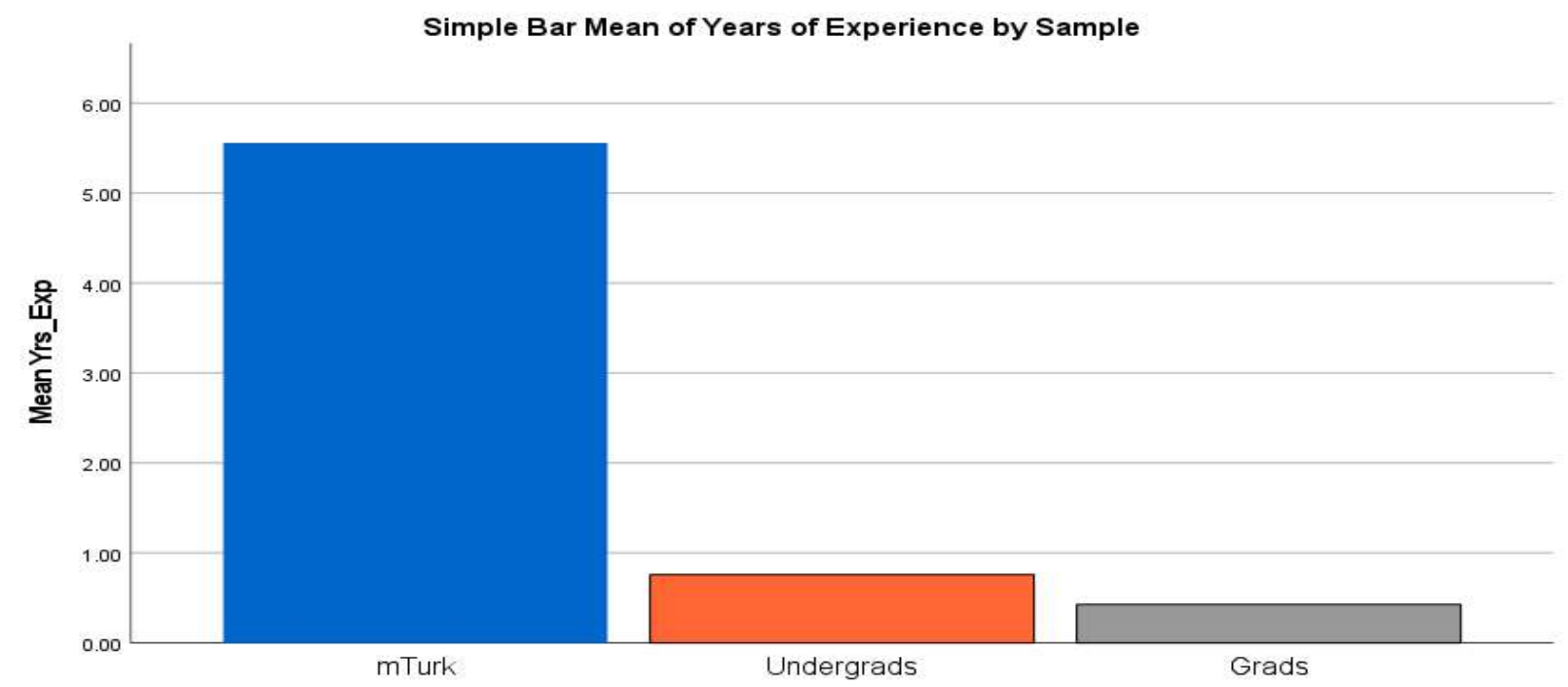


Figure 6 Median Duration to Complete the Study in Minutes by Sample

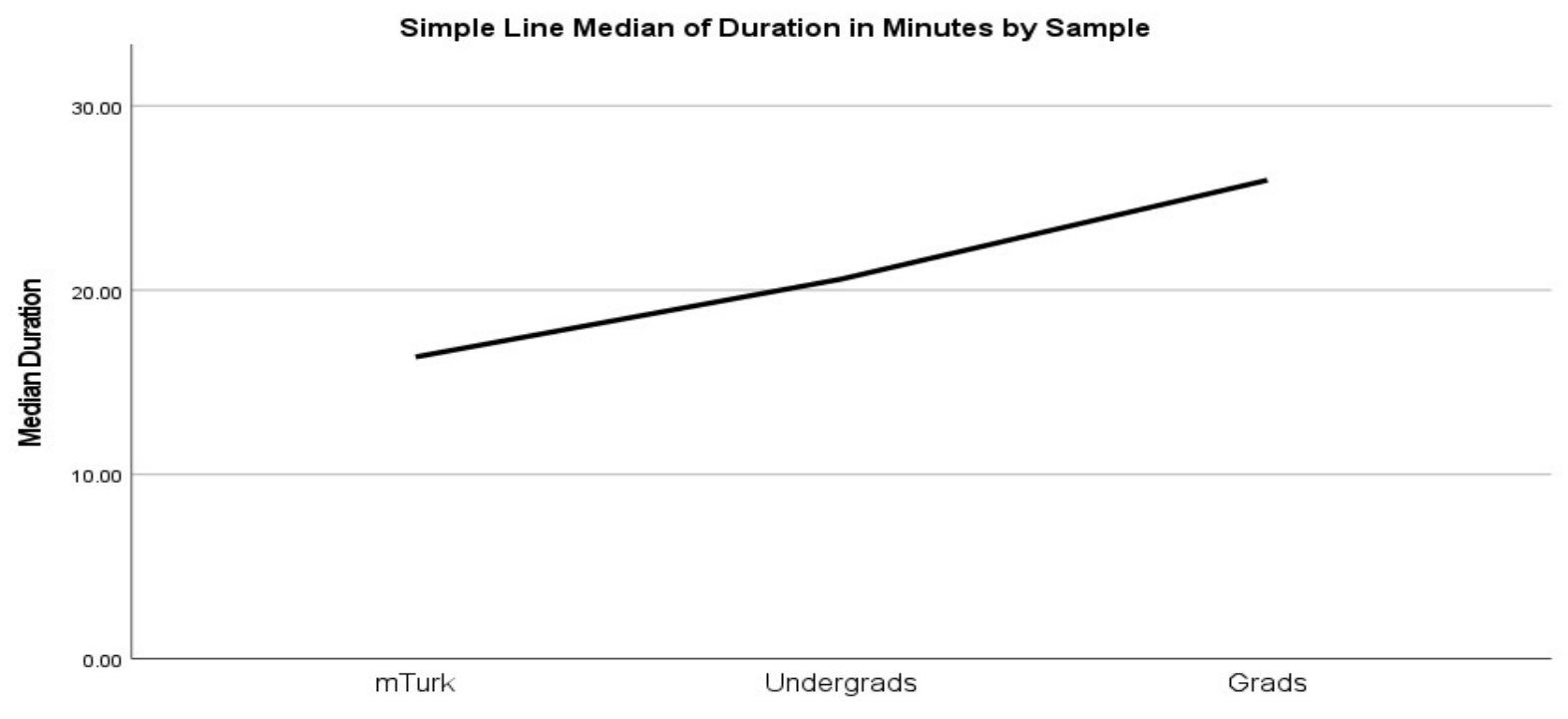


Figure 7 Quantity of Fraud Risk Factors Identified by mTurkers, Depending on Whether They are Prompted to Consider Discrepancies within Financial Information or Not

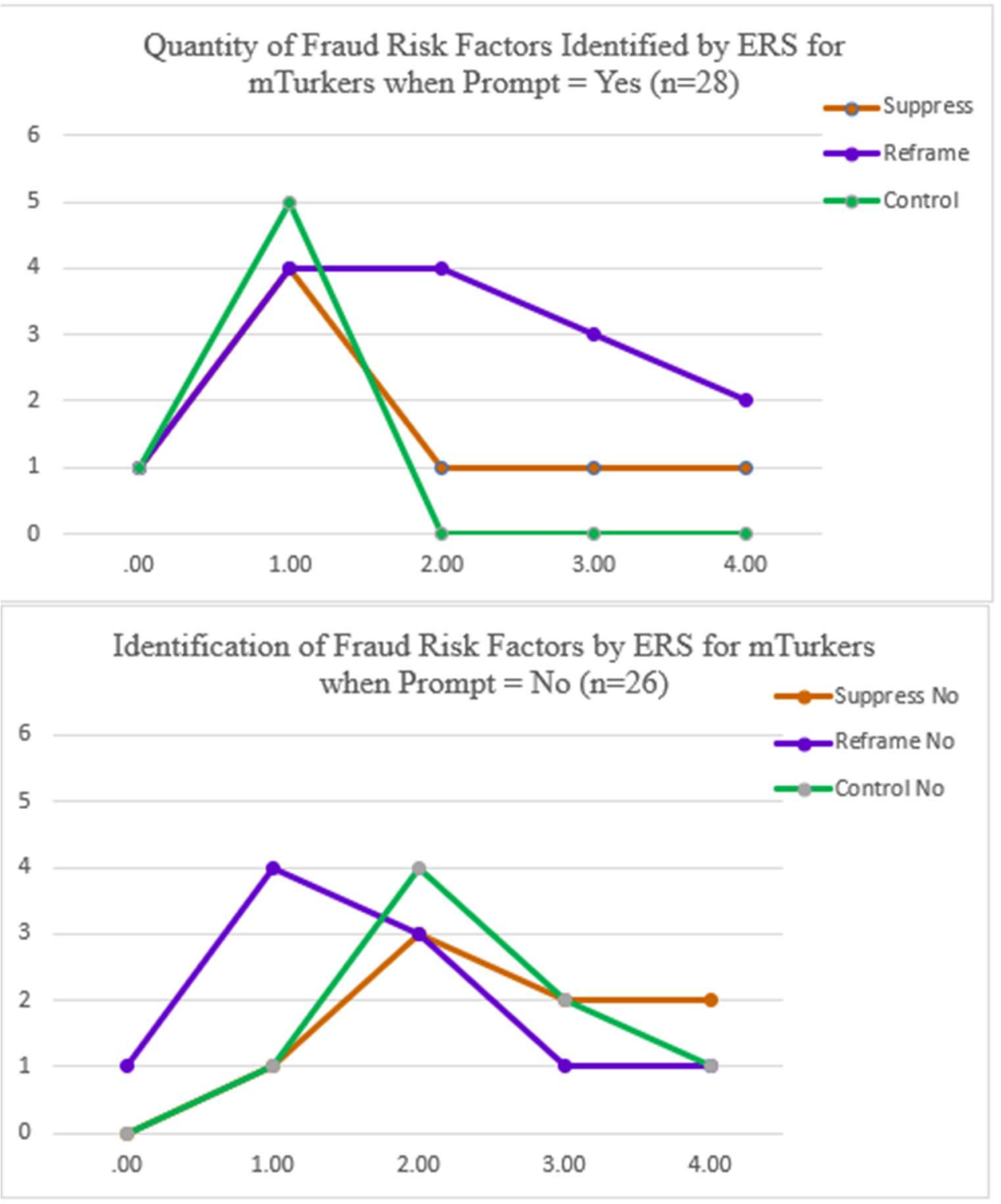


Figure 8 Accuracy of Fraud Risk Factors Identified by mTurkers

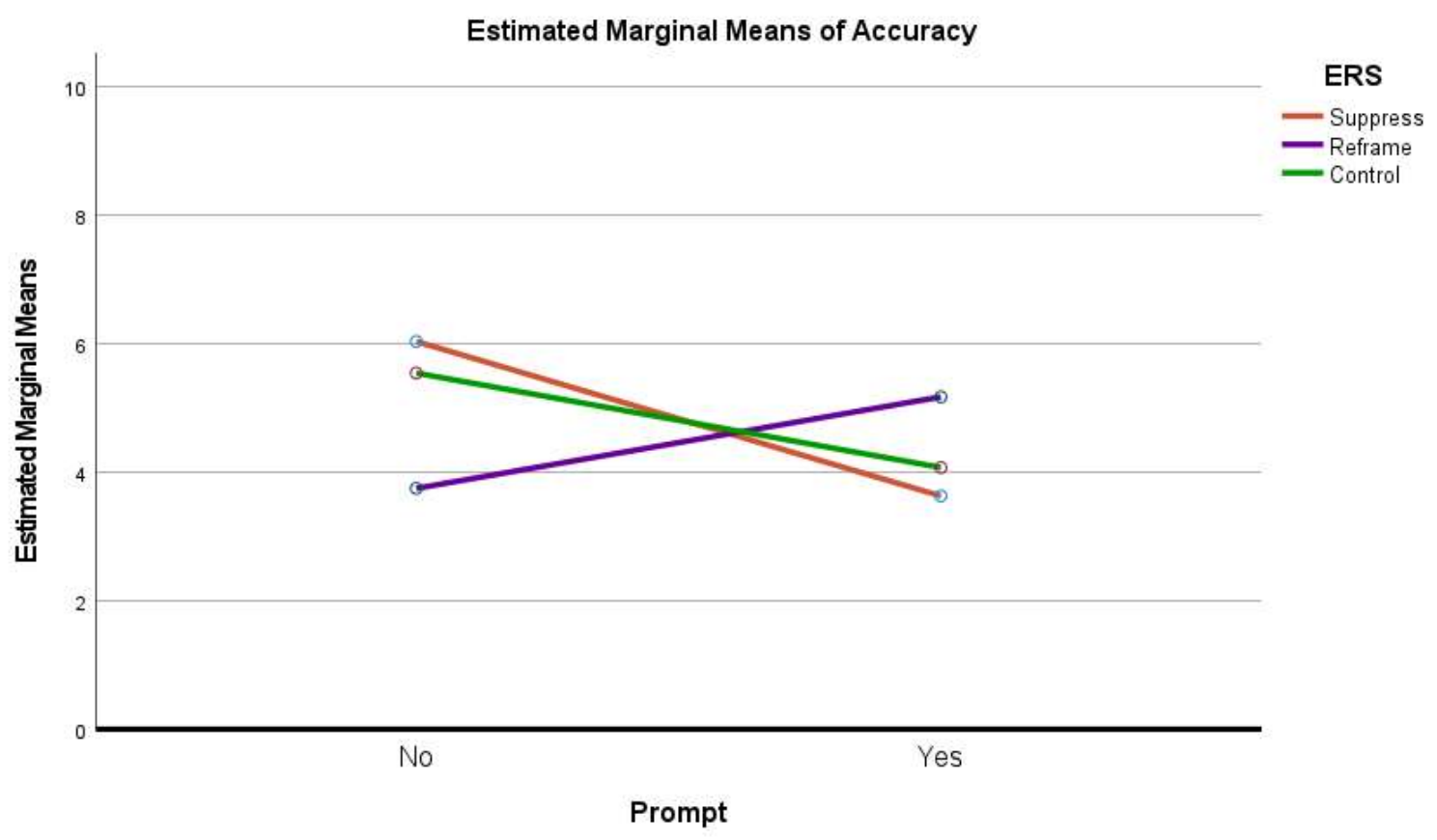


Figure 9 Quantity of Fraud Risk Factors Identified by Undergrads, Depending on Whether They are Prompted to Consider Discrepancies within Financial Information or Not

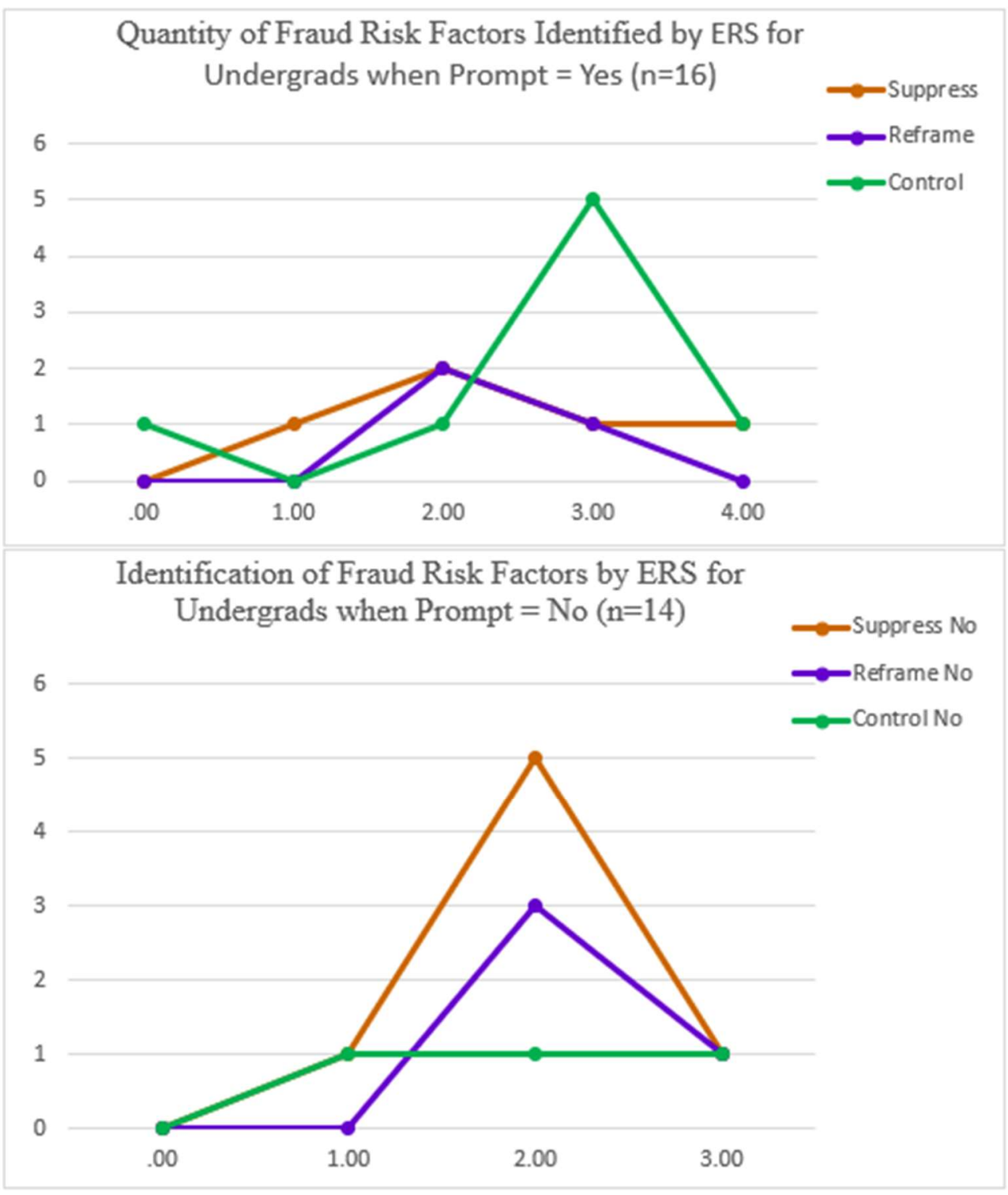


Figure 10 Accuracy of Fraud Risk Factors Identified by Undergrads

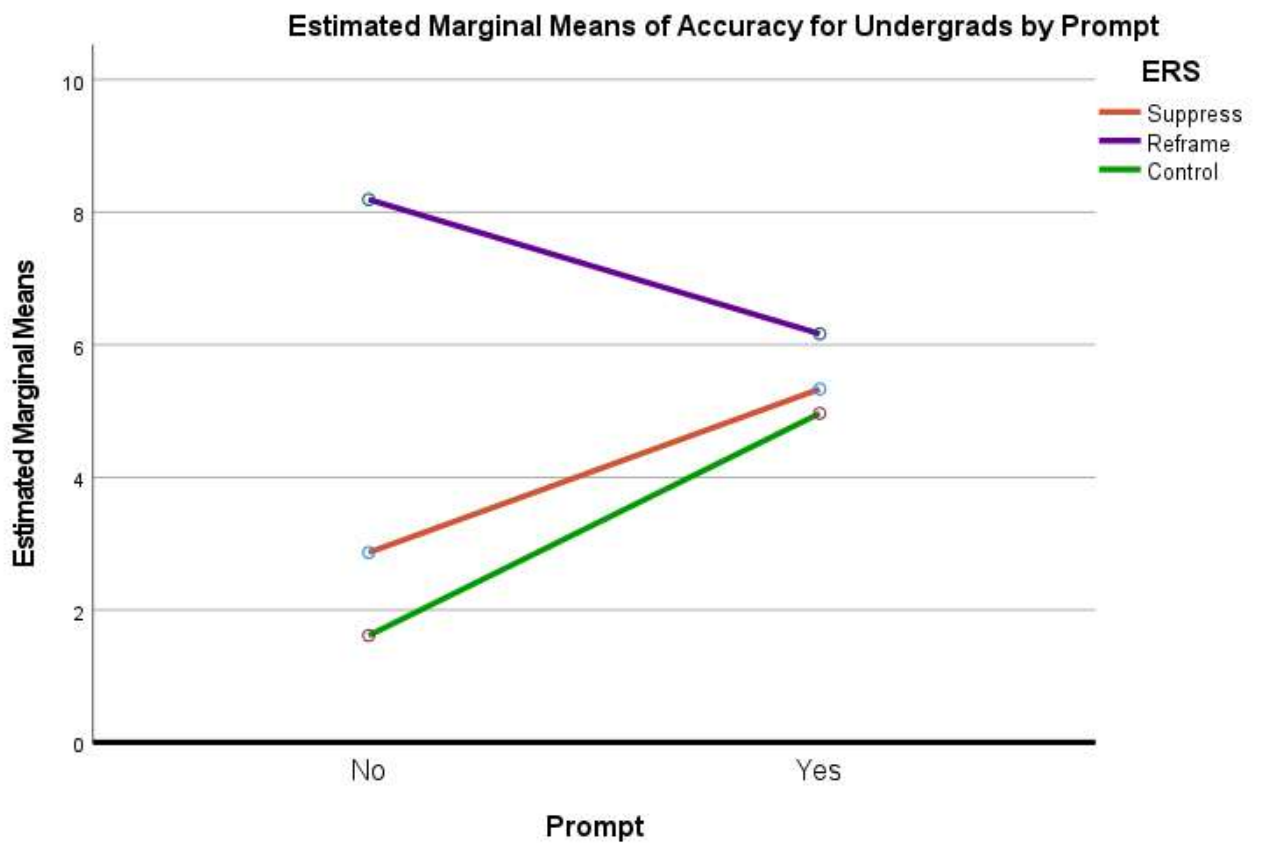


Figure 11 Quantity of Fraud Risk Factors Identified by Grads, Depending on Whether They are Prompted to Consider Discrepancies within Financial Information or Not

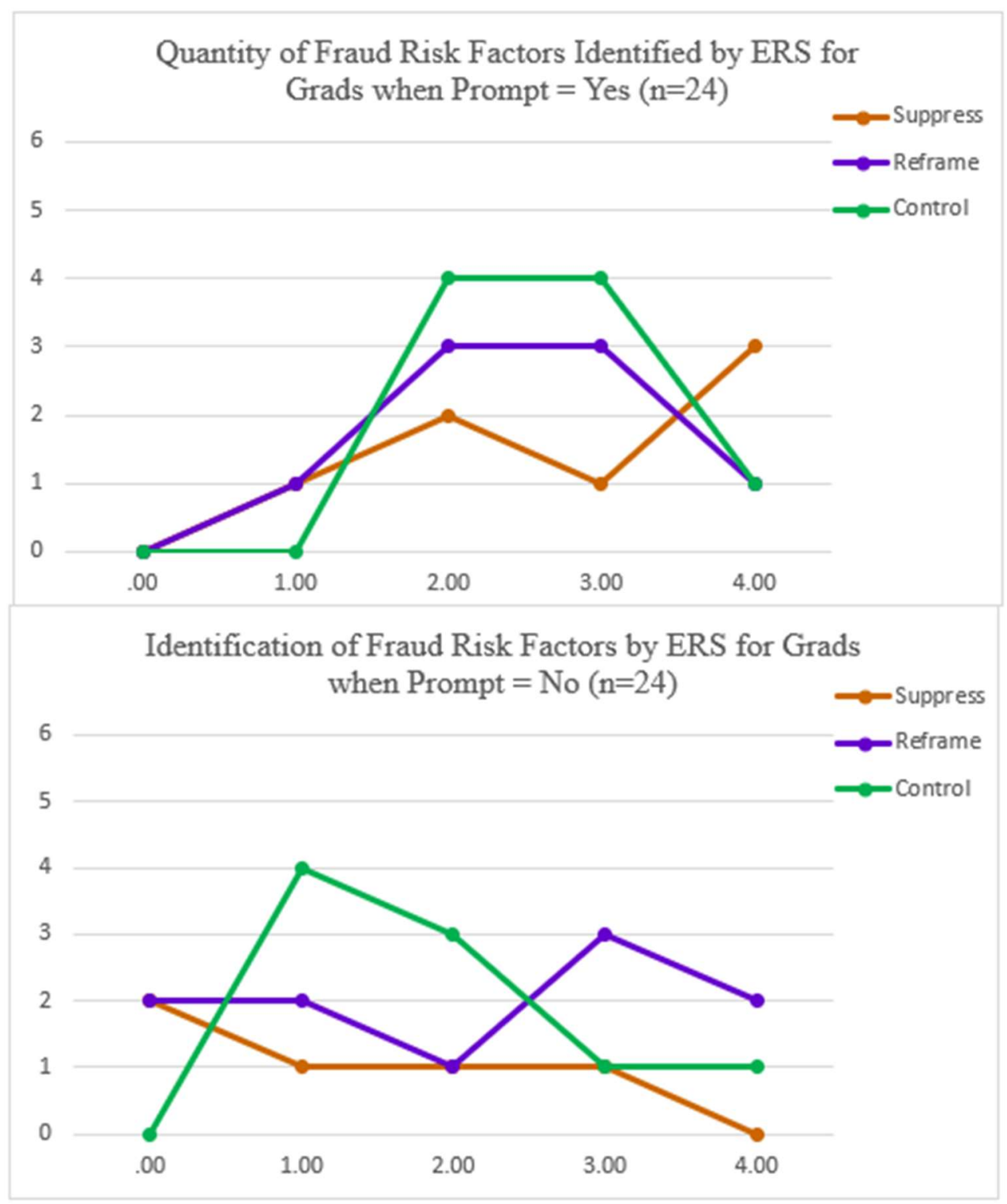


Figure 12 Accuracy of Fraud Risk Factors Identified by Grads

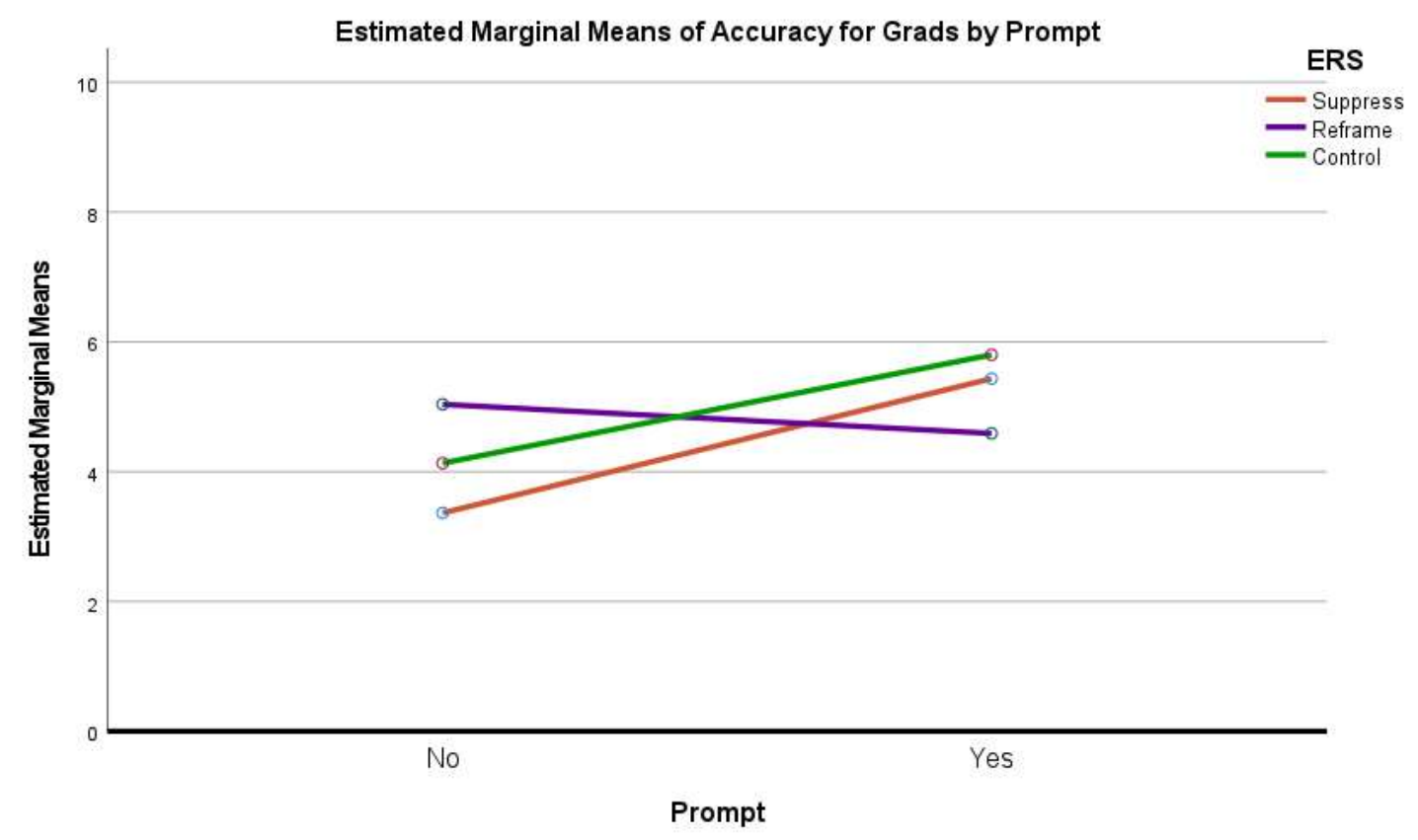

Figure 13 Mean Reporting of the Likelihood that Management is Engaging in Financial Misreporting

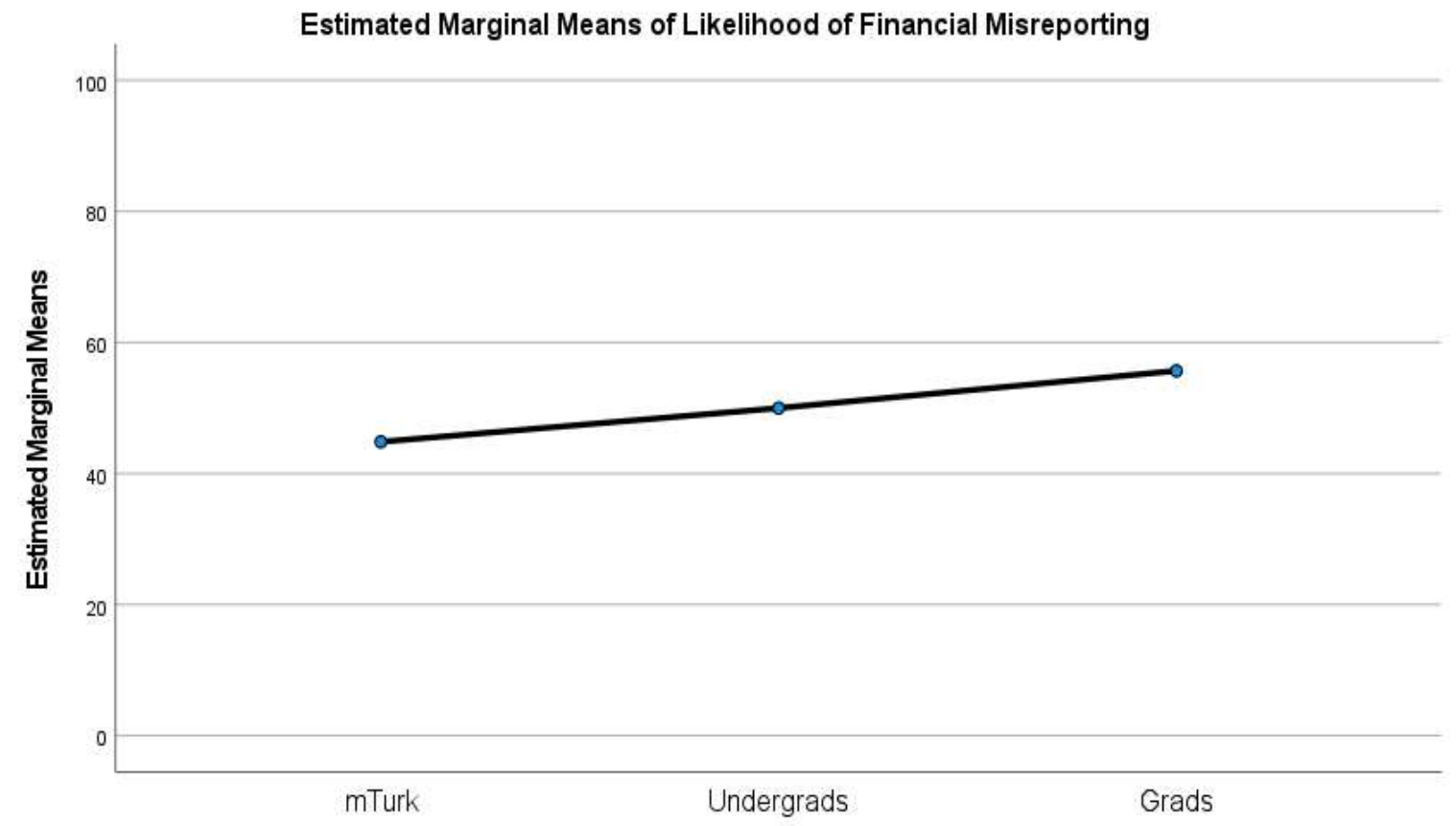


Figure 14 Accurate Identification of Fraud Risk Factors by Prompt $x$ Sample

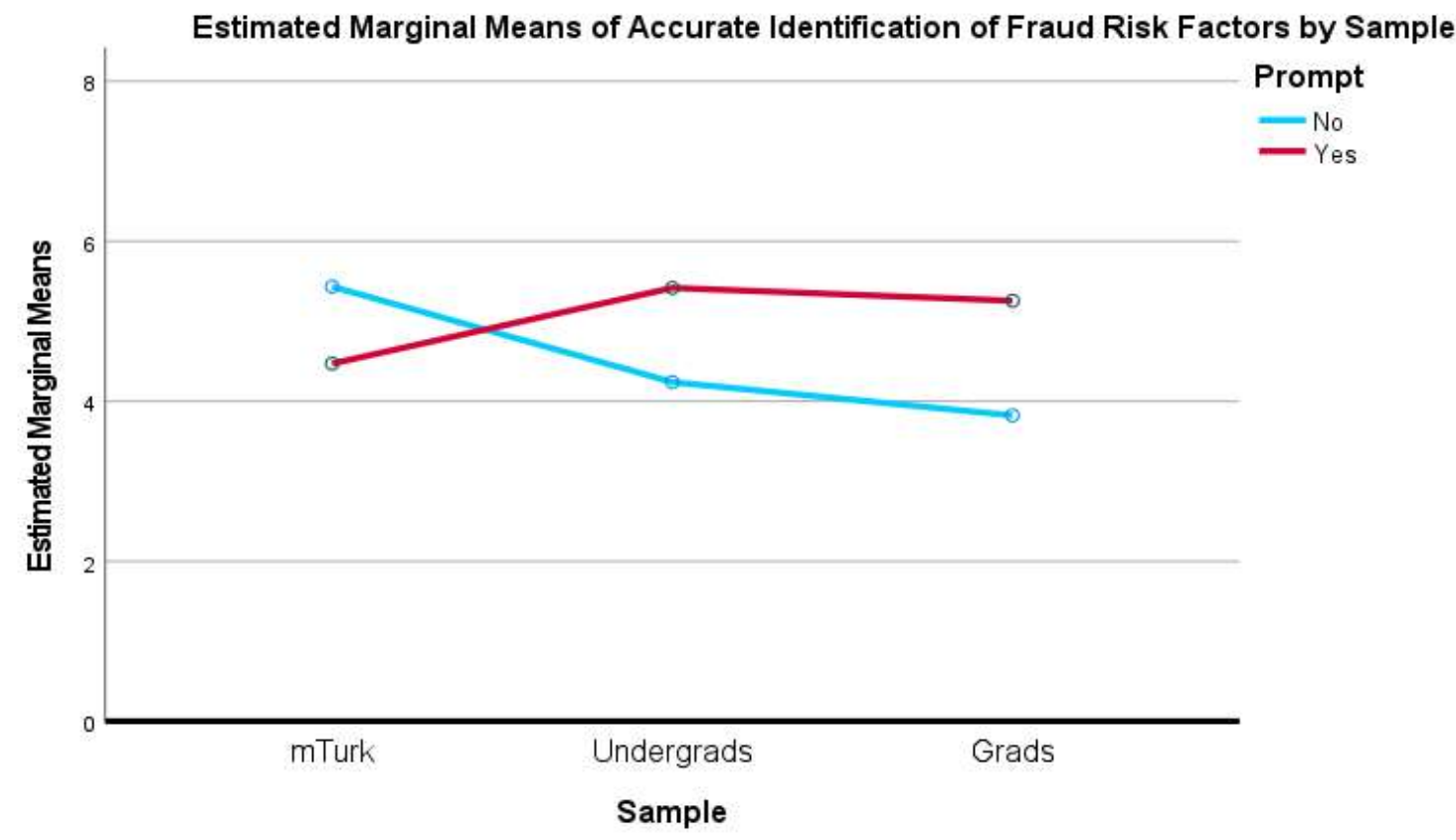

Covariates appearing in the model are evaluated at the following values: \#FSAnalyzed $=7.8750$, Mindful freq $=4.3281$, EmoRegFreq $=4.12$, CurrFirm $=3.95$, Yrs_Exp $=2.6738$, POS_Consolidated $=1.6094$, Gender $=.72$, Education $=1.68$, Duration $=78.7004$ 
Figure 15 Results for All Samples by ERS Condition and Prompt

Identification of Fraud Risk Factors in the Reframe ERS Condition by Prompt

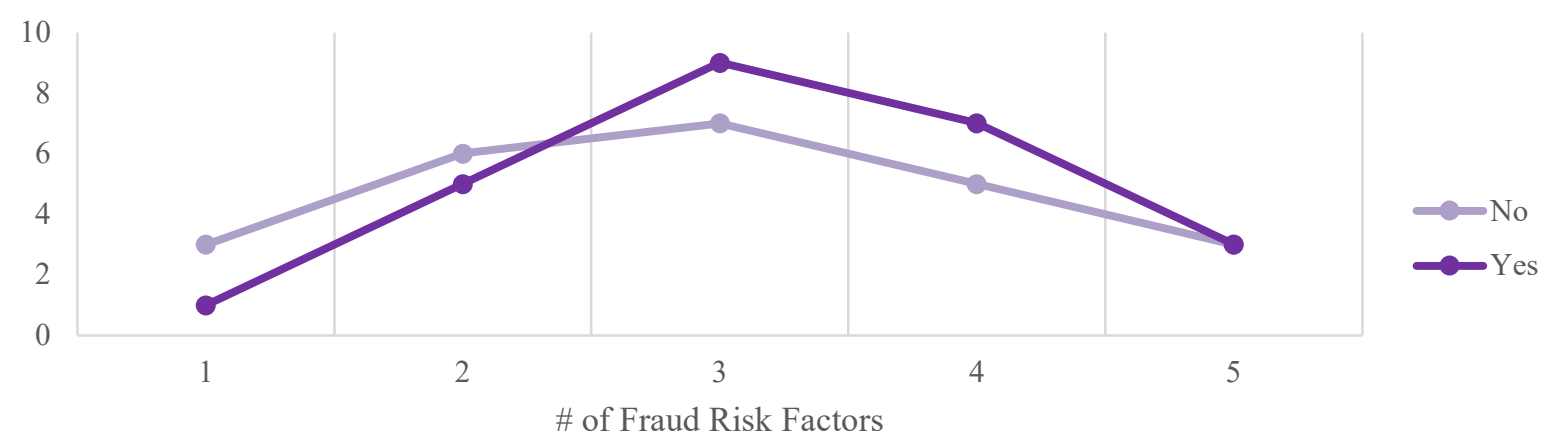

Identification of Fraud Risk Factors in the Control ERS Condition by Prompt

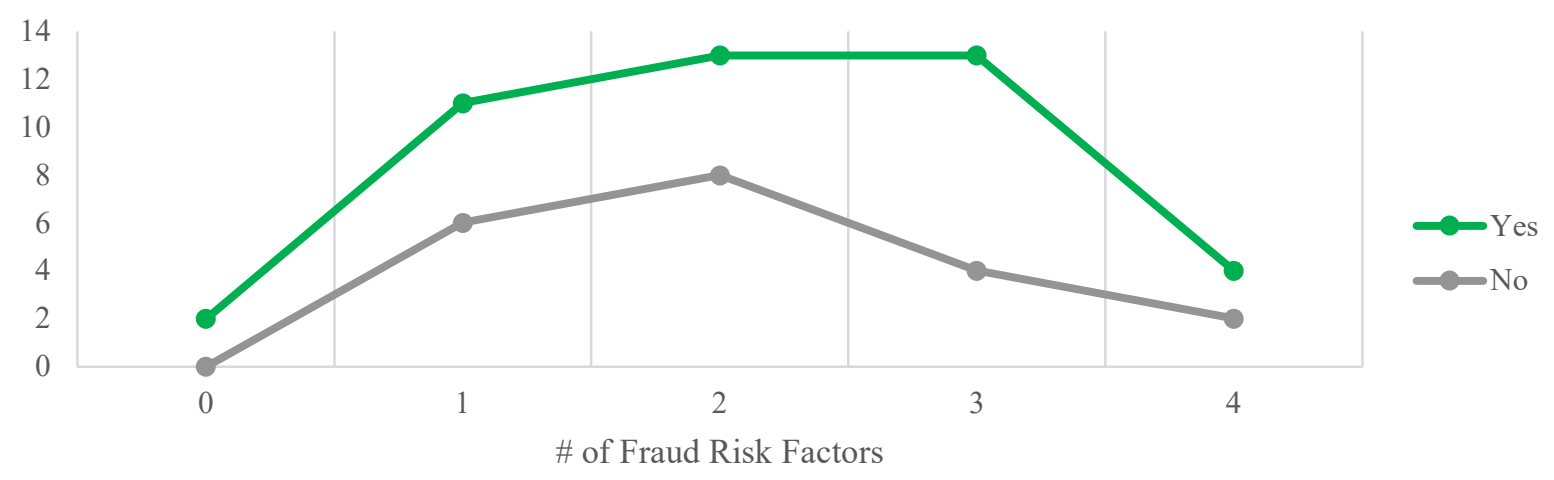

Identification of Fraud Risk Factors in the Suppress ERS Condition by Prompt

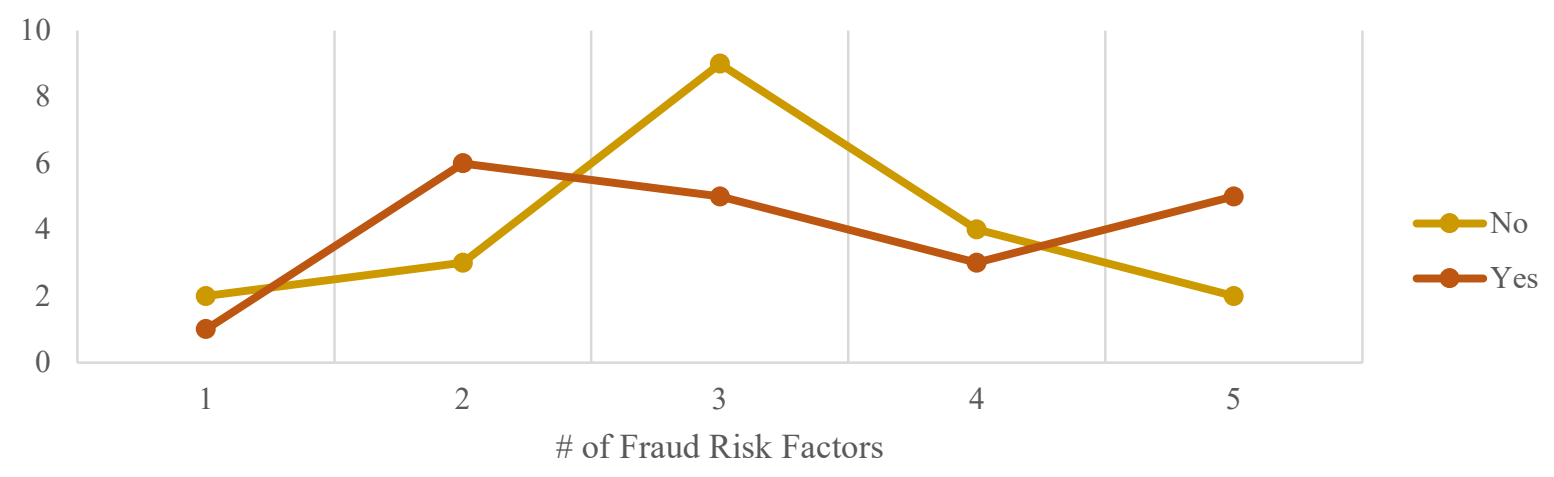


Figure 16 Comparison of Accurate Identification of Fraud Risk Factors Between mTurkers and Grads
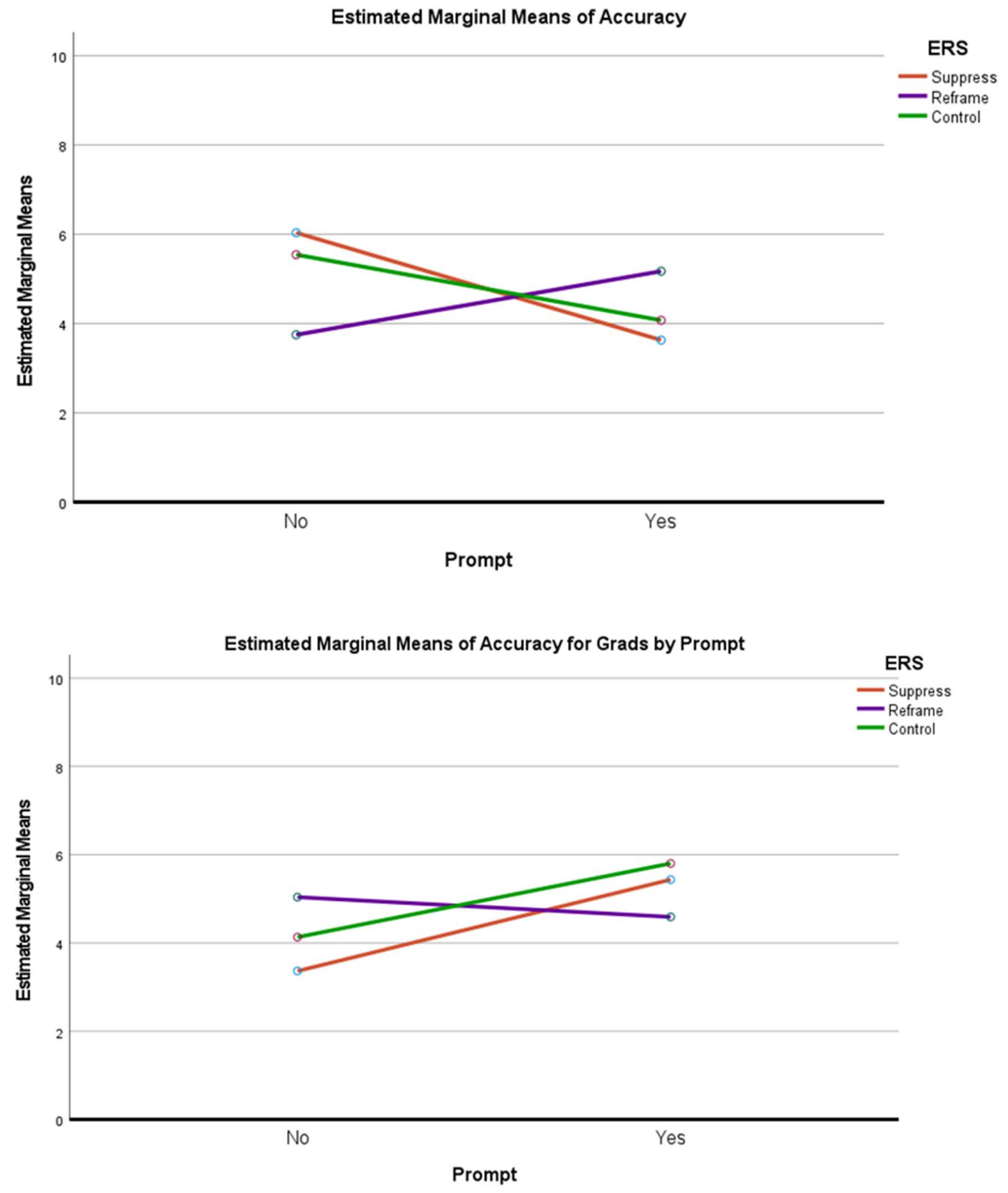
Figure 17 Estimated Average Accuracy of Fraud Risk Identification by Sample, Depending on Whether the Participant is Prompted to Identify Discrepancies within Experimental Materials

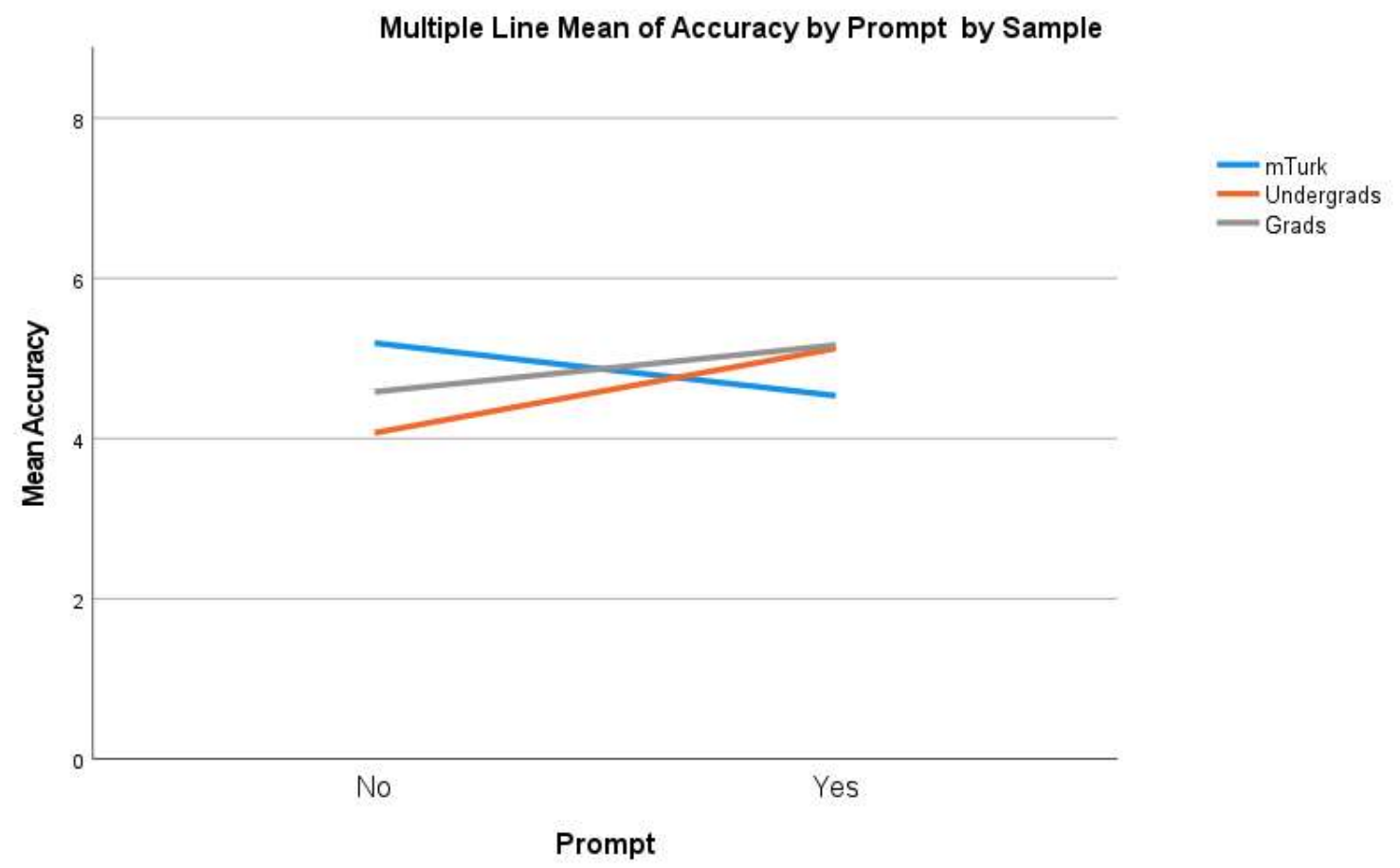


Table 1 Summary of Conditions and (Cell Sizes)

\begin{tabular}{|l|l|l|l|}
\hline \multicolumn{2}{|c|}{ Condition } & \multicolumn{1}{|c|}{ Yes } & \multicolumn{1}{c|}{ No } \\
\hline \multirow{2}{*}{$\begin{array}{l}\text { Mindfulness } \\
\text { practice }\end{array}$} & Emotion suppression & Prompt/suppression (20) & No Prompt/suppression (20) \\
\cline { 2 - 4 } & Control & Prompt/control (23) & No Prompt/control (20) \\
\cline { 2 - 5 } & Cognitive reappraisal & Prompt/reappraisal (25) & No Prompt/reappraisal (24) \\
\hline
\end{tabular}

Table 2 Descriptive Statistics for Continuous Variables

\begin{tabular}{llrrrrr}
\hline \multicolumn{1}{c}{ Variable } & N & Mean & Median & \multicolumn{1}{c}{ SD } & \multicolumn{1}{c}{ Min. } & \multicolumn{1}{c}{ Max. } \\
\hline Accuracy & 132 & 4.81 & 5.00 & 2.05 & -1 & 8 \\
Financial Misreporting & 130 & 50.45 & 51.00 & 21.08 & 2 & 100 \\
$\begin{array}{l}\text { Duration in Minutes } \\
\text { Participant had Difficulty }\end{array}$ & 132 & 76.74 & 21.51 & 390.18 & 2.68 & 4107 \\
$\quad$ & & & & & & \\
$\quad$ Focusing & 130 & 3.97 & 4.00 & 1.64 & 1 & 7 \\
$\quad$ Stopping to Think & 130 & 3.73 & 4.00 & 1.95 & 1 & 7 \\
$\quad$ Remembering Details & 130 & 5.18 & 5.00 & 1.48 & 2 & 7 \\
Likelihood Current Firm Promotes & 130 & 3.98 & 4.00 & 1.70 & 1 & 7 \\
Mindfulness & & & & & & \\
Mindfulness Frequency & 131 & 4.38 & 5.00 & 2.15 & 1 & 7 \\
Emotional Regulation Frequency & 130 & 4.12 & 4.00 & 1.82 & 1 & 7 \\
Years of Experience & 132 & 2.60 & 0.83 & 3.77 & 0 & 15 \\
\hline
\end{tabular}

Table 3 Descriptive Statistics for Continuous Variables by ERS Condition

\begin{tabular}{lrrrrrr}
\hline & \multicolumn{2}{c}{ Suppress } & \multicolumn{2}{c}{ Control } & \multicolumn{2}{c}{ Reappraisal } \\
\multicolumn{1}{c}{ Variable } & N & Mean & N & Mean & N & \multicolumn{1}{c}{ Mean } \\
\hline Accuracy of Discrepancies Identified & 40 & 5 & 43 & 5 & 49 & 5 \\
Financial Misreporting & 40 & 50 & 43 & 53 & 49 & 49 \\
Duration in Minutes & 40 & 62.01 & 43 & 117.29 & 49 & 53.19 \\
Participant had Difficulty & & & & & & \\
$\quad$ Focusing & 40 & 4 & 43 & 4 & 49 & 4 \\
$\quad$ Stopping to Think & 40 & 4 & 43 & 4 & 49 & 3 \\
$\quad$ Remembering Details & 40 & 5 & 43 & 5 & 49 & 5 \\
Likelihood Current Firm Promotes & 40 & 4 & 43 & 4 & 49 & 4 \\
Mindfulness & & & & & & \\
Mindfulness Frequency & 40 & 4.78 & 43 & 4.30 & 49 & 4.12 \\
Emotional Regulation Frequency & 40 & 4 & 43 & 4 & 49 & 4 \\
Years of Experience & 40 & 2.85 & 43 & 2.26 & 49 & 2.70 \\
\hline
\end{tabular}


Table 4 Frequencies of Categorical Variables by ERS Condition

\begin{tabular}{crrrr}
\hline \multicolumn{1}{c}{ Variable } & N & Suppress & Control & Reappraisal \\
\hline Quantity of Discrepancies Identified & & & & \\
0 & 9 & $3 *$ & $2^{*}$ & $4^{*}$ \\
1 & 41 & 9 & 11 & 11 \\
2 & 43 & 14 & 13 & 16 \\
3 & 32 & 7 & 13 & 12 \\
4 & 17 & 7 & $4 *$ & 6 \\
Additional Tests to Address Deficiencies & & & & 27 \\
Internal Controls & 70 & 23 & 20 & 28 \\
Allowance for Doubtful Accounts & 76 & 23 & 9 & 11 \\
Goodwill Impairment & 28 & 8 & 24 & 25 \\
New Product Revenue & 69 & 20 & 24 & \\
\hline
\end{tabular}

*Cell sizes less than 5 preclude chi square test of association to test for proportionality. 


\begin{tabular}{|c|c|c|c|c|}
\hline Variable & $\mathrm{N}$ & Suppress & Control & Reappraisal \\
\hline \multicolumn{5}{|l|}{ Why Participant Practices Mindfulness } \\
\hline Heightened attention & 9 & 3 & 3 & 3 \\
\hline Self-awareness & 1 & 0 & 0 & 1 \\
\hline Self-regulation & 33 & 8 & 10 & 15 \\
\hline Stress reduction & 12 & 7 & 2 & 3 \\
\hline \multicolumn{5}{|l|}{ Number of Financial Statements Analyzed Quarterly } \\
\hline 50 or more (Including 50 ) & 7 & 1 & 2 & 4 \\
\hline At least 25 but fewer than $50(25-49)$ & 64 & 23 & 18 & 23 \\
\hline At least 10 and fewer than $25(10-24)$ & 43 & 11 & 17 & 15 \\
\hline At least 1 but fewer than $10(1-9)$ & 11 & 3 & 4 & 4 \\
\hline Fewer than $1(0)$ & 5 & 2 & 1 & 2 \\
\hline \multicolumn{5}{|l|}{ Position } \\
\hline Partner/principal/owner & 5 & 2 & 2 & 1 \\
\hline Director/ sr. director & 10 & 3 & 4 & 3 \\
\hline Manager/sr. manager/supervisor & 47 & 14 & 13 & 20 \\
\hline Staff/associate/employee & 65 & 20 & 22 & 23 \\
\hline \multicolumn{5}{|l|}{ Education } \\
\hline Doctorate or post-graduate degree & 3 & 0 & 1 & 2 \\
\hline Masters or graduate degree & 19 & 10 & 6 & 3 \\
\hline Bachelors or undergraduate degree & 71 & 15 & 24 & 32 \\
\hline Associates or professional certificate & 8 & 1 & 2 & 5 \\
\hline High school graduate & 29 & 14 & 9 & 6 \\
\hline \multicolumn{5}{|l|}{ Gender } \\
\hline Female & 36 & 15 & 9 & 12 \\
\hline Male & 93 & 25 & 33 & 35 \\
\hline \multicolumn{5}{|l|}{ Number of Employees at Participant's Workplace } \\
\hline 10,000 or more & 9 & 4 & 3 & 2 \\
\hline $5,001-9,999$ & 5 & 2 & 0 & 3 \\
\hline $2,501-5,000$ & 1 & 0 & 0 & 1 \\
\hline $500-2,500$ & 10 & 2 & 1 & 6 \\
\hline $101-499$ & 9 & 2 & 5 & 3 \\
\hline Fewer than 100 & 18 & 6 & 4 & 8 \\
\hline
\end{tabular}


Table 6 Pearson (Lower)/ Spearman (Upper) Correlations Table

\begin{tabular}{|c|c|c|c|c|c|c|c|c|c|c|c|c|c|c|c|c|c|c|c|}
\hline Variable & 1 & 2 & 3 & 4 & 5 & 6 & 7 & 8 & 9 & 10 & 11 & 12 & 13 & 14 & 15 & 16 & 17 & 18 & 19 \\
\hline 1. Sample & -- & 0.144 & 0.021 & 0.089 & -0.015 & $.226^{* *}$ & $-.398^{* *}$ & $-.381^{* *}$ & $-.307^{* *}$ & $.294^{* *}$ & $.184^{*}$ & $.341^{* *}$ & $.257^{* *}$ & 0.000 & 0.018 & 0.008 & $.203^{*}$ & $-.768^{* *}$ & $.426^{* *}$ \\
\hline 2. Quantity & 0.144 & -- & $.575^{* *}$ & 0.002 & 0.085 & 0.023 & 0.018 & 0.121 & -0.015 & $.353^{* *}$ & -0.156 & -0.020 & -0.147 & -0.228 & -0.021 & -0.020 & 0.152 & 0.015 & $.280^{* *}$ \\
\hline 3. Accuracy & -0.007 & $.568^{* *}$ & -- & -0.006 & 0.060 & -0.060 & 0.073 & -0.001 & -0.047 & 0.141 & $-.198^{*}$ & -0.132 & -0.151 & $-.505^{* *}$ & $.174^{*}$ & 0.080 & 0.129 & 0.065 & $.242^{* *}$ \\
\hline 4. ERS & 0.077 & -0.003 & .007 & -- & 0.028 & 0.081 & -0.066 & -0.112 & -0.004 & -0.021 & 0.020 & 0.139 & 0.052 & 0.011 & 0.040 & -0.025 & 0.064 & -0.084 & -0.070 \\
\hline 5. Prompt & -0.011 & 0.085 & 0.044 & 0.028 & -- & -0.032 & -0.056 & 0.018 & 0.036 & 0.000 & 0.080 & -0.014 & -0.064 & -0.105 & -0.165 & -0.046 & $-.221^{*}$ & -0.113 & -0.043 \\
\hline 6. FinMisrept & $.217^{*}$ & 0.025 & -0.059 & 0.065 & -0.022 & -- & -0.004 & -0.092 & 0.031 & $.227^{* *}$ & 0.029 & 0.088 & 0.085 & -0.353 & -0.075 & 0.081 & -0.081 & $-.218^{*}$ & 0.058 \\
\hline 7. Mindful & $-.405^{* *}$ & 0.033 & 0.108 & -0.085 & -0.042 & -0.027 & -- & $.656^{* *}$ & $.179^{*}$ & -0.099 & -0.151 & -0.108 & $-.234^{* *}$ & -0.245 & -0.056 & -0.061 & -0.019 & $.267^{* *}$ & $-.212^{*}$ \\
\hline 8. EmoReg & $-.359^{* *}$ & 0.114 & -0.021 & -0.119 & 0.003 & -0.089 & $.664^{* *}$ & -- & $.265^{* *}$ & 0.001 & -0.164 & -0.149 & -0.172 & -0.036 & -0.002 & -0.114 & -0.110 & $.390^{* *}$ & -0.113 \\
\hline 9. CurrFirm & $-.313^{* *}$ & -0.027 & -0.059 & 0.000 & 0.041 & 0.043 & $.220^{*}$ & $.269^{* *}$ & -- & -0.002 & -0.141 & $-.235^{* *}$ & $-.178^{*}$ & 0.144 & 0.016 & -0.020 & -0.028 & $.284^{* *}$ & -0.093 \\
\hline 10. \#AddlTests & $.261^{* *}$ & $.337^{* *}$ & 0.116 & -0.017 & -0.021 & $.201^{*}$ & -0.109 & -0.005 & 0.009 & -- & -0.025 & 0.050 & 0.006 & -0.122 & 0.047 & -0.023 & -0.012 & -0.108 & $.313^{* *}$ \\
\hline 11. Focus & $.173^{*}$ & -0.148 & $-.191^{*}$ & 0.030 & 0.076 & 0.077 & $-.184^{*}$ & -0.162 & -0.148 & -0.020 & -- & $.541^{* *}$ & $.458^{* *}$ & -0.304 & 0.055 & 0.077 & -0.104 & -0.138 & -0.012 \\
\hline 12. StopThink & $.328^{* *}$ & -0.045 & -0.164 & 0.142 & -0.018 & 0.098 & -0.140 & -0.154 & $-.252^{* *}$ & 0.040 & $.551^{* *}$ & -- & $.318^{* *}$ & -0.325 & 0.079 & -0.171 & -0.030 & $-.328^{* *}$ & -0.070 \\
\hline 13. Remember & $.282^{* *}$ & -0.152 & -0.136 & 0.063 & -0.064 & 0.083 & $-.256^{* *}$ & $-.189^{*}$ & $-.189^{*}$ & -0.018 & $.435^{* *}$ & $.299^{* *}$ & -- & -0.239 & 0.030 & -0.060 & $-.176^{*}$ & $-.266^{* *}$ & 0.026 \\
\hline 14. \#EEs &.${ }^{\mathrm{c}}$ & -0.199 & $-.481^{*}$ & 0.000 & -0.105 & -0.380 & -0.052 & 0.045 & 0.135 & -0.174 & -0.301 & -0.292 & -0.233 & -- & -0.217 & $-.412^{*}$ & 0.194 & -0.207 & 0.020 \\
\hline 15. Education & -0.106 & -0.036 & 0.142 & 0.071 & -0.165 & -0.065 & -0.078 & -0.017 & 0.022 & 0.067 & 0.057 & 0.076 & 0.028 & -0.204 & -- & $.317^{* *}$ & -0.114 & 0.089 & -0.018 \\
\hline 16. Position & -0.072 & 0.025 & 0.082 & -0.020 & -0.012 & 0.057 & -0.106 & $-.177^{*}$ & -0.012 & 0.003 & 0.071 & -0.158 & -0.048 & $-.394^{*}$ & $.287^{* *}$ & -- & 0.042 & $.264^{* *}$ & 0.170 \\
\hline 17. FSAnalyzed & $.221^{*}$ & 0.168 & $.201^{*}$ & 0.013 & -0.163 & -0.107 & -0.045 & -0.055 & -0.071 & 0.050 & -0.098 & -0.063 & -0.107 & 0.028 & -0.129 & 0.000 & -- & -0.017 & $.182^{*}$ \\
\hline 18. Yrs_Exp & 0.049 & -0.063 & -0.160 & -0.084 & $.227^{* *}$ & $.230^{* *}$ & $.189^{*}$ & 0.028 & -0.056 & $-.235^{* *}$ & $-.223^{*}$ & -0.071 & $.200^{*}$ & $.241^{* *}$ & -0.104 & 0.049 & -0.063 & -- & $-.182^{*}$ \\
\hline 19. Duration & -0.073 & 0.057 & 0.061 & -0.084 & -0.016 & 0.038 & 0.097 & 0.035 & 0.030 & 0.015 & 0.023 & 0.011 & -0.160 & -0.054 & 0.032 & -0.073 & 0.057 & -0.076 & -- \\
\hline
\end{tabular}

${ }^{* *}$ Correlation is significant at the 0.01 level (2-tailed)

${ }^{*}$ Correlation is significant at the 0.05 level (2-tailed). 
Table 7 Descriptive Statistics for Continuous Variables by Sample

\begin{tabular}{lcrrrrr}
\hline \multicolumn{1}{c}{ Variable } & \multicolumn{2}{c}{ mTurk } & \multicolumn{2}{c}{ Undergrads } & \multicolumn{2}{c}{ Grads } \\
& $\mathrm{N}$ & Mean & $\mathrm{N}$ & Mean & $\mathrm{N}$ & Mean \\
\hline Accuracy of Discrepancies Identified & 54 & 4.85 & 30 & 4.63 & 48 & 4.88 \\
Financial Misreporting & 52 & 45.23 & 30 & 50.97 & 48 & 55.79 \\
Duration in Minutes & 54 & 17.11 & 30 & 165.01 & 48 & 88.67 \\
Participant had Difficulty & & & & & & \\
$\quad$ Focusing & 52 & 3.67 & 30 & 3.80 & 48 & 4.40 \\
$\quad$ Stopping to Think & 52 & 3.00 & 30 & 3.80 & 48 & 4.48 \\
$\quad$ Remembering Details & 52 & 4.69 & 30 & 5.33 & 48 & 5.63 \\
Likelihood Current Firm Promotes & 52 & 4.58 & 30 & 3.97 & 48 & 3.33 \\
Mindfulness & & & & & & \\
Mindfulness Frequency & 54 & 5.26 & 29 & 5.00 & 48 & 3.02 \\
Emotional Regulation Frequency & 52 & 4.83 & 30 & 4.30 & 48 & 3.23 \\
Years of Experience & 52 & 5.56 & 30 & 0.76 & 48 & 0.43 \\
\hline
\end{tabular}

Table 8 Frequencies of Categorical Variables by Sample

\begin{tabular}{crrrr}
\hline \multicolumn{1}{c}{ Variable } & $\mathrm{N}$ & mTurk & Undergrads & Grads \\
\hline Quantity of Discrepancies Identified & & & & \\
0 & 9 & $4 *$ & $4^{*}$ & $1^{*}$ \\
1 & 31 & 19 & 9 & $3^{*}$ \\
2 & 43 & 15 & 14 & 14 \\
3 & 32 & 9 & 13 & 10 \\
4 & 17 & 7 & 8 & $2^{*}$ \\
Additional Tests to Address Deficiencies & & & & 30 \\
Internal Controls & 60 & 20 & 20 & 28 \\
Allowance for Doubtful Accounts & 76 & 33 & 15 & 10 \\
Goodwill Impairment & 28 & 12 & 6 & 31 \\
New Product Revenue & 69 & 20 & 18 & \\
\hline
\end{tabular}

*Cell sizes less than 5 preclude chi square test of association to test for proportionality. 


\begin{tabular}{|c|c|c|c|c|}
\hline Variable & $\mathrm{N}$ & mTurk & Undergrads & Grads \\
\hline \multicolumn{5}{|l|}{ Why Participant Practices Mindfulness } \\
\hline Heightened attention & 9 & 6 & 1 & 2 \\
\hline Self-awareness & 33 & 18 & 5 & 10 \\
\hline Self-regulation & 12 & 4 & 5 & 3 \\
\hline Stress reduction & 66 & 26 & 17 & 23 \\
\hline \multicolumn{5}{|l|}{ Number of Financial Statements Analyzed Quarterly } \\
\hline 50 or more (Including 50 ) & 5 & 0 & 3 & 2 \\
\hline At least 25 but fewer than $50(25-49)$ & 11 & 2 & 2 & 7 \\
\hline At least 10 and fewer than $25(10-24)$ & 43 & 16 & 13 & 14 \\
\hline At least 1 but fewer than $10(1-9)$ & 64 & 28 & 11 & 25 \\
\hline Fewer than $1(0)$ & 7 & 6 & 1 & 0 \\
\hline \multicolumn{5}{|l|}{ Position } \\
\hline Partner/principal/owner & 5 & 3 & 0 & 2 \\
\hline Director/ sr. director & 10 & 5 & 0 & 5 \\
\hline Manager/sr. manager/supervisor & 47 & 22 & 4 & 21 \\
\hline Staff/associate/employee & 65 & 22 & 24 & 19 \\
\hline \multicolumn{5}{|l|}{ Education } \\
\hline High school graduate & 29 & 4 & 19 & 6 \\
\hline Associates or professional certificate & 8 & 4 & 3 & 1 \\
\hline Bachelors or undergraduate degree & 71 & 34 & 8 & 29 \\
\hline Masters or graduate degree & 19 & 10 & 0 & 9 \\
\hline Doctorate or post-graduate degree & 3 & 0 & 0 & 3 \\
\hline \multicolumn{5}{|l|}{ Gender } \\
\hline Female & 36 & 14 & 11 & 11 \\
\hline Male & 93 & 37 & 19 & 37 \\
\hline \multicolumn{5}{|l|}{ Number of Employees at Participant's Workplace } \\
\hline 10,000 or more & 9 & 9 & 0 & 0 \\
\hline $5,001-9,999$ & 5 & 5 & 0 & 0 \\
\hline $2,501-5,000$ & 1 & 1 & 0 & 0 \\
\hline $500-2,500$ & 10 & 8 & 1 & 0 \\
\hline $101-499$ & 9 & 9 & 0 & 0 \\
\hline Fewer than 100 & 18 & 9 & 5 & 4 \\
\hline
\end{tabular}


Table 10 Multiple Analysis of Covariance Results for the Relationship Between Emotion Regulation Strategy and the Frequency of Practicing Mindfulness or Emotion Regulation, or the Likelihood that the Current Employer Encourages Mindfulness by Sample (i.e. mTurk, Grads, Undergrads)

\begin{tabular}{|c|c|c|c|c|c|}
\hline Variable & $\begin{array}{l}\text { Sum of } \\
\text { Squares }\end{array}$ & $\mathrm{df}$ & $\begin{array}{c}\text { Mean } \\
\text { Square } \\
\text { Error }\end{array}$ & $F(111)$ & Sig. \\
\hline \multicolumn{6}{|c|}{ Frequency Practicing Mindfulness } \\
\hline Sample & 86.461 & 2 & 43.231 & 11.160 & $0.000 * * *$ \\
\hline Position & 10.974 & 4 & 2.744 & 0.708 & 0.588 \\
\hline \# FS Analyzed & 5.857 & 4 & 1.464 & 0.378 & 0.824 \\
\hline Education & 8.597 & 4 & 2.149 & 0.555 & 0.696 \\
\hline Gender & 1.118 & 1 & 1.118 & 0.289 & 0.592 \\
\hline Years' Experience & 8.154 & 1 & 8.157 & 0.000 & 0.996 \\
\hline \multicolumn{6}{|c|}{ Frequency Practicing Emotion Regulation } \\
\hline Sample & 34.807 & 2 & 17.404 & 6.612 & $0.002 * * *$ \\
\hline Position & 25.087 & 4 & 6.272 & 2.383 & $0.056^{*}$ \\
\hline \# FS Analyzed & 1.309 & 4 & 0.327 & 0.124 & 0.973 \\
\hline Education & 19831 & 4 & 4.958 & 1.884 & 0.118 \\
\hline Gender & 0.403 & 1 & 0.403 & 0.153 & 0.696 \\
\hline Years' Experience & 0.004 & 1 & 0.004 & 0.002 & 0.968 \\
\hline \multicolumn{6}{|c|}{ Likelihood Current Firm Promotes Mindfulness } \\
\hline Sample & 18.894 & 2 & 9.447 & 3.456 & $0.035 * *$ \\
\hline Position & 13.555 & 4 & 3.389 & 1.240 & 0.298 \\
\hline \# FS Analyzed & 6.548 & 4 & 1.637 & 0.599 & 0.664 \\
\hline Education & 1.441 & 4 & 0.360 & 0.132 & 0.970 \\
\hline Gender & 0.005 & 1 & 0.005 & 0.002 & 0.966 \\
\hline Years' Experience & 0.000 & 1 & 0.000 & 0.000 & 0.993 \\
\hline
\end{tabular}

***significant at the 0.01 level (2-tailed).

** Significant at the 0.05 level (2-tailed).

*Significant at the 0.10 level (2-tailed). 
Table 11 Analysis of Covariance Results for the Relationship Between Emotion Regulation Strategy and the Frequency of Practicing Mindfulness or Emotion Regulation, or the Likelihood that the Current Employer Encourages Mindfulness by Sample (i.e. mTurk, Grads, Undergrads)

\begin{tabular}{|c|c|c|c|c|c|}
\hline Variable & $\begin{array}{l}\text { Sum of } \\
\text { Squares }\end{array}$ & $\mathrm{df}$ & $\begin{array}{c}\text { Mean } \\
\text { Square } \\
\text { Error }\end{array}$ & $F(86)$ & Sig. \\
\hline \multicolumn{6}{|l|}{ Accuracy } \\
\hline Sample & 0.863 & 2 & 0.431 & 0.107 & 0.899 \\
\hline ERS & 2.388 & 2 & 1.194 & 0.295 & 0.745 \\
\hline Prompt & 4.841 & 1 & 4.841 & 1.196 & 0.277 \\
\hline Sample * ERS & 1.308 & 4 & 0.327 & 0.061 & 0.988 \\
\hline Sample * Prompt & 21.209 & 2 & 10.605 & 2.620 & $0.079 *$ \\
\hline Sample * ERS * Prompt & 24.434 & 6 & 4.072 & 1.006 & 0.427 \\
\hline Current Firm & 24.215 & 6 & 4.036 & 0.997 & 0.433 \\
\hline EmoRegFreq & 38.909 & 6 & 6.485 & 1.602 & 0.156 \\
\hline Gender & 2.374 & 1 & 2.374 & 0.586 & 0.446 \\
\hline Education & 18.929 & 1 & 18.929 & 4.686 & $0.033 * *$ \\
\hline Position & 0.221 & 1 & 0.221 & 0.055 & 0.816 \\
\hline \# FS Analyzed & 33.951 & 1 & 33.951 & 8.387 & $0.005 * *$ \\
\hline Years'Experience & 1.511 & 1 & 1.511 & 0.373 & 0.543 \\
\hline
\end{tabular}

***significant at the 0.01 level (2-tailed).

${ }^{*}$ Significant at the 0.05 level (2-tailed).

*Significant at the 0.10 level (2-tailed). 
Table 12 Descriptive Statistics for Duration in Minutes by ERS, Removing Outliers

\begin{tabular}{llrrrrrr}
\hline & & \multicolumn{3}{c}{ Prompt = Yes } & \multicolumn{3}{c}{ Prompt = No } \\
ERS & \multicolumn{1}{c}{ Sample } & N & Mean & Median & N & Mean & Median \\
\hline Suppress & mTurk & 6 & 17.43 & 18.71 & 7 & 22.34 & 22.60 \\
& Undergrads & 5 & 22.33 & 22.27 & 6 & 34.30 & 25.81 \\
& Grads & 6 & 37.87 & 40.98 & 5 & 50.11 & 25.65 \\
Control & mTurk & 5 & 12.88 & 7.50 & 7 & 18.34 & 17.87 \\
& Undergrads & 6 & 21.05 & 20.14 & 3 & 16.13 & 15.75 \\
& Grads & 9 & 34.41 & 28.65 & 9 & 27.49 & 28.23 \\
Reframe & mTurk & 13 & 20.32 & 13.00 & 10 & 18.44 & 16.24 \\
& Undergrads & 3 & 19.02 & 17.90 & 4 & 17.00 & 15.92 \\
& Grads & 8 & 24.41 & 22.33 & 9 & 37.06 & 21.68 \\
\hline
\end{tabular}

Table 13 Descriptive Statistics for Duration in Minutes by Sample, Removing Outliers

\begin{tabular}{llrrrrrr}
\hline \multirow{2}{*}{ Sample } & \multicolumn{3}{c}{ Prompt $=$ Yes } & \multicolumn{3}{c}{ Prompt = No } \\
\hline mTurk & \multicolumn{1}{c}{ ERS } & N & Mean & Median & N & Mear & Median \\
& Suppress & 6 & 17.43 & 18.71 & 7 & 22.34 & 22.60 \\
& Control & 5 & 12.88 & 7.50 & 7 & 18.34 & 17.87 \\
Undergrads & Reframe & 13 & 20.32 & 13.00 & 10 & 18.44 & 16.24 \\
& Suppress & 5 & 22.33 & 22.27 & 6 & 34.30 & 25.81 \\
& Control & 6 & 21.05 & 20.14 & 3 & 16.13 & 15.75 \\
Grads & Reframe & 3 & 19.02 & 17.90 & 4 & 17.00 & 15.92 \\
& Suppress & 6 & 37.87 & 40.98 & 5 & 50.11 & 25.65 \\
& Control & 9 & 34.41 & 28.65 & 9 & 27.49 & 28.23 \\
& Reframe & 8 & 24.41 & 22.33 & 9 & 37.06 & 21.68 \\
\hline
\end{tabular}


Table 14 Analysis of Variance of the Relationship Between Sample and Duration to Complete the Experiment in Minutes

\begin{tabular}{|c|c|c|c|c|c|}
\hline $\begin{array}{l}\mathrm{DV}=\text { Duration in Minutes } \\
\text { Variable }\end{array}$ & $\begin{array}{l}\text { Sum of } \\
\text { Squares }\end{array}$ & $\mathrm{df}$ & $\begin{array}{l}\text { Mean } \\
\text { Square } \\
\text { Error }\end{array}$ & $F(69)$ & Sig \\
\hline Sample & 96475.64 & 2 & 48237.82 & 0.299 & 0.743 \\
\hline ERS & 30447.56 & 2 & 15223.78 & 0.094 & 0.910 \\
\hline Prompt & 6600.13 & 1 & 6600.3 & 0.041 & 0.840 \\
\hline Sample * ERS & 927169.18 & 69 & 231792.30 & 1.436 & 0.232 \\
\hline Sample $*$ Prompt & 23976.98 & 4 & 11988.49 & 0.074 & 0.929 \\
\hline Sample * ERS * Prompt & 556600.68 & 6 & 92766.78 & 0.575 & 0.749 \\
\hline Mindful_Freq & 721573.96 & 7 & 103082.00 & 0.638 & 0.723 \\
\hline Current Firm & 879161.33 & 6 & 146526.89 & 0.907 & 0.495 \\
\hline EmoReg_Freq & 1439776.99 & 6 & 239962.83 & 1.486 & 0.196 \\
\hline Focus & 790430.34 & 6 & 131738.39 & 0.816 & 0.561 \\
\hline Stop and Think & 2101671.78 & 6 & 350278.63 & 2.169 & $0.056^{*}$ \\
\hline Remember & 484671.27 & 5 & 96934.26 & 0.600 & 0.700 \\
\hline Gender & 231284.89 & 1 & 231284.89 & 1.432 & 0.235 \\
\hline Education & 196297.03 & 1 & 196297.03 & 1.216 & 0.274 \\
\hline Position & 9.304 & 1 & 9.304 & 0.000 & 0.994 \\
\hline Years' Experience & 8131.537 & 1 & 8131.537 & 0.050 & 0.823 \\
\hline \# FS Analyzed & 8143.83 & 1 & 82143.83 & 0.509 & 0.478 \\
\hline
\end{tabular}

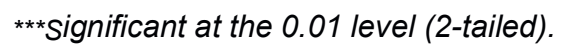

${ }^{*}$ Significant at the 0.05 level (2-tailed).

*Significant at the 0.10 level (2-tailed). 
Table 15 Ordinal Regression Results for the Relationship Between Emotion Regulation Strategy and the Ability to Identify Fraud Risk Factors (DV= Quantity), Tests of Hypotheses $1 a$ and $2 a-2 b$ for mTurkers +

\begin{tabular}{|c|c|c|c|c|c|}
\hline & Estimate & $\mathrm{SE}$ & Wald & $\mathrm{df}$ & Sig. \\
\hline \multicolumn{6}{|l|}{ Threshold } \\
\hline Frequency $=0$ & -0.921 & 0.823 & 1.251 & 1 & 0.263 \\
\hline Frequency=1 & 1.802 & 0.898 & 4.023 & 1 & $0.045 * *$ \\
\hline Frequency $=2$ & 3.210 & 0.945 & 11.540 & 1 & $0.001 * * *$ \\
\hline Frequency $=3$ & 4.324 & 0.999 & 18.742 & 1 & $0.000 * * *$ \\
\hline \multicolumn{6}{|l|}{ Location } \\
\hline ERS=Suppress (1) & 1.430 & 1.083 & 1.744 & 1 & 0.187 \\
\hline $\mathrm{ERS}=$ Control $(2)$ & 2.454 & 1.018 & 5.804 & 1 & $0.018^{* *}$ \\
\hline Prompt=Yes $(8)$ & -2.952 & 1.115 & 7.044 & 1 & $0.008 * * *$ \\
\hline $\mathrm{ERS}=1 *$ Prompt $=8$ & 1.054 & 1.405 & 0.563 & 1 & 0.453 \\
\hline $\mathrm{ERS}=2 *$ Prompt $=8$ & 3.650 & 1.372 & 7.083 & 1 & $0.008 * * *$ \\
\hline
\end{tabular}

***significant at the 0.01 level (2-tailed).

**Significant at the 0.05 level (2-tailed).

*Significant at the 0.10 level (2-tailed).

${ }^{+}$Reference categories are excluded from the table 
Table 16 Analysis of Variance Results for the Relationship Between Emotion Regulation Strategy and the Ability to Accurately Recall Fraud Risk Factors (DV=Accuracy) Tests of Hypotheses $1 b$ and $2 c-2 d$ for mTurkers

\begin{tabular}{lrrrrr}
\hline & Sum of & Mean & Square \\
Variable & Squares & df & Error & $F(69)$ & Sig. \\
\hline ERS & 0.254 & 2 & 0.127 & 0.046 & 0.955 \\
Prompt & 0.237 & 1 & 0.237 & 0.089 & 0.777 \\
ERS * Prompt & 0.314 & 2 & 0.157 & 0.057 & 0.945 \\
Mindful_Freq & 6.052 & 5 & 1.210 & 0.443 & 0.807 \\
Current Firm & 11.332 & 5 & 2.266 & 0.829 & 0.567 \\
EmoReg_Freq & 13.206 & 6 & 2.201 & 0.805 & 0.596 \\
Focus & 15.857 & 6 & 2.643 & 0.966 & 0.508 \\
Stop and Think & 21.563 & 6 & 3.594 & 1.314 & 0.361 \\
Remember & 6.717 & 5 & 1.343 & 0.491 & 0.774 \\
Gender & 2.561 & 1 & 2.561 & 0.936 & 0.365 \\
Education & 11.138 & 1 & 11.138 & 4.073 & $0.083 *$ \\
Position & 0.202 & 1 & 0.202 & 0.074 & 0.794 \\
Years' Experience & 0.008 & 1 & 0.008 & 0.003 & 0.958 \\
\# FS Analyzed & 1.806 & 1 & 1.806 & 0.660 & 0.443 \\
\hline
\end{tabular}

***Significant at the 0.01 level (2-tailed).

**Significant at the 0.05 level (2-tailed).

*Significant at the 0.10 level (2-tailed). 
Table 17 Multinomial Logistic Regression Results for the Relationship Between Emotion Regulation Strategy and the Ability to Identify Fraud Risk Factors (DV= Quantity), Tests of Hypotheses $1 a$ and $2 a-2 b$ for Undergrads +

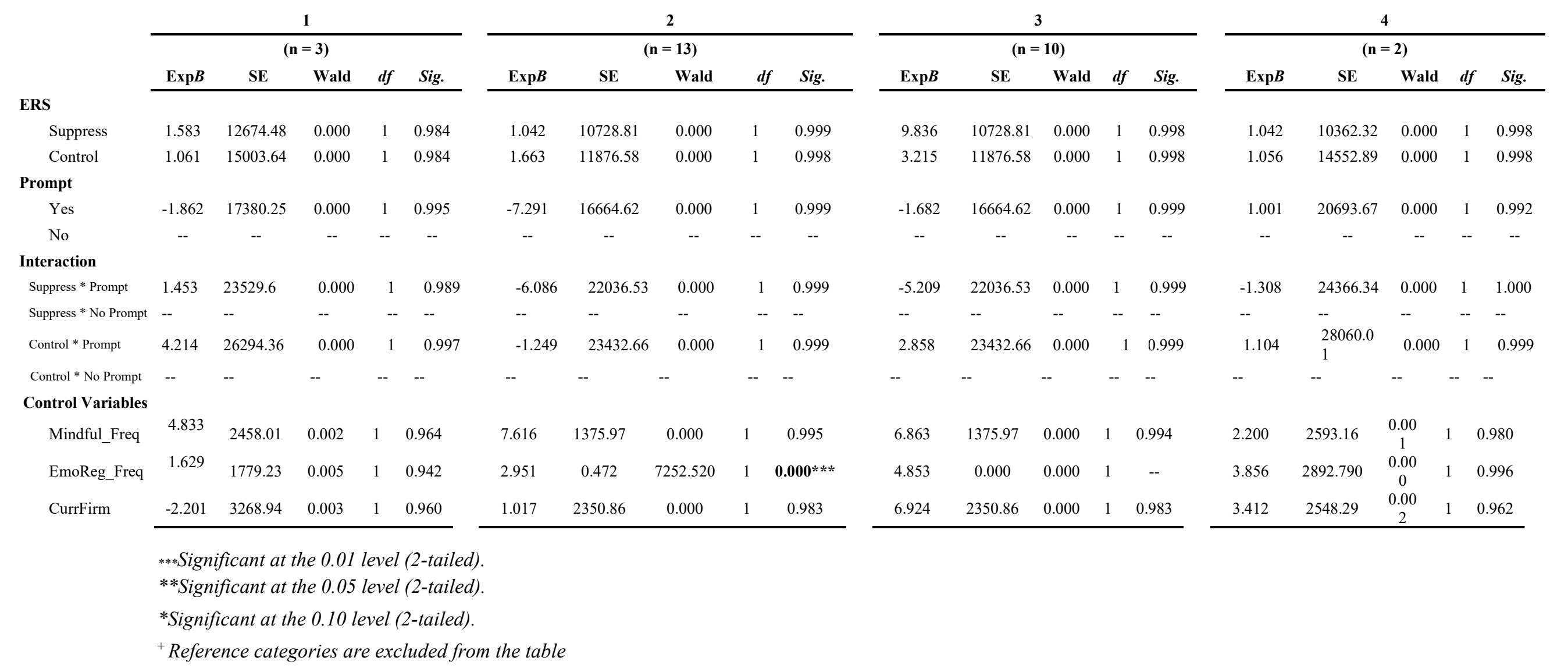


Table 18 Analysis of Variance Results for the Relationship Between Emotion Regulation Strategy and the Ability to Accurately Recall Fraud Risk Factors (DV=Accuracy) Tests of Hypotheses $1 b$ and $2 c-2 d$ for Undergrads ++

\begin{tabular}{lrrrrrr}
\hline & \multicolumn{7}{c}{ Mean } \\
Variable & Sum of & Square \\
Squares & df & Error & $F(69)$ & Sig. \\
\hline ERS & 3.920 & 2 & 1.960 & 0.404 & 0.672 \\
Prompt & 7.064 & 1 & 7.064 & 1.455 & 0.239 \\
ERS * Prompt & 0.046 & 2 & 0.023 & 0.005 & 0.995 \\
\hline
\end{tabular}

***:Significant at the 0.01 level (2-tailed).

**Significant at the 0.05 level (2-tailed).

*Significant at the 0.10 level (2-tailed).

++ Controls are removed from this model as the model with controls was overfit and resulted in zero residuals. As such, to free degrees of freedom, variables were pruned, and the model run with simple effects. 
Table 19 Ordinal Regression Results for the Relationship Between Emotion Regulation Strategy and the Ability to Identify Fraud Risk Factors (DV= Frequency), Tests of Hypotheses $1 a$ and $2 a-2 b$ for Grads +

\begin{tabular}{lccccc}
\hline & Estimate & SE & Wald & df & Sig. \\
\hline Threshold & & & & & \\
Frequency=0 & -3.252 & 0.816 & 15.891 & 1 & $0.000^{* * *}$ \\
Frequency=1 & -1.651 & 0.667 & 6.137 & 1 & $0.013^{* *}$ \\
Frequency=2 & -0.248 & 0.616 & 0.162 & 1 & 0.687 \\
Frequency=3 & 1.208 & 0.652 & 3.433 & 1 & $0.064 *$ \\
Location & & & & & \\
ERS=Suppress (1) & 0.489 & 0.913 & 0.286 & 1 & 0.593 \\
ERS=Control (2) & -0.219 & 0.873 & 0.063 & 1 & 0.802 \\
Prompt=Yes $(8)$ & 1.233 & 0.863 & 2.041 & 1 & 0.153 \\
ERS=1 * Prompt=8 & 1.640 & 1.377 & 1.418 & 1 & 0.234 \\
ERS=2* Prompt=8 & 0.720 & 1.204 & 0.358 & 1 & 0.550 \\
\hline
\end{tabular}

***Significant at the 0.01 level (2-tailed).

**Significant at the 0.05 level (2-tailed).

*Significant at the 0.10 level (2-tailed).

+ Reference categories are excluded from the table 
Table 20 Analysis of Variance Results for the Relationship Between Emotion Regulation Strategy and the Ability to Accurately Recall Fraud Risk Factors (DV=Accuracy) Tests of Hypotheses $1 b$ and $2 c-2 d$ for Grads+

\begin{tabular}{lrrrrr}
\hline & Sum of & \multicolumn{1}{c}{ Mean } & Square \\
Variable & Squares & df & Error & $F(69)$ & Sig. \\
\hline ERS & 0.562 & 2 & 0.281 & 0.279 & 0.782 \\
Prompt & 1.089 & 1 & 1.089 & 1.080 & 0.408 \\
ERS * Prompt & 7.930 & 2 & 3.965 & 3.930 & 0.203 \\
Mindful_Freq & 35.004 & 7 & 5.001 & 4.957 & 0.178 \\
Current Firm & 30.948 & 6 & 5.158 & 5.113 & 0.173 \\
EmoReg_Freq & 37.411 & 6 & 6.235 & 6.181 & 0.146 \\
Focus & 14.472 & 6 & 2.412 & 2.391 & 0.324 \\
Stop and Think & 13.602 & 6 & 2.267 & 2.247 & 0.340 \\
Remember & 35.528 & 4 & 8.882 & 8.804 & 0.105 \\
Gender & 2.435 & 1 & 2.435 & 2.414 & 0.260 \\
Education & 0.811 & 1 & 0.811 & 0.804 & 0.465 \\
Position & 0.104 & 1 & 0.104 & 0.104 & 0.778 \\
Years' Experience & 6.790 & 1 & 6.790 & 6.730 & 0.122 \\
\# FS Analyzed & 3.322 & 1 & 3.322 & 3.293 & 0.211 \\
\hline
\end{tabular}

***Significant at the 0.01 level (2-tailed).

**Significant at the 0.05 level (2-tailed).

*Significant at the 0.10 level (2-tailed). 
Table 21 Analysis of Variance of the Relationship Between Sample and the Likelihood that Management is Engaging in Financial Misreporting

\begin{tabular}{lrrrrr}
\hline DV = Financial Misreporting (FRF) & \multicolumn{5}{c}{ Mean } \\
Variable & $\begin{array}{r}\text { Sum of } \\
\text { Squares }\end{array}$ & df & Equare & & \\
\hline ERS & 773.80 & 2 & 385.90 & 0.867 & 0.423 \\
Prompt & 354.35 & 1 & 354.35 & 0.794 & 0.375 \\
Sample & 2738.05 & 2 & 1369.02 & 3.069 & $0.050^{*}$ \\
ERS * Prompt & 149.80 & 2 & 74.90 & 0.168 & 0.846 \\
ERS * Sample & 1240.99 & 4 & 310.25 & 0.696 & 0.597 \\
Prompt * Sample & 1566.59 & 2 & 783.30 & 1.756 & 0.177 \\
ERS * Prompt * Sample & 2013.33 & 4 & 503.33 & 1.129 & 0.347 \\
\hline
\end{tabular}

***Significant at the 0.01 level (2-tailed).

**Significant at the 0.05 level (2-tailed).

*Significant at the 0.10 level (2-tailed). 


\section{AppendiX A: Fraud Firm Source Materials}

\section{SEC Charges Quantum with Internal}

Accounting Controls Failures

\section{ADMINISTRATIVE PROCEEDING}

File No. 3-19626

December 20, 2019

The Securities and Exchange Commission today charged Silicon Valley-based data storage company Quantum Corporation with internal accounting controls violations that resulted in repeated revenue recognition errors from 2015 to 2017 . Quantum has agreed to pay a \$1 million penalty to settle the charges.

According to the SEC's order, Quantum recognized revenue from dozens of transactions with third parties, known as channel partners, without meeting the necessary revenue recognition criteria under GAAP. Quantum's business involves selling its hardware to channel partners, who then resell the products to end users or other channel partners. The SEC's order finds that in 2015, Quantum decided to rely more heavily on sales practices that allowed channel partners to build up stock of Quantum products. However, unbeknownst to management, Quantum's sales personnel began regularly adding terms to channel partner deals that undermined the company's ability to recognize revenue under GAAP. Accounting personnel responsible for revenue recognition determinations were either unaware of these extra terms or lacked sufficient expertise to analyze them under GAAP. According to the order, Quantum's revenue recognition errors continued unchecked for almost three years.

The SEC's order finds that these errors resulted from internal accounting control failures. Specifically, Quantum did not devise or maintain sufficient controls to provide reasonable assurance that its accounting personnel had sufficient expertise and knowledge regarding channel partner transactions to make revenue recognition determinations. Further, the order finds that sales personnel did not communicate material deal terms to accounting personnel. In the absence of sufficient controls, Quantum overstated or understated up to approximately $7 \%$ of its total quarterly revenue in incorrect periods and had to restate its previously issued financial statements.

The SEC's order finds that Quantum violated the reporting, books and records, and internal accounting controls provisions of Sections 13(a), 13(b)(2)(A) and 13(b)(2)(B) of the Securities Exchange Act of 1934 and Rules 13a-1 and 13a-13 thereunder. Without admitting or denying the allegations, the company agreed to pay a penalty of $\$ 1$ million and to cease and desist from future violations of these provisions.

The SEC's investigation was conducted by Walker Newell and Ellen Chen. The case was supervised by Jennifer J. Lee, Monique Winkler, and Erin E. Schneider. 
UNITED STATES OF AMERICA

Before the

SECURITIES AND EXCHANGE COMMISSION

SECURITIES EXCHANGE ACT OF 1934

Release No. 87812 / December 20, 2019

ACCOUNTING AND AUDITING ENFORCEMENT

Release No. 4110 / December 20, 2019

ADMINISTRATIVE PROCEEDING

In the Matter of

QUANTUM CORPORATION,

\section{Respondent.}

ORDER INSTITUTING CEASE-AND- DESIST PROCEEDINGS PURSUANT TO SECTION 21C OF THE SECURITIES EXCHANGE ACT OF 1934, MAKING FINDINGS, AND IMPOSING A CEASEAND-DESIST ORDER

File No. 3-19626

I. The Securities and Exchange Commission ("Commission") deems it appropriate that ceaseand-desist proceedings be, and hereby are, instituted pursuant to Section 21C of the Securities Exchange Act of 1934 (“Exchange Act”) against Quantum Corporation (“Quantum" or "Respondent").

II. In anticipation of the institution of these proceedings, Respondent has submitted an Offer of Settlement ("Offer") which the Commission has determined to accept. Solely for the purpose of these proceedings and any other proceedings brought by or on behalf of the Commission, or to which the Commission is a party, and without admitting or denying the findings herein, except as to the Commission's jurisdiction over it and the subject matter of these proceedings, which are admitted, Respondent consents to the entry of this Order Instituting Cease-and-Desist Proceedings Pursuant to Section 21C of the Securities Exchange Act of 1934, Making Findings, and Imposing a

Cease-and-Desist Order ("Order"), as set forth below.

III. On the basis of this Order and Respondent's Offer, the Commission finds that: 


\section{$\underline{\text { Summary }}$}

Quantum is a public data storage company that manufactures and sells hardware to channel partners such as distributors and resellers, as well as to end-user customers. Between the fourth quarter of its 2015 fiscal year (which ended March 31, 2015) and the second quarter of its 2018 fiscal year (which ended September 30, 2017) ("the restatement period"), Quantum recognized revenue from dozens of transactions with channel partners without meeting the necessary revenue recognition criteria under Generally Accepted Accounting Principles (“GAAP”). These errors caused Quantum to materially overstate its revenue for certain reporting periods and to understate its revenue in other periods.

Quantum's revenue recognition errors resulted from internal accounting control failures, including insufficient controls to provide reasonable assurance that the relevant accounting personnel had sufficient expertise and knowledge regarding channel partner transactions to make appropriate revenue recognition determinations. In this environment, Quantum's revenue recognition errors continued unchecked for almost three years.

In 2019, Quantum disclosed material misstatements in its consolidated financial statements for three annual periods and five quarterly periods and announced a restatement, as well as material weaknesses in its internal control over financial reporting.

\section{$\underline{\text { Respondent }}$}

Quantum is a Delaware corporation with its principal executive offices in San Jose, California. Quantum's common stock is registered with the Commission pursuant to Section 12(g) of the Exchange Act. Until January 2019, Quantum's common stock traded on the New York Stock Exchange ("NYSE") under the ticker symbol QTM. Currently, Quantum's common stock trades on the OTC Pink exchange under the ticker symbol QMCO.

\section{Facts}

Quantum's Business and Historical Revenue Recognition Policy

At all relevant times, Quantum's business focused on manufacturing and selling data storage devices and systems, including physical hardware such as disk drives. Quantum works with a network of numerous channel partners, including distributors and value-added resellers. Channel partners purchase hardware from Quantum and then resell the products to end users or other channel partners.

Quantum disclosed in its Forms 10-K for fiscal years 2015, 2016, and 2017 that it prepared its financial statements in accordance with GAAP. Under Accounting Standards Codification (“ASC”) 605, Revenue Recognition, revenue should be recognized only when it is both earned and realized or realizable. 
Consistent with GAAP, in its Forms 10-K, Quantum's critical accounting policies explained that the company considered revenue to be earned and realized or realizable when: (1) persuasive evidence of an arrangement exists; (2) delivery has occurred or services have been rendered; (3) the seller's price to the buyer is fixed or determinable; and (4) collectability is reasonably assured. As disclosed in its Forms 10K, Quantum told investors that it generally recognized revenue upon shipment (i.e., on a "sell-in" basis) for hardware products sold to channel partners. Quantum's Forms 10-K also disclosed that when significant post-delivery obligations existed, the related revenue was deferred until such obligations were fulfilled.

For Almost Three Years, Quantum Repeatedly Recognized Revenue in Incorrect Periods

During the restatement period, Quantum did not design or maintain sufficient internal accounting controls to provide reasonable assurance that the company complied with the revenue recognition criteria under GAAP. In the absence of sufficient controls, Quantum overstated or understated up to approximately $7 \%$ of its total quarterly revenue in incorrect periods as a result of (1) certain sales practices of granting favorable deal terms to channel partners that were not properly accounted for at the time of revenue recognition; and (2) bill and hold arrangements. As a result, Quantum materially misstated its financial statements from the fourth quarter of fiscal year 2015 through the second quarter of fiscal year 2018 and failed to make and keep accurate books and records.

\section{Quantum's Sales Practices to Encourage Channel Partners to Buy More Inventory}

Quantum's revenue recognition issues began in early 2015. By that time, Quantum had experienced waning market demand for certain products, causing its total revenues to shrink from about $\$ 1.01$ billion in fiscal year 2007 to about $\$ 553$ million in fiscal year 2014. In 2014, an activist investor approached Quantum regarding its performance and entered into a standstill agreement with the company. Among other things, the standstill agreement set forth business objectives (including revenue targets) that Quantum needed to hit in its 2015 fiscal year. If Quantum missed the targets, the activist investor would gain two additional seats on Quantum's board of directors.

In response, Quantum made a business decision to rely more heavily on two pre- existing sales practices to help the company achieve the revenue targets in the standstill agreement. First, Quantum increasingly encouraged channel partners to place "stocking orders." The general purpose of "stocking orders" was to enable channel partners to build up inventory of new Quantum products that they would resell in later periods to satisfy expected future end user demand. Second, Quantum encouraged channel partners to "pre-buy" products for specific, already-identified deals that were expected to close in later 
periods but had not yet been ordered by end users. Quantum's management did not, however, sufficiently consider the risks presented by these types of transactions, including whether their increased use may have warranted additional consideration of whether Quantum's existing internal accounting controls were sufficient.

In fact, unbeknownst to management, sales personnel regularly added deal terms to stocking orders and pre-buys that undermined the company's revenue recognition under ASC 605. However, Quantum's lower-level accounting personnel responsible for making revenue recognition determinations lacked both appropriate accounting expertise and relevant information from sales personnel regarding channel partner transactions. In many instances, the existence of additional deal terms was not communicated to the accounting personnel. In the absence of sufficient internal accounting controls around revenue recognition, Quantum prematurely recorded revenue for many stocking orders and pre-buys with such deal terms, as set forth below.

\section{Guaranteed Profit Margins and Extra Return Rights}

Quantum prematurely recognized revenue from channel partner transactions where the pricing was not fixed or determinable. For example, in connection with certain transactions, Quantum agreed to provide channel partners with guaranteed profit margins. For these deals, Quantum's ultimate price to the relevant channel partners was not fixed or determinable because the guaranteed profit margins caused the ultimate payment from the channel partner to be contingent on the subsequent resale price of the product to the end user, which at times was lower than anticipated.

Quantum also allowed certain channel partners to return previously purchased inventory beyond the return rights specified in the original contractual agreements. In its

Forms 10-K for the restatement period, Quantum told investors that it recognized hardware revenue upon shipment and, for deals involving future product returns, recorded an allowance for estimated future price adjustments in the period revenue was recognized. However, Quantum could not reasonably estimate future price adjustments in deals involving extra-contractual return rights, so its ultimate price on the transactions was not fixed or determinable at the time of shipment.

\section{Post-Delivery Obligations}

Quantum also prematurely recognized revenue for certain transactions because it continued to have significant post-delivery obligations after products had been shipped to channel partners. Because Quantum had not substantially accomplished all it must do to earn the revenue, Quantum should have deferred revenue until it had fulfilled its post-delivery obligations. 
Among other post-delivery obligations, in connection with certain transactions, Quantum arranged for the shipment of channel partners' orders to third party warehouses, paid for channel partners' storage costs, relabeled products for the benefit of channel partners, and/or paid for shipping and insurance to end users. Quantum also had continuing involvement in channel partners' resale efforts after deals had ostensibly closed, including arranging for certain partners to purchase stale inventory from other partners and facilitating pricing for such partner-to-partner deals. For transactions involving such obligations, revenue should not have been recognized at the time of shipment.

\section{$\underline{\text { Transactions Did Not Meet Bill and Hold Criteria }}$}

15. Separate from certain stocking orders and pre-buys, Quantum also determined that it had not recognized revenue consistently with GAAP and its own accounting policies for bill and hold arrangements. In bill and hold arrangements, the buyer is billed for products ready for delivery, but the seller retains possession until the buyer requests delivery at a later date. Quantum determined that it should not have recognized revenue at the time of sale because Quantum — not the buyer — requested the bill and hold arrangements, and certain transactions required specific performance obligations from Quantum after shipment in order to sell the products to end users.

Quantum's Deficient Controls

Quantum's revenue recognition issues stemmed from a failure to design and maintain internal accounting controls sufficient to provide reasonable assurance that its financial statements were presented in accordance with GAAP. Quantum accounting personnel did not have the necessary expertise or knowledge to reach the appropriate accounting treatment for certain transactions with channel partners.

During the restatement period, Quantum's tone-at-the-top contributed to its insufficient internal accounting controls environment. While management encouraged sales personnel to pursue stocking orders and pre-buys, Quantum did not sufficiently consider the risks presented by these transactions, including whether these transactions may have required them to design any additional internal accounting controls.

Personnel within Quantum's sales, accounting, and other departments at times lacked knowledge, experience, and training regarding channel partner arrangements and relationships and proper application of revenue recognition. Contributing to this issue, Quantum's accounting department experienced significant turnover during the relevant period. Key accounting personnel lacked knowledge of the details and scope of Quantum's overall business practices with channel partners, which limited their ability to appropriately recognize revenue for certain transactions. 
In addition, Quantum's sales teams did not communicate material terms of arrangements with channel partners to the relevant accounting personnel. Instead, personnel outside the accounting department had discretion for escalating deals that may have had revenue recognition implications to the appropriate accounting personnel. However, sales personnel became accustomed to offering additional deal terms without adequate policies or procedures requiring that they disclose these terms to the relevant accounting personnel. Due to a lack of clear reporting structures and responsibilities, accounting personnel were ultimately left unaware of critical information about certain deals necessary to properly recognize revenue in accordance with GAAP.

Finally, Quantum failed to adequately prepare, analyze, and review revenue recognition and other significant account reconciliations. As a result, revenue transactions were recorded prematurely and not in accordance with GAAP during the relevant period.

Quantum Restated Three Years of Financial Statements

Quantum began an internal investigation into its revenue recognition practices after being contacted by the staff in the Commission's Division of Enforcement. On February 8, 2018, Quantum filed a Form 8-K disclosing that it had postponed its quarterly earnings call to allow its audit committee to complete an investigation into accounting matters and related internal controls. By the close of trading that day, Quantum's stock price had declined by approximately 30 percent. On January 15, 2019, due to Quantum's failure to meet SEC reporting requirements, its stock was delisted from the NYSE.

On August 6, 2019, Quantum announced that it had completed its restatement of financial statements for prior periods. Quantum concluded that there were material misstatements in its consolidated financial statements reported on Forms 10-K for the fiscal years ending March 31, 2015, 2016 and 2017, as well as in the unaudited condensed consolidated financial statements reported on Forms 10-Q for the quarters ending June 30, 2016, September 30, 2016, December 31, 2016, June 30, 2017, and September 30, 2017. The restatement revealed that Quantum's revenue, once adjusted for the correct reporting periods, would have missed the objectives set forth in the standstill agreement, as well as the company's public revenue guidance for fiscal year 2017.

Quantum also disclosed that it had identified material weaknesses in its internal control over financial reporting, which had contributed to the restatement. Among other things, Quantum identified material weaknesses related to its tone-at-the top, including a lack of sufficient personnel with appropriate accounting knowledge, a failure to establish clear reporting structures in the organization, 
and a failure to design effective controls over the period-end financial reporting process. As part of its remediation efforts, Quantum terminated several sales, accounting, and operations personnel and enhanced its policies and procedures regarding revenue recognition, stocking orders, pre-buys, and bill-and-hold transactions.

\section{Violations}

As a result of the conduct described above, Quantum violated Section 13(a) of the Exchange Act and Rules 13a-1 and 13a-13 thereunder, which require every issuer of securities registered pursuant to Section 12 of the Exchange Act to file with the Commission accurate periodic reports, including annual Reports on Form 10-K and quarterly Reports on Form 10-Q.

As a result of the conduct described above, Quantum also violated Section 13(b)(2)(A) of the Exchange Act, which requires an issuer to make and keep books, records, and accounts which, in reasonable detail, accurately and fairly reflect the issuer's transactions and disposition of assets.

As a result of the conduct described above, Quantum also violated Section 13(b)(2)(B) of the Exchange Act, which requires an issuer to devise and maintain a system of internal accounting controls sufficient to provide reasonable assurances that: transactions are executed in accordance with management's general and specific authorization; transactions are recorded as necessary to permit preparation of financial statements in conformity with GAAP or any other criteria applicable to such statements, and to maintain accountability for assets; access to assets is permitted only in accordance with management's general or specific authorization; and the recorded accountability for assets is compared with the existing assets at reasonable intervals and appropriate action is taken with respect to any differences.

IV. In view of the foregoing, the Commission deems it appropriate to impose the sanctions agreed to in Respondent Quantum Corporation's Offer.

Accordingly, it is hereby ORDERED that:

Pursuant to Section $21 \mathrm{C}$ of the Exchange Act, Respondent shall cease and desist from committing or causing any violations and any future violations of Sections 13(a), 13(b)(2)(A), and 13(b)(2)(B) of the Exchange Act and Rules 13a-1 and 13a-13 thereunder.

Respondent shall, within 10 days of the entry of this Order, pay a civil money penalty in the amount of $\$ 1,000,000.00$ to the Securities and Exchange Commission for transfer to the general fund of the United States Treasury, subject to Exchange Act Section $21 \mathrm{~F}(\mathrm{~g})(3)$. If timely payment is not made, additional interest shall accrue pursuant to 31 U.S.C. $\S 3717$. 
Payment must be made in one of the following ways:

Respondent may transmit payment electronically to the Commission, which will provide detailed ACH transfer/Fedwire instructions upon request;

Respondent may make direct payment from a bank account via Pay.gov through the SEC website athttp://www.sec.gov/about/offices/ofm.htm; or

Respondent may pay by certified check, bank cashier's check, or United States postal money order, made payable to the Securities and Exchange Commission and hand-delivered or mailed to:

Enterprise Services Center Accounts Receivable Branch HQ Bldg., Room 181, AMZ-341

6500 South MacArthur Boulevard Oklahoma City, OK 73169

Payments by check or money order must be accompanied by a cover letter identifying Quantum Corporation as a Respondent in these proceedings, and the file number of these proceedings; a copy of the cover letter and check or money order must be sent to Monique Winkler, Division of Enforcement, Securities and Exchange Commission, 44 Montgomery Street, Suite 2800, San Francisco, CA 94104.

C. Amounts ordered to be paid as civil money penalties pursuant to this Order shall be treated as penalties paid to the government for all purposes, including all tax purposes. To preserve the deterrent effect of the civil penalty, Respondent agrees that in any Related Investor Action, it shall not argue that it is entitled to, nor shall it benefit by, offset or reduction of any award of compensatory damages by the amount of any part of Respondent's payment of a civil penalty in this action ("Penalty Offset"). If the court in any Related Investor Action grants such a Penalty Offset, Respondent agrees that it shall, within 30 days after entry of a final order granting the Penalty Offset, notify the Commission's counsel in this action and pay the amount of the Penalty Offset to the Securities and Exchange Commission. Such a payment shall not be deemed an additional civil penalty and shall not be deemed to change the amount of the civil penalty imposed in this proceeding. For purposes of this paragraph, a "Related Investor Action" means a private damages action brought against Respondent by or on behalf of one or more investors based on substantially the same facts as alleged in the Order instituted by the Commission in this proceeding.

By the Commission.

Vanessa A. Countryman

Secretary 


\section{Appendix B: Experimental Design, Expert Panel Process}

Phase

Task

Purpose of task

\begin{tabular}{|c|c|c|}
\hline 1. Introduction & $\begin{array}{l}\text { Expert panel participants are instructed to read } \\
\text { through the materials provided, and provide } \\
\text { detailed feedback on the materials, the process, } \\
\text { and their findings }\end{array}$ & $\begin{array}{l}\text { To set the context of the } \\
\text { experiment }\end{array}$ \\
\hline 2. Prime & $\begin{array}{l}\text { Panel participants read an article from the } \\
\text { Journal of Accountancy on the benefits of } \\
\text { Mindfulness in accounting (Vetter 2020) }\end{array}$ & $\begin{array}{l}\text { Prime participants to consider } \\
\text { mindfulness }\end{array}$ \\
\hline $\begin{array}{ll}\text { 3. Experimental } \\
\text { Task }\end{array}$ & $\begin{array}{l}\text { Panel participants evaluate information related to } \\
\text { two firms, one subject to a SEC AAER and } \\
\text { another firm in the same industry was not subject } \\
\text { to an enforcement action. Materials included: } \\
4 \text {. A 5minute } 46 \text { second audio file } \\
\text { from the fraud firm's } 4^{\text {th }} \text { quarter } 2015 \\
\text { earnings call question and answer session, } \\
\text { and the accompanying transcript } \\
5 . \quad \text { A } 6 \text { minute } 8 \text { second audio file } \\
\text { from the non-fraud firm's } 4^{\text {th }} \text { quarter } 2015 \\
\text { earnings call question and answer session, } \\
\text { and the accompanying transcript }{ }^{31} \\
6 \text {. Excerpts from the } 4^{\text {th }} \text { quarter } 2015 \\
\text { Management Discussion and Analysis and } \\
\text { Financial Statements from Form } 10-\mathrm{k} \text { for } \\
\text { each firm. }\end{array}$ & $\begin{array}{l}\text { Materials were provided to panel } \\
\text { participants by firm, randomized } \\
\text { by firm to minimize order effects, } \\
\text { such that half of the panel } \\
\text { participants saw materials related } \\
\text { to the fraud firm first and half saw } \\
\text { materials related to the non-fraud } \\
\text { firm first. } \\
\text { Participants were asked to provide } \\
\text { a list of discrepancies they noted } \\
\text { between the information provided } \\
\text { for each firm. } \\
\text { Panel participants also reported } \\
\text { (on a sliding scale) their belief that } \\
\text { the firm engaged in financial } \\
\text { misreporting and listed the } \\
\text { substantive tests to address the } \\
\text { discrepancies noted. }\end{array}$ \\
\hline $\begin{array}{l}\text { 7. Reading } \\
\text { check }\end{array}$ & $\begin{array}{l}\text { Panel participants are asked to confirm the type } \\
\text { of documents they reviewed during the } \\
\text { experimental task }\end{array}$ & $\begin{array}{l}\text { Confirm participants' recall of the } \\
\text { documents reviewed }\end{array}$ \\
\hline 8. Conclusion & $\begin{array}{l}\text { Panel participants submit their feedback on the } \\
\text { experimental task and other materials }\end{array}$ & $\begin{array}{l}\text { Collect feedback to inform } \\
\text { experiment }\end{array}$ \\
\hline
\end{tabular}

${ }^{30}$ A transcript of the audio file is also provided for accessibility and is available in Appendix F.

${ }^{31}$ Each audio file covered revenue-related discussion between the firm's management and investment analysts. 


\section{APPEndix C: Final List Of Discrepancies AND AdDitional TeSts SElected}

Please select all of the items below that apply to the Company's financial information:

A $\$ 23 \mathrm{M}$ increase in A/R was stated to be indicative of growth, but the decline in the Allowance for Doubtful Accounts generated a $\$ 61 \mathrm{M}$ increase.

A material contract was discussed and noted to increase A/R in the short term and cash in the next quarter, but the actual change in A/R is immaterial.

A new acquisition generated a $\$ 50 \mathrm{M} N O L$ carryforward.

Inventory increased while revenue remained stagnant from the prior year.

Expenditures decreased but the company reports investing in a growth strategy.

A new accounting standard was adopted in 2011, but corresponding revenue didn't reflect the expected change.

The CFO claims the balance sheet has $\$ 20 \mathrm{M}$ room for improvement, but the company took on $\$ 83 \mathrm{M}$ in convertible debt in the current year.

The Company's new product line generated $50 \%$ of annual sales.

Please select any additional procedures below that you believe may be warranted for the Company:

Tests of controls over revenue

Recalculation of allowance for doubtful accounts

Goodwill impairment test

Allocation of sales by product type 


\section{APPENDIX D: EXPERIMENTAL DESIGN}

\section{Experimental}

\section{Phase}

1. Introduction

2. Attention check

3. Prime

3. Prime
4. Participant

measures
5. Attention check

6. Treatment-

Emotional

Regulation

7. TreatmentPrompt
Experimental Task

Purpose of task

To set the context of the experiment

benefits of mindfulness

Participants are asked about the benefits of mindfulness

Participants read information about the benefits of mindfulness

Participants are asked how frequently they practice mindfulness and their reasons for doing so
Check understanding of construct

Prime participants to consider mindfulness

Evaluate relevance of mindfulness practice to participants

Participant attention is monitored through a simple task

Participants are randomly assigned to a mindfulness practice (Suppress, Control, or Reappraise group) based on their session attendance

Participants are informed that auditors, investors, and analysts evaluate certain information.

Participants in the Prompt-Y condition are further instructed to consider discrepancies in information provided.

\begin{tabular}{ll}
\hline 8. Manipulation & $\begin{array}{l}\text { Participants are asked about the mindfulness } \\
\text { check }\end{array}$
\end{tabular}

9. Attention check

Participant attention is monitored through a simple task

10. Experimental Task

\section{Participants listen to a 5minute 46 second audio} file $^{32}$ and read the experimental materials, reporting:

- Discrepancies that relate to the experimental materials (multiple choice answer).

- The likelihood of financial reporting irregularities. (sliding scale)
Attempt to manipulate participant's emotion regulation mechanism Provide instruction to participants

\section{Verify participants' understanding of the manipulation}

Measure dependent variables related to the frequency and accuracy with which participants identify fraud risk red flags

\begin{tabular}{ll}
\hline $\begin{array}{l}\text { 11. Manipulation } \\
\text { check }\end{array}$ & $\begin{array}{l}\text { Participants are asked about the mindfulness } \\
\text { practice they are assigned to }\end{array}$
\end{tabular}

12. Reading check

Participants are asked to confirm the type of documents they reviewed during the experimental task

Participants are asked about the mindfulness

practice they are assigned to
Confirm participants' memory of the experimental conditions to which they are assigned Confirm participants' recall of the documents reviewed

${ }^{32}$ A transcript of the audio file is also provided for accessibility and is available in Appendix F. 


\section{Experimental}

Phase

\begin{tabular}{lll}
\hline $\begin{array}{l}\text { 13. Participant } \\
\text { response }\end{array}$ & $\begin{array}{l}\text { Participants are asked, on a sliding scale, to report } \\
\text { their level of ease or difficulty in completing the } \\
\text { experimental task }\end{array}$ & $\begin{array}{l}\text { Evaluate effects of emotion } \\
\text { regulation on working memory }\end{array}$ \\
\hline $\begin{array}{l}\text { 14. Participant } \\
\text { measures }\end{array}$ & $\begin{array}{l}\text { Participants report the likelihood that they might } \\
\text { engage in mindfulness }\end{array}$ & $\begin{array}{l}\text { Evaluate relevance of } \\
\text { mindfulness practice to } \\
\text { participants }\end{array}$ \\
\hline $\begin{array}{l}\text { 15. Demographic } \\
\text { collection }\end{array}$ & Participants report their demographic characteristics & $\begin{array}{l}\text { Measure effect of participant } \\
\text { characteristics on measured } \\
\text { variables }\end{array}$ \\
\hline $\begin{array}{l}\text { 16. Closing } \\
\text { Participants are provided a completion code and }\end{array}$ & \\
\hline
\end{tabular}




\section{APPENDIX E: INSTRUCTIONS FOR PARTICIPANTS}

Prime:

Mindfulness can help improve cognition, focus, attention, and decision-making and may reduce stress by increasing awareness of one's immediate situation and surroundings. These benefits are useful in the workplace because they help improve interpersonal relations and satisfaction with these relationships. The Big 4 accounting firms (Deloitte, EY, KPMG and PwC) have emphasized practicing mindfulness and the profession is embracing its usefulness. In this study, we ask you to use mindfulness techniques as you review information.

Instructions by Random Assignment:

\begin{tabular}{|l|l|}
\hline \multicolumn{1}{|c|}{ Condition } & \multicolumn{1}{c}{ Instructions } \\
$\begin{array}{l}\text { Suppression (Adapted } \\
\text { from Richards and }\end{array}$ & $\begin{array}{l}\text { It is extremely important for the sake of this study that if you have any } \\
\text { feelings, you please try your best not to let those feelings show. In other } \\
\text { words, please try to behave in such a way that a person watching you would } \\
\text { not know you are feeling anything at all. }\end{array}$ \\
\hline $\begin{array}{l}\text { Control (Richards and } \\
\text { Gross 2000) }\end{array}$ & Please review the following information carefully. \\
$\begin{array}{l}\text { Reframe (Adapted } \\
\text { from Scheppes et al. }\end{array}$ & $\begin{array}{l}\text { Try your best to feel less negative about the information you are about to } \\
\text { see by trying to change the meaning of it. That means you think of } \\
\text { something to tell yourself about the information that helps you feel less } \\
\text { negative about it. So, for example, you could tell yourself something about } \\
\text { the outcome, so that whatever is going on will soon be resolved or that help } \\
\text { is on the way. You could also focus on a detail of the situation that may not } \\
\text { be as bad as it first seemed. We want you to stay focused on the information } \\
\text { and not think of random things that make you feel better, but rather to } \\
\text { change something about the information that helps you to feel less negative } \\
\text { about it. }\end{array}$ \\
\hline
\end{tabular}




\begin{tabular}{|l|l|}
\hline Condition & Instructions \\
\hline Prompt & $\begin{array}{l}\text { Auditors, analysts, and investors review information provided by the } \\
\text { company, in addition to that obtained from outside sources. Some of this } \\
\text { information includes transcripts from earnings calls and the accompanying } \\
\text { financial statements. As you review these documents, please be mindful of } \\
\text { discrepancies that may exist in the information provided between these } \\
\text { documents. }\end{array}$ \\
\hline No Prompt & $\begin{array}{l}\text { Auditors, analysts, and investors review information provided by the } \\
\text { company, in addition to that obtained from outside sources. Some of this } \\
\text { information includes transcripts from earnings calls and the accompanying } \\
\text { financial statements. }\end{array}$ \\
\hline
\end{tabular}




\section{Appendix F: Experimental Materials, Seen by All Participants after Assignment}

Transcript of Earnings Call Q\&A segment:

The following is a transcript of the mp3 file for the Company's Earnings Call. The transcript is provided in case the mp3 file does not play properly.

Question-and-Answer Session

Operator

Thank you. [Operator Instructions] We'll go first to Chad with Craig-Hallum.

Please go ahead.

Chad

So nice job on the quarter, the StorNext growth was great and it sounds like obviously we're expecting good growth this year. Just on the fiscal '16 guide if we kind of back out the scale-out growth of 50\% that implies I think a pretty -- it depends on how you mix it up but a pretty big deceleration in DXi growth and/or kind of take declines that are at or kind of above historical norms, are we just being conservative or could you provide any other color into the other segments of the business and how you're thinking about them next year?

\section{$\mathrm{CEO}$}

Yes, so first I thought you were going to comment on the 30\% DXi growth in Q4.

Chad

Well I'm assuming it's going to grow 30\% again this year which wouldn't mean the guidance doesn't make sense.

CEO

Yes, I know. We're really targeting the market around on that piece. Basically, one of the things we decided to do is we have so many really strong moving parts for the year that we wanted to get Q1 under our belt and we'll provide more guidance as we get along

here. We think there is a huge opportunity for us in video surveillance. And we want to see how that materializes I think from a plan perspective we expect DXi to grow next year. We expect tape to kind of be down in the 5\% to $7 \%$ range and I think if you do all that math that should be pretty close to reconciling.

Chad

Okay.

$\mathrm{CEO}$

And OEM piece I commented on that for the quarter, that's down its half the size of scaleout, now less than half the size. It's still about $\$ 60$ million. It bid by far is the piece that we have the least control over and the lowest expectations for, for next year. Having said that it's getting to be a fairly nominal amount compared to the other growth pieces so it depends I think Chad on what you pick for all those pieces I think for the royalty it's been a great royalty year for tape better than we anticipated at the start of the year 
it's hard to forecast it that way but tape's increasing role in Archive might surprise us so I think the second thing that is down in that analysis is royalty.

Chad

Okay. So, royalty kind of from our expectation standpoint should be down in line with kind of tape?

CEO

I would probably make it a little or we're probably $10 \%$ for the royalty and probably $7 \%$ for tape. That's what we're starting with and as you know and you've asked this question before because tape is such an important part of the company both in terms of install base and profitability we're trying to not we're going to drive to get every tape dollar we can but from a modeling standpoint if we miss it on the revenue it hurts us from a profitability standpoint. So, we're trying to be conscious about that.

Chad

Yes, and then a couple of things more. On the scale-out growth that you are talking about 50\% I know you are definitely investing and penetrating into to new verticals there, but can we get to the 50\% growth just I don't know if you call it blocking and tackling in media and entertainment market and just kind of rolling within that vertical or do we need these each other verticals to really kick in to achieve that $50 \%$ growth rate?

CEO

I would say we feel really good about the $50 \%$ growth rate in the terms of what we know what we see I think it's -- so these other verticals take off in anyway shape of formula we see a lot of upside.

Chad

Okay and then maybe last one from me and this might be more for Linda. Linda is there any kind of ballpark you can give us over the next couple of quarters of what you can generate from working capital on a cash flow basis I know December quarters are pretty good use and March quarters are pretty use of working capital how much can we expect to kind of realize in the next couple of quarters?

Linda Breard

Yes, let me -- as you know we ended the year with as we ended the year with 50 million in inventory which is higher than we have outsourced for 35 million and we kind of expect being lower with the outsource model so there is definitely cash that will come off the balance sheet with those AR and inventory over the next couple of quarters.

\section{CEO}

Yes. And I think if you look Chad we got to get used to this growth company thing for sure we don't want to leave revenue in the docks as you might say but the balance sheet definitely has I don't know Linda had talked about maybe \$20 million of improvement and maybe even a little more than that.

Chad

Okay. That's perfect. Thank you. 


\section{Excerpts from Fourth Quarter 2015 Management Discussion and Analysis:}

\section{Results}

We had total revenue of $\$ 553.1$ million in fiscal 2015 , which is essentially flat compared to fiscal 2014. This is the net result of increased revenue from scale-out storage solutions, disk backup systems and service, offset by decreased tape automation systems and devices and media revenue and a $\$ 15.0$ million royalty received in fiscal 2014 in connection with finalizing an intellectual property agreement that is not expected to recur. We had record revenue from scale-out storage solutions due to increased branded revenue in all geographies - Asia-Pacific (APAC), Europe, the Middle East and Africa (EMEA) and North America. Our total branded product and service revenue increased 7\% from fiscal 2014 and our continued focus on our branded business is reflected in a greater proportion of non-royalty revenue from branded products and services, which grew to $88 \%$ in fiscal 2015 compared to $84 \%$ in fiscal 2014 and $83 \%$ in fiscal 2013.

Our gross margin percentage increased 90 basis points from fiscal 2014 to $44.2 \%$, the net result of higher service revenue driven by the growth in scale-out storage and the improvements we have made in our business model over the past yearend-a -half, offset by lower royalty revenue. Operating expenses decreased \$20.9 million, or 8\%, from fiscal 2014 primarily due to cost controls and spending reductions that were implemented over the past year. Restructuring charges decreased by $\$ 9.5$ million compared to fiscal 2014 , primarily related to lower severance and benefits. Compensation and benefits also decreased due to reduced staffing levels. Intangible amortization expense decreased due to certain intangibles becoming fully amortized during fiscal 2015. Our operating results improved by $\$ 26.2$ million, from a loss of \$11.8 million in fiscal 2014 to $\$ 14.4$ million of income from operations in fiscal 2015.

Net income improved by $\$ 38.2$ million, from a net loss of $\$ 21.5$ million in fiscal 2014 to net income of $\$ 16.8$ million in fiscal 2015, which included a gain of $\$ 13.6$ million resulting from the sale of our investment in a privately held company.

Excerpts from Fourth Quarter 2015 Form 10-k:

\section{RESULTS OF OPERATIONS FOR FISCAL 2015, 2014 and 2013 Revenue}

Total revenue in fiscal 2015 remained relatively flat compared to fiscal 2014. Revenue from scale-out storage solutions, disk backup systems and service revenue increased. These increases were offset by decreases in OEM and branded tape automation systems revenue, royalty revenue as well as branded devices and media revenue. The decrease in royalty revenue was primarily due to a $\$ 15.0$ million royalty in connection with an intellectual property agreement received in the prior year.

We believe the changes in our product and service revenue are driven by the changing storage environment, including increased market demand for scale-out storage solutions and reduced demand for tape products. Revenue from branded data protection products and services decreased $\$ 13.7$ million, or $4 \%$, from fiscal 2014, largely due to decreases 
in tape automation systems and media revenue. Data protection products include our tape automation systems, disk backup systems and devices and media offerings. Revenue from branded scale-out storage solutions and services increased $\$ 43.4$ million, or $74 \%$, from fiscal 2014 largely due to increased sales of our StorNext appliances. Scale-out storage solutions include StorNext software, torNext appliances, StorNext Pro Solutions and Lattus extended online storage solutions. In addition, OEM product and service revenue, which primarily comprises tape automation systems, decreased \$14.0 million from fiscal 2014.

\begin{tabular}{|c|c|c|c|c|c|c|c|c|c|c|}
\hline \multirow{3}{*}{ (dollars in thousands) } & \multicolumn{6}{|c|}{ For the year ended March 31, } & \multicolumn{4}{|c|}{ Change } \\
\hline & \multicolumn{2}{|c|}{2015} & \multicolumn{2}{|c|}{2014} & \multicolumn{2}{|c|}{2013} & \multicolumn{2}{|c|}{2015 vs. 2014} & \multicolumn{2}{|c|}{2014 vs. 2013} \\
\hline & & $\begin{array}{l}\% \text { of } \\
\text { revenue }\end{array}$ & & $\begin{array}{l}\% \text { of } \\
\text { revenue }\end{array}$ & & $\begin{array}{l}\% \text { of } \\
\text { revenue }\end{array}$ & & & & \\
\hline Product revenue & $\$ 355,579$ & $64.3 \%$ & $\$ 348,318$ & $63.0 \%$ & $\$ 398,910$ & $67.9 \%$ & S 7,261 & $2.1 \%$ & $\$(50,592)$ & $(12.7) \%$ \\
\hline Service revenue & 155,674 & $28.1 \%$ & 147,199 & $26.6 \%$ & 144,037 & $24.5 \%$ & 8,475 & $5.8 \%$ & 3,162 & $2.2 \%$ \\
\hline Royalty revenue & 41,842 & $7.6 \%$ & 57,648 & $10.4 \%$ & 44,492 & $7.6 \%$ & $(15,806)$ & $(27.4) \%$ & 13,156 & $29.6 \%$ \\
\hline Total revenue & $\$ 553,095$ & $100.0 \%$ & $\$ 553,165$ & $100.0 \%$ & $\$ 587,439$ & $100.0 \%$ & S (70) & $-\%$ & $\$(34,274)$ & $(5.8) \%$ \\
\hline
\end{tabular}




\section{CONSOLIDATED BALANCE SHEETS}

(In thousands, except par value)

\section{Assets}

\begin{tabular}{|c|c|}
\hline $\begin{array}{c}\text { March } 31, \\
2015\end{array}$ & $\begin{array}{c}\text { March 31, } \\
2014\end{array}$ \\
\hline & \\
\hline$\$ 67,948$ & $\$ 99,125$ \\
\hline 2,621 & 2,760 \\
\hline 124,159 & 101,605 \\
\hline 50,274 & 34,815 \\
\hline 24,640 & 25,629 \\
\hline 12,332 & 10,161 \\
\hline 281,974 & 274,095 \\
\hline 14,653 & 17,574 \\
\hline 731 & 3,911 \\
\hline 55,613 & 55,613 \\
\hline 5,784 & 10,605 \\
\hline 76,781 & 87,703 \\
\hline$\$ 358,755$ & $\$ 361,798$ \\
\hline
\end{tabular}

Current assets:

Cash and cash equivalents

Restricted cash

Accounts receivable, net of allowance for doubtful accounts of $\$ 27$ and $\$ 88$, respectively

Manufacturing inventories

Service parts inventories

Other current assets

Total current assets

Long-term assets:

Property and equipment, less accumulated depreciation

Intangible assets, less accumulated amortization

Goodwill

Other long-term assets

Total long-term assets

\section{Liabilities and Stockholders' Deficit}

Current liabilities:

Accounts payable

Accrued warranty

Deferred revenue, current

Accrued restructuring charges, current

Convertible subordinated debt, current

Accrued compensation

Other accrued liabilities

Total current liabilities

Long-term liabilities:

Deferred revenue, long-term

Accrued restructuring charges, long-term

Convertible subordinated debt, long-term

Other long-term liabilities

Total long-term liabilities

\begin{tabular}{rrr}
$\$ 54,367$ & $\$ 41,792$ \\
4,219 & 6,116 \\
95,899 & 98,098 \\
3,855 & 4,345 \\
83,735 & - \\
35,414 & 25,036 \\
20,740 & & 15,168 \\
\cline { 3 - 3 } 298,229 & & 190,555 \\
& & \\
39,532 & & 40,054 \\
9991 & 4,023 \\
70,000 & 203,735 \\
10,441 & 10,831 \\
\cline { 1 - 1 } 120,964 & 258,643
\end{tabular}




\section{APPENDIX G: LIST OF VARIABLES}

Variable Label

Variable Name

Description

ERS

Prompt

Quantity

Accuracy

FinMisrept Financial misreporting

\#AddlTests Number of additional tests to address fraud risk factors identified

Focus Difficulty focusing

StopThink Difficulty stopping and thinking about the information reviewed

Remember Difficulty remembering details about the materials reviewed

CurrFirm

Likelihood that participants' current employer encourages mindfulness

EmoRegFreq Frequency of practicing emotional regulation

Mindful_freq Frequency of practicing mindfulness

\#FSAnalyzed Number of financial statements analyzed per quarter

Yrs_Exp Number of years' experience working full-time
$1=$ Suppress $; 2=$ Control 3= Reframe

Coded as Yes $=8$, No $=5$

Participants' ability to identify fraud risk factors, measured as a count $(0-4)$

Calculated as the number of correctly identified fraud risk factors plus the number of accurately avoided factors that are not fraud risks to the company minus the number of incorrectly identified fraud risk factors

Perceived likelihood that the company is engaging in financial misreporting (scale of 0 to 100)

Count variable of the number of substantive tests participants select to address fraud factors identified ( 0 to 4 )

Likert scale of 1 (Not difficult) to 7 (Extremely difficult)

Likert scale of 1 (Not difficult) to 7 (Extremely difficult)

Likert scale of 1 (Not difficult) to 7 (Extremely difficult)

Likert scale of 1 (Not likely) to 7 (Very likely)

Likert scale of 0 (Never) to 7 (More than once per day)

Likert scale of 0 (Never) to 7 (More than once per day)

Ordinal variable from 1 (Less than 1) to 5 (50 or more)

Continuous variable on a 1 to 50 scale 


\begin{tabular}{|c|c|c|}
\hline Variable Label & Variable Name & Description \\
\hline \#EEs & $\begin{array}{l}\text { Number of employees in } \\
\text { participants' current workplace }\end{array}$ & $\begin{array}{l}\text { Ordinal variable from } 1 \text { (Fewer than } 100) \text { to } 4 \\
(10,000+)\end{array}$ \\
\hline Position & $\begin{array}{l}\text { Participant's position in their } \\
\text { current workplace }\end{array}$ & $\begin{array}{l}\text { Nominal variable with } 4 \text { levels (staff, manager, } \\
\text { director, partner) }\end{array}$ \\
\hline Education & Level of education & $\begin{array}{l}\text { Ordinal variable from } 1 \text { (High school) to } 5 \text { (Post- } \\
\text { graduate degree) }\end{array}$ \\
\hline Gender & Participant's gender & Coded as Male $=1$, Female $=0$ \\
\hline Duration & Time spent on study & Measured in minutes \\
\hline Sample & Participant source & $\begin{array}{l}\text { mTurk }=1 \text {; Undergraduate students }=4 \text {; Graduate } \\
\text { (MBA/MAcc) students }=5\end{array}$ \\
\hline
\end{tabular}




\title{
Chapter Three - The Fraud Goes On: The EfFects of Fraud Duration, Victim Organization Type and Perpetrator Status on Punishment
}

\author{
Erlina Papakroni \\ William G. Rohrer College of Business, Rowan University \\ papakroni@,rowan.edu
}

\begin{abstract}
Marie Rice
John Chambers College of Business and Economics, West Virginia University mmr0016@mix.wvu.edu
\end{abstract}

\begin{abstract}
Author Note:
We would like to thank the Association of Certified Fraud Examiners (ACFE) for providing access to their survey data and the Institute for Fraud Prevention (IFP) for sponsoring this study. We appreciate comments from the 2020 AAA Forensic Accounting Section meeting, and from Richard Riley, Jr., Kip Holderness, Jr., Richard Dull, Lisa Dilks, and Trevor Sorenson on prior drafts of this paper. * Corresponding author
\end{abstract}




\begin{abstract}
When occupational fraud is detected, the organization - the victim to the fraud casedecides whether or not to terminate, and/or to refer the principal perpetrator to law enforcement for prosecution. We use survey data collected by the Association of Certified Fraud Examiners (ACFE) to examine the impact of fraud severity, organization type and perpetrator's status on the victim organization's decisions to pursue a particular outcome against the principal perpetrator. We find that fraud duration is an important attribute in examining whether and how victim organizations pursue punishments. Specifically, the interactions between fraud duration with victim organization type and fraud duration with perpetrator status influence the punishment outcome selected by the victim organization. To our knowledge, this study is the first to consider the interactions between perpetrator and victim organization characteristics on punishment outcomes.
\end{abstract}

Keywords: Occupational fraud, fraud victim organization, principal perpetrator, status characteristics theory. 


\section{INTRODUCTION}

When high-profile fraud cases were detected in the early 2000s, many victim organizations rushed to replace their top executives. Some executives resigned voluntarily while others were terminated. For instance, Enron's CEO, Jeffrey Skilling had resigned in August 2001, a few months before accounting manipulations were revealed to the public. WorldCom's CEO, Bernard Ebbers, resigned right after the fraudulent scheme had become public, and CFO, Scott Sullivan, was terminated at the same time. HealthSouth's CEO, Richard Scrushy, and CFO, Weston Smith, were terminated weeks after the fraud scheme had become public information. At the same time, there were many other victim organizations, such as First USA Inc., 3COM, Boston Scientific, and Bausch and Lomb that did not terminate their CEOs or CFOs subsequent to the accounting scandals (Agrawal and Cooper 2017).

Organizations, the victims of occupational fraud, choose whether and how to punish perpetrators involved in fraud schemes. The purpose of this study is to examine the factors that are associated with the victim organization's decision to pursue a particular outcome against the principal perpetrator. Prior research has shown that crime severity is positively associated with outcome severity, but that this relationship is moderated by the perpetrator's characteristics (Albonetti 1998; Wheeler, Weisburd, Waring, and Bode 1988; Hagan and Parker 1985). The outcomes of white-collar crime cases, such as occupational frauds, are often situation-specific (Holtfreter, Piquero and Piquero 2008a) and vary by the victim and perpetrator characteristics (Agrawal and Cooper 2017; Beneish 1999; Garrett 2015; Hermanson, Justice, Ramamoorti, and Riley 2017; Holtfreter 2005; Karpoff et al. 2008). Victim organizations determine which outcomes to pursue against the perpetrators, considering the facts and circumstances of the fraud case. Further, victim organizations need to consider the cost-benefit of deterrence measures (Rae and 
Subramanian 2008), such as physical and monitoring controls (Townsley and Birks 2008), and how their own organizational type affects the punishment pursued (Beneish, Marshall, and Yang 2017). Punishment outcomes, such as termination and/or referral for criminal prosecution, may generate short-term or long-term costs to the organization, and it may impact the level of scrutiny, that the victim organization, faces from outside stakeholders (Holtfreter et al. 2008a; Dugan and Gibbs 2009). Thus, fraud punishment is determined not only by the severity of fraud scheme, but, also, by the perpetrator's characteristics and/or the cost-benefit to the victim organization (Eitle 2000; Dilks et al. 2015; Arnulf and Gottschalk 2013; van Prooijen and Lam 2007; Roberts and Lyons 2009)

We examine the deterrence costs victim organizations incur and Status Characteristics Theory to understand the impact of organization type and perpetrator's status on the victim organization's decision to pursue or not to pursue an outcome against the principal perpetrator. The first part of our study examines the main effects of these factors on the outcome pursued, whereas the second part of the study explores how the organization type or perpetrator's status interact with the association of fraud severity and outcome severity in occupational fraud cases. To our knowledge, no prior study has examined these interactions in an occupational fraud setting.

We use the occupational fraud data obtained from the Institute for Fraud Prevention (IFP). The data are collected by the Association of Certified Fraud Examiners (ACFE) through a biennial survey of Certified Fraud Examiners (CFEs). In most fraud cases, the principal perpetrator faces harsh consequences by losing their employment and being referred to law enforcement for criminal prosecution. Yet, in over 10 percent of the cases, the victim organization decides neither to terminate the principal perpetrator nor to file any criminal charges. 
We use multinomial logistic regression and graph distance theory to examine the moderating effects of the type of organization and the perpetrator status on the association between the occupational fraud outcome, pursued by victim organizations, and the severity of the fraud scheme. We find that non-profit, governmental, and privately held organizations are less likely to terminate the principal perpetrator as compared to publicly-traded companies. That is, the interaction between the organization type and fraud duration affects the punishment selected by the victim organization. We further find that, in support of Status Characteristics Theory, victim organizations pursue less severe outcomes against high status perpetrators, as compared to low status perpetrators, in fraud cases that lasted a short period of time. As the fraud duration increases, however, all types of victim organizations pursue equally severe outcomes against all perpetrators, despite their status. Thus, fraud duration, organization type and perpetrator's status are meaningful attributes when victim organizations choose whether and how to punish occupational fraudsters.

These findings matter to the anti-fraud profession, organizational leaders, and occupational fraud researchers. CFEs and organizational leaders, designing and implementing anti-fraud controls, refer often to the ACFE's Report to the Nations (2020) for the descriptive statistics of current occupational fraud trends, to monitor who commits occupational fraud, where, and how. During their work, CFEs are often engaged to oversee fraud examinations on behalf of organizations, including advising which outcome to pursue, given the facts and circumstances of the case. CFEs advising clients on fraud examinations benefit from considering these inputs and their interactions when helping clients select an appropriate outcome. Enforcement agencies, regulators, investors, and other stakeholders may also benefit from the results of our study when they consider pursuing outcomes against individual or organizational perpetrators. This study adds context to the ACFE's Report to the Nations (2020), which serves the anti-fraud profession, by 
showing interactions between the occupational fraud characteristics, the perpetrator's status, and the punishment pursued.

This study also enhances researchers' understanding of victim organizations' reactions to fraudulent instances and highlights a need for future research into the impact of fraud duration. Our findings extend the application of status characteristics theory to a specific type of whitecollar crimes (i.e. occupational fraud) and demonstrate the effects of the status liability hypothesis in occupational frauds. By being first to examine the interaction of the perpetrator's status and the victim organization type, we also generate ideas for a potential extension and future fraud research. Importantly, the results show that fraud duration interacts with both victim organization type and perpetrator status to influence fraud outcome. While prior studies have shown that crime environment (e.g. victim organization) and perpetrator status have direct effects on punishment, to our knowledge, this is the first study to show that these attributes are further influenced by crime duration in occupational fraud cases. We recommend further research into the effects of fraud duration.

The rest of the paper is organized as follows: Section II develops the hypotheses about the main effects and the interaction effects of organization type and/or the perpetrator's status on outcome severity. Section III describes the sample and the empirical model used in this study. Section IV presents the results, and section V concludes this study.

\section{THEORETICAL BACKGROUND AND HYPOTHESIS DEVELOPMENT}

Prior literature shows that there is a positive relationship between crime severity and punishment (Bedau 1978; Wheeler, et al. 1988; Weisburd et al. 1990; Tillman and Pontell 1992; Hagan and Parker 1985); however, this relationship is affected by the facts and circumstances of the crime, such as the perpetrator's and victim's characteristics, and the loss and duration of the 
crime. Further, termination rates, criminal sentences, and the likelihood of civil remedies differ based on the victim organization's characteristics and the perpetrator's characteristics (Agrawal and Cooper 2017; Garrett 2015; Karpoff et al. 2008). In occupational fraud, victim organization type affects whether organizations pursue punishment. Also, the perpetrator's status affects whether and how victim organizations choose to punish occupational fraudsters. Finally, the amount of loss incurred by the organization and the number of months the fraud occurred affect the type of punishment issued.

\section{Victim Organizations Choose Whether and How to Punish Occupational Fraudsters}

Victim organizations are both the crime environment and the evaluators of the fraud act, determining whether and how to punish the perpetrator. Organizations incur direct and indirect losses from fraud, including the fraud loss and image repair costs (Caldiero, Taylor, and Ungureanu 2009). To protect themselves, victim organizations employ internal controls to prevent, deter and detect fraudulent activity. They employ internal controls in lieu of societal controls to reduce the situational opportunities available for crimes to occur (Holtfreter 2005; Benson and Madensen 2007; Fleming, Hermanson, Kranachar, and Riley 2016); however, those internal controls vary by the type of the organization (Fleming et al. 2016).

For example, Fleming et al. (2016) find that publicly traded companies employ stronger anti-fraud measures than their privately held counterparts. This is likely because of the level of public scrutiny that these organizations face and their structural complexity. The complexity of internal controls employed by an organization is affected by the regulatory requirements for the organization. More complex organizational structures may also have more complex control systems to help identify the individuals responsible for certain activities. Dugan and Gibbs (2009) show that the separation of duties amongst many employees in corporations reduces the ability to 
identify those responsible for wrongdoing. They explain that "attention must be paid to the organizational structure to determine the viability of" (Dugan and Gibbs, 2009, p.118) crime controls. Each situation is different, causing the level of control to vary by the victim organization type, and the punishment severity to vary correspondingly.

In addition to the organizational considerations of internal controls, deterrence theory explains that the punishments pursued against criminals are chosen based on cost-benefit analyses (Rae and Subramanian 2008; Townsley and Birks 2008). Harsher prevention and deterrence measures often incur higher costs in the short-term but may decrease costs in the long-term by sending a strong anti-fraud message. Organizations prefer lower cost alternatives for prevention and deterrence and will likely select occupational fraud outcomes that limit their overall costs (Beneish et al. 2017). Such costs may include preventative anti-fraud measures, such as the cost of physical and process controls (Townsley and Birks 2008); detective anti-fraud measures, such as the costs of anomaly identification (Becker 1968; Kim and Kogan 2014); or costs associated with employee turnover or damaged reputation (Desai, Hogan, and Wilkins 2006).

A victim organization that pursues the termination and/or refer the case for criminal prosecution will incur greater short-term costs through attrition, legal fees, time spent by current employees, and a loss of good reputation, but the message sent may reduce future fraudulent behavior and the likelihood of legal actions by third parties. Therefore, organizations with more complex internal control systems, or those subject to regulatory oversight, such as governmental entities or publicly traded companies, may be more willing to incur higher short-term costs by sending strong signals through harsh punishment. Incurring high short-term costs may prevent much larger long-term costs (Karpoff et al. 2008). At the same time, taking no action against a fraud perpetrator will result in no cost in the short-term, but it may send a signal to other employees 
and stakeholders that the company condones or dismisses fraudulent behavior, which may result in long-term costs through the furtherance of fraudulent behavior by other employees or a reaction by stakeholders or regulatory agencies. In some cases, victim organizations may elect to retain an occupational fraudster to avoid the short-term costs of replacement (Beneish et al. 2017).

When organizations are victimized by occupational fraud perpetrators, public knowledge of the event can hurt the organization's reputation. Caldiero et al. (2009) explain that victim organizations often have options when dealing with crises, but in the case of fraud they are limited to repairing their image. Where there is a "high public visibility, organizational decisions may be shaped by" (Holtfreter, Van Slyke, Bratton, and Gertz 2008b, p. 309) formal sanctions, as public companies may suffer from reputation damage if their control environment is not strong (Dugan and Gibbs 2009). The organizational costs related to regulatory compliance, internal controls management, and reputation management differs between organizations and is likely higher for publicly-traded companies than other organization types, leading to our first hypothesis:

H1: Compared to publicly-traded organizations, fraud perpetrators in privately held, governmental and not-for-profit organizations face less severe outcomes.

Kennedy (2014) further explains that perpetrators gain a deep knowledge of the victim organization through their occupational duties. This knowledge enables the perpetrator to develop a cognitive map (Brantingham and Brantingham 1993) of when, where, and how to commit occupational fraud without being detected by internal controls, as well as increasing their ability to conceal the crime (Benson and Madensen 2007). While there is debate as to whether the severity of a crime is more heavily influenced by the fraud characteristics or the crime environment (Benson and Moore 1992), we contend in $\mathrm{H}_{2}$ that it is the interaction of these attributes that has the greatest impact on our punishment measure, occupational fraud outcomes. 
$\mathrm{H}_{2}$ : Both the fraud scheme and the type of organization impact victim organization's decision in pursuing an outcome against fraud perpetrators.

\section{Status Shields Offenders from Punishment}

Fraud type, the victim organization type, and the perpetrator's characteristics, including their status, influence the victim organization's decision whether and how to punish fraudsters. Status characteristics theory (SCT) describes the perceptions one forms when encountering another based on the second person's age, race, gender, and/or position that guide the first person's beliefs about the second person's capabilities (Berger, Cohen, and Zelditch 1971). Berger et al. (1971) define a status characteristic as "a characteristic that is differentially evaluated and implies possession of other characteristics" (p.3) and a diffuse status characteristic as one that produces general assumptions about the second person. Status characteristics also capture beliefs and perceptions about a target individual's influence over decisions (Berger et al. 1971) that are developed through interpersonal interactions (Ridgeway 1991). During these interactions, individuals form schemas, or mental descriptions, of each other that categorize traits and behavioral profiles (Ridgeway 2001) related to the perceived position or authority.

In the workplace, status characteristics may include the target's physical features as well as their position within the company. The position within the company is correlated with the individual's education, tenure, and age and is the most salient of these status characteristics. Webster and Driskell (1978) explain that when a target possesses multiple status characteristics, the most salient characteristic to the domain determines the perceptions others have of his/her abilities and influence over decisions. Therefore, the perceived influence one has over others in the workplace is derived from a combination of his/her status characteristics, with an emphasis on the position within the company. 
SCT explains how the perceived seriousness of an occupational fraud, and therefore related punishment, may differ between perpetrators. Specifically, the evaluator may believe a perpetrator should have a harsher or more lenient punishment, depending on their perceived status characteristics. Prior literature shows that perpetrators with different statuses receive different levels of punishment, even when the crimes are similar in severity. Eitle (2000) finds that the position within the victim organization influences the punitive response. For example, Garrett (2015) finds that management-level offenders are more frequently penalized than their executivelevel counterparts. Dilks, McGrimmon, and Thye (2015) examine accumulative differences in diffuse and specific status characteristics between victims and offenders, finding that the higher the offenders' status in relation to the victim, the less serious their crime is perceived to be. Likewise, Weisburd, Waring, and Wheeler (1990) find that officers are less likely to be imprisoned for white-collar crimes than workers or managers. Longer jail sentences are also noted by Gottschalk (2012) for lower status white-collar criminals, when comparing fraud to other types of white-collar crimes.

Extant literature finds that the status variance among occupational fraudsters indeed affects the punishment that they face due to the influence that higher status individuals have on others and the opportunities they are afforded. Rosenmerkel (2001) finds that some of the respondent's characteristics, such as "age, gender, and SES have a slight effect" (p. 320) on the relationship between crime severity and punishment severity. In a study of federal white-collar crime cases in seven separate districts, Albonetti (1998) explains that the perpetrator's characteristics have a significant direct effect on the perceived severity of the assigned punishment. Opportunities available for occupational fraud via the perpetrator's position further affect the consequences that the perpetrators experience (Hagan and Parker 1985). Thus, higher status individuals are shielded 
from the repercussions of their transgressions (Niedermeier, Horowitz, and Kerr 2001) and receive lower punishments than lower status individuals, which leads to our third hypothesis:

$H_{3}$ : Fraud perpetrators with higher status face less severe outcomes than perpetrators with lower status.

\section{Perpetrator's Status Can Also be a Liability}

Status can also have negative implications (Wiggins, Dill, and Schwartz 1965) in frauds related to the perpetrator's occupation (Skolnick and Shaw 1994). For example, Rosoff (1989) finds that when a high status individual commits a low to moderately serious crime, they are likely to receive a low punishment. Contrarily, when a high status individual commits a very serious crime, their status becomes a liability (Skolnick and Shaw 1994) and a severe punishment is issued. Wiggins et al. (1965) explains that high status individuals are afforded leniency with minor transgressions because they are perceived to have earned respect and gratitude from others, which "forgives" minor wrongdoing. Niedermeier, Horowitz, and Kerr (2001) further explain that evaluators' perception of whether the perpetrator abused their status, or treated the victim unfairly influences the punishment issued. Thus, status shields perpetrators from harsh punishment when the offense is not correlated with the status, but becomes a liability when status affects the opportunity to commit the offense. Whether there is a negative or positive association between the perpetrator's status and punishment severity, prior studies show that the differences in the perpetrators' positions create different perceptions of the perpetrators' abilities and influence, in part because of the opportunities that the perpetrators have to engage in fraud, which results in varying punishments.

The ACFE (2020) reports that 20 percent of the fraud cases in their survey were committed by owners/executives, 35 percent by managers, and 41 percent by employees. Further, it reports 
that the sex split of the perpetrators is 72 percent male and 28 percent female. Finally, although occupational fraudsters are more educated than street criminals, the ACFE report finds that 22 percent have a high-school or lower education. These status differences within occupational fraudsters yield the varying punishment severity for similar acts. However, as previously explained, the status becomes a liability (McGrimmon et al. 2018) when it is used to engage in wrongdoing. Therefore, we hypothesize the following:

$H_{4}$ : Both the fraud scheme and the perpetrators' status impact victim organization's decision in pursuing an outcome against fraud perpetrators.

\section{ANALYSES AND RESULTS}

\section{Sample}

We use data collected by the Association of Certified Fraud Examiners (ACFE) to generate our sample of occupational fraud cases. The ACFE is the world's largest anti-fraud organization, with more than 80,000 members, most of whom are Certified Fraud Examiners (CFE). The ACFE distributes a biennial survey to its CFE members (ACFE 2020, 1996) that includes 80 questions related to the CFE's single largest fraud case that closed within the prior two years. In the 2013, 2015, 2017 and 2019 surveys, participating CFEs were asked to provide information related to a second fraud case that they investigated during the same timeframe. We obtained the ACFE data via a grant from the Institute for Fraud Prevention (IFP). Our sample includes fraud cases reported between 2002 (ACFE 2004) and 2015 (ACFE 2016), a 14-year period.

\section{Descriptive Statistics}


Our final sample consists of 2,096 fraud cases. Table 16 reports the descriptive statistics for the full sample, whereas Table 23 reports the descriptive statistics ${ }^{33}$ by outcome pursued against the principal fraud perpetrator. We examine three outcomes pursued against the principal perpetrator by the victim organization, namely no-termination, termination, termination and referral for criminal prosecution. The internal actions taken against the principal perpetrator is measured as a multiple response question in the ACFE survey. The multiple responses are "termination," "permitted or required the individual to resign," "probation/suspension," "restitution agreement," "no punishment," "perpetrator had resigned before fraud was discovered or action was taken," and "other." In our study, termination indicates whether the perpetrator continued to work for the victim organization after the fraud had been detected or not. Therefore, "termination", "permitted or required the individual to resign" and "perpetrator had resigned before fraud was discovered or action was taken" are coded as 1 to indicate that the perpetrators no longer works for the victim organization. However, "probation/suspension," "restitution agreement," and "no punishment" are coded as 0 to indicate that the perpetrators still work for the victim organization. Observations that had only "others" as a selected response are not included in the final sample. Additionally, within the termination category, we distinguish whether the principal perpetrator was referred to law enforcement for criminal prosecution or not. Criminal prosecution is measured as an indicator variable, where it equals 1 if the fraud case was referred to law enforcement for criminal prosecution, and 0 otherwise.

${ }^{33}$ The list of variables and their definition is provided in Appendix A. 
The principal perpetrator is neither terminated nor referred for criminal prosecution in 217 fraud cases in our data (10.4 percent), is terminated in 535 fraud cases ( 25.5 percent), and is both terminated and referred for criminal prosecution in 1,344 fraud cases $\left(64.1\right.$ percent) ${ }^{34}$. In most fraud cases, the principal perpetrator faces harsh punishment by losing their employment and facing criminal prosecution. Yet, in over 10 percent of the cases, the victim organization decides not to terminate the principal perpetrator and not to file any charges against him/her.

The average age of the principal perpetrator is 41.5 years old, and there is a 65 percent 35 percent gender split between males and females, respectively. Principal perpetrators are well educated, with 69.8 percent having at least some college education (30.2 percent have high school or lower education). Only 11 percent of the principal perpetrators have had prior charges or convictions of a fraud-related offense. Most of the perpetrators in the data have an employee or managerial position, 42.9 percent and 39.6 percent, respectively. Perpetrators in the position of an executive, officer or owner comprise 17.5 percent of the cases in our data.

There are four types of organizations that are victims to a fraud scheme in our sample, namely publicly traded, privately held, governmental, and not-for-profit. As shown in Table 22,

\footnotetext{
${ }^{34}$ The distribution of the outcomes, pursed by the victim organization, in this study differs slightly from the distribution reported in the Report to the Nations. First, RTTN sample includes fraud cases that took place over a 2-year period, whereas our sample consists of a 14-year sample period. Second, RTTN reports the data on the two survey questions related to the outcome pursued by the victim organization, slightly differently than our study. The RTTN reports a separate percentage rate for each type of the internal action taken by the victim organization. Whereas, in our study, we group the responses in two groups, no-termination and termination. From 2008 until 2020, the RTTN reports an average rate of 62.1 percent of fraud cases were referred to law enforcement, ranging from 58 percent to 69 percent. Our referral for criminal prosecution percentage rate is slightly higher at 64.1 percent. Further, we excluded from our final sample fraud cases where the perpetrator was referred for criminal prosecution but was not terminated.
} 
73.3 percent of fraud occurred in for-profit organizations, with 30.8 percent of the victim organizations being public companies and 42.5 percent being private companies. Governmental and not-for-profit organizations consist 15.6 percent and 11.1 percent of the victim organizations, respectively, in our sample.

--Insert Table 22 --

We examine the sample descriptive statistics by outcomes pursued by victim organizations and find several differences among the three groups. Results are reported in Table 23. On average, the fraud schemes where victim organizations pursue the harshest outcome, i.e. termination and referral for criminal prosecution, cost more $(\mathrm{M}=2.4$ natural $\log$ of fraud), last longer $(\mathrm{M}=27.7$ months), and have the highest percentage of asset misappropriation schemes (92.7 percent), as compared to the other two outcome groups, not-terminated and terminated only. The average age of principal perpetrators who were not terminated is higher ( $\mathrm{M}=45$ years old) than perpetrators who were only terminated $(\mathrm{M}=41.2$ years old $)$ or perpetrators who were terminated and referred for criminal prosecution $(M=41$ years old). Furthermore, principal perpetrators who were not terminated, have the longest tenure with the victim organization, are the most educated, and have the highest ranked perpetrators among the three groups. In contrast, the perpetrators who were terminated and referred for criminal prosecution are the youngest among the three groups ( $M=41$ years old). In comparing the composition of this group, it has the highest percentages of lowtenured perpetrators, females, lower-ranked employees, and less educated perpetrators, and the highest percentage of perpetrators with prior fraud related charges.

--Insert Table 23 -- 
Table 24 reports the Pearson and the Spearman correlation among the independent variables. The results show a statistically significant and positive Pearson correlation between the fraud severity indicators and the perpetrator's status indicators.

--Insert Table 24 --

\section{Multivariate Tests}

We examine three fraud outcomes that the victim organizations pursue against the principal perpetrators in occupation fraud cases: no-termination, termination, and termination and referral for criminal prosecution. We use Multinomial Logit Regression, where the termination outcome is used as a reference category, to compare the odds of the principal perpetrator facing one of the three outcomes.

First, we test $\mathrm{H}_{1}$ and $\mathrm{H}_{3}$, which argues that there is a main effect of victim organization type and perpetrator status on fraud outcomes using Model 1.

\section{Model 1:}

$$
\begin{aligned}
& \text { Fraud Outcome }=\alpha+\beta_{1} * F R \_D U R A T I O N+\beta_{2} * F R \_A M O U N T+\beta_{3} * F R \_T Y P E+ \\
& \beta_{4}{ }^{*} \text { COLLUSION }+\beta_{5} * A G E+\beta_{6} * \text { TENURE }+\beta_{7} * \text { GENDER }+ \\
& \beta_{8} * \text { POSITION }+\beta_{9} * E D U C A T I O N+\beta_{10} * P R I O R C H A R G+\beta_{11} * O R G_{-} \text {TYPE } \\
& +\beta_{12} * O R G \_S I Z E+\beta_{13} * I N D U S T R Y+\beta_{14} * A N T I F R A U D+\beta_{15} * O R G_{-} L O C \\
& +\varepsilon \quad(1)
\end{aligned}
$$

Table 4 reports the results from multinomial logistic regression, which we detail in Model 1. In support of prior literature, we find that the coefficients of the fraud severity indicators, except for collusion, are positive and significantly different from zero, when comparing the odds of the perpetrator being only terminated to being terminated and referred for criminal prosecution. More specifically, the effects of FR_DURATION $\left(\beta_{1}=+0.01\right.$, two-tailed $\left.p<0.05\right)$, FR_AMOUNT $\left(\beta_{2}=\right.$ 
+0.37 , two-tailed $\mathrm{p}<0.01)$, and FR_TYPE $\left(\beta_{3}=+1.16\right.$, two-tailed $\left.\mathrm{p}<0.01\right)$ are all positive and significant. Thus, these results indicate that as fraud severity increases, the odds of being terminated and referred for criminal prosecution increase compared to the odds of being terminated only. Thus, there is a direct and positive association between the fraud severity and the severity of the punishment, consistent with prior research.

When comparing no-termination to termination only, the coefficients of the fraud severity indicators are not significantly different from zero. The lack of significant association between the fraud severity indicators can be explained by two main factors. First, the sample of fraud cases, where the principal perpetrator was not terminated, is smaller than the other two groups. More specifically, it only encompasses 10.4 percent of the entire sample. Second, the question included in the ACFE surveys asks whether the perpetrator was terminated, or any other internal action was taken against the perpetrator, such as probation, suspension, or restitution agreement. Therefore, the no-termination group included cases where milder forms of punishment were pursued.

Consistent with $\mathrm{H}_{1}$, the coefficient of ORG_TYPE $\left(\beta_{11}\right)$ is positive and significantly different from zero. More specifically, when we compare the odds of the perpetrator not being terminated to the odds of being terminated, the coefficient of $O R G_{-} T Y P E\left(\beta_{11}\right)$ is positive and significantly different from zero for Governmental Organizations $(+1.19$; two-tailed $\mathrm{p}<0.01)$, Not-for-profit Organizations $(+0.86$; two-tailed $p<0.05)$, and Privately-held Organizations (+ 0.84; two-tailed $\mathrm{p}<0.01)$ when Publicly-held Organizations are used as the reference category. When comparing the odds of the perpetrator being terminated to being terminated and referred for criminal prosecution, the coefficient of $O R G_{-} T Y P E\left(\beta_{11}\right)$ is positive and significantly different from zero for Governmental Organizations $(+0.96$; two-tailed $\mathrm{p}<0.01)$ and Not-for-profit Organizations $(+0.58$; two-tailed $\mathrm{p}<0.05)$. These findings indicate that compared to publicly 
traded organizations, governmental, not-for-profit, and privately held organizations are more likely not to terminate the principal perpetrator than to terminate him/her.

In other words, governmental, not-for-profit, and privately-held organizations choose extreme outcomes against the perpetrators. Governmental and not-for-profit organization are more likely to not terminate than to terminate the perpetrator and are also more likely to terminate and refer for criminal prosecution the perpetrator than to just terminate the perpetrator. Thus, governmental and not-for-profit organizations either decide not to terminate or pursue the harshest outcome possible, as compared to just terminating the perpetrator.

--Insert Table 25 --

When comparing the odds of the perpetrators not being terminated with being only terminated, we find that the coefficient of $A G E\left(\beta_{5}\right)$ is positive $(+0.03)$ and significantly different from zero (two-tailed $\mathrm{p}<0.01$ ). Also, when comparing the odds of being terminated to being terminated and referred for criminal prosecution, the coefficient of $A G E\left(\beta_{5}\right)$ is negative and significant $(-0.02$, two-tailed $p<0.05)$, the coefficient of TENURE $\left(\beta_{6}\right)$ is positive and significant $(+0.28$, two-tailed $p<0.05)$, the coefficient of GENDER $\left(\beta_{7}\right)$ is negative and significant $(-0.59$, two-tailed $\mathrm{p}<0.01)$, the coefficient of both levels of POSITION $\left(\beta_{8}\right)$, employee $(+0.60$, two-tailed $p<0.01)$ and manager are positive and significant $(+0.42$, two-tailed $p<0.05)$, the coefficient of EDUCATION $\left(\beta_{9}\right)$ is negative and significant $(-0.52$, two-tailed $\mathrm{p}<0.01)$, and lastly, the coefficient of PRIORCHARG $\left(\beta_{10}\right)$ is positive and significant $(+0.95$, two-tailed $\mathrm{p}<0.01)$. Consistent with our $\mathrm{H}_{3}$, these findings indicate that the perpetrator's status reduces the odds of being terminated and referred for criminal prosecution compared to only being terminated. Thus, older, male, better educated perpetrators, who are in an executive position and have worked for the victim organization for more than five years, are less likely to be terminated and referred for 
criminal prosecution than younger, female, less educated perpetrators, who are in an employee or managerial position and have worked for the victim organization for less than five years. Only prior fraud charges increase the odds of being terminated and referred for criminal prosecution as compared to only being terminated. Overall, we find that as the perpetrator's status increases, the odds of being terminated and referred for criminal prosecution decrease. Therefore, there is a direct and negative association between the perpetrator's status and the severity of the punishment as predicted in $\mathrm{H}_{3}$.

\section{Testing for Moderation}

Finally, we test hypotheses 2 and 4 . H2 examines whether the main effect of fraud severity on fraud outcomes is moderated by the type of the victim organization. In other words, we examine whether the positive association between fraud severity and fraud outcome is moderated by the type of the victim organization. In Model 2, we interact ORG_TYPE with fraud severity variables.

\section{Model 2:}

Fraud Outcome $=\alpha+\beta_{1}{ }^{*} F R_{-} D U R A T I O N+\beta_{2}{ }^{*} F R \_A M O U N T+\beta_{3} * F R \_T Y P E+$

$$
\begin{aligned}
& \beta_{4} * \text { COLLUSION }+\beta_{5} * A G E+\beta_{6} * \text { TENURE }+\beta_{7} * \text { GENDER }+\beta_{8} * \text { POSITION }+ \\
& \beta_{9} * E D U C A T I O N+\beta_{10} * P R I O R C H A R G+\beta_{11} * O R G \_T Y P E+\beta_{12} * O R G \_S I Z E+ \\
& \beta_{13} * \text { INDUSTRY }+\beta_{14} * \text { ANTIFRAUD }+\beta_{15} * \text { ORG_LOC }+\beta_{16} \\
& \text { *ORG_TYPE*FR_DURATION }+\beta_{17} * O R G_{-} T Y P E^{*} F R \_A M O U N T+ \\
& \beta_{18} * O R G \_T Y P E^{*} C O L L U S I O N+\beta_{19} * O R G \_T Y P E * F R \_T Y P E+\varepsilon
\end{aligned}
$$

Table 5 reports the results from the multinomial logistic regression, which we define in Model 2. Consistent with our predictions, we find that the coefficients of the fraud severity indicators interact with the organization type. When comparing the odds of no-termination to termination, the coefficient of ORG_TYPE*FR_DURATION $\left(\beta_{16}\right)$ is positive and significantly 
different from zero. More specifically, the coefficient of Governmental*FR_DURATION is +0.06 (two-tailed $\mathrm{p}<0.01$ ), the coefficient of Non-Profit*FR_DURATION is +0.06 (two-tailed $p<0.01$ ), and the coefficient of Private*FR_DURATION is +0.04 (two-tailed $p<0.01$ ), as compared to publicly traded organizations, the reference category.

When comparing the odds of termination to termination and referral for criminal prosecution, the coefficient of ORG_TYPE*FR_DURATION $\left(\beta_{16}\right)$ is significant only for governmental organizations, specifically, the coefficient of Governmental*FR_DURATION is +0.02 (two-tailed $\mathrm{p}<0.1$ ). Figures 1 and 2 show the graphic representation of the fraud duration and organization type interaction. As the fraud duration increases, not-for-profit organizations are more likely not to terminate than to terminate the perpetrator, as compared to publicly traded companies. Thus, as the fraud severity increases, the not-for-profit organizations tend not to pursue less severe outcomes against the principal perpetrator. Conversely, as fraud duration increases, governmental and privately held organizations are more likely to terminate the perpetrators than not to terminate or to terminate and refer for criminal prosecution the perpetrator, as compared to publicly traded companies. Thus, as the fraud severity increases, governmental and privately held organizations are more likely to pursue a harsher outcome. Further, Table 5 shows that there is a positive relationship between the fraud severity and punishment severity when the victim organization is either a governmental entity or a privately held company, as compared to publicly traded companies.

--Insert Figures 18 and 19 --

Further, the results in Table 25 indicate a significant interaction between the organization type and fraud amount, ORG_TYPE*FR_AMOUNT $\left(\beta_{17}\right)$. In comparing the odds of not being terminated and being terminated, the coefficient of governmental*FR_AMOUNT is negative (- 
0.24 ) and significantly different from zero (two-tailed $\mathrm{p}<0.1$ ). Whereas in comparing the odds of being terminated to being terminated and referred for criminal prosecution, the coefficient of notfor-profit*FR_AMOUNT is positive $(+0.46)$ and significantly different from zero (two-tailed $\mathrm{p}<$ 0.01). Results further show a significant interaction between the organization type (ORG_TYPE) and fraud amount (FR_AMOUNT). As the amount of the misappropriated assets (i.e. fraud severity) increases, the probability that a governmental organization does not terminated the perpetrator decreases, as compared to publicly traded organizations. In contrast, results show that not-for profit organizations are more likely than publicly traded organizations to terminate and refer for criminal prosecution perpetrators as the amount of misappropriated assets increases.

Lastly, the results in Table 26 report a significant interaction between ORG_TYPE*COLLUSION $\left(\beta_{18}\right)$ and ORG_TYPE*FR_TYPE $\left(\beta_{19}\right)$ when comparing the probability of being terminated to being terminated and referred for criminal prosecution. The coefficient of governmental*COLLUSION is negative (- 0.12) and significantly different from zero (two-tailed, $p<0.10)$, and the coefficient of governmental*FR_TYPE is negative $(-1.13)$ and significantly different from zero (two-tailed, $p<0.10$ ). Results also show that as the number of perpetrators involved in the fraud increases, governmental organizations are less likely to terminate and criminally persecute the principal perpetrators as compared to publicly traded organizations and that governmental organizations are less likely to terminate and refer for criminal prosecution the principal perpetrator in fraud cases that involve assets misappropriation than in other type of fraud cases, when compared to publicly traded organizations.

--Insert Table 26 -- 


\section{Signed Graph Theory Provides a Mechanism to Measure Status}

In $\mathrm{H}_{4}$, we examine the interactive effect of fraud severity and perpetrator status on the victim organization's decision whether and how to punish fraudsters. To test this hypothesis, we construct a composite variable of the perpetrator's status (STATUSCOMP) using graph-theoretic procedures (Dilks, McGrimmon, and Thye 2015). Signed graph theory explains that when multiple characteristics differentiate group members and that the distribution of those characteristics between group members is inequitable, outcomes are inconsistently applied (Berger, Norman, Blackwell, and Smith 1992). Further, signed graph theory explains that differentiating characteristics may have either diffuse, or indirect, effects or specific/direct effects on the outcome of interest (Dilks et al. 2015).

Graph-theoretic procedures include building diagrams that connecting actors' characteristics to the expected task outcomes. These paths are characterized by the sign (positive or negative) and the length (various lengths based on how relevant the characteristic is to the task) dubbed graph theoretical distance. In our model, the diffused (D) status characteristics are age, tenure, gender, position, and education, whereas the specific (C) status characteristic is prior fraud related charges. Next, we determine the length of the paths for the diffused and specific variables, which in our case are paths of length three and four for both diffused and specific variables.

The perpetrator's ("P's") aggregate expectations values ${ }^{35}$ are reported in Table 6. To determine the specific variable combination for each path, we converted the perpetrator's position

35 The P's aggregate expectations values are estimated using a worksheet developed by Dr. David Melamed at University of Arizona. More information can be found at Melamed (2011). 
variable into a binary variable, where it equals to 1 if the perpetrator is an employee and zero otherwise. We also split age at 40 years old to obtain a binary variable.

--Insert Table 27 --

In our study, graph-theoretical procedure generates a Likert-scale score for the status of the perpetrators using the perpetrator's age, tenure, gender, position, education, and prior charges as status characteristics. Values closer to +1 indicate a high status, whereas values closer to -1 indicate a low status. $\mathrm{H}_{4}$ examines whether the main effect of fraud severity on fraud outcomes is moderated by the perpetrator's status. We test $\mathrm{H}_{4}$, which examines whether the main effect of fraud severity on fraud outcomes is moderated by the perpetrator's status. In Model 3 we interact STATUSCOMP with fraud severity variables.

Model 3:

Fraud Outcome $=\alpha+\beta_{1} * F R \_D U R A T I O N+\beta_{2} * F R \_A M O U N T+\beta_{3} * F R \_T Y P E+$

$$
\begin{aligned}
& \beta_{4} * \text { COLLUSION }+\beta_{5} * \text { STATUSCOMP }+\beta_{6} * \text { FR_DURATION } * \text { STATUSCOMP } \\
& +\beta_{7} * F R \_ \text {AMOUNT } * S T A T U S C O M P+\beta_{8} * F R \_T Y P E * S T A T U S C O M P+ \\
& \beta_{9} * \text { COLLUSION } * S T A T U S C O M P+\beta_{10} * O R G \_T Y P E+\beta_{11} * O R G \_S I Z E+ \\
& \beta_{12} * \text { INDUSTRY }+\beta_{13} * A N T I F R A U D+\beta_{14} * O R G_{-} L O C+\varepsilon
\end{aligned}
$$

Table 28 reports the results from the multinomial logistic regression, which we detail in Model 3. In comparing the odds of not being terminated to being terminated, the coefficient of the interaction term FR_DURATION*STATUSCOMP $\left(\beta_{6}\right)$, FR_AMOUNT*STATUSCOMP $\left(\beta_{7}\right)$, FR_TYPE*STATUSCOMP $\left(\beta_{8}\right)$, and COLLUSION*STATUSCOMP $\left(\beta_{9}\right)$ is not statistically significant from zero. However, in comparing the odds of being terminated to being terminated and referred for criminal prosecution, we find that the status of the perpetrators interacts with the 
fraud duration, i.e. the coefficient of FR_DURATION*STATUSCOMP is positive $(+0.02)$ and significantly different from zero (two-tailed $\mathrm{p}<0.01$ ). Figure 3 shows the graphic representation of the interaction between the fraud duration and the perpetrator's status. In fraud cases with a short duration, low status perpetrators have a higher probability of being terminated and referred for criminal prosecution than high status perpetrators. As the fraud duration increases, perpetrators with different status have equal probability of being terminated and referred for criminal prosecution. In low severity cases, low status perpetrators receive a harsher punishment than high status perpetrators. As the fraud severity increases, perpetrators with different statuses receive the equal punishment. Thus, victim organizations take in consideration the perpetrator's status when pursuing an outcome in occupational fraud cases.

--Insert Table 28 and Figure 20 --

\section{CONCLUSION}

When high-profile fraud cases were detected in early 2000s, organizations, victim to these fraud schemes, rushed to replace their top executives. Some executives resigned voluntarily while others were terminated. There was also a group of organizations which did not pursue any outcome against their principal perpetrators. This evidence indicates that organizations, victimized by these frauds, choose whether and how to punish fraudsters. In this study, we examine whether the victim organization's decision to pursue an outcome against their executives is affected by the severity of fraud, by the type of the organization, and by the perpetrator's status.

We find that governmental, not-for-profit, and privately held organizations are more likely not to terminate principal perpetrators as compared to publicly traded organizations over time. Additionally, governmental and not-for-profit organizations are more likely to terminate and refer for criminal prosecution the principal perpetrators as compared to just terminate. Thus, 
governmental and not-for-profit organizations decide to pursue the two extreme outcomes against the fraudsters (i.e. the perpetrator is either not terminated or is terminated and the case is referred for prosecution). We find, also, that the victim organizations pursue less severe outcomes against high status perpetrators, as compared to low status perpetrators in fraud cases with a short duration. As the fraud duration increases, however, victim organizations pursue equally severe outcomes against all perpetrators. The findings of this study shed light on the importance of fraud duration and its effect on the outcomes pursued against the occupational fraud perpetrators. We conclude that the fraud outcome is determined not only by the severity of the fraud act, but also by the type of victim organization and the status of the perpetrator who perpetrated the fraud scheme.

Our study contributes to criminology and white-collar crime literature by being the first to consider the perpetrator's status characteristics and the victim organization type as moderators to the relationship between crime severity and punishment severity. It further adds to occupational fraud literature in accounting by providing a context to the descriptive data in the ACFE's Report to the Nations. Our study further offers anti-fraud professionals, such as forensic accounting and fraud examination professionals, an insight into the interactions between the fraud scheme attributes and victim and perpetrator characteristics. This information may aid them in the design of internal controls or when advising victim organization clients. As such, our study has both research and practical implications.

As with any archival study, there are several limitations to this study. First, civil litigation is not examined as a potential fraud outcome due to data availability. Anecdotally, civil litigation is less common than referral for criminal prosecution; however, it is still pursued in a considerable number of occupational fraud cases. Second, certain observations are deleted as the responses of the CFEs were contradictory or incomplete. For instance, when asked about the actions taken 
against the principal perpetrator, both probation/suspension and termination are selected. We cannot determine whether this is by mistake or by choice when the perpetrator is initially suspended and then terminated. Despite these limitations, this study makes important contribution to the accounting fraud literature. 


\section{FIGURES AND TABLES}

Figure 18 Graphing Interaction - Pr (No-Termination)

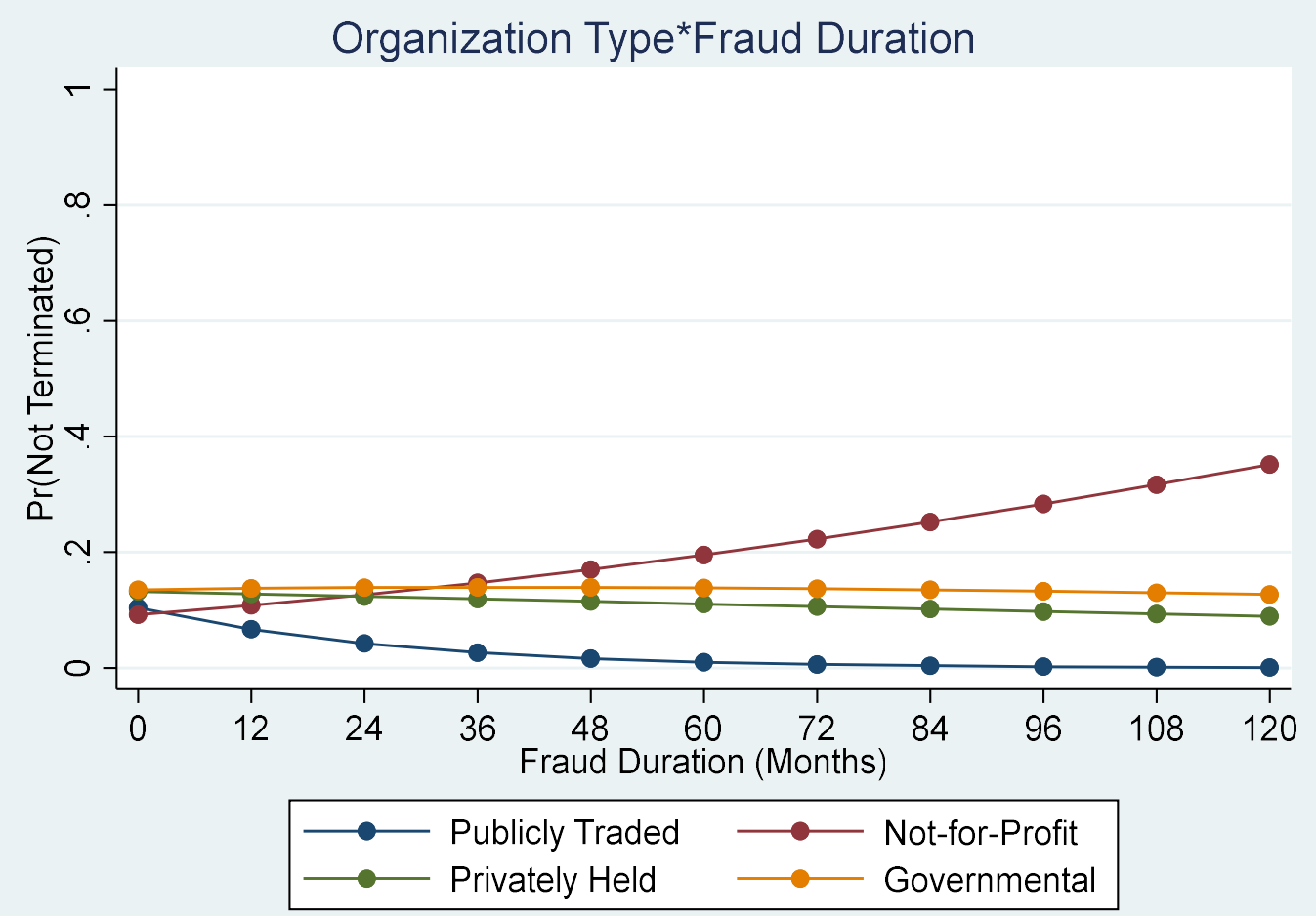


Figure 19 Graphing Interaction - Pr (Termination and Referral for Criminal Prosecution)

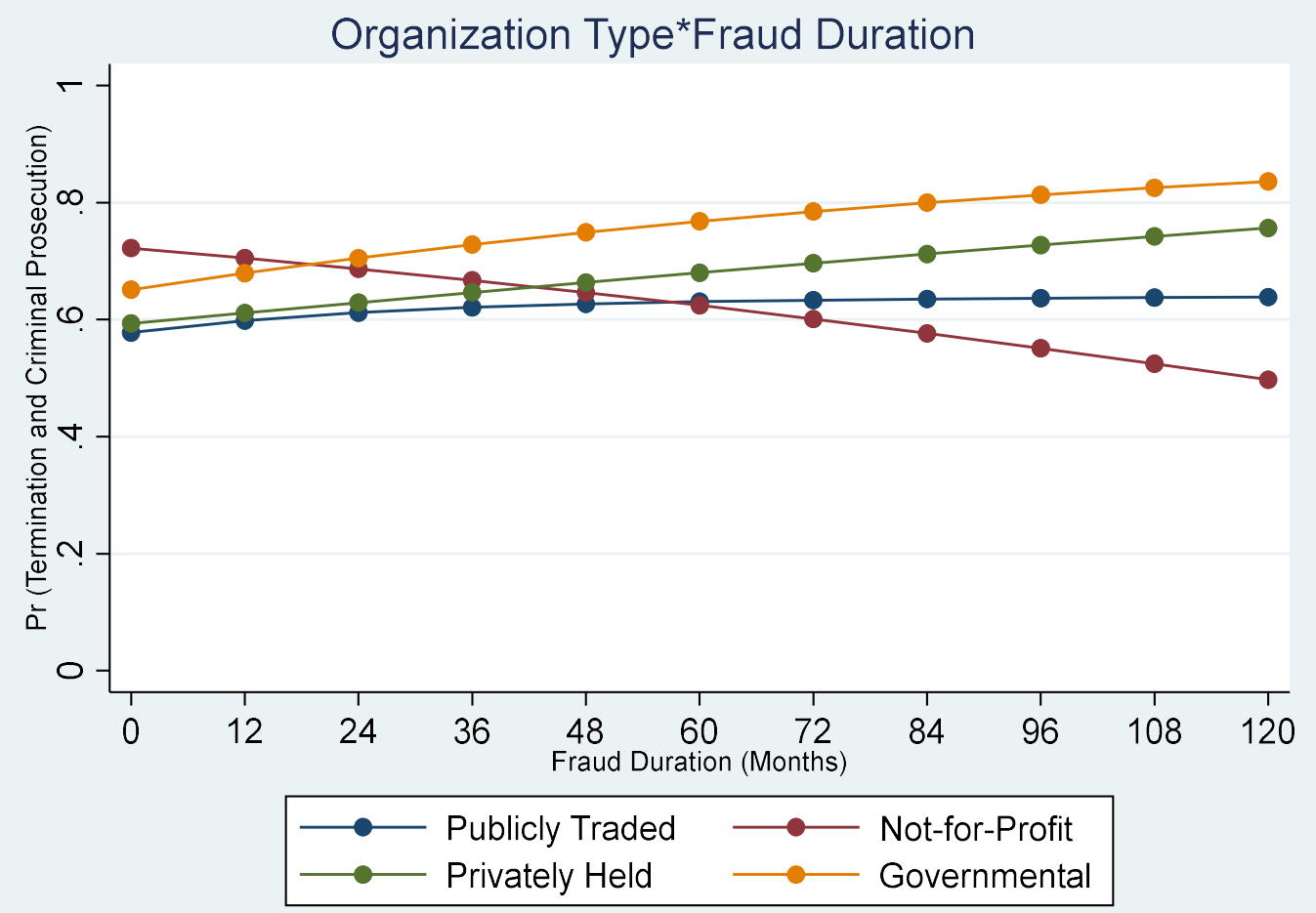


Figure 20 Graphing Interaction - Pr (Termination and Referral for Criminal Prosecution)

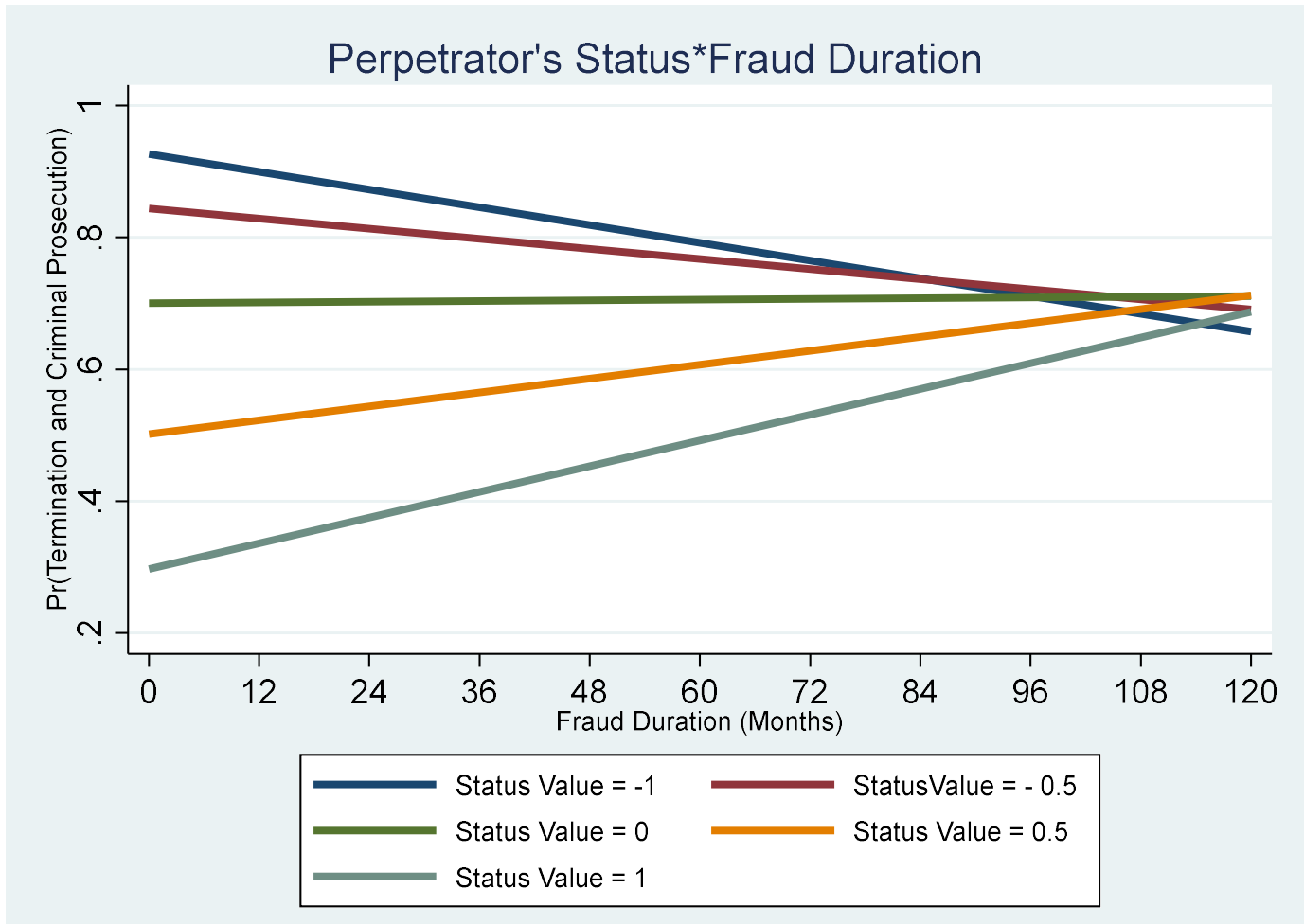


Table 22 Full Sample-Descriptive Statistics

$\mathrm{N}=\mathbf{2 , 0 9 6}$

\begin{tabular}{cccccc}
\multicolumn{6}{c}{$\mathbf{N}=\mathbf{2 , 0 9 6}$} \\
\cline { 1 - 2 } Freq. & Mean & Median & Min. & Max. & Std. Dev. \\
\cline { 1 - 2 } & & & & & \\
& 25.6 & 18.0 & 1.0 & 120.0 & 24.4 \\
& 12.1 & 12.2 & 4.8 & 19.1 & 2.2 \\
& 2.4 & 1.0 & 1.0 & 27.0 & 2.8 \\
\cline { 1 - 1 } Obs. & $\mathbf{\%}$ & & & & \\
\cline { 1 - 2 } 1,860 & 88.7 & & & & \\
236 & 11.3 & & & &
\end{tabular}

\section{Perpetrator Status}

AGE

TENURE:

Less than 5 years

More than 5 years

\begin{tabular}{cc} 
& 41.5 \\
\hline Obs. & \% \\
\hline 1,005 & 47.9 \\
1,091 & 52.1
\end{tabular}

GENDER:

$\begin{array}{rcr}\text { Male } & 1,355 & 64.6 \\ \text { Female } & 741 & 35.4\end{array}$

POSITION:

$\begin{array}{ccc}\text { Employee } & 899 & 42.9 \\ \text { Manager } & 830 & 39.6 \\ \text { Executive } & 367 & 17.5\end{array}$

EDUCATION:

$\begin{array}{lll}H S \text { or less } & 632 & 30.2\end{array}$

Some college or more $\quad 1,464 \quad 69.8$

PRIORCHARG:

$\begin{array}{ccc}\text { Yes } & 230 & 11.0 \\ \text { No } & 1,866 & 89.0\end{array}$

\section{Victim Organization Type}

ORG_TYPE:

Publicly traded

\begin{tabular}{cc}
\hline Obs. & \% \\
\hline 645 & 30.8 \\
891 & 42.5 \\
328 & 15.6 \\
232 & 11.1
\end{tabular}

\section{Control Variables}

ORG_SIZE

$\begin{array}{ccccc}18.2 & 18.1 & 4.6 & 32.6 & 3.5 \\ 7.3 & 7.0 & 0.0 & 18.0 & 4.9\end{array}$

ANTIFRAUD 
INDUSTRY:

$\begin{array}{rrr}\text { Banking } & 380 & 18.1 \\ \text { Manufacturing } & 305 & 14.6 \\ \text { Public Service } & 261 & 12.5 \\ \text { Customer Service } & 598 & 28.5 \\ \text { Others } & 552 & 26.3\end{array}$

LOCATION:

$\begin{array}{rrr}\text { US firms } & 1,240 & 59.2 \\ \text { Non-US firms } & 856 & 40.8\end{array}$

Variable Definitions:

FR_DURATION = number of months that the scheme had been ongoing before it was detected

$F R_{-} A M O U N T=$ natural logarithm of the total dollar value of the number of misappropriated assets or the amount of the caused loss

FR_TYPE $=$ indicator variable equal to 1 if the fraud scheme involved asset misappropriation and 0 otherwise

COLLUSION = number of perpetrators involved in the fraud scheme

$A G E=$ Age of the principal perpetrator in years at the time of the occupational fraud

$T E N U R E=$ Indicator variable equal 1 if the principal perpetrator had worked for the victim organization less than five years at the time occupational fraud occurred, and 0 if $\mathrm{s} / \mathrm{he}$ had worked for more than five years

GENDER $=$ It equals 1 if perpetrator is a male and 0 if $\mathrm{s} / \mathrm{he}$ is a female

POSITION $=$ The perpetrator position is measured at three levels: employee, manager (includes supervisor), and executive (includes owner and officer)

$E D U C A T I O N=$ Indicator variable equal to 1 if the principal perpetrator's education equals some college or even higher education, and 0 otherwise, i.e. if the perpetrator has high school or lower education

PRIORCHARG $=$ Indicator variable, where it equals 1 if the perpetrator received prior fraud-related charges and 0 otherwise

$O R G_{-} T Y P E=$ The type of the organization is measured at four levels: governmental agency, publicly traded company, privately held company, and not-for-profit organization.

ORG_SIZE = Natural logarithm of the victim organization's approximate gross annual revenue

INDUSTRY = The following industries are examined: banking/financial services, manufacturing, public services (includes government and public administration, religious, charitable, social services), customer service (includes transportation and warehousing), and others.

$A N T I F R A U D=$ Total number of antifraud measures that victim organizations had in place at the time that occupational fraud occurred

$O R G_{-} L O C=$ Indicator variable, where it equals 1 if the victim organization is in the United States and 0 otherwise 
Table 23 Descriptive Statistics by Outcome Type

\begin{tabular}{|c|c|c|c|c|c|c|c|c|c|c|c|c|}
\hline & \multicolumn{4}{|c|}{$\begin{array}{l}\text { No Termination } \\
\quad(\mathrm{n}=\mathbf{2 1 7}) \\
\end{array}$} & \multicolumn{4}{|c|}{$\begin{array}{l}\text { Termination Only } \\
\quad(n=535) \\
\end{array}$} & \multicolumn{4}{|c|}{$\begin{array}{l}\text { Termination and Criminal Prosecution } \\
\qquad(\mathrm{n}=1,344)\end{array}$} \\
\hline & Freq. & Mean & Median & $\begin{array}{l}\text { Std. } \\
\text { Dev. }\end{array}$ & Freq. & Mean & Median & $\begin{array}{l}\text { Std. } \\
\text { Dev. }\end{array}$ & Freq. & Mean & Median & $\begin{array}{l}\text { Std. } \\
\text { Dev. }\end{array}$ \\
\hline \multicolumn{13}{|l|}{ Fraud severity } \\
\hline FR_DURATION & & 24.5 & 16.0 & 25.8 & & 20.9 & 14.0 & 20.2 & & 27.7 & 20.0 & 25.4 \\
\hline FR_AMOUNT & & 11.4 & 11.2 & 2.5 & & 11.6 & 11.5 & 2.2 & & 12.4 & 12.4 & 2.1 \\
\hline COLLUSION & & 2.4 & 2.0 & 2.3 & & 2.4 & 2.0 & 2.6 & & 2.4 & 1.0 & 2.9 \\
\hline FR_TYPE: & Obs. & $\%$ & & & Obs. & $\%$ & & & Obs. & $\%$ & & \\
\hline$A M$ & 188 & 86.6 & & & 426 & 79.6 & & & 1,246 & 92.7 & & \\
\hline Non-AM & 29 & 13.4 & & & 109 & 20.4 & & & 98 & 7.3 & & \\
\hline \multicolumn{13}{|l|}{ Perpetrator Status } \\
\hline AGE & & 45.0 & 45.0 & 9.7 & & 41.2 & 40.0 & 8.9 & & 41.0 & 40.0 & 9.7 \\
\hline TENURE: & Obs. & $\%$ & & & Obs. & $\%$ & & & Obs. & $\%$ & & \\
\hline Less than 5 years & 81 & 37.3 & & & 249 & 46.5 & & & 675 & 50.2 & & \\
\hline More than 5 years & 136 & 62.7 & & & 286 & 53.5 & & & 669 & 49.8 & & \\
\hline \multicolumn{13}{|l|}{ GENDER: } \\
\hline Male & 164 & 75.6 & & & 414 & 77.4 & & & 777 & 57.8 & & \\
\hline Female & 53 & 24.4 & & & 121 & 22.6 & & & 567 & 42.2 & & \\
\hline \multicolumn{13}{|l|}{ POSITION: } \\
\hline Employee & 58 & 26.7 & & & 201 & 37.6 & & & 640 & 47.6 & & \\
\hline Manager & 94 & 43.3 & & & 234 & 43.7 & & & 502 & 37.4 & & \\
\hline Executive & 65 & 30.0 & & & 100 & 18.7 & & & 202 & 15.0 & & \\
\hline \multicolumn{13}{|l|}{ EDUCATION: } \\
\hline HS or less & 47 & 21.7 & & & 117 & 21.9 & & & 468 & 34.8 & & \\
\hline Some college or more & 170 & 78.3 & & & 418 & 78.1 & & & 876 & 65.2 & & \\
\hline
\end{tabular}


PRIORCHARG:

$\begin{array}{ccc}\text { Yes } & 15 & 6.9 \\ \text { No } & 202 & 93.1\end{array}$

Victim Organization Type ORG_TYPE:

Publicly traded Privately held Governmental Not-for-profit

\begin{tabular}{cc}
\hline Obs. & \% \\
\hline 35 & 16.1 \\
108 & 49.8 \\
45 & 20.7 \\
29 & 13.4
\end{tabular}

\section{Control Variables}

\begin{tabular}{lcc} 
ORG_SIZE & & 17.3 \\
ANTIFRAUD & & 6.3 \\
\cline { 2 - 3 } INDUSTRY: & Obs. & $\mathbf{\%}$ \\
\cline { 2 - 3 } Banking & 22 & 10.1 \\
Manufacturing & 39 & 18.0 \\
Public Service & 40 & 18.4 \\
Customer Service & 64 & 29.5 \\
Others & 52 & 24.0 \\
LOCATION: & & \\
US firms & 118 & 54.4 \\
Non-US firms & 99 & 45.6
\end{tabular}

$\overline{\text { Variables are defined in Appendix A. }}$

\begin{tabular}{cc}
27 & 5.0 \\
508 & 95.0 \\
& \\
\hline Obs. & \% \\
\hline 219 & 40.9 \\
221 & 41.3 \\
51 & 9.5 \\
44 & 8.2
\end{tabular}

$\begin{array}{cr}188 & 14.0 \\ 1,156 & 86.0\end{array}$

\begin{tabular}{cc}
\hline Obs. & \% \\
\hline 391 & 29.1 \\
562 & 41.8 \\
232 & 17.3 \\
159 & 11.8
\end{tabular}

\begin{tabular}{cccccc}
16.8 & 3.3 & & 18.5 & 18.6 & 3.5 \\
6.0 & 4.6 & & 8.1 & 8.0 & 4.6 \\
\cline { 3 - 3 } & & Obs. & \% & & \\
\cline { 3 - 3 } & 80 & 15.0 & & \\
& 113 & 21.1 & & \\
& 44 & 8.2 & & \\
& 142 & 26.5 & & \\
& 156 & 29.2 & & \\
& & & \\
& 247 & 46.2 & \\
& 288 & 53.8 &
\end{tabular}

\begin{tabular}{|c|c|c|}
\hline & 18.2 & \multirow{2}{*}{$\begin{array}{c}18.0 \\
7.0\end{array}$} \\
\hline & 7.1 & \\
\hline Obs. & $\%$ & \\
\hline 278 & 20.7 & \\
\hline 153 & 11.4 & \\
\hline 177 & 13.2 & \\
\hline 392 & 29.2 & \\
\hline 344 & 25.6 & \\
\hline 875 & 65.1 & \\
\hline 469 & 34.9 & \\
\hline
\end{tabular}


Table 24 Pearson (Upper)/Spearman (Lower) Correlation Coefficients

\begin{tabular}{|c|c|c|c|c|c|c|c|c|c|c|c|c|c|c|}
\hline & 1 & 2 & 3 & 4 & 5 & 6 & 7 & 8 & 9 & 10 & 11 & 12 & 13 & 14 \\
\hline 1 & & $0.36^{* *}$ & 0.02 & 0.00 & $0.34^{* *}$ & $0.36^{* *}$ & $-0.08^{* *}$ & $0.17^{* *}$ & -0.01 & 0.00 & $-0.11^{* *}$ & 0.04 & $0.05^{*}$ & $0.05^{*}$ \\
\hline 2 & $0.42^{* *}$ & & $-0.15^{* *}$ & $0.22^{* *}$ & $0.29^{* *}$ & $0.18^{* *}$ & $0.16^{* *}$ & $0.33^{* *}$ & $-0.18^{* *}$ & 0.00 & $0.06^{* *}$ & $0.08^{* *}$ & $-0.10^{* *}$ & $-0.10^{* *}$ \\
\hline 3 & 0.02 & $-0.13^{* *}$ & & $-0.09^{* *}$ & -0.02 & -0.03 & $-0.14^{* *}$ & $-0.09^{* *}$ & $0.12^{* *}$ & $0.06^{* *}$ & $-0.08^{* *}$ & 0.01 & $0.08^{* *}$ & 0.02 \\
\hline 4 & 0.02 & $0.30^{* *}$ & $-0.12^{* *}$ & & 0.04 & $0.05^{*}$ & $0.17^{* *}$ & $0.11^{* *}$ & $-0.07^{* *}$ & -0.02 & $0.11^{* *}$ & $-0.08^{* *}$ & $-0.07^{* *}$ & 0.02 \\
\hline 5 & $0.37^{* *}$ & $0.30^{* *}$ & -0.02 & $0.08^{* *}$ & & $0.39^{* *}$ & $0.08^{* *}$ & $0.40^{* *}$ & $-0.09^{* *}$ & -0.02 & $-0.11^{* *}$ & -0.01 & $0.05^{*}$ & $0.11^{* *}$ \\
\hline 6 & $0.37^{* *}$ & $0.18^{* *}$ & -0.03 & $0.07^{* *}$ & $0.39^{* *}$ & & 0.03 & $0.18^{* *}$ & -0.01 & $-0.12^{* *}$ & -0.02 & $-0.05^{*}$ & -0.01 & $0.17^{* *}$ \\
\hline 7 & $-0.08^{* *}$ & $0.16^{* *}$ & $-0.14^{* *}$ & $0.25^{* *}$ & $0.09^{* *}$ & 0.03 & & $0.28^{* *}$ & $-0.24^{* *}$ & $-0.09^{* *}$ & $0.12^{* *}$ & -0.01 & $-0.09^{* *}$ & $-0.07^{* *}$ \\
\hline 8 & $0.21^{* *}$ & $0.32^{* *}$ & $-0.09^{* *}$ & $0.21^{* *}$ & $0.41^{* *}$ & $0.18^{* *}$ & $0.28^{* *}$ & & $-0.29^{* *}$ & $-0.05^{*}$ & $-0.07^{* *}$ & $0.08^{* *}$ & 0.02 & -0.04 \\
\hline 9 & -0.03 & $-0.18^{* *}$ & $0.12^{* *}$ & $-0.11^{* *}$ & $-0.09^{* *}$ & -0.01 & $-0.24^{* *}$ & $-0.29^{* *}$ & & $0.11^{* *}$ & $-0.06^{* *}$ & 0.04 & -0.01 & 0.03 \\
\hline 10 & -0.01 & 0.00 & $0.06^{* *}$ & -0.04 & -0.02 & $-0.12^{* *}$ & $-0.09^{* *}$ & $-0.06^{* *}$ & $0.11^{* *}$ & & $-0.09^{* *}$ & $0.05^{*}$ & 0.04 & 0.01 \\
\hline 11 & $-0.11^{* *}$ & $0.05^{*}$ & $-0.08^{* *}$ & $0.12^{* *}$ & $-0.10^{* *}$ & -0.02 & $0.12^{* *}$ & $-0.06^{* *}$ & $-0.06^{* *}$ & $-0.09^{* *}$ & & $-0.57^{* *}$ & $-0.24^{* *}$ & $-0.28^{* *}$ \\
\hline 12 & 0.04 & $0.09^{* *}$ & 0.01 & $-0.07^{* *}$ & -0.02 & $-0.05^{*}$ & -0.01 & $0.07^{* *}$ & 0.04 & $0.05^{*}$ & $-0.57^{* *}$ & & $-0.30^{* *}$ & $-0.37^{* *}$ \\
\hline 13 & $0.05^{*}$ & $-0.10^{* *}$ & $0.08^{* *}$ & $-0.09^{* *}$ & $0.05^{*}$ & -0.01 & $-0.09^{* *}$ & 0.02 & -0.01 & 0.04 & $-0.24^{* *}$ & $-0.30^{* *}$ & & $-0.15^{* *}$ \\
\hline 14 & $0.05^{*}$ & $-0.10^{* *}$ & 0.02 & 0.02 & $0.11^{* *}$ & $0.11^{* *}$ & $-0.07^{* *}$ & -0.04 & 0.03 & 0.01 & $-0.29^{* *}$ & $-0.37^{* *}$ & $-0.15^{* *}$ & \\
\hline
\end{tabular}

**. Correlation is significant at the 0.01 level (2-tailed).

*. Correlation is significant at the 0.05 level (2-tailed).

$$
(\mathrm{n}=2,096)
$$

\begin{tabular}{|c|c|c|c|c|c|}
\hline $1=$ & FR_DURATION & $6=$ & TENURE & $11=$ & PUBLICLY TRADED \\
\hline $2=$ & FR_AMOUNT & $7=$ & GENDER & $12=$ & PRIVATELY HELD \\
\hline $3=$ & FR_TYPE & $8=$ & POSITION & $13=$ & NOT-FOR-PROFIT \\
\hline $4=$ & COLLUSION & $9=$ & EDUCATION & $14=$ & GOVERNMENTAL \\
\hline $5=$ & AGE & $10=$ & PRIORCHARG & Variak & are defined in Table 16 and Appendix A \\
\hline
\end{tabular}


Table 25 Multinomial Logit Regression for Outcome Pursued and Fraud Severity, Perpetrator Status and Victim Organization Type.

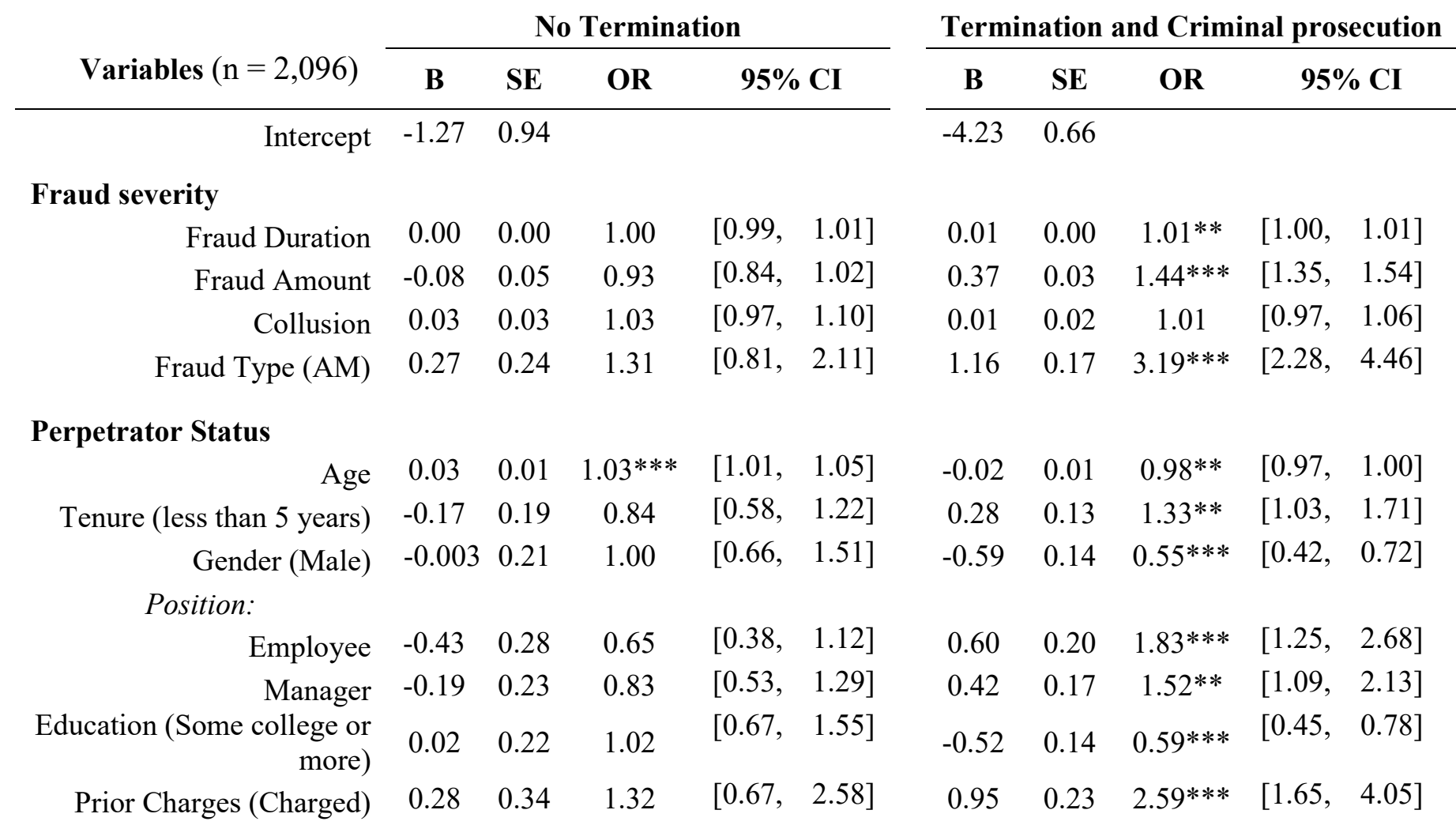

\section{Victim Organization Type}

Organization Type:

\begin{tabular}{|c|c|c|c|c|c|c|c|c|c|c|}
\hline Governmental & 1.19 & 0.35 & $3.30 * * *$ & {$[1.66$,} & $6.55]$ & 0.96 & 0.24 & $2.62 * * *$ & {$[1.63$} & $4.22]$ \\
\hline Not-for-profit & 0.86 & 0.36 & $2.37 * *$ & {$[1.16$} & 4.82] & 0.58 & 0.25 & $1.78 * *$ & {$[1.10$} & 2.88] \\
\hline Privately held & 0.84 & 0.24 & $2.32 * * *$ & {$[1.44$} & $3.75]$ & 0.23 & 0.15 & 1.26 & {$[0.94$} & 1.67] \\
\hline \multicolumn{11}{|l|}{ l Variables } \\
\hline Organization Size & -0.04 & 0.03 & 0.96 & {$[0.91$,} & $1.02]$ & -0.02 & 0.02 & 0.98 & {$[0.94$} & $1.02]$ \\
\hline Anti-fraud measures & -0.03 & 0.02 & 0.97 & {$[0.93$} & $1.01]$ & 0.01 & 0.01 & 1.01 & {$[0.98$} & $1.04]$ \\
\hline US firms (US) & 0.03 & 0.19 & 1.03 & {$[0.72$} & 1.49] & 0.68 & 0.13 & $1.97 * * *$ & {$[1.54$} & 2.53] \\
\hline \multicolumn{11}{|l|}{ Industry: } \\
\hline Banking & -0.01 & 0.30 & 0.99 & {$[0.55$} & $1.78]$ & 0.55 & 0.18 & $1.73 * * *$ & {$[1.21$,} & $2.48]$ \\
\hline Manufacturing & 0.11 & 0.26 & 1.12 & {$[0.66$} & $1.88]$ & -0.48 & 0.19 & $0.62 * * *$ & {$[0.43$} & $0.89]$ \\
\hline Public Services & 0.28 & 0.32 & 1.32 & {$[0.71$} & 2.48] & 0.08 & 0.25 & 1.09 & {$[0.67$,} & $1.76]$ \\
\hline Others & -0.11 & 0.24 & 0.90 & {$[0.56$,} & 1.44] & -0.07 & 0.16 & 0.93 & {$[0.68$,} & $1.28]$ \\
\hline
\end{tabular}

\section{Control Variables}

\footnotetext{
$*, * *, * * *$ Indicate $\mathrm{p}<0.1, \mathrm{p}<0.05$, and $\mathrm{p}<0.01$ levels, respectively, for the two-tailed test.
} 
Table 26 Multinomial Logit Regression for Outcome Pursued and Fraud Severity, Perpetrator Status and Victim Organization Type.

\begin{tabular}{|c|c|c|c|c|c|c|c|c|c|c|}
\hline \multirow{2}{*}{ Variables } & \multicolumn{5}{|c|}{ No Termination } & \multicolumn{5}{|c|}{ Termination and criminal prosecution } \\
\hline & $\begin{array}{c}\mathbf{B} \\
-1.80\end{array}$ & $\begin{array}{c}\text { SE } \\
1.51\end{array}$ & OR & \multicolumn{2}{|c|}{$95 \% \mathrm{CI}$} & $\begin{array}{c}\mathbf{B} \\
-4.22\end{array}$ & $\frac{\text { SE }}{0.87}$ & OR & \multicolumn{2}{|c|}{$95 \%$ CI } \\
\hline \multicolumn{11}{|l|}{ Fraud severity } \\
\hline Fraud Duration & -0.04 & 0.02 & $0.96 * * *$ & {$[0.93$} & 0.99] & 0.00 & 0.00 & 1.00 & {$[0.99$} & $1.01]$ \\
\hline Fraud Amount & -0.01 & 0.10 & 0.99 & {$[0.81$,} & $1.21]$ & 0.36 & 0.05 & $1.43 * * *$ & {$[1.28$,} & $1.59]$ \\
\hline Collusion & 0.02 & 0.07 & 1.02 & {$[0.89$} & $1.17]$ & 0.05 & 0.03 & $1.06^{*}$ & {$[0.99$} & $1.13]$ \\
\hline Fraud Type (AM) & 0.73 & 0.54 & 2.07 & {$[0.71$} & $6.02]$ & 1.14 & 0.27 & $3.11 * * *$ & {$[1.85$,} & $5.24]$ \\
\hline Governmental *Fraud Duration & 0.06 & 0.02 & $1.06^{* * *}$ & {$[1.02$,} & $1.10]$ & 0.02 & 0.01 & $1.02 *$ & {$[1.00$} & $1.04]$ \\
\hline Non-Profit * Fraud Duration & 0.06 & 0.02 & $1.06^{* * *}$ & {$[1.02$,} & $1.10]$ & -0.01 & 0.01 & 0.99 & {$[0.97$} & $1.02]$ \\
\hline Private*Fraud Duration & 0.04 & 0.02 & $1.04 * * *$ & {$[1.01$} & $1.08]$ & 0.01 & 0.01 & 1.01 & {$[1.00$} & $1.02]$ \\
\hline Governmental * Fraud Amount & -0.24 & 0.14 & $0.78 *$ & {$[0.59$} & $1.04]$ & -0.07 & 0.09 & 0.93 & {$[0.78$} & $1.11]$ \\
\hline Non-Profit * Fraud Amount & -0.27 & 0.19 & 0.76 & {$[0.53$} & $1.10]$ & 0.46 & 0.15 & $1.59 * * *$ & {$[1.18$,} & $2.15]$ \\
\hline Private $*$ Fraud Amount & 0.03 & 0.12 & 1.04 & {$[0.82$} & $1.31]$ & -0.03 & 0.07 & 0.97 & {$[0.85$} & $1.12]$ \\
\hline Governmental * Collusion & 0.01 & 0.09 & 1.01 & {$[0.84$} & $1.22]$ & -0.12 & 0.06 & $0.89 *$ & {$[0.79$} & $1.00]$ \\
\hline Non-Profit * Collusion & 0.22 & 0.19 & 1.25 & {$[0.87$} & $1.80]$ & -0.02 & 0.16 & 0.98 & {$[0.72$} & $1.34]$ \\
\hline Private $*$ Collusion & -0.03 & 0.09 & 0.97 & {$[0.82$} & $1.15]$ & -0.06 & 0.05 & 0.94 & {$[0.85$} & $1.03]$ \\
\hline Governmental * Fraud Type & -0.82 & 0.91 & 0.44 & {$[0.07$} & $2.61]$ & -1.13 & 0.61 & $0.32 *$ & {$[0.10$} & $1.07]$ \\
\hline Non-Profit * Fraud Type & -1.65 & 1.19 & 0.19 & {$[0.02$} & $1.99]$ & -0.73 & 1.02 & 0.48 & {$[0.07$} & $3.57]$ \\
\hline Private $*$ Fraud Type & -0.49 & 0.63 & 0.61 & {$[0.18$} & $2.10]$ & 0.38 & 0.38 & 1.46 & {$[0.69$} & $3.09]$ \\
\hline \multicolumn{11}{|l|}{ Perpetrator Status } \\
\hline Age & 0.03 & 0.01 & $1.04 * * *$ & {$[1.01$,} & $1.06]$ & -0.02 & 0.01 & $0.98 * *$ & {$[0.97$} & $1.00]$ \\
\hline Tenure (less than 5 years) & -0.13 & 0.19 & 0.88 & {$[0.60$} & $1.27]$ & 0.31 & 0.13 & $1.37 * *$ & {$[1.06$} & $1.76]$ \\
\hline Gender (Male) & 0.01 & 0.21 & 1.01 & {$[0.66$} & $1.54]$ & -0.61 & 0.14 & $0.54 * * *$ & {$[0.41$} & $0.71]$ \\
\hline
\end{tabular}




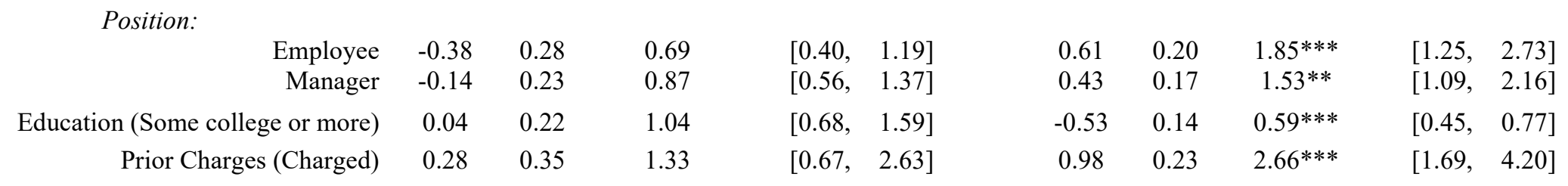

\section{Victim Organization Complexity}

Organization Type:

$\left.\begin{array}{llllllllll}\text { Governmental } & 3.46 & 1.85 & 31.90^{*} & {\left[\begin{array}{ll}0.84, & 1209.84\end{array}\right]} & 2.70 & 1.24 & 14.82^{* *} & {\left[\begin{array}{lll}1.31, & 167.85\end{array}\right]} \\ \text { Not-for-profit } & 3.70 & 2.22 & 40.60^{*} & {\left[\begin{array}{ll}0.52, & 3146.78\end{array}\right]} & -3.57 & 1.84 & 0.03 * & {[0.00,} & 1.03\end{array}\right]$

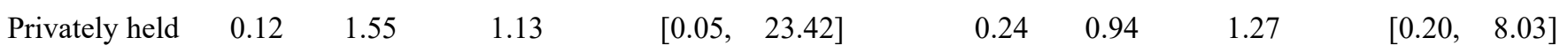

\section{Control Variables}

\begin{tabular}{|c|c|c|c|c|c|c|c|c|c|c|}
\hline Organization Size & -0.04 & 0.03 & 0.96 & {$[0.90$,} & $1.02]$ & -0.02 & 0.02 & 0.98 & {$[0.95$,} & 1.02] \\
\hline Anti-fraud measures & -0.03 & 0.02 & 0.97 & {$[0.93$,} & $1.02]$ & 0.01 & 0.02 & 1.01 & {$[0.98$,} & $1.04]$ \\
\hline US firms (US) & 0.02 & 0.19 & 1.02 & {$[0.70$,} & $1.48]$ & 0.67 & 0.13 & $1.95^{* * *}$ & {$[1.52$,} & 2.50] \\
\hline Banking & -0.11 & 0.31 & 0.90 & {$[0.49$,} & $1.64]$ & 0.53 & 0.19 & $1.70^{* * *}$ & {$[1.18$,} & 2.45] \\
\hline Manufacturing & 0.12 & 0.27 & 1.12 & {$[0.67$,} & $1.90]$ & -0.44 & 0.19 & $0.64 * *$ & {$[0.45$,} & $0.93]$ \\
\hline Public Services & 0.29 & 0.33 & 1.34 & {$[0.69$,} & $2.58]$ & 0.06 & 0.26 & 1.07 & {$[0.65$,} & $1.76]$ \\
\hline Others & -0.16 & 0.24 & 0.86 & {$[0.53$,} & $1.38]$ & -0.09 & 0.16 & 0.91 & {$[0.67$,} & $1.25]$ \\
\hline
\end{tabular}

$*, * *, * * *$ Indicate $p<0.1, p<0.05$, and $p<0.01$ levels, respectively, for the two-tailed test. 
Table 27 P's Aggregate Expectations

\begin{tabular}{|c|c|c|}
\hline Paths & Perpetrators & P's Aggregate Expectation \\
\hline 6 positive; 0 negative & $\begin{array}{c}\text { Male perpetrators, who are over } \\
40 \text { years old in managerial or } \\
\text { executive position, and have } \\
\text { some college education and no } \\
\text { prior charges. }\end{array}$ & 0.9834 \\
\hline 5 positive; 1 negative & & 0.4722 \\
\hline 4 positive; 2 negative & & 0.19 \\
\hline 3 positive; 3 negative & & 0.00 \\
\hline 2 positive; 4 negative & & -0.19 \\
\hline 1 positive; 5 negative & & -0.4722 \\
\hline 0 positive; 6 negative & $\begin{array}{l}\text { Female perpetrators, who are } \\
\text { under } 40 \text { years old in an } \\
\text { employee position, and have } \\
\text { only high school education or } \\
\text { less, and have prior charges. }\end{array}$ & -0.9834 \\
\hline
\end{tabular}


Table 28 Multinomial Logit Regression for Outcome Pursued and Fraud Severity, Perpetrator Status and Victim Organization Type.

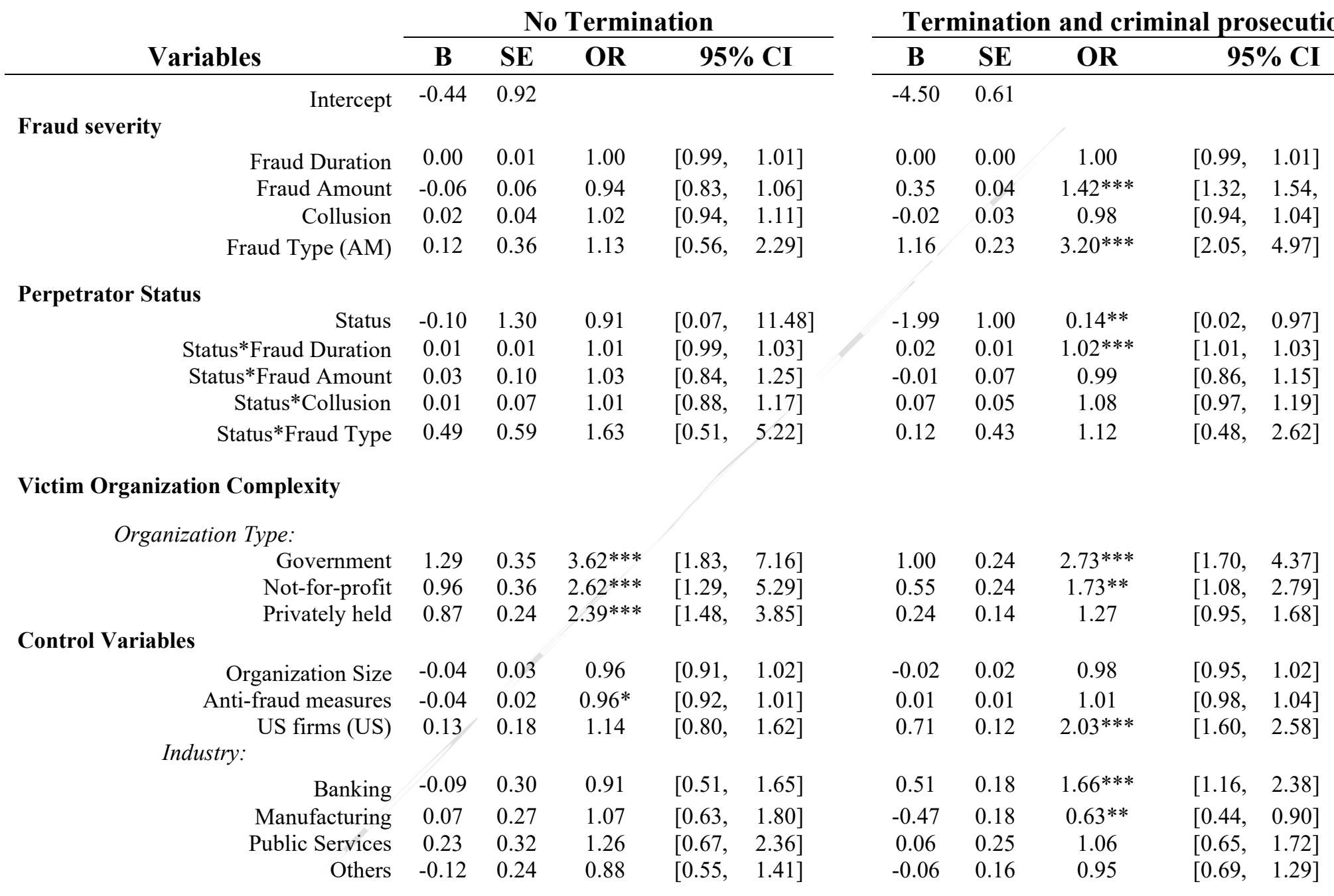

$*, * *, * *$ Indicate $\mathrm{p}<0.1, \mathrm{p}<0.05$, and $\mathrm{p}<0.01$ levels, respectively, for the two-tailed test. 


\section{APPENDIX H - VARIABLE DEFINITIONS}

\begin{tabular}{|c|c|c|}
\hline Variable & Measurement & $\begin{array}{l}\text { ACFE } \\
\text { survey } \\
\text { Question } \\
\end{array}$ \\
\hline \multicolumn{3}{|c|}{ DV - Dependent variable } \\
\hline Termination & $\begin{array}{l}\text { Indicator variable, where it equals } 1 \text { if the perpetrator no longer } \\
\text { worked for the victim organization after fraud was detected, and } 0 \\
\text { otherwise. }\end{array}$ & Q74 \\
\hline Criminal & $\begin{array}{l}\text { Indicator variable, where it equals } 1 \text { if the fraud case was referred } \\
\text { to law enforcement for criminal prosecution, and } 0 \text { otherwise }\end{array}$ & Q75 \\
\hline \multicolumn{3}{|l|}{ Prosecution } \\
\hline 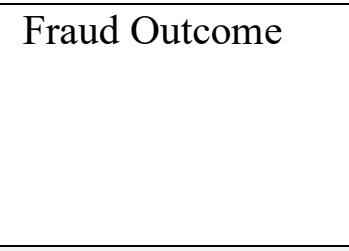 & $\begin{array}{l}\text { It equals } 0 \text { if the perpetrator was not terminated and was not } \\
\text { referred to law enforcement for prosecution; it equals } 1 \text { if the } \\
\text { perpetrator was only terminated; and it equals } 2 \text { if the perpetrator } \\
\text { was terminated and was referred to law enforcement for } \\
\text { prosecution. }\end{array}$ & Q74/Q75 \\
\hline \multicolumn{3}{|c|}{ IV- Fraud Severity } \\
\hline $\begin{array}{l}\text { Fraud Duration } \\
\text { (FR_DURATION) }\end{array}$ & $\begin{array}{l}\text { The number of months that the scheme had been ongoing before } \\
\text { it was initially detected. }\end{array}$ & Q41 \\
\hline $\begin{array}{l}\text { Fraud Amount } \\
(\text { FR_AMOUNT) }\end{array}$ & $\begin{array}{l}\text { Natural logarithm of the total dollar value of the amount of assets } \\
\text { that was misappropriated, or the amount of loss caused. }\end{array}$ & Q2 \\
\hline $\begin{array}{l}\text { Fraud } \quad \text { Type } \\
(\text { FR_TYPE) }\end{array}$ & $\begin{array}{l}\text { Indicator variable equal to } 1 \text { if the fraud scheme involved asset } \\
\text { misappropriation, and } 0 \text { otherwise. }\end{array}$ & Q6 \\
\hline $\begin{array}{l}\text { Collusion } \\
\text { (COLLUSION) }\end{array}$ & The number of perpetrators involved in the fraud scheme. & Q59 \\
\hline \multicolumn{3}{|c|}{ IV- Perpetrator Status } \\
\hline $\begin{array}{l}\text { Age } \\
\text { (AGE) }\end{array}$ & $\begin{array}{l}\text { Age of the principal perpetrator in years at the time of the } \\
\text { occupational fraud. }\end{array}$ & Q60 \\
\hline
\end{tabular}




\begin{tabular}{llc}
\hline Variable & \multicolumn{1}{c}{ Measurement } & $\begin{array}{c}\text { ACFE } \\
\text { survey } \\
\text { Question }\end{array}$ \\
\hline Tenure & $\begin{array}{l}\text { Indicator variable equal 1 if the principal perpetrator had worked } \\
\text { for the victim organization less than five years at the time } \\
\text { occupational fraud occurred, and 0 if s/he had worked for more } \\
\text { than five years. }\end{array}$ & Q61 \\
\hline Gender & $\begin{array}{l}\text { It equals 1 if perpetrator is a male and 0 if s/he is a female. } \\
\text { (GENDER) }\end{array}$ & Q65 \\
\hline Position & $\begin{array}{l}\text { The perpetrator position is a categorical variable with three levels: } \\
\text { employee, manager (includes supervisor) and executive (includes } \\
\text { owner and officer). }\end{array}$ & Q62 \\
(POSITION) & $\begin{array}{l}\text { Indicator variable equal to 1 if the principal perpetrator's } \\
\text { education equals some college education or more, and 0 otherwise, } \\
\text { i.e. the perpetrators received high school graduation or less. }\end{array}$ & Q66 \\
\hline Education & $\begin{array}{l}\text { Indicator variable, where it equals 1 if the perpetrators has } \\
\text { received prior fraud-related charges, and 0 otherwise. }\end{array}$ & Q69 \\
\hline (EDUCATION) & & \\
\hline Prior Charges &
\end{tabular}

\section{IV- Victim Organization Type}

Organization Type The type of organization is a categorical variable with four levels: governmental agency, publicly traded company, privately held

Q45 (ORG_TYPE) company and not-for-profit organization.

\begin{tabular}{lll}
\hline CV - Control Variables & \\
\hline Organization Size & $\begin{array}{l}\text { Natural logarithm of the victim organization's approximate gross } \\
\text { annual revenue. }\end{array}$ & Q47 \\
(ORG_SIZE) & $\begin{array}{l}\text { The following industries are controlled for: banking/financial } \\
\text { services, manufacturing, public services (includes government and } \\
\text { public administration, religious, charitable, social services), } \\
\text { customer service (includes transportation and warehousing) and } \\
\text { others. }\end{array}$ & Q49 \\
\hline Industry & $\begin{array}{l}\text { Total number of antifraud measures that victim organizations had } \\
\text { in place at the time that occupational fraud occurred. }\end{array}$ & Q51 \\
\hline Anti-fraud &
\end{tabular}

\section{(ANTIFRAUD)}




\begin{tabular}{lcc}
\hline \multicolumn{1}{c}{ Variable } & Measurement & $\begin{array}{c}\text { ACFE } \\
\text { survey } \\
\text { Question }\end{array}$ \\
\hline Organization & $\begin{array}{c}\text { Indicator variable, where it equals 1 if the victim organization is } \\
\text { located in the U.S.A., and 0 otherwise. }\end{array}$ & Q50 \\
Location & & \\
(ORG_LOC) & & \\
\hline
\end{tabular}




\title{
CHAPTER FOUR - SPILLOVER EFFECTS OF MANAGEMENT'S RESPONSE TO FRAUD
}

\author{
D. Kip Holderness, Jr. \\ John Chambers College of Business and Economics, West Virginia University \\ kip.holderness@mail.wvu.edu \\ Michael Majerczyk \\ J. Mack Robinson College of Business, Georgia State University \\ mmajerczyk@gsu.edu
}

\begin{abstract}
Marie Rice*
John Chambers College of Business and Economics, West Virginia University mmr0016@mix.wvu.edu
\end{abstract}

\begin{abstract}
Author Note
We would like to thank the Institute of Management Accountants (IMA) for providing financial support of this study through the IMA Research Foundation's Doctoral Scholarship Grant Program Submitted in partial fulfillment of Ms. Rice's requirements for the degree of Doctor of Philosophy in Accounting at West Virginia University. The corresponding author may be reached at mmr0016@mix.wvu.edu.
\end{abstract}




\begin{abstract}
Management teams often increase or modify formal controls when fraud, such as employee theft, is detected. However, doing so may have unintended consequences for the perpetrator's coworkers. For example, affective event theory explains that when employees believe that the response is unfair, they become counterproductive, reducing the firm's overall productivity. We test whether theft by a coworker reduces non-offending employee productivity using a two-period experiment with groups of two employees and one manager. Employees can steal each period and, if theft is detected in period one, managers can increase detection for all employees in period two. We find that two out of three managers increase inspections for all employees, even without incentive to do so. Further, we find that employees' affect intensity and ability to be influenced by others are related to their levels of productivity and likelihood of taking in period 1 but not taking in period 2 .
\end{abstract}

Keywords: Theft, management controls, counterproductive workplace behavior, affective event theory, fairness judgment 


\section{INTRODUCTION}

Employee theft has a substantial effect on businesses and total losses from theft of cash and noncash assets range between $\$ 40$ billion and \$120 billion each year (Buss 1993; Lipman and McGraw 1998). These losses are attributable to approximately 30\% of business failures (Lipman and McGraw 1998; Snyder and Blair 1989; Marasi, Bennet, and Budden 2018), generating a nontrivial impact to the economy. Further, 33\% of retail, manufacturing, and service employees surveyed self-reported stealing from their employer (Clark and Hollinger 1983).

Managers use formal controls, such as inspections of employees' work, to accomplish organizational goals (Chenhall 2007), to increase workplace conformity (Bedford, Malmi, and Sandelin 2016), and to punish workplace deviance (Parilla, Hollinger, and Clark 1988) like employee theft (Kennedy 2014). While the intent of the controls is to increase the efficiency and effectiveness of business processes, they can have unintended consequences. For example, when management implements inspections of employees' work in response to deviant behavior, other employees may perceive the inspections to be an unfair punitive or threatening action against them (Chenhall, Hall, and Smith 2010; Penney and Spector 2005). Coworkers base their fairness judgments on the perceived inequity of the situation and the organization's response to it.

Affective event theory (AET) explains that perceived unfairness results in a decline in organizational productivity through reduced job satisfaction, decreased job commitment, and increased withdrawal behaviors (Weiss and Cropanzano 1996). When employees perceive these actions to be unfair,

they may avoid work, call in sick, or otherwise become counterproductive (Bennett and Robinson 1995). Counterproductive workplace behavior occurs when employees seek retribution against the organization for the perceived unfair treatment. Robinson and Bennett (1995) define CWB as "voluntary behavior that violates significant organizational norms and in so doing threatens the well-being of an organization" (p. 
556). CWB may be intentional or unintentional and includes loss of motivation to conform to group norms and increasing motivation to deviate from group norms (Kaplan 1982). Counterproductive workplace behaviors have a serious effect on the organization (Robinson and Bennett 1995; Penney and Spector 2005 ) and can reduce productivity by as much as $10 \%$ of the organization's total productivity (Belot and Schroder 2012). Even though reduced productivity can have detrimental effects on organizations, prior literature has not examined the effects of reduced productivity from employee fairness judgments.

To evaluate coworker productivity and management's response to fraud, we conduct a two-period experiment with groups of three participants, including one manager and two employees. Both roles, manager and employee, are explained to all participants. Managers oversee employees' productivity and an investment fund. They are compensated based on the number of hours employees work toward the company's productivity, as well as the investment fund balance at the end of the study. In period 1, managers have a $50 \%$ chance of detecting fraud. If they detect fraud in period one, managers have the option to increase the likelihood of detection to $100 \%$ in period two. Employees choose how many hours to contribute toward the company's productivity and have the opportunity to take $\$ 0.50$ from an investment fund at the end of each period. Employees are compensated a flat rate of $\$ 1.00$ and are able to keep whatever money they take from the investment fund.

We find that two out of every three managers increase inspections for all employees, even with no incentive to do so. We assign one in three employees to the "No Increase" condition and two in three employees to either the "Increase Inspections" or "Detect fraud, but No Increase" conditions. Results show that there is no difference in employee productivity nor likelihood of taking from the investment fund between these conditions. However, in supplemental analyses we find that employee participants' affect intensity and ability to be influenced by others affect their levels of productivity and their likelihood of taking in period 1 but not taking in period 2. We use this information to design future pilot studies. 


\section{BACKGROUND}

\section{Employee Theft as Fraud}

Employee theft is defined as "the unauthorized taking, control, or transfer of money and/or property" (Clark and Hollinger 1983, p. 1) from one's employer during the course of one's employment (Clark and Hollinger 1983) and is a form of occupational fraud called asset misappropriation (ACFE 2018). Asset misappropriation cases are the most prolific type of fraud, comprising $89 \%$ of all cases reported by Certified Fraud Examiners in 2018, averaging \$114,000 per incident (ACFE 2018). Losses from asset misappropriation are both staggering and difficult to prevent, as offenders have an intimate knowledge of the organization's systems and processes. Kennedy (2014) states, "it is likely through the proper performance of one's job that an employee gains the trust and knowledge needed to engage in employee theft" (p.13). Indeed, the specific attributes of one's job, particularly access to assets, and their skills and capabilities (Mustaine and Tewksbury 2002) influence the likelihood of committing employee theft.

The antecedents and consequences of employee theft have been examined across white-collar crime, organizational justice, and occupational fraud disciplines. Antecedents have included organizational attributes and the interaction between organizational attributes and individual characteristics. Prior studies on organizational attributes show that employee perception is a key indicator of the likelihood of committing fraud. For example, when employees feel supported (Clark and Hollinger 1983) they are less likely to steal from the company. Similarly, employees who perceive that organizational norms discourage unethical behavior (Kulas, McInnerney, DeMuth, and Jadwinski 2007) or who perceive punishment to be certain or severe (Hollinger and Clark 1982) are less likely to engage in employee theft. Clark and Hollinger (1983) also find that company policy is a better deterrent against employee theft than physical security. 


\section{Management Controls in Response to Fraud}

The quality of the control environment has a strong effect on reducing fraud (Rae and Subramanian 2008) and a lack of internal controls or override of controls is often a factor in fraud cases (ACFE 2018). Specifically, the control goal of safeguarding assets (Ouchi 1979) is violated when employee theft occurs. The security orientation of organizational controls "facilitates a response after an employee has been caught stealing" (Tomlinson and Greenberg 2007, p. 288) that involves modifying processes and technology to increase deterrence of future incidents of theft and to identify and hold future offenders accountable (Tomlinson 2016).

When management modifies the control environment, they signal to non-offending employees (i.e. the perpetrator's coworkers) the level of tolerance management has for employee theft. Signaling theory explains that when information is asymmetric between two parties, one party (the sender) must choose whether and how to communicate (or signal) that information to the other party, the receiver (Spence 1973). In selecting the communication mechanism, management must consider the intent of the message and the whether the signal is strong enough that the recipient understands the message (Connelly, Certo, Ireland, and Reutzel 2011). Additionally, management should consider the potential vicarious effects of the signal on other employees (Butterfield, Treviño, and Ball 1996) and whether the message will also be understood by the perpetrator's coworkers.

Controls offer management tools to communicate their signal to both the individual perpetrator and to other employees. Management may choose, for example, to increase the likelihood that the same theft act will be detected in the future. Conversely, management may choose to "turn a blind eye" to deviant behavior by not acknowledging known wrongful acts or may choose to "sweep under the rug" wrongful acts that are known only to management by not responding to the event. Taking no action against 
a perpetrator may send a signal to other employees that management condones or dismisses wrongful behavior, which may result in the furtherance of such behavior by other employees.

While the intent of controls is to increase the efficiency and effectiveness of business processes while monitoring employees (Litzky, Eddleston, and Kidder 2006) and deterring deviant behavior, their modification can have unintended consequences. For example, when management implements inspections of employees' work in response to workplace deviance, other employees may perceive the inspections to be an unfair punitive or threatening action against them (Chenhall et al. 2010; Penney and Spector 2005: Tomlinson and Greenberg 2007; Litzky et al. 2006). Further, increasing controls can signal distrust between management and employees that may incite counterproductive workplace behavior, such as property or production deviance (Litzky et al. 2006). Thus, management's use of controls to deter fraud may have unintended consequences and a detrimental effect on employees.

Management controls have been pervasively examined in organizational justice, organizational behavior, and accounting literature. Researchers have been evaluating the behavioral facets of internal control (Carmichael 1970), proposed frameworks for management controls (Ouchi 1979), organizational inputs of and attributes related to controls (Parilla et al. 1988; Tomlinson and Greenberg 2007), internal control quality and tests of controls (Schroeder and Shepardson 2016; Bhaskar, Schroeder, and Shepardson 2018), and the impacts of individuals' characteristics (Christ, Emett, Summers, and Wood 2012). While management controls have been studied prolifically (Merchant and Otley 2007), prior literature has not examined the effects of management controls on workgroup productivity in response to fraud.

\section{Coworkers Observe Management's Response to Fraud}

Coworkers witness social interactions in the workplace, such as management's response to deviant behavior (Totterdell, Hershcovis, Niven, Reich, and Stride 2012; Robinson, Wang, and Kiewitz 2014) and 
are undervalued third-party observers in these situations (Robinson et al. 2014). These observations are impactful, as coworkers spend a large quantity of time together and coworker relationships influence organizational dissent (Solito and Myers 2015), job affect, and organizational citizenship behavior (Lee and Allen 2002). Indeed, "relationships between coworkers are an important, yet understudied source of influence in peoples' lives" (Basford and Offermann 2012, p. 807). Although overlooked in the literature, misbehaving employees have a vicarious impact on their coworkers and "trigger potentially potent reactions" (Robinson et al. 2014, p.124) to organizational situations. For example, coworkers may imitate deviant behavior (Schmidtke 2007), particularly when they perceive the organizational response to tolerate the activity (Litzky et al. 2006). Therefore, coworker relationships can have large positive and negative impacts on the organization and should be studied.

\section{Affective Event Theory and Fairness Judgments}

Calls from the industrial/organizational psychology and neuroscientific communities to further investigate what context and information is relevant when individuals form moral decisions led to the development of Affective Event Theory (“AET”). AET explains that feelings elicited by workplace activities influence job satisfaction, organizational commitment, and other workplace behaviors (Weiss and Cropanzano 1996). Instead of processing information cognitively, affective events such as employee theft cause emotional responses to supersede cognitive processing (Kennedy 2014), which leads to cognitive dissonance (Weiss and Cropanzano 1996) that is increased by uncertainty (Lind and van den Bos 2002). To resolve this dissonance, employees judge the perceived fairness of the situation and the organizational response to it (Ball, Treviño, and Sims 1994; Henle 2005; Fehr and Schmidt 1999).

Coworkers who observe workplace wrongdoing and perceive the situation to be unfair (Treviño 1992) may seek retribution against the offender. Contrarily, employees who perceive the organizational response to be unfair may feel dissent (Turillo, Folger, Lavelle, Umphress, and Gee 2002; Butterfield et 
al. 1996) toward the organization. Under fairness theory, organizational research shows that these decisions induce third-party observers to consider what the wrongdoer would have done if they could have, and what they should have done (Folger and Cropanzano 2001), and to judge the fairness of the situation (Fehr and Schmidt 1999). Fairness judgments are based on the equity and consistency of applied justice, absence of bias, and "its representativeness of important subgroups" (Leventhal 1980, p.1).

\section{Counterproductive Workplace Behavior}

When employees perceive a situation or an organizational response to a situation to be unfair, they may engage in retributive behavior by becoming counterproductive (Skarlicki and Kulik 2004). Robinson and Bennett (1995) define counterproductive workplace behavior ("CWB") as "voluntary behavior that violates significant organizational norms and in so doing threatens the well-being of an organization" (p. 556) and may include avoiding work, calling in sick, or otherwise reducing productivity (Bennett and Robinson 1995). CWB may be intentional or unintentional and includes loss of motivation to conform to group norms and increasing motivation to deviate from group norms (Kaplan 1982).

Counterproductive workplace behaviors have a serious effect on the organization (Robinson and Bennett 1995; Penney and Spector 2005) and can reduce productivity by as much as $10 \%$ of the organization's total productivity (Belot and Schroder 2012). The impact is not only costly, but also pervasive. Clark and Hollinger (1983) find that two-thirds of survey respondents participated in counterproductive workplace behavior. The impact and prevalence of CWB is detrimental to organizations and is predicated by the employees' perception that the situation or the organizational response to it is unfair.

Whether an employee engages in CWB is dependent upon the individual's attributes, including self-control and integrity (Marcus, Schuler, Quell, and Hümpfner 2002), as well as the organizational climate attributes, such as incivility, organizational constraints, and interpersonal conflict (Penney and 
Spector 2005). For example, the relationship between job stress and CWB is mediated by opportunities for career advancement (Roxana 2013). Thus, like fairness judgments, whether an employee engages in CWB is dependent on individual characteristics and perceived situational variables (Martinko, Gundlach, and Douglas 2002)

\section{CWB varies by Affective Intensity}

Coworker counterproductive workplace behavior increases losses due to fraud (Greenberg and Robinson 1998) but those losses vary by the extent to which the employee engages in CWB. Employees who are faced with affective events in the workplace experience the event at different levels of intensity (Larsen and Diener 1987) of either negative or positive affect. Some employees may have strong negative reactions to the event and may seek retribution against either the wrongdoer or the organization. These employees will likely experience the greatest reduction in productivity subsequent to the event, as compared to other employees. Contrarily, employees who perceive the situation or management's response to it to be fair may experience positive affect and may increase their subsequent productivity. Still others may be apathetic toward the situation and may either engage in lower levels of CWB or may maintain their pre-event levels of productivity.

Coworker CWB will result in indirect losses in productivity, which increase the organization's overall loss from the fraud, thus organizational losses will vary with coworker CWB. While prior research has examined the effects of direct losses from employee theft, it has negated the indirect effects from lost productivity.

\section{DESIGN AND HYPOTHESIS DEVELOPMENT}

\section{Participants}

We obtain participants using Amazon mTurk for our study. mTurk has been shown to yield samples that are more representative of the general population than student samples, but participants often lack 
attention (Paolacci and Chandler 2014; Goodman, Cryder, and Cheema 2013). Additionally, participants self-select into studies (Sharpe Wessling, Huber, and Netzer 2017). However, mTurkers have a variety of professional and academic experience levels and are more representative of the U.S. workforce than student samples (Buccheit, Dalton, Pollard, and Stinson 2018). Another specific risk in this population relates to the number of studies participants engage in. Those who complete a high number of studies are labeled "Super Turkers" and post on certain comment boards to other participants, sharing information and commenting about the quality of the study.

To mitigate the risks that participant inattentiveness, self-selection, experimental experience, or interaction interfered with the results, we employ certain measures. We deploy Turk Prime's data integrity controls to ensure our participants are higher quality, have an internet protocol address within the United States, and are not duplicate participants. To monitor for inattention, we deploy attention and manipulation checks throughout the study and examine participants' times for completing each section of the study.

Prior studies have shown that Super Turkers' non-naiveté yields faster response times than average participants (Sharpe Wessling et al. 2017). Therefore, we evaluate response times on a case-by-case basis to evaluate whether winsorizing is necessary. We also monitor Turker boards for commentary or information regarding the experiment while it is running to assess the likelihood that participants identified the hypotheses, or otherwise advise potential participants of its contents.

\section{Design}

To evaluate coworker productivity, depending on whether theft occurs and management's response to the theft, we conduct a two-stage interactive experiment with groups of three participants, including one manager and two employees. Both roles, manager and employee, and the compensation structures for each role are explained to all participants. At the beginning of each period, the company contributes to an investment fund. 
Study One - Managers. Managers oversee employees' productivity and the investment fund. They are compensated based on the number of hours contributed to the company's productivity by employees, as well the investment fund balance at the end of the study. We use this compensation structure to assimilate pay-for-performance measures often found in real-world office settings where organizations compensate a manager based on their team's performance.

In an initial study, 108 managers are solicited on Amazon mTurk. Managers read information about the company, each role and its responsibilities, and the related compensation procedures. Managers are then told that one employee took from the investment account in period one and asked to choose whether to increase the likelihood of theft detection by increasing the rate of inspections for all employees in the future.

Study Two- Employees. In a second study, 121 participants who have not previously engaged in studies related to this project are solicited through Amazon Turk Prime to act as employees. Participants are assigned to one of three conditions: management did not increase controls, management increased controls, or management detected fraud but did not increase controls. Employees are assigned to the three conditions based on the proportion of managers who decide whether to increase controls or not in Study One. ${ }^{36}$

Employees choose to contribute hours toward the company's productivity and can take $\$ 0.50$ from an investment fund at the end of each period. Employees are compensated a flat rate of $\$ 1.00$, plus can keep whatever money they take from the investment fund. We seek to achieve mundane realism with this compensation structure as many office workers receive flat compensation, outside of performance review

\footnotetext{
${ }^{36}$ Two out of every three manager participants in Study One increased controls for all employees in period two. These results were similar to those obtained from prior pilot studies.
} 
increases. Coworker connection is enhanced by having employees report the first letter of their first name and their favorite color to their coworker at the beginning of the study.

Employees are instructed that the system will select one of the two employees for inspection. Instructions also state that if the selected employee took from the investment fund, all employees will be notified. The intent of this notification is to induce social desirability bias. Further, employees are told that the manager may increase inspections for all employees in period two to enhance participants desire to hold coworkers accountable.

Employees are monetarily incented to take from the investment fund with no threat of individual punishment. However, the exchange of information between coworkers at the beginning of the study should reduce employees' intent to take from the investment fund and increase their sense of duty to their coworker. When an employee takes from the investment fund, they are endogenously assigned to the "fraud" group.

After period one, employees are notified whether the inspected employee took from the investment fund, and whether management increased inspections or not. Thus, employees are endogenously assigned to the $\operatorname{detect}(\mathrm{Y} / \mathrm{N})$ and increased inspections $(\mathrm{Y} / \mathrm{N})$ groups.

In period two, employees again choose how many hours to contribute to the company's productivity and whether to take from the investment fund. When an employee takes from the investment fund, other employees may signal their dissatisfaction with the event. Therefore, we hypothesize that:

H1: Employee productivity, on average, will be lower when fraud occurs than when fraud does not occur.

\section{Fairness impacts future productivity.}

When management responds to fraud by increasing the rate of detection for all employees in future periods, non-offending coworkers may perceive the response to be an unfair universal punishment. The 
judgment that management's response to the event is unfair is likely to increase counterproductive measures and reduce productivity after the event. As such, we hypothesize:

$H 2$ : When theft is detected and management increases inspections, employee productivity will decline in subsequent periods.

\section{Failure to act.}

Management's response to fraud detection may also nudge accepted norms and modify employees' fairness judgments. For example, when managers turn a blind eye to fraud, they may signal that fraudulent behavior is an acceptable cost of business. In these cases, employees may perceive theft to be an acceptable norm and may be more likely to take from the investment account in future periods. Therefore, we hypothesize:

H3: When management detects fraud, but does not increase inspections, other employees will be more likely to take from the investment account in future periods.

Within the fraud group, employee productivity levels will likely vary by coworkers' affective responses to the situation and management's behaviors. For example, employee productivity is likely negatively related to the level of affective intensity the employee feels about the theft (Larsen and Diener, 1987). However, productivity may not decline when employees feel a sense of duty to the organization, or high moral responsibility and/or a belief that management should hold wrongdoers accountable for their actions $^{37}$. Employees' sense of duty to the organization may negate the influence of coworker behavior on individual productivity as the employee may place greater value in fulfilling their duties than in maintaining coworker relationships. Alternatively, employees who believe that a coworker who steals should be blamed and/or held accountable may perceive increased inspections as positive outcomes and

\footnotetext{
${ }^{37}$ Post-experimental questionnaires also include Likert-scale questions related to employees' propensity to trust, fairness judgement, and feeling of belongingness.
} 
may not reduce their productivity in response. That is, the more upset an employee is about the theft, the lower their individual productivity will be in future periods. Conversely, the more justifiable management's response seems to be, the less likely coworkers' productivity will be to decline. We hypothesize:

H4a: When fraud occurs, employees' productivity after the theft will be negatively related to how upset the employee reported being about the theft.

$H 4 b$ : When fraud occurs, employees' productivity after the theft will not be affected when coworkers believe that managers should hold wrongdoers accountable.

\section{Methodology and ANALYSIS}

\section{Variables}

\section{Dependent Variables}

We measure employee productivity via the difference in the number of hours contributed toward the company's productivity from period one to period two to determine whether the presence or absence of fraud and/or management's punitive response affects employee productivity in subsequent periods. Using the incremental change in hours contributed between periods allows us to account for within-subject effects.

We measure whether employees are more likely to take from the investment fund in period two, based on their decisions to take or not take in period one. It is important to capture employees' decision in period one as it is likely to influence their decision in period two.

\section{Independent Variables}

We record the endogenous choices made by managers and impose them exogenously on employees. We then elicit employees' decisions endogenously and record them as observable factors that affect performance. Specifically, we document employees' decision whether to take money from the investment 
fund in each period and the number of hours contributed toward company productivity each period. Managers may elect to 1) take no action or 2) increase inspections of all employees in period 2. Managers are assigned to groups based on whether they chose to increase inspections or not.

Our design (i.e. Increase - Y/N, Detect- Y/N, Fraud- Y/N) is therefore endogenously derived. However, the manager's decision whether to increase inspections (IV1) is distributed across employee groups exogenously, based on the pro-rata apportionment of increased inspections. That is, the percentage of groups assigned to either the No Increased Inspections condition or the Yes Increased Inspections condition is consistent with the percentage of managers who chose to either not increase or increase inspections in study one.

--Insert Figure 21--

\section{Analysis}

Our design is quasi-experimental because participants are endogenously assigned to cells based on their and their group members' decisions (i.e. Increased inspections $\mathrm{Y} / \mathrm{N}$, Detect $\mathrm{Y} / \mathrm{N}$, and Fraud $\mathrm{Y} / \mathrm{N}$ ). Therefore, we measure variance between groups and within individuals using a repeated measures linear design ${ }^{38}$. Our model examines individual variation within-participants to account for carry-over effects in productivity and likelihood of taking between periods. Supplemental analyses are performed to evaluate the impact of our endogenous design, and to search for potential omitted correlated variables that may influence participant's decisions and therefore contribute to the self-selection bias in the study. We further examine variance between conditions, fraud/no-fraud and increased inspection $\mathrm{Y} / \mathrm{N}$, and multivariate combinations of these variables. We are most interested in examining the effects of fraud on employees'

\footnotetext{
${ }^{38}$ Supplemental analyses are conducted to evaluate the likelihood of omitted correlated variables that contribute to selfselection bias and estimate average treatment effects.
} 
subsequent productivity. Therefore, we evaluate the differences in productivity between fraud and no fraud conditions and within the fraud condition.

In addition to these results, we confirm that process measures effectively represent the underlying theoretical constructs. We use Exploratory Factor Analysis (EFA) to confirm that manager process measures represent two factors: blame attribution/ retributive justice and fairness. We further conduct an EFA to ensure employee process measures generate three factors: fairness, affect intensity, and social influence.

\section{RESULTS}

The results of Study One show that two out of every three managers $\left(\mathrm{N}=76\right.$ out of 108 managers ${ }^{39}$; see Table 16) increase inspections for all employees in period 2 when given a hypothetical scenario stating that one of the employees took from the investment fund in period 1. Therefore, we assign 2 out of every 3 employee groups to the increase inspections condition, and 1 out of every 3 employee groups to the no increase condition. We find that managers who increase inspections statistically significantly differ from those who choose not to increase inspections in their perceptions of fairness and blame attribution (see Table 16). In particular, managers who increase inspections are more likely to agree with the statement "Increased inspections achieve justice for theft in period $1 "(t=-4.48, p<0.001, \mathrm{M}=4.24, \mathrm{SD}=1.211)$ than those who do not increase inspections $(\mathrm{M}=2.30, \mathrm{SD}=1.577$; see Table 16). Figure 2 shows the results of statistically significant differences in managers' perceptions between groups.

\section{--Insert Figure 22--}

In Study Two, we examine the effects of managers' decisions to increase inspections in response to fraud on employees. Pearson correlations show that employee productivity in period two is positively

\footnotetext{
${ }^{39}$ These results are similar to results obtained in prior pilot studies.
} 
related to participants' beliefs that their pay is fair $(r=0.256, \mathrm{p}<0.0010$ and that increased monitoring is a fair way to reduce fraud $(r=0.202, \mathrm{p}<0.10)$. We use repeated measures analysis of variance to account for participants' carryover effects from period one to period two in our tests of hypotheses. Results show that there is no difference in employee productivity between groups when fraud exists, refuting hypothesis 1. Repeated measures ANOVA models also show that employee productivity (H2) and the likelihood of taking from the investment fund (H3) in period 2 do not statistically significantly differ depending on management's response to detected fraud.

--Insert Table 29 and Figure 23--

Finally, employee productivity is not statistically significantly related to how upset the employee reported being about the theft or employee participants' belief that managers should hold wrongdoers accountable, refuting hypotheses $4 \mathrm{a}$ and $4 \mathrm{~b}$.

\section{Supplemental Analyses}

\section{Additional Sample}

We collect additional employee participants via Turk Prime $(n=32)$ and assign them to the role of employee 1. Employees in this condition are informed that employee 2 was detected taking from the investment fund in period 1. Like Study Two, we manipulate whether management increased inspections. We compare productivity and the likelihood of taking in period 2 for our new sample to productivity and the likelihood of taking in period 2 from employee participants in our prior sample. Our selection of employee participants from our prior sample met the following criteria: management detected theft in period 1 and the participant is employee 1.

We retest hypotheses two and three using this additional sample. We find that employees are marginally statistically significantly more likely to take from the investment fund in period 2 when fraud is detected and management does not increase inspections, as compared to when fraud is detected and 
management increases inspections (Greenhouse-Geisser $F(1,109)=2.903, p=0.091)$, supporting the retest of H3.

\section{--Insert Figures 24 and 25--}

Our results refute the retest of $\mathrm{H} 2$ as we find that employee productivity does not statistically significantly differ between conditions (e.g. increase $\mathrm{Y} / \mathrm{N}$ ), regardless of whether employee 1 is aware that management detected employee 2. Contrarily, results show that the change in productivity from period 1 to period 2 directionally differs depending on whether management increased inspections for all employees in period 2 and whether management informed employee 1 that employee 2 was detected taking from the investment fund in period 1.

\section{Cluster Analysis of Employee Process Measures}

To evaluate similarities and differences within employee participants, we examine employee participants from both samples using cluster analysis. Clustering is a well-known technique for finding groups in data (Frayley and Raftery 1998) and is helpful in classifying profiles of individuals, based on their responses to questionnaires. Process measures collected from employee participants were grouped into profiles with Ward's method, measuring squared Euclidean distance utilized by Janssens et al. (2003), and k-means clustering (Ketchen and Shook 1996).

We use hierarchical clustering methods with Ward's linkage before partition clustering with kmeans for pragmatic reasons. First, hierarchical clustering builds a dendrogram and an agglomeration

schedule that can be visually inspected to show how similar empathy profiles are and the ranking of clusters based on the a priori validation via EFA of three factors present in the process measures. Second, Ward's linkage performs well with the data set, given that the clusters are similar in sample sizes and number of observations. Third, partition-clustering with k-means requires a priori specification of the 
number of clusters, $\mathrm{k}$, to create distinct non-overlapping groups. The first phase of the hierarchical cluster is calculating the distance between objects with Euclidean distance method and cluster formation.

Cluster analysis shows that employee participants subscribe to one of three profiles related to their affect intensity and their ability to be influenced by others. Specifically, employee participants in cluster 1 exhibit high affect intensity and a high ability to be influenced by their manager or others, while those in cluster 3 have low affect intensity and are unlikely to be influenced by others. Finally, employee participants in cluster 3 have a moderate level of affect intensity but are highly influenced by others. We use these clusters to examine individual variance within employee participants that may contribute to employee participants' productivity levels and/or likelihood of taking from the investment fund. --Insert Figure 26--

We find that employees in cluster 3 differ from other employee participants in both their productivity and their likelihood of taking from the investment fund. Specifically, omnibus repeated ANOVA model (Pillai's trace $F(6,234)=2.973, p=0.008$ ) shows that members of cluster 3 have higher average productivity in period 1 than employee participants in cluster $1(F(2,120)=3.578, p=0.031, t(2)$ $=2.674, p=0.009)$. Similarly, employees in cluster 3 have higher average productivity in period $2(F$ $(2,120)=7.745, p=0.001, t(2)=3.933, p<0.001)$.

--Insert Figures 27 and 28--

Employee participants in cluster 3 are also more likely to take from the investment fund in period 1 but not take in period 2 when fraud is detected, as compared to employee participants in other clusters (Pillai's trace $F(6,234)=2.677, p=0.016$ ). Specifically, members of cluster 3 are less likely to take in period 2 when they took from the investment fund in period 1 than members of cluster $2(t(2)=5.679$, $\left.p=0.004, \mathrm{M}_{\text {Diff }}=0.2283\right)$. These results show the theoretical relevance of affect intensity and social 
desirability to our research question. We will use this information to examine the interplay of coworker relationships and productivity when fraud is detected in future studies.

--Insert Figure 29--

\section{LIMITATIONS AND CONTRIBUTIONS}

This paper includes many limitations. Notably, conditions are not manipulated exogenously, and all independent variables arise endogenously leading to self-selection bias. For example, it is possible that participants' risk-taking preferences will influence employees' decisions to contribute time to company productivity and whether to take from the investment fund or not. Therefore, we conduct supplemental analyses to address endogeneity issues and to test for potential omitted correlated variables, particularly those that may contribute to participants' self-selection into conditions.

Participants' decisions to contribute hours and to take from the investment in period two may be correlated with their decisions in period one. We account for within-participant variance using hierarchical linear modeling to account for carry-over effects and use incremental changes between periods one and two as variables of interest.

We use mTurk participants in our study. mTurkers are a more representative sample of the U.S. workforce than student participants but are experienced experimental participants; however, participants self-select into studies. We monitor for the likelihood that participants communicate with each other, recruit one another, and/or identify our hypotheses by monitoring chatrooms and mTurk worker boards.

Further, our study lacks mundane realism. For example, in a professional setting, managers face confounds and exogenous factors that influence their decisions to investigate allegations of fraud and/or establish policies and procedures to mitigate the risk of future occurrences of fraud. However, we believe that our design provides ecological validity and experimental realism related to our constructs of interest. Specifically, our study isolates the effects of increased inspections on the coworkers of fraud perpetrators. 
Our study contributes to accounting, management controls, fraud, and organizational justice literature by being the first to examine the effects of management's decision to increase controls when

fraud occurs. While prior literature has examined the effects of management controls on the likelihood of fraud prevention or detection, no prior study has considered the spillover effects on the perpetrator's coworkers. Coworkers spend a significant amount of time together and their relationships are an "integral component of the everyday working lives of most people" (Basford and Offermann 2012). Coworker support can influence an individual's satisfaction with both their job and their life in general (Simon, Judge, and Halvorsen-Ganepola 2010). Therefore, the effects of management's decisions on coworkers are empirically important.

Our study also has practical implications by informing management's decision-making when organizations face employee theft. Specifically, our study evaluates the potential risk of non-offending employees' counterproductivity. Management teams need to choose whether and how to spend limited resources responding to fraud, and unintended consequences such as reduced productivity, should be considered as part of those decisions.

\section{CONCLUSION}

Managers use formal controls in response to fraudulent activity but responding in this way can have unintended consequences for the firm through reduced productivity. This study examines the potential negative effects increasing controls has on the perpetrator's coworkers. Our preliminary evaluations of these effects have shown opportunities for us to explore these constructs in other settings. For example, our sample was obtained from Amazon Mechanical Turk which in which participants autonomously interact with a website. Therefore, the setting lacks mundane realism in that participants are not in contact with one another nor are they interacting within a group. Supplemental analyses show that individuals' level emotional intensity and ability to be influenced by others are related to their 
productivity and the likelihood that they will take from the investment fund in period 1, but not in period 2 when fraud is detected. Therefore, it is likely that group social norms and personality traits may affect coworker's affective event response. We continue to pursue our research question: What effect does management's use of controls in response to fraud on coworker's productivity? in future studies. 


\section{TABLES AND FiguRES}

Table 29 Descriptive Statistics and t-Test Results for Differences between Manager Conditions

\begin{tabular}{|c|c|c|c|c|}
\hline Variable & $\begin{array}{l}\text { Increase } \\
\mathrm{M}(\mathrm{SD})\end{array}$ & $\begin{array}{l}\text { No Increase } \\
\mathrm{M}(\mathrm{SD})\end{array}$ & $t$ & $p$ \\
\hline $\begin{array}{l}\text { If you were an employee, how } \\
\text { much would you enjoy being } \\
\text { monitored at work? }\end{array}$ & $\begin{array}{r}2.25 \\
(1.570)\end{array}$ & $\begin{array}{r}1.71 \\
(1.274)\end{array}$ & -2.410 & $0018 * *$ \\
\hline $\begin{array}{l}\text { How powerful of a deterrent } \\
\text { against theft do you think } \\
\text { monitoring is? }\end{array}$ & $\begin{array}{r}5.62 \\
(1.012)\end{array}$ & $\begin{array}{r}4.69 \\
(1.673)\end{array}$ & -2.498 & $0.016 * *$ \\
\hline $\begin{array}{l}\text { It was unfair that a manager was } \\
\text { able to increase inspections for } \\
\text { those who did not take from the } \\
\text { investment fund. }\end{array}$ & $\begin{array}{r}3.41 \\
(1.499)\end{array}$ & $\begin{array}{r}5.00 \\
(1.374)\end{array}$ & 3.317 & $0.001 * * *$ \\
\hline $\begin{array}{l}\text { Increasing monitoring is a fair } \\
\text { way to reduce theft. }\end{array}$ & $\begin{array}{r}5.68 \\
(0.944)\end{array}$ & $\begin{array}{r}4.11 \\
(1.560)\end{array}$ & -3.704 & $0.001 * * *$ \\
\hline $\begin{array}{l}\text { It is important to blame the } \\
\text { employee who took from the } \\
\text { investment count. }\end{array}$ & $\begin{array}{r}4.35 \\
(1.379)\end{array}$ & $\begin{array}{r}3.00 \\
(1.633)\end{array}$ & -2.864 & $0.005 * *$ \\
\hline $\begin{array}{l}\text { Increased inspections achieve } \\
\text { justice for theft in period } 1 .\end{array}$ & $\begin{array}{r}4.24 \\
(1.211)\end{array}$ & $\begin{array}{r}2.47 \\
(1.577)\end{array}$ & -4.480 & $0.000 * * *$ \\
\hline
\end{tabular}


Figure 21 Experimental Design Flowchart

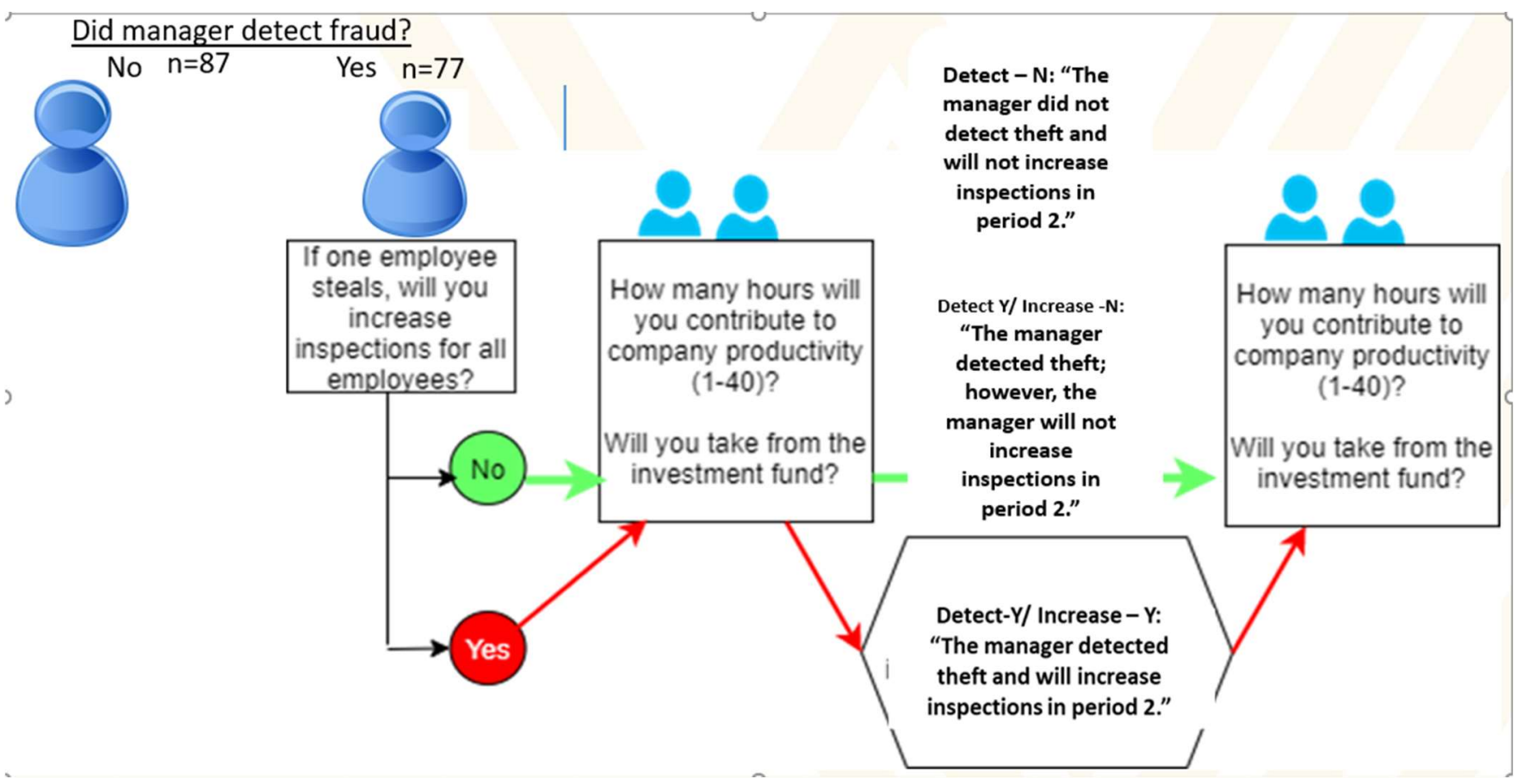

Figure 22 Managers' Perceptions of Fairness toward Employees

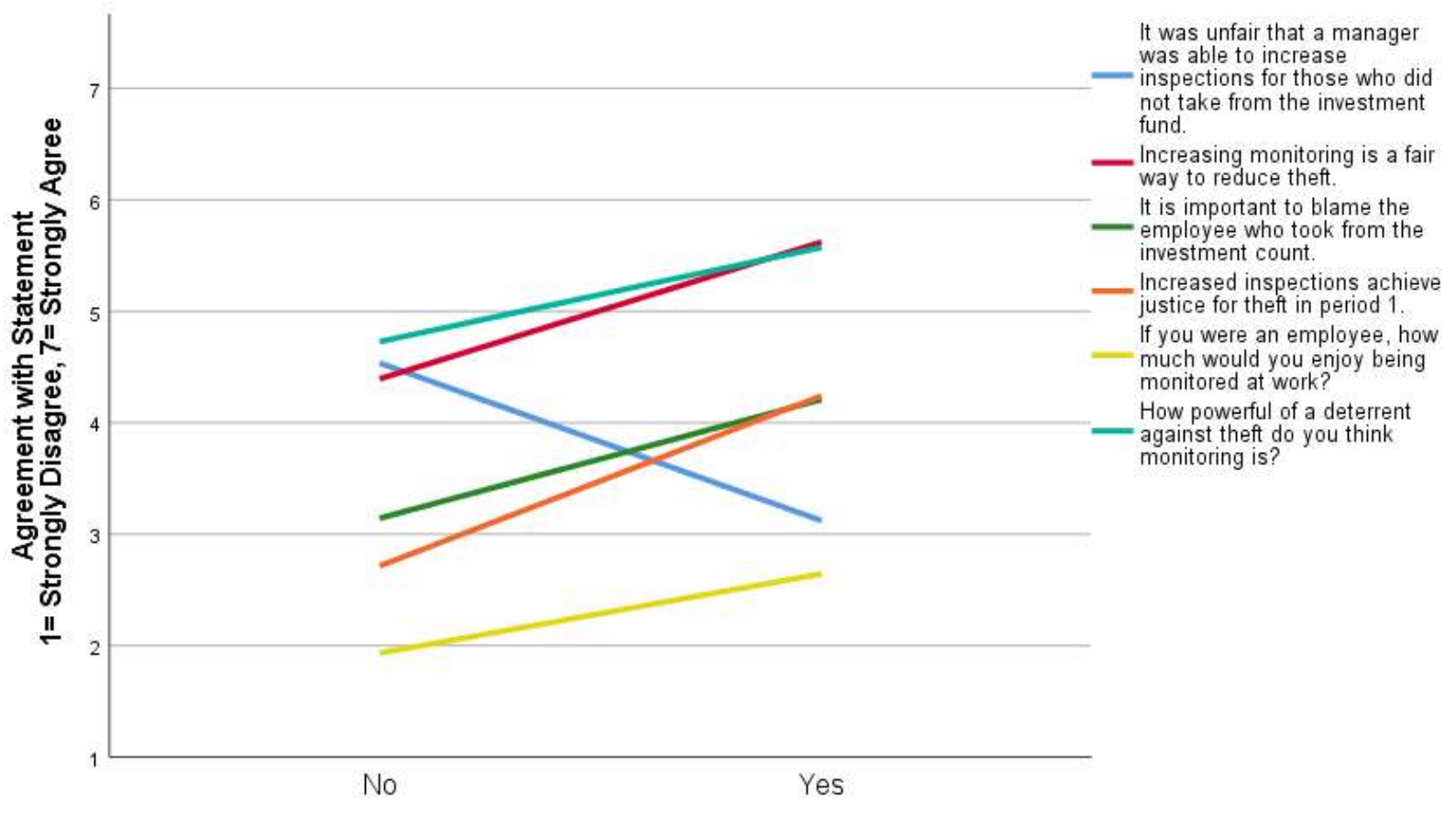

Manager Chose to Increase Inspections in Period 2 for All Employees 
Figure 23 Test H3, Likelihood of Taking from the Investment Fund When Fraud is Detected by Condition

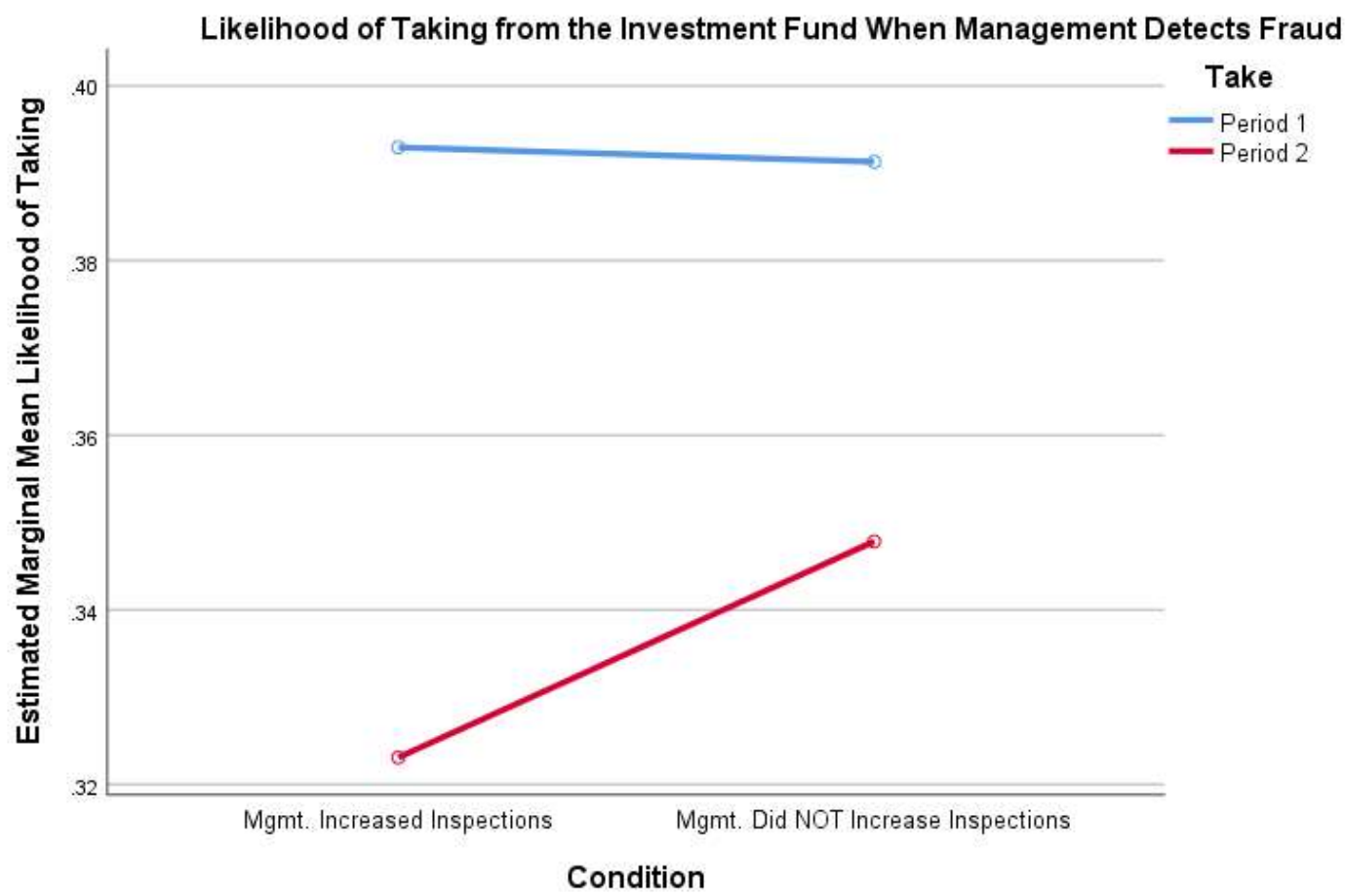

Figure 24 Test of Supplemental H2, Difference in Productivity When Fraud is Detected, by Condition

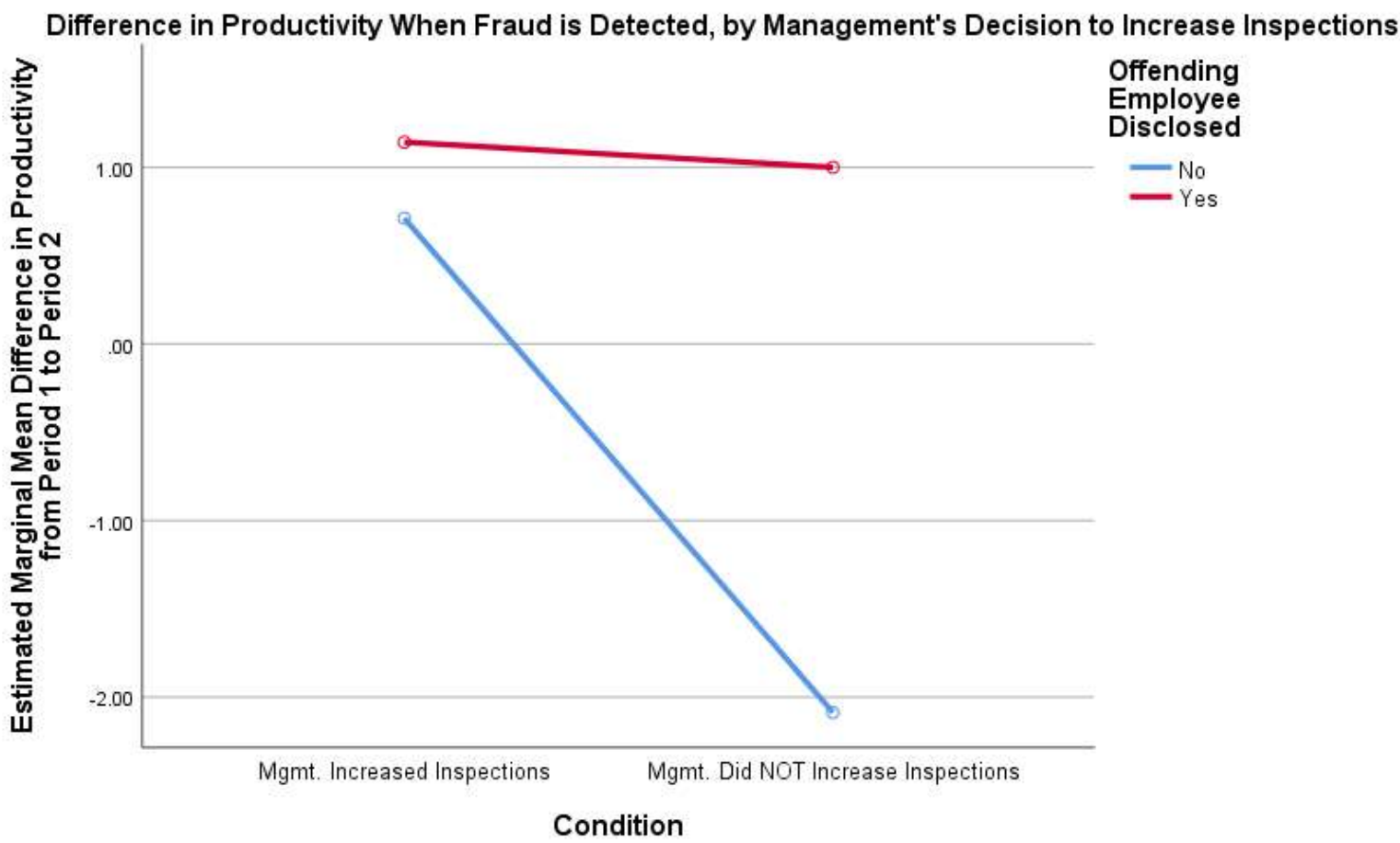


Figure 25 Test of Supplemental H3, Likelihood of Taking from the Investment Account in Period 2 When Fraud is Detected, by Condition

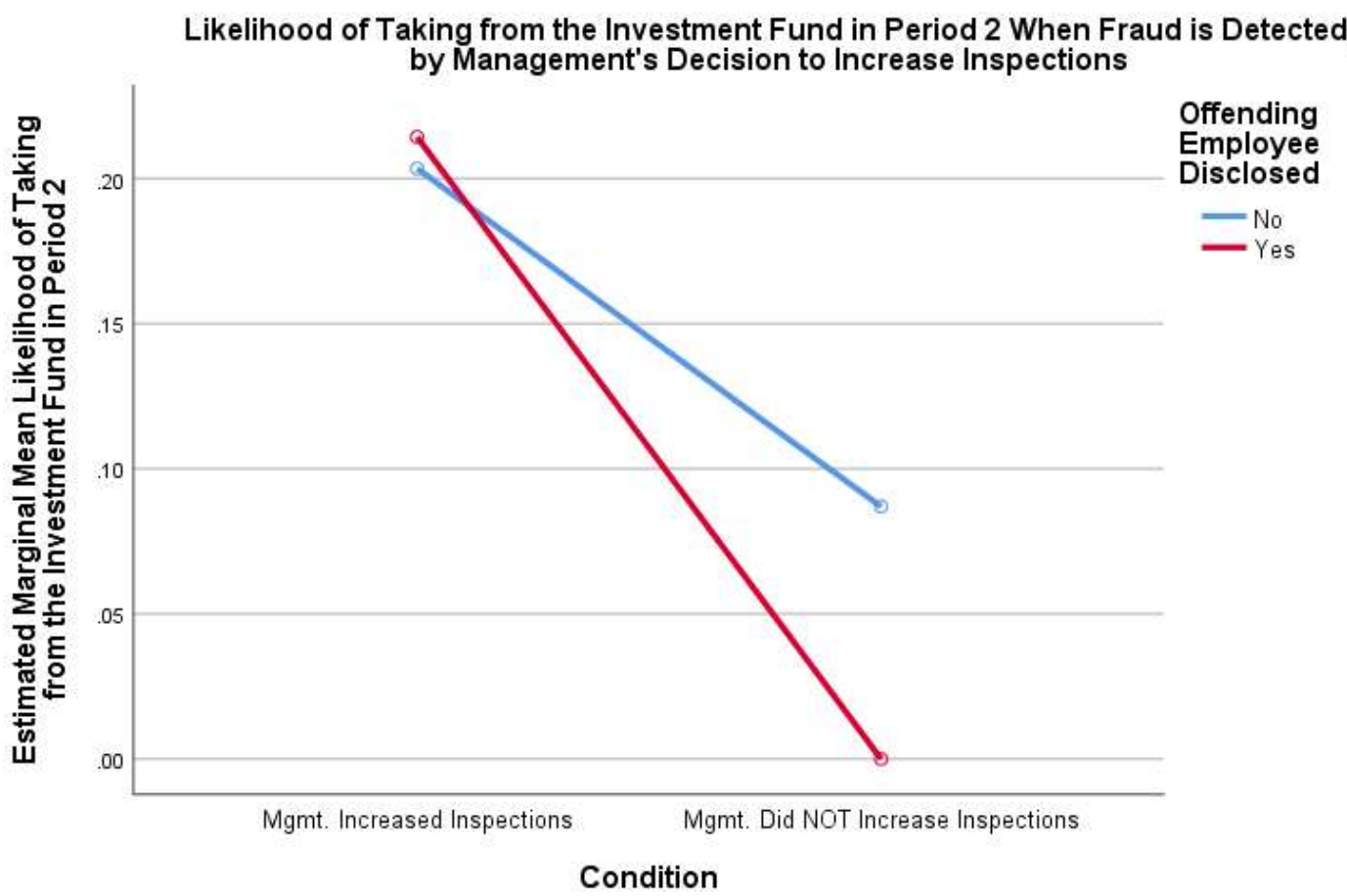

Figure 26 Cluster Analysis of Process Measures for Employee Participants

Cluster Analysis of Employee Participants' Standardized Scores for Process Measures

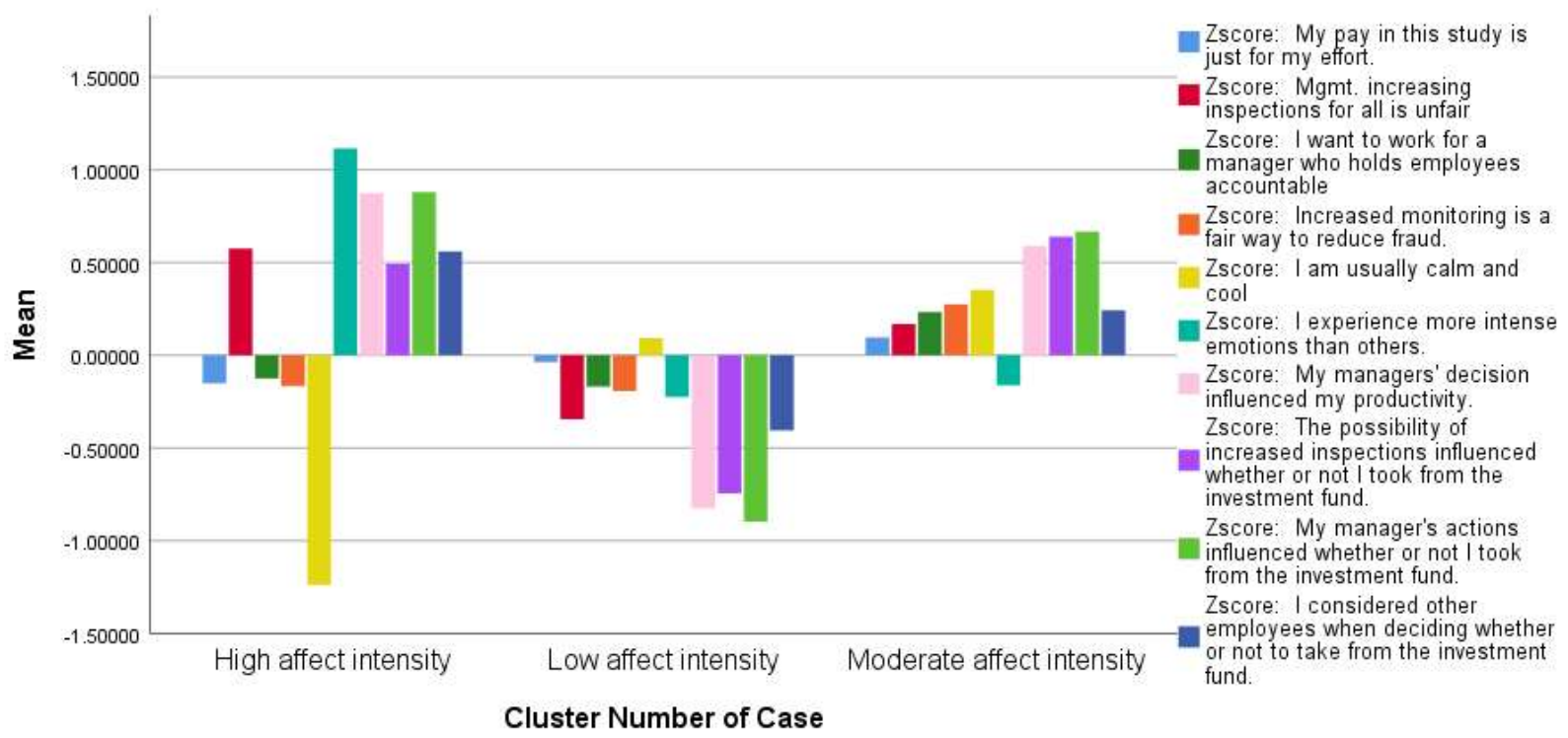


Figure 27 Mean Productivity in Period 1 by Employee Participant Cluster

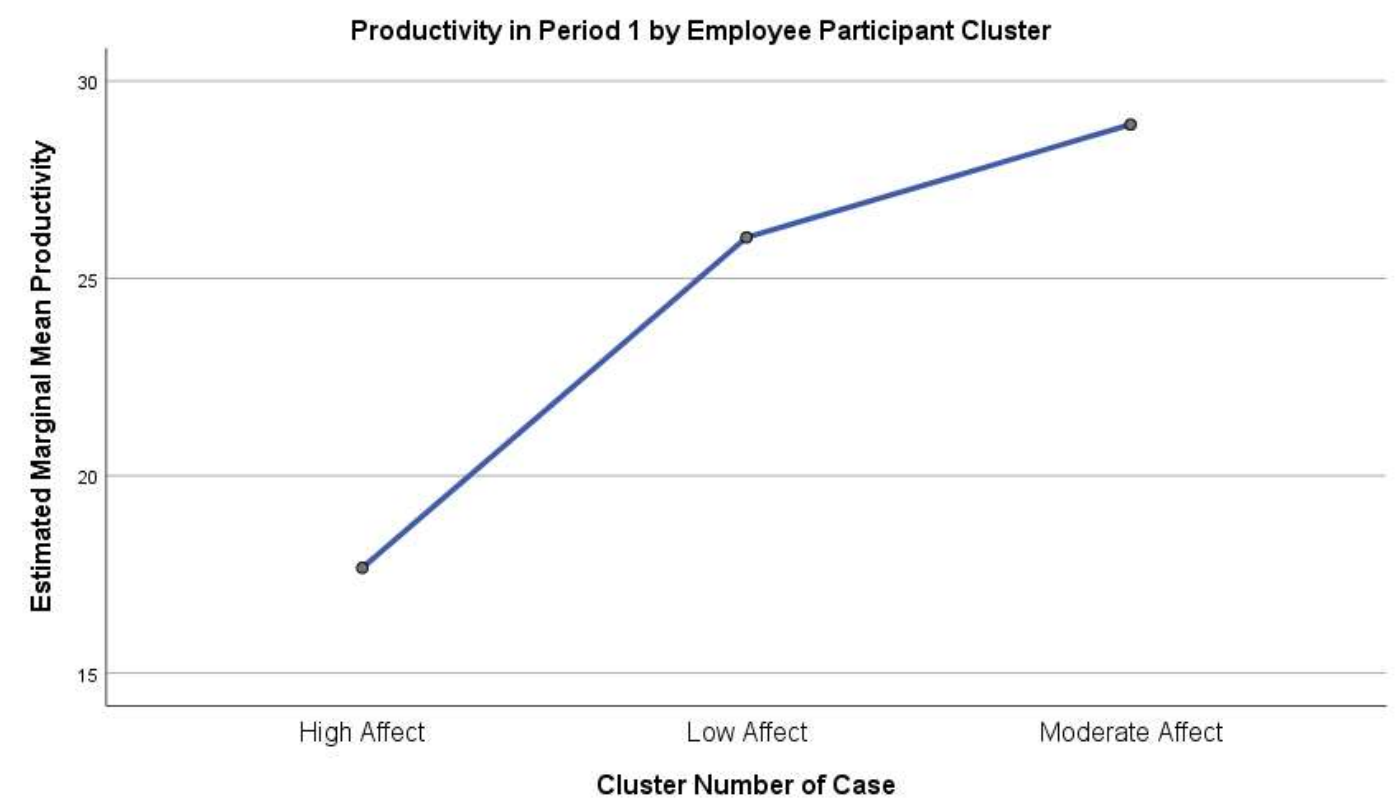

Figure 28 Mean Productivity in Period 2 by Employee Participant Cluster

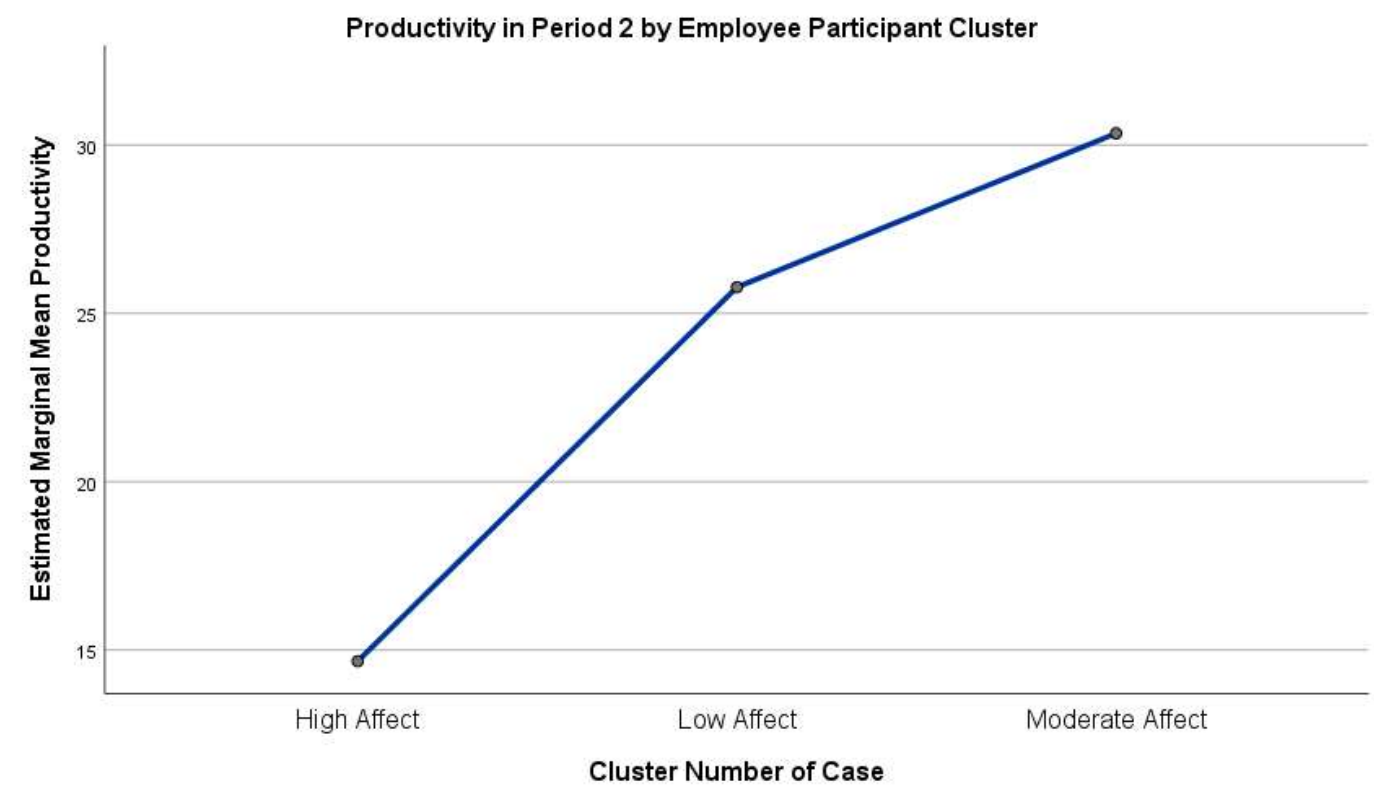


Figure 29 Likelihood of Not Taking in Period 2 by Employee Participant Cluster

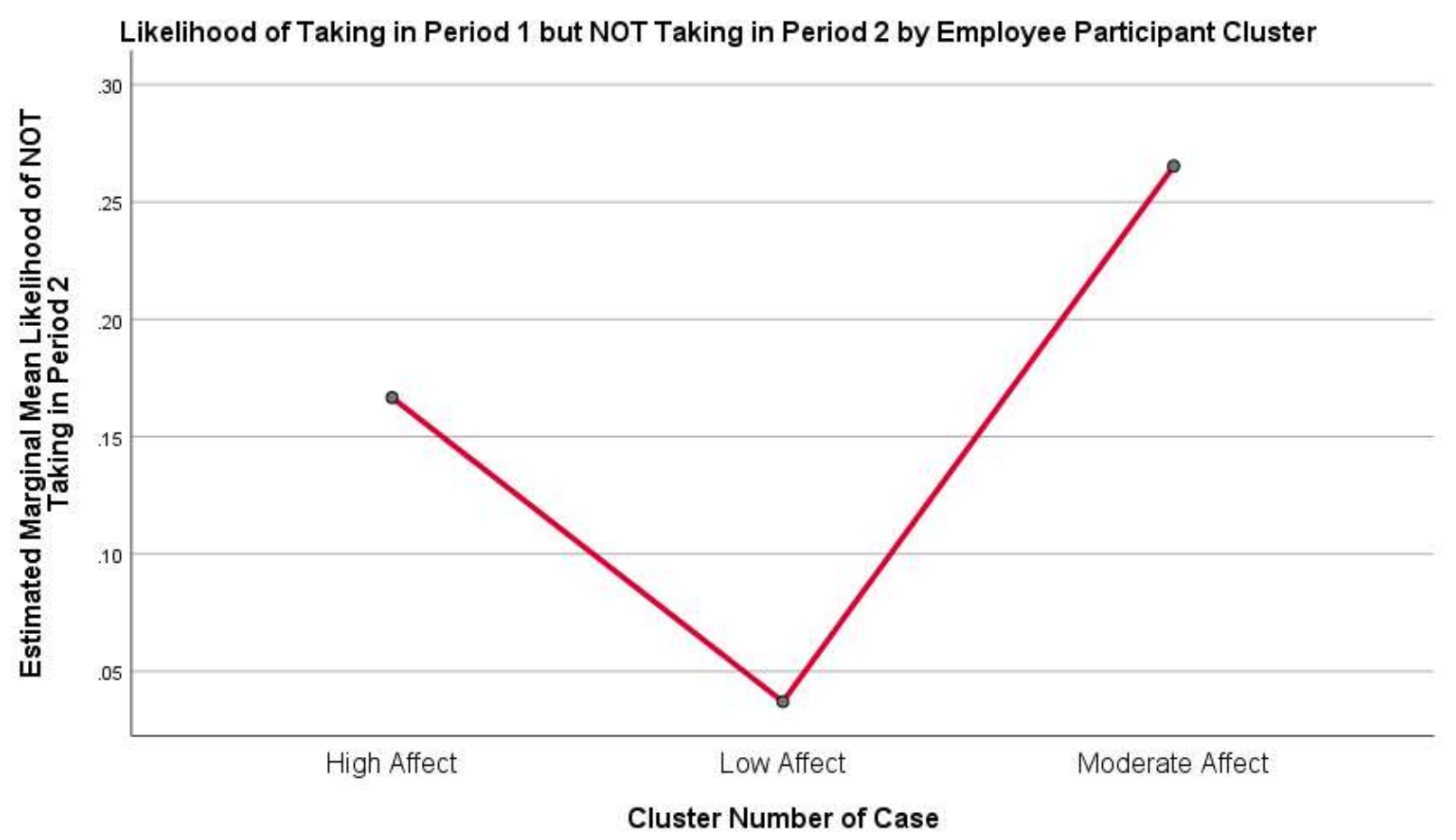




\section{CHAPTER FIVE - CONCLUSION}

This dissertation includes three studies that examine key processes in managing occupational fraud: detecting fraud, assigning punishment to the perpetrator, and evaluating the effects of changes to the management control environment when fraud is detected. Taken together, these studies contribute to the fraud literature by highlighting important nuances in occupational fraud management and the implications that management's decisions regarding fraud have on organizations and their stakeholders (e.g. employees and external regulators). This dissertation provides suggestions for future research, based on the results from each study.

Results of study one show that prompts to identify discrepancies between financial information, a tool commonly used in audit practice to increase focus, may not always be effective. The effectiveness of prompts was found to differ between graduate students and Amazon Mechanical Turk workers. However, these groups differed in the level of cognitive processing they used during the experiment, their familiarity with the manipulations (i.e. emotion regulation strategies), and their years of experience. While graduate students took longer to complete the study, indicating a higher level of cognitive processing, mTurkers were more familiar with the constructs of interest and had more years of work experience. Therefore, future studies should examine whether, when, and how prompts affect fraud detection.

Results of study two show that organizations differ when issuing punishments for occupational fraud. Higher status perpetrators received weaker punishments than lower status perpetrators when their frauds were short in duration. However, as duration increased, higher and lower status perpetrators received similar punishments. This finding aligns with Status Characteristics Theory by showing that perpetrator's status may benefit them, if they rectify their behavior early on. Results further show that publicly traded companies are less likely to formally punish (i.e. pursue no outcome) than to terminate a fraud perpetrator than other organization types, and that nonprofits and governmental organizations are 
more likely to both terminate and prosecute than just terminate fraud perpetrators. Future research may examine how these differences affect organizational fraud risk management, anti-fraud policy development, and workplace deviance.

Results of study three show that affect and one's ability to be influenced by others may affect whether and how fraud perpetrators' coworkers perceive management's response to detected fraud. For example, high affect intensity is correlated with changing one's behavior by taking from the investment fund in period one, but not in period two. Those who report moderate levels of affect intensity are more likely to take from the investment fund in both periods. These results highlight the importance of monitoring affective responses of a fraud perpetrator's coworkers to reduce the likelihood that fraud will occur again. Future studies may further examine whether group dynamics, coworker support systems, or employee engagement tools mitigate the effects of emotional response on workplace deviance.

This dissertation contributes to occupational fraud literature and offers suggestions for future research to answer questions related to fraud detection tools, organizational fraud management, and ways for organizations to mitigate future instances of fraud. 


\section{REFERENCES}

Agrawal, A., and T. Cooper. 2017. Corporate Governance Consequences of Accounting Scandals: Evidence from Top Management, CFO and Auditor Turnover. Quarterly Journal of Finance 07 (01).

Aguinis, H., I. Villamor, and R. S. Ramani. 2021. MTurk Research: Review and Recommendations. Journal of Management 47 (4):823-837.

Albonetti, C. A. 1998. Direct and indirect effects of case complexity, guilty pleas, and offender characteristics on sentencing for offenders convicted of a white-collar offense prior to sentencing guidelines. Journal of Quantitative Criminology 14 (4):353 - 378.

Albonetti, C. A. 1998. The role of gender and departures in the sentencing of defendants convicted of a white-collar offense under the federal sentencing guidelines. Sociology of crime, law, and deviance 1:3-48.

Allen, D., W. G. Heninger, S. L. Summers, and D. A. Wood. 2016. The Effects of Different Types of Internal Controls on Employee Self-Control. SSRN Electronic Journal.

Anderson, A. 2020. Mindfulness: A Promising Practice to Reduce Accountant Stress. Marriott Student Review 3 (4):37.

Anderson, L. M., E. E. Reilly, S. Gorrell, K. Schaumberg, and D. A. Anderson. 2016. Gender-based differential item function for the difficulties in emotion regulation scale. Personality and individual differences 92:87-91.

Antonova, E., K. Schlosser, R. Pandey, and V. Kumari. 2021. Coping with COVID-19: Mindfulnessbased approaches for mitigating mental health crisis. Frontiers in psychiatry 12:322.

Arnulf, J. K., and P. Gottschalk. 2013. Heroic Leaders as White-Collar Criminals: An Empirical Study. Journal of Investigative Psychology and Offender Profiling 10 (1):96-113.

Asare, S. K., and A. M. Wright. 2004. The effectiveness of alternative risk assessment and program planning tools in a fraud setting. Contemporary Accounting Research 21 (2):325-352.

.2012. Investors', auditors', and lenders' understanding of the message conveyed by the standard audit report on the financial statements. Accounting Horizons 26 (2):193-217.

Association of Certified Fraud Examiners (ACFE).1996. Report to the nations on Occupational Fraud.

- 2004. Report to the Nations on Occupational Fraud.

- 2016. Report to the Nations on Occupational Fraud

- 2018. Report to the Nations on Occupational Fraud.

- 2020. Report to the Nations on Occupational Fraud.

B1. 2021. Sr. Manager, Interviewed by M. Rice. January 21, 2021. 
Ball, G. A., L. K. Treviño, and H. P. Sims Jr. 1994. Just and unjust punishment: Influences on subordinate performance and citizenship. Academy of Management journal 37 (2):299-322.

Bandura, A. 1991. Social cognitive theory of self-regulation. Organizational Behavior and Human Decision Processes 50 (2):248-287.

Bannert, M. 2002. Managing cognitive load—recent trends in cognitive load theory. Learning and instruction 12 (1):139-146.

Basford, T. E., and L. R. Offermann. 2012. Beyond leadership: The impact of coworker relationships on employee motivation and intent to stay. Journal of Management and Organization 18 (6):807817.

Baumeister, R. F., and K. D. Vohs. 2016. Strength model of self-regulation as limited resource: Assessment, controversies, update. In Advances in experimental social psychology: Elsevier, 67127.

Becker, G. S. 1968. Crime and punishment; An economic approach. Journal of Political Economy.

Bedau, H. A. 1978. Retribution and the theory of punishment. The Journal of Philosophy 75 (11):601 620.

Bedford, D. S., and T. Malmi. 2015. Configurations of control: An exploratory analysis. Management Accounting Research 27:2-26.

Bedford, D. S., T. Malmi, and M. Sandelin. 2016. Management control effectiveness and strategy: An empirical analysis of packages and systems. Accounting, Organizations and Society 51:12-28.

Bellingtier, J., and S. Neupert. 2017. Comparing Daily Diary Methodologies: mTurk vs. Traditional Approaches. Innovation in Aging 1 (Suppl 1):234.

Belot, M., and M. Schröder. 2013. Sloppy work, lies and theft: A novel experimental design to study counterproductive behaviourtabe. Journal of Economic Behavior and Organization 93:233-238.

Beneish, M. D. 1999. Incentives and Penalties Related to Earnings Overstatements That Violate GAAP. The Accounting Review 74 (4):425 - 457.

Beneish, M. D., C. D. Marshall, and J. Yang. 2017. Explaining CEO retention in misreporting firms. Journal of Financial Economics 123 (3):512-535.

Benson, M. L., and E. Moore. 1992. Are white-collar and common offenders the same? An empirical and theoretical critique of a recently proposed general theory of crime. Journal of Research in Crime and Delinquency 29 (3):251-272. 
Benson, M.L., and T. D. Madensen. 2007. Situational crime prevention and white-collar crime. In International handbook of white-collar and corporate crime (pp. 609-626). Springer, Boston, MA.

Bentley, J. W. 2021. Improving the Statistical Power and Reliability of Research Using Amazon Mechanical Turk: Accounting Horizons. Forthcoming.

Berger, J., B. P. Cohen, and M. Zelditch, Jr. 1971. Status characteristics and social interaction. Technical Report No. 42.

Berger, J., R. Z. Norman, J. W. Balkwell, and R. F. Smith. 1992. Status inconsistencty in task situations: A test of four status processing principles. American Sociological Review 57 (6):843-855.

Bergner, J. M., S. A. Peffer, and R. J. Ramsay. 2016. Concession, contention, and accountability in auditor-client negotiations. Behavioral Research in Accounting 28 (1):15-25.

Berry, K. J., and P. W. Mielke Jr. 1988. A generalization of Cohen's kappa agreement measure to interval measurement and multiple raters. Educational and Psychological Measurement 48 (4):921-933.

Bhaskar, L. S., J. H. Schroeder, and M. L. Shepardson. 2018. Integration of Internal Control and Financial Statement Audits: Are Two Audits Better than One? The Accounting Review 94 (2):5381.

Bishop, S. R., M. Lau, S. Shapiro, L. Carlson, N. D. Anderson, J. Carmody, Z. V. Segal, S. Abbey, M. Speca, and D. Velting. 2004. Mindfulness: A proposed operational definition. Clinical psychology: Science and practice 11 (3):230-241.

Block, R. A., P. A. Hancock, and D. Zakay. 2010. How cognitive load affects duration judgments: A meta-analytic review. Acta psychologica 134 (3):330-343.

Bonanno, G. A., A. Papa, K. Lalande, M. Westphal, and K. Coifman. 2004. The importance of being flexible: The ability to both enhance and suppress emotional expression predicts long-term adjustment. Psychological science 15 (7):482-487.

Bono, J. E., H. J. Foldes, G. Vinson, and J. P. Muros. 2007. Workplace emotions: The role of supervision and leadership. Journal of applied psychology 92 (5):1357.

Bowlin, K. 2011. Risk-based auditing, strategic prompts, and auditor sensitivity to the strategic risk of fraud. The Accounting Review 86 (4):1231-1253.

Bowling, N. A., and M. L. Gruys. 2010. Overlooked issues in the conceptualization and measurement of counterproductive work behavior. Human Resource Management Review 20 (1):54-61.

Boynton, M. H., and L. S. Richman. 2014. An online daily diary study of alcohol use using Amazon's Mechanical Turk. Drug and Alcohol Review 33 (4):456-461. 
Brantingham, P. L., and P. J. Brantingham. 1993. Notes, paths and edges: considerations on the complexity of crime and the physical environment. Journal of Environmental Psychology 13:328.

Brazel, J. F., K. L. Jones, and D. F. Prawitt. 2014. Auditors' reactions to inconsistencies between financial and nonfinancial measures: The interactive effects of fraud risk assessment and a decision prompt. Behavioral Research in Accounting 26 (1):131-156.

Brazel, J. F., K. L. Jones, and M. F. Zimbelman. 2009. Using nonfinancial measures to assess fraud risk. Journal of Accounting Research 47 (5):1135-1166.

Brockman, R., J. Ciarrochi, P. Parker, and T. Kashdan. 2017. Emotion regulation strategies in daily life: Mindfulness, cognitive reappraisal and emotion suppression. Cognitive Behaviour Therapy 46 (2):91-113.

Brooks, G. 2020. Mindfulness in the working world: EY. Available at https://www.ey.com/en_gl/workforce-resources/mindfulness-in-the-working-world. Accessed May 27, 2021.

Brown, K. W., and R. M. Ryan. 2003. The benefits of being present: mindfulness and its role in psychological well-being. Journal of Personality and Social Psychology 84 (4):822.

Brown, K. W., R. M. Ryan, and J. D. Creswell. 2007a. Addressing fundamental questions about mindfulness. Psychological inquiry 18 (4):272-281.

- 2007b. Mindfulness: Theoretical foundations and evidence for its salutary effects. Psychological inquiry 18 (4):211-237.

Buchheit, S., M. M. Doxey, T. Pollard, and S. R. Stinson. 2018. A technical guide to using Amazon's Mechanical Turk in behavioral accounting research. Behavioral Research in Accounting 30 (1):111-122.

Burgoon, J. K., J. A. Bonito, A. Ramirez Jr, N. E. Dunbar, K. Kam, and J. Fischer. 2002. Testing the interactivity principle: Effects of mediation, propinquity, and verbal and nonverbal modalities in interpersonal interaction. Journal of communication 52 (3):657-677.

Bush, M. 2014. What's it like to take Google's mindfulness training? In mindful. Available at https://www.mindful.org/whats-it-like-to-take-googles-mindfulness-training/. Accessed May 27, 2017.

Buss, D. 1993. Ways to curtail employee theft. Nation's Business 81 (4):36-37.

Butler, E. A., F. H. Wilhelm, and J. J. Gross. 2006. Respiratory sinus arrhythmia, emotion, and emotion regulation during social interaction. Psychophysiology 43 (6):612-622.

Butterfield, K. D., L. K. Treviño, and G. A. Ball. 1996. Punishment from the manager's perspective: A grounded investigation and inductive model. Academy of Management Journal 39 (6):14791512. 
C1. 2021. Training Leader, Interviewed by M. Rice. February 16, 2021.

Caldiero, C. T., M. Taylor, and L. Ungureanu. 2009. Image repair tactics and information subsidies during fraud crises. Journal of Public Relations Research 21 (2):218-228.

Cambridge Dictionary. 2020. Poker Face. 2020 Available from https://dictionary.cambridge.org/us/dictionary/english/poker-face. Accessed February 242020.

Cannon, N. H., and D. N. Herda. 2016. Auditors' organizational commitment, burnout, and turnover intention: A replication. Behavioral Research in Accounting 28 (2):69-74.

Carmichael, D. R. 1970. Behavioral hypotheses of internal control. The Accounting Review 45 (2):235245.

Cen, L., J. Chen, S. Dasgupta, and V. Ragunathan. 2021. Do analysts and their employers value access to management? Evidence from earnings conference call participation. Journal of Financial and Quantitative Analysis 56 (3):745-787.

Chambers, R., E. Gullone, and N. B. Allen. 2009. Mindful emotion regulation: An integrative review. Clinical psychology review 29 (6):560-572.

Chang, Y.-T., and D. Stone. 2019. Workplace Mindfulness in Accounting Practice: Issues, Opportunities and Challenges. Accounting Horizons 33(4), 167-185.

Chapman, K. 2018. Earnings notifications, investor attention, and the earnings announcement premium. Journal of accounting and economics 66 (1):222-243.

Chapman, K., G. S. Miller, and H. D. White. 2019. Investor relations and information assimilation. The Accounting Review 94 (2):105-131.

Charoensukmongkol, P., and V. Aumeboonsuke. 2016. Does mindfulness enhance stock trading performance? the moderating and mediating effects of impulse control difficulties. International Journal of Work Organisation and Emotion 7 (4):257-274.

— 2018. The Role of Mindfulness Meditation on Stock Trading Performance. Thammasat Review 21 (1):111-130.

Charron, K. F., and D. J. Lowe. 2008. Skepticism and the Management Accountant: Insights for Fraud Detection. Management Accounting Quarterly 9 (2).

Chen, J., D. Cumming, W. Hou, and E. Lee. 2016. Does the external monitoring effect of financial analysts deter corporate fraud in China? Journal of Business Ethics 134 (4):727-742.

Chen, Y.-J., C.-H. Wu, Y.-M. Chen, H.-Y. Li, and H.-K. Chen. 2017. Enhancement of fraud detection for narratives in annual reports. International Journal of Accounting Information Systems 26:32-45. 
Chenhall, R. H., M. Hall, and D. Smith. 2010. Social capital and management control systems: A study of a non-government organization. Accounting, Organizations and Society 35 (8):737-756.

Christ, M. H. 2013. An experimental investigation of the interactions among intentions, reciprocity, and control. Journal of Management Accounting Research 25 (1):169-197.

Christ, M. H., K. L. Sedatole, K. L. Towry, and M. A. Thomas. 2008. When formal controls undermine trust and cooperation. Strategic finance 89 (7):39.

Christ, M. H., S. A. Emett, S. L. Summers, and D. A. Wood. 2012. The effects of preventive and detective controls on employee performance and motivation. Contemporary Accounting Research 29 (2):432-452.

Citterman, T. 2016. Five Tips to Cultivate A CEO's Poker Face. In Forbes Magazine: Forbes Coaches Council. Available at https://www.forbes.com/sites/forbescoachescouncil/2016/08/26/five-tipsto-cultivate-a-ceos-poker-face/?sh=68032fdce3b3. Accessed May 27, 2021.

City Mental Health Alliance. 2021. Available from https://citymha.org.uk/Membership/Our-Members. Accessed May 25, 2021.

Clark, J. P., R. C. Hollinger, and J. National Institute of. 1983. Theft by employees in work organizations : executive summary. Washington, D.C.: U.S. Dept. of Justice, National Institute of Justice.

Colquitt, J. A., D. E. Conlon, M. J. Wesson, C. O. Porter, and K. Y. Ng. 2001. Justice at the millennium: a meta-analytic review of 25 years of organizational justice research. Journal of applied psychology 86 (3):425.

Connelly, B. L., S. T. Certo, R. D. Ireland, and C. R. Reutzel. 2011. Signaling theory: A review and assessment. Journal of management 37 (1):39-67.

Conversano, C., M. Di Giuseppe, M. Miccoli, R. Ciacchini, A. Gemignani, and G. Orrù. 2020. Mindfulness, age and gender as protective factors against psychological distress during Covid-19 pandemic. Frontiers in psychology 11:1900.

Cote, S., and L. M. Morgan. 2002. A longitudinal analysis of the association between emotion regulation, job satisfaction, and intentions to quit. Journal of Organizational Behavior: The International Journal of Industrial, Occupational and Organizational Psychology and Behavior 23 (8):947-962.

Cropanzano, R., Z. S. Byrne, D. R. Bobocel, and D. E. Rupp. 2001. Moral virtues, fairness heuristics, social entities, and other denizens of organizational justice. Journal of vocational behavior 58 (2):164-209.

Curtis, A. M., A. R. Dennis, and K. O. McNamara. 2017. From monologue to dialogue: performative objects to promote collective mindfulness in computer-mediated team discussions. MIS quarterly 41 (2):559-581. 
Davis, D. M., and J. A. Hayes. 2011. What are the benefits of mindfulness? A practice review of psychotherapy-related research. Psychotherapy 48 (2):198.

Denson, T. F., J. R. Grisham, and M. L. Moulds. 2011. Cognitive reappraisal increases heart rate variability in response to an anger provocation. Motivation and Emotion 35 (1):14-22.

Desai, H., C. E. Hogan, and M. S. Wilkins. 2006. The Reputational Penalty for Aggressive Accounting; Earnings Restatements and Management Turnover. The Accounting Review 81 (1):83-112.

Dilks, L. M. T. M., and S. Marshall. 2018. Need or Greed? The Role of Motivational Attributions on White-Collar Crime Sentencing. Working Paper.

Dilks, L. M., T. S. McGrimmon, and S. R. Thye. 2015. Status, emotional displays, and the relationallybased evaluation of criminals and their behavior. Social Science Research 50:246-263.

Dugan, L., and C. Gibbs.2009. The role of organizational structure in the control of corporate crime and terrorism. In The criminology of white-collar crime (pp. 111-128). Springer, New York, NY.

Dunne, J. 2011. Toward an understanding of non-dual mindfulness. Contemporary Buddhism 12 (1):7188.

Dyck, A., A. Morse, and L. Zingales. 2010. Who blows the whistle on corporate fraud? The Journal of Finance 65 (6):2213-2253.

Eby, L. T., T. D. Allen, K. M. Conley, R. L. Williamson, T. G. Henderson, and V. S. Mancini. 2019. Mindfulness-based training interventions for employees: A qualitative review of the literature. Human Resource Management Review 29 (2):156-178.

Eitle, D. J. 2000. Regulatory Justice: A re-examination of the influence of class position on the punishment of white-collar crime. Justice Quarterly 17 (4).

Endsley, M. R. 1995. Measurement of situation awareness in dynamic systems. Human factors 37 (1):65-84.

Engels, C., K. Kumar, and D. Philip. 2020. Financial literacy and fraud detection. The European Journal of Finance 26 (4-5):420-442.

F1. 2021. CPA, Interviewed by M. Rice. January 21, 2021.

F2. 2021. JD, CPA, Interviewed by M. Rice. February 15, 2021.

Falk, T. 2016. Mindfulness and Work: Keeping a Clear Head. Available at https://news.sap.com/2016/07/keeping-a-clear-head/. Accessed May 27, 2021. 
Fehr, E., and U. Fischbacher. 2004. Third-party punishment and social norms. Evolution and human behavior 25 (2):63-87.

Fiol, C. M., and E. J. O'Connor. 2003. Waking up! Mindfulness in the face of bandwagons. Academy of management review 28 (1):54-70.

Fisher, J. 2020. Training your mind. In WorkWell. Available at WorkWell - Training Your Mind | Deloitte US. Accessed May 27, 2021.

Fleming, A. S., D. R. Hermanson, M.-J. Kranacher, and R. A. Riley. 2016. Financial Reporting Fraud: Public and Private Companies. Journal of Forensic Accounting Research 1 (1):A27-A41.

Folger, R., and R. Cropanzano. 2001. Fairness theory: Justice as accountability. Advances in organizational justice 1:1-55.

Forret, M., and M. Sue Love. 2008. Employee justice perceptions and coworker relationships. Leadership and Organization Development Journal 29 (3):248-260.

Fraser, K., I. Ma, E. Teteris, H. Baxter, B. Wright, and K. McLaughlin. 2012. Emotion, cognitive load and learning outcomes during simulation training. Medical education 46 (11):1055-1062.

Fulford, D., G. Feldman, B. A. Tabak, M. McGillicuddy, and S. L. Johnson. 2013. Positive affect enhances the association of hypomanic personality and cognitive flexibility. International journal of cognitive therapy 6 (1):1-16.

Garrett, B. L. 2015. The Corporate Criminal as Scapegoat. Virginia Law Review 101 (7):1789 - 1854.

Glomb, T. M., M. K. Duffy, J. E. Bono, and T. Yang. 2011. Mindfulness at work. In Research in personnel and human resources management: Emerald Group Publishing Limited, 115-157.

Goguen-Hughes. 2011. Aetna employees being mindful. mindful. Available at https://www.mindful.org/aetna-employees-being-mindful/. Accessed May 27, 2021.

Goldin, P. R., K. McRae, W. Ramel, and J. J. Gross. 2008. The neural bases of emotion regulation: reappraisal and suppression of negative emotion. Biological psychiatry 63 (6):577-586.

Goleman, D. 2001. An EI-based theory of performance. The emotionally intelligent workplace: How to select for, measure, and improve emotional intelligence. In individuals, groups, and organizations 1:27-44.

Gonzalez, M., and G. Byron. 2010. The mindful investor: How a calm mind can bring you inner peace and financial security: John Wiley and Sons.

Good, D. J., C. J. Lyddy, T. M. Glomb, J. E. Bono, K. W. Brown, M. K. Duffy, R. A. Baer, J. A. Brewer, and S. W. Lazar. 2016. Contemplating mindfulness at work: An integrative review. Journal of management 42 (1):114-142. 
Goodman, J. K., C. E. Cryder, and A. Cheema. 2013. Data collection in a flat world: The strengths and weaknesses of Mechanical Turk samples. Journal of Behavioral Decision Making 26 (3):213224.

Gottschalk, P. 2012. White-collar criminals in Norway: An empirical study. International Journal of Law, Crime and Justice 40 (3):211-222.

Grandey, A. A. 2000. Emotional regulation in the workplace: A new way to conceptualize emotional labor. Journal of occupational health psychology 5 (1):95. 2003. When "the show must go on": Surface acting and deep acting as determinants of emotional exhaustion and peer-rated service delivery. Academy of Management Journal 46 (1):86-96.

Grecucci, A., C. Giorgetta, M. Van't Wout, N. Bonini, and A. G. Sanfey. 2013. Reappraising the ultimatum: an fMRI study of emotion regulation and decision making. Cerebral Cortex 23 (2):399-410.

Grecucci, A., E. Pappaianni, R. Siugzdaite, A. Theuninck, and R. Job. 2015. Mindful emotion regulation: Exploring the neurocognitive mechanisms behind mindfulness. BioMed research international 2015.

Greenberg, J. 1987. A taxonomy of organizational justice theories. Academy of Management review 12 (1):9-22.

- 2002. Who stole the money, and when? Individual and situational determinants of employee theft. Organizational Behavior and Human Decision Processes 89 (1):985-1003.

Greenberg, L., and J. Barling. 1996. Employee theft. Journal of Organizational Behavior (19861998):49.

Greenhaus, J. H., K. M. Collins, R. Singh, and S. Parasuraman. 1997. Work and family influences on departure from public accounting. Journal of vocational behavior 50 (2):249-270.

Gross, J. J. 2001. Emotion regulation in adulthood: Timing is everything. Current directions in psychological science 10 (6):214-219.

- 2002. Emotion regulation: Affective, cognitive, and social consequences. Psychophysiology 39 (3):281-291.

- 2013. Handbook of emotion regulation: Guilford publications.

Gross, J. J. 2002. Emotion regulation: Affective, cognitive, and social consequences. Psychophysiology 39 (3):281-291.

Gross, J. J., and R. W. Levenson. 1997. Hiding feelings: the acute effects of inhibiting negative and positive emotion. Journal of abnormal psychology 106 (1):95.

Gross, J. J., J. M. Richards, and O. P. John. 2006. Emotion regulation in everyday life. 
Gyurak, A., J. J. Gross, and A. Etkin. 2011. Explicit and implicit emotion regulation: a dual-process framework. Cognition and emotion 25 (3):400-412.

Haag, J., C. Hofmann, A. Paulus, N. Schwaiger, and T. Sellhorn. 2020. Financial Analysts' Questioning in Conference Calls.Available at https:/www.accounting-for-transparency.de/publication/no-38to-share-or-not-to-share-financial-analysts-questioning-in-conference-calls/. Accessed May 27, 2021.

Hagan, J., and P. Parker. 1985. White-collar crime and punishment: the class structure and legal sanctioning of securities violations. American Sociological Review 50 (3):302-316.

Halperin, E., and J. J. Gross. 2011. Emotion regulation in violent conflict: Reappraisal, hope, and support for humanitarian aid to the opponent in wartime. Cognition and Emotion 25 (7):12281236.

Hammersley, J. S., E. M. Bamber, and T. D. Carpenter. 2010. The influence of documentation specificity and priming on auditors' fraud risk assessments and evidence evaluation decisions. The Accounting Review 85 (2):547-571.

Henle, C. A. 2005. Predicting workplace deviance from the interaction between organizational justice and personality. Journal of Managerial Issues:247-263.

Herda, D. N. 2012. Auditors' relationship with their accounting firm and its effect on burnout, turnover intention, and post-employment citizenship. Current Issues in Auditing 6 (2):P13-P17.

Herda, D. N., and J. J. Lavelle. 2012. The auditor-audit firm relationship and its effect on burnout and turnover intention. Accounting Horizons 26 (4):707-723.

Herda, D. N., N. H. Cannon, and R. F. Young. 2018a. Practitioner Summary: The Effects of Supervisor Coaching and Workplace Mindfulness on Audit Quality-Threatening Behavior among Staff Auditors. Current Issues in Auditing 13 (1): 1-6.

- 2018b. Workplace Mindfulness and its Effect on Staff Auditors' Audit Quality-Threatening Behavior. Behavioral Research in Accounting 31(1): 55-64.

Hermanson, D. R., S. Justice, S. Ramamoorti, and R. A. Riley. 2017. Unique characteristics of predator frauds. Journal of Forensic Accounting Research 2(1): A31-A48.

Hill, W. 2020. How mindfulness in the workplace prevents stress and improves focus: Thomason Reuters. Available at https://tax.thomsonreuters.com/blog/how-mindfulness-in-the-workplaceprevents-stress-and-improves-focus/. Acceessed May 27, 2021.

Hobson, J. L., W. J. Mayew, and M. Venkatachalam. 2012. Analyzing speech to detect financial misreporting. Journal of Accounting Research 50 (2):349-392. 
Hobson, J. L., W. J. Mayew, M. E. Peecher, and M. Venkatachalam. 2017. Improving experienced auditors' detection of deception in CEO narratives. Journal of Accounting Research 55 (5):11371166.

Hollinger, R. C., and J. P. Clark. 1982. Formal and informal social controls of employee deviance. Sociological quarterly 23 (3):333-343.

. 1983. Deterrence in the workplace: Perceived certainty, perceived severity, and employee theft. Social forces 62 (2):398-418.

Hollinger, R., and J. Clark. 1982. Employee deviance: A response to the perceived quality of the work experience. Work and occupations 9 (1):97-114.

Holtfreter, K. 2005. Is occupational fraud "typical" white-collar crime? A comparison of individual and organizational characteristics. Journal of Criminal Justice 33 (4):353-365.

Holtfreter, K., N. L. Piquero, and A. R. Piquero. 2008a. And justice for all? Investigators' perceptions of punishment for fraud perpetrators. Crime, Law and Social Change 49 (5):397-412.

Holtfreter, K., S. Van Slyke, J. Bratton, and M. Gertz. 2008b. Public perceptions of white-collar crime and punishment. Journal of Criminal Justice 36 (1):50-60.

Hülsheger, U. R., A. Walkowiak, and M. S. Thommes. 2018. How can mindfulness be promoted? Workload and recovery experiences as antecedents of daily fluctuations in mindfulness. Journal of occupational and organizational psychology 91 (2):261-284.

Jamieson, S. D., and M. R. Tuckey. 2017. Mindfulness interventions in the workplace: A critique of the current state of the literature. Journal of occupational health psychology 22 (2):180.

Jeung, D.-Y., C. Kim, and S.-J. Chang. 2018. Emotional labor and burnout: A review of the literature. Yonsei medical journal 59 (2):187.

Jiménez-Picón, N., M. Romero-Martín, J. A. Ponce-Blandón, L. Ramirez-Baena, J. C. Palomo-Lara, and J. Gómez-Salgado. 2021. The Relationship between Mindfulness and Emotional Intelligence as a Protective Factor for Healthcare Professionals: Systematic Review. International Journal of Environmental Research and Public Health 18 (10):5491.

Kadous, K., C. A. Proell, J. Rich, and Y. Zhou. 2019. It goes without saying: The effects of intrinsic motivational orientation, leadership emphasis of intrinsic goals, and audit issue ambiguity on speaking up. Contemporary Accounting Research 36 (4):2113-2141.

Kaplan, H. B. 1982. Self-attitudes and deviant behavior: New directions for theory and research. Youth and Society 14 (2):185-211.

Karpoff, J. M., D. Scott Lee, and G. S. Martin. 2008. The consequences to managers for financial misrepresentation. Journal of Financial Economics 88 (2):193-215. 
Katella, K. 2020. Mindfulness: How It Can Help Amid the COVID-19 Pandemic, edited by Yale Medicine. Available at https://www.yalemedicine.org/news/mindfulness-covid/. Accessed May $27,2021$.

Keith, M. G., L. Tay, and P. D. Harms. 2017. Systems perspective of Amazon Mechanical Turk for organizational research: Review and recommendations. Frontiers in psychology 8:1359.

Kelly, L., and M. Dorian. 2017. Doing well and good: an exploration of the role of mindfulness in the entrepreneurial opportunity recognition and evaluation process. New England Journal of Entrepreneurship. Available at https://digitalcommons.sacredheart.edu/cgi/viewcontent.cgi? article=1389\&context=neje. Accessed May 27, 2021.

Kennedy, J. P. 2014. A view from the top: Managers' perspectives on the problem of employee theft in small businesses. University of Cincinnati. Available at http://cech.uc.edu/content/dam/cech/programs/criminaljustice/Docs/Dissertations/kennedyJay.pd f. Accessed April 29, 2018.

Kennedy, J. P. 2014. A View from the Top: Managers' Perspectives on the Problem of Employee Theft in Small Businesses: University of Cincinnati.

Kersemaekers, W., S. Rupprecht, M. Wittmann, C. Tamdjidi, P. Falke, R. Donders, A. Speckens, and N. Kohls. 2018. A workplace mindfulness intervention may be associated with improved psychological well-being and productivity. A preliminary field study in a company setting. Frontiers in psychology 9:195.

Kiken, L. G., E. L. Garland, K. Bluth, O. S. Palsson, and S. A. Gaylord. 2015. From a state to a trait: Trajectories of state mindfulness in meditation during intervention predict changes in trait mindfulness. Personality and individual differences 81:41-46.

Kim, Y., and A. Kogan. 2014. Development of an Anomaly Detection Model for a Bank's Transitory Account System. Journal of Information Systems 28 (1):145-165.

Kimbrough, M. D., and H. Louis. 2011. Voluntary disclosure to influence investor reactions to merger announcements: An examination of conference calls. The Accounting Review 86 (2):637-667.

Koole, S. L. 2009. The psychology of emotion regulation: An integrative review. Cognition and emotion 23 (1):4-41.

KPMG. 2015. Clear Minds make Clever Decisions. Available at https://home.kpmg/xx/en/home/insights/2015/12/clear-minds-make-cleverdecisions.html\#: :text=\%20Clear\%20Minds\%20make\%20Clever\%20Decisions\%20\%201,every $\% 20$ variable\%20into\%20account\%20for\%20every..\%20More\%20. Accessed May 27, 2021.

Kulas, J. T., J. E. McInnerney, R. F. DeMuth, and V. Jadwinski. 2007. Employee satisfaction and theft: Testing climate perceptions as a mediator. The Journal of Psychology 141 (4):389-402. 
Larsen, R. J., and E. Diener. 1987. Affect intensity as an individual difference characteristic: A review. Journal of Research in personality 21 (1):1-39.

Lau, Y. 2020. Increasing Mindfulness in the Workplace. In Forbes Magazine. Available at https://www.forbes.com/sites/forbeshumanresourcescouncil/2020/10/05/increasing-mindfulnessin-the-workplace/?sh=f054ae76956a. Accessed May 27, 2021.

Le, B. M., and E. A. Impett. 2013. When holding back helps: Suppressing negative emotions during sacrifice feels authentic and is beneficial for highly interdependent people. Psychological science 24 (9):1809-1815.

Lee, K., and N. J. Allen. 2002. Organizational citizenship behavior and workplace deviance: The role of affect and cognitions. Journal of applied psychology 87 (1):131.

Leiby, J., K. M. Rennekamp, and K. T. Trotman. 2021. Challenges to experimental audit JDM research and the role of online platforms in resolving these challenges. Auditing: A Journal of Practice and Theory. Forthcoming.

Leventhal, G. S. 1980. What should be done with equity theory? In Social exchange: Springer, 27-55.

Lipman, M., and W. McGraw. 1988. Employee theft: A \$40 billion industry. The Annals of the American Academy of Political and Social Science 498 (1):51-59.

Litzky, B. E., K. A. Eddleston, and D. L. Kidder. 2006. The good, the bad, and the misguided: How managers inadvertently encourage deviant behaviors. Academy of management perspectives 20 (1):91-103.

Liu, L., F. Margoni, Y. He, and H. Liu. 2021. Neural substrates of the interplay between cognitive load and emotional involvement in bilingual decision making. Neuropsychologia 151:107721.

MacKenzie, M. J., and R. F. Baumeister. 2015. Self-regulatory strength and mindfulness. In Handbook of mindfulness and self-regulation: Springer, 95-105.

Marasi, S., R. J. Bennett, and H. Budden. 2018. The Structure of an Organization: Does It Influence Workplace Deviance and Its' Dimensions? And to What Extent? Journal of Managerial Issues 30 (1).

Marcus, B., H. Schuler, P. Quell, and G. Hümpfner. 2002. Measuring counterproductivity: Development and initial validation of a German self - report questionnaire. International Journal of selection and assessment $10(1-2): 18-35$.

Martinko, M. J., M. J. Gundlach, and S. C. Douglas. 2002. Toward an integrative theory of counterproductive workplace behavior: A causal reasoning perspective. International Journal of selection and assessment $10(1-2): 36-50$. 
Mason, L., S. Scrimin, S. Zaccoletti, M. C. Tornatora, and T. Goetz. 2018. Webpage reading: Psychophysiological correlates of emotional arousal and regulation predict multiple-text comprehension. Computers in Human Behavior 87:317-326.

Matsumoto, D., M. Pronk, and E. Roelofsen. 2011. What makes conference calls useful? The information content of managers' presentations and analysts' discussion sessions. The Accounting Review 86 (4):1383-1414.

Matthews, G., M. Zeidner, and R. D. Roberts. 2004. Emotional intelligence: Science and myth: MIT press.

Mauss, I. B., and M. D. Robinson. 2010. Measures of emotion: A review: Psychology Press.

Mauss, I. B., C. L. Cook, J. Y. Cheng, and J. J. Gross. 2007. Individual differences in cognitive reappraisal: Experiential and physiological responses to an anger provocation. International Journal of Psychophysiology 66 (2):116-124.

Mayew, W. J., M. Sethuraman, and M. Venkatachalam. 2020. Individual Analysts' Stock Recommendations, Earnings Forecasts, and the Informativeness of Conference Call Question and Answer Sessions. The Accounting Review 95 (6):311-337.

McGrimmon, T. S., L. M. Dilks, and M. Schmidt. 2018. White-collar crime and the reverse status liability hypothesis. Working Paper.

McRae, K., K. N. Ochsner, I. B. Mauss, J. J. Gabrieli, and J. J. Gross. 2008. Gender differences in emotion regulation: An fMRI study of cognitive reappraisal. Group processes and intergroup relations 11 (2):143-162.

McRae, K., S. E. Jacobs, R. D. Ray, O. P. John, and J. J. Gross. 2012. Individual differences in reappraisal ability: Links to reappraisal frequency, well-being, and cognitive control. Journal of Research in personality 46 (1):2-7.

Melamed, D. 2011. Graded status characteristics and expectation states. Advances in group processes 28 (1):1-31.

Merchant, K. A., and D. T. Otley. 2006. A review of the literature on control and accountability. Handbook of management accounting research 2:785-802.

Mo, S., and J. Shi. 2017. Linking ethical leadership to employee burnout, workplace deviance and performance: Testing the mediating roles of trust in leader and surface acting. Journal of Business Ethics 144 (2):293-303.

Moore, S. 2016. Mental health and stress in accountancy: Institute of Chartered Accountants in England and Wales. Available at https://www.icaew.com/library/news/its-all-in-the-mindfulness/mentalhealth-and-stress-in-accountancy. Accessed May 27, 2021. 
Mustaine, E. E., and R. Tewksbury. 2002. Workplace theft: An analysis of student-employee offenders and job attributes. American Journal of Criminal Justice 27 (1):111-127.

NF1. 2021. Sr. Manager, Interviewed by M. Rice. January 27, 2021.

NF2. 2021. Manager, Interviewed by M. Rice. January 27, 2021.

NF3. 2021. Program Manager, Interviewed by M. Rice. February 12, 2021.

Ng, E. C. 2018. Mindfulness and Buddhist economics in the financial market-generating Delta or Alpha? Society and Economy 40 (4):515-529.

Niedermeier, K. E., I. A. Horowitz, and N. L. Kerr. 2001. Exceptions to the Rule: The Effects of Remorse, Status, and Gender on Decision Making 1. Journal of Applied Social Psychology 31 (3):604-623.

Nolen-Hoeksema, S. 2012. Emotion regulation and psychopathology: The role of gender. Annual review of clinical psychology 8:161-187.

Ochsner, K. N., and J. J. Gross. 2005. The cognitive control of emotion. Trends in cognitive sciences 9 (5):242-249.

Ohira, H., M. Nomura, N. Ichikawa, T. Isowa, T. Iidaka, A. Sato, S. Fukuyama, T. Nakajima, and J. Yamada. 2006. Association of neural and physiological responses during voluntary emotion suppression. Neuroimage 29 (3):721-733.

Parilla, P. F., R. C. Hollinger, and J. P. Clark. 1988. Organizational control of deviant behavior: The case of employee theft. Social Science Quarterly 69 (2):261.

Parker, R. J., and J. M. Kohlmeyer Iii. 2005. Organizational justice and turnover in public accounting firms: A research note. Accounting, Organizations and Society 30 (4):357-369.

Peer, E., L. Brandimarte, S. Samat, and A. Acquisti. 2017. Beyond the Turk: Alternative platforms for crowdsourcing behavioral research. Journal of Experimental Social Psychology 70:153-163.

Penney, L. M., and P. E. Spector. 2005. Job stress, incivility, and counterproductive work behavior (CWB): The moderating role of negative affectivity. Journal of Organizational Behavior: The International Journal of Industrial, Occupational and Organizational Psychology and Behavior 26 (7):777-796.

Persellin, J. S., J. J. Schmidt, S. D. Vandervelde, and M. S. Wilkins. 2019. Auditor perceptions of audit workloads, audit quality, and job satisfaction. Accounting Horizons 33 (4):95-117.

Petty, R. E., and J. T. Cacioppo. 1986. The elaboration likelihood model of persuasion. In Communication and persuasion: Springer, 1-24. 
Purda, L., and D. Skillicorn. 2015. Accounting variables, deception, and a bag of words: Assessing the tools of fraud detection. Contemporary Accounting Research 32 (3):1193-1223.

PwC. 2021. Ways of working 2019. Available from

https://www.pwc.com/my/en/publications/2019/pwc-annual-report-2019/attractive-place-towork/enhance-value-proposition-for-our-people/ways-of-working.html. Accessed May 272021.

Rae, K., and N. Subramaniam. 2008. Quality of internal control procedures. Managerial Auditing Journal 23 (2):104-124.

.2008. Quality of internal control procedures: Antecedents and moderating effect on organisational justice and employee fraud. Managerial Auditing Journal 23 (2):104-124.

Reb, J., J. Narayanan, and Z. W. Ho. 2015. Mindfulness at work: Antecedents and consequences of employee awareness and absent-mindedness. Mindfulness 6 (1):111-122.

Richards, J. M., and J. J. Gross. 2000. Emotion regulation and memory: the cognitive costs of keeping one's cool. Journal of Personality and Social Psychology 79 (3):410.

Ridgeway, C. 1991. The social construction of status value: Gender and other nominal characteristics. Social Forces, 70(2), 367-386.

Ridgeway, C.L. 2001. Gender, status, and leadership. Journal of Social issues, 57(4), 637-655.

Rimé, B. 2007. Interpersonal emotion regulation. Handbook of emotion regulation 1:466-468.

Roberts, A., and C. J. Lyons. 2009. Victim-Offender Racial Dyads and Clearance of Lethal and Nonlethal Assault. Journal of Research in Crime and Delinquency 46 (3):301-326.

Robinson, S. L., and J. Greenberg. 1998. Employees behaving badly: Dimensions, determinants and dilemmas in the study of workplace deviance. Journal of Organizational Behavior (19861998):1.

Robinson, S. L., and R. J. Bennett. 1995. A typology of deviant workplace behaviors: A multidimensional scaling study. Academy of management journal 38 (2):555-572.

Robinson, S.L., W. Wang, and C. Kiewitz, 2014. Coworkers behaving badly: The impact of coworker deviant behavior upon individual employees. Annu. Rev. Organ. Psychol. Organ. Behav., 1(1), pp.123-143.

Roelle, J., C. Nowitzki, and K. Berthold. 2017. Do cognitive and metacognitive processes set the stage for each other? Learning and instruction 50:54-64.

Rosenblatt, Z., and O. Shapira-Lishchinsky. 2016. A Re-examination of the Withdrawal Syndrome vis-àvis Organizational Ethics in Schools. In Crime and Corruption in Organizations: Routledge, 207-232. 
Rosoff, S. M. 1989. Physicians as criminal defendants: Specialty, sanctions, and status liability. Law and Human Behavior 13 (2):231.

Roxana, A.-C. 2013. Antecedents and mediators of employees' counterproductive work behavior and intentions to quit. Procedia-Social and Behavioral Sciences 84:219-224.

Sapienza, B. 2021. Amazon introduces 'ZenBooths; for warehouse workers. In NY Daily News. Available at https://www.vice.com/en/article/wx5nmw/amazon-introduces-tiny-zenbooths-forstressed-out-warehouse-workers/. Accessed May 27, 2021.

Saricali, M., S. A. Satici, B. Satici, E. Gocet-Tekin, and M. D. Griffiths. 2020. Fear of COVID-19, mindfulness, humor, and hopelessness: a multiple mediation analysis. International Journal of Mental Health and Addiction:1-14.

Schaufenbuel, K. 2014. Bringing mindfulness to the workplace. UNC Kenan-Flagier Business School:113. Available at http://execdev.kenanflagler.unc.edu/hubfs/White\%20Papers/Bringing\%20Mindfulness\%20to\%20the\%20Workplace_f inal.pdf/ Accessed May 27, 2021.

Schimmack, U., and E. Diener. 1997. Affect intensity: Separating intensity and frequency in repeatedly measured affect. Journal of Personality and Social Psychology 73 (6):1313.

Schmeichel, B. J. 2007. Attention control, memory updating, and emotion regulation temporarily reduce the capacity for executive control. Journal of Experimental Psychology: General 136 (2):241.

Schmidtke, J. M. 2007. The relationship between social norm consensus, perceived similarity, and observer reactions to coworker theft. Human Resource Management: Published in Cooperation with the School of Business Administration, The University of Michigan and in alliance with the Society of Human Resources Management 46 (4):561-582.

Schroeder, J. H., and M. L. Shepardson. 2015. Do SOX 404 control audits and management assessments improve overall internal control system quality? The Accounting Review 91 (5):1513-1541.

Selva, J. 2019. History of mindfulness: from east to west and religion to science. Positive Psychology. Available at https://positivepsychology.com/history-of-mindfulness/. Accessed May 27, 2021.

Seppälä, E. 2017. How meditation benefits CEOs. Harvard Business Review. https://hbr. org/2015/12/how-meditation-benefits-CEOs/. Accessed May 27, 2021.

Shapiro, S. L., and G. E. Schwartz. 2000. The role of intention in self-regulation: Toward intentional systemic mindfulness. In Handbook of self-regulation: Elsevier, 253-273.

Shefrin, H. 2008. A behavioral approach to asset pricing: Elsevier.

Sheppes, G., S. Scheibe, G. Suri, P. Radu, J. Blechert, and J. J. Gross. 2014. Emotion regulation choice: a conceptual framework and supporting evidence. Journal of Experimental Psychology: General 143 (1):163. 
Simon, L. S., Judge, T. A., and Halvorsen-Ganepola, M. D. (2010). In good company? A multi-study, multi-level investigation of the effects of coworker relationships on employee well-being. Journal of Vocational Behavior, 76(3), 534-546.

Skarlicki, D. P., and C. T. Kulik. 2004. Third-party reactions to employee (mis) treatment: A justice perspective. Research in organizational behavior 26:183-229.

Skolnick, P. and J. Shaw. 1994. Is defendant status a liability or a shield? Crime severity and professional relatedness. Journal of Applied Social Psychology, 24(20), 1827-1836.

Smith, T. E., K. V. Richards, and V. M. Shelton. 2016. Mindfulness in financial literacy. Journal of Human Behavior in the Social Environment 26 (2):154-161.

Snyder, N. H., and K. E. Blair. 1989. Dealing with employee theft. Business Horizons 32 (3):27-35.

Sollitto, M., and S. A. Myers. 2015. Peer coworker relationships: Influences on the expression of lateral dissent. Communication Reports 28 (1):36-47.

Spence, M. 1978. Job market signaling. In Uncertainty in Economics: Elsevier, 281-306.

Sripada, R. K., C. E. Marx, A. P. King, J. C. Rampton, S. S. Ho, and I. Liberzon. 2013. Allopregnanolone elevations following pregnenolone administration are associated with enhanced activation of emotion regulation neurocircuits. Biological psychiatry 73 (11):10451053.

Stanley, S., R. E. Purser, and N. N. Singh. 2018. Ethical foundations of mindfulness. In Handbook of Ethical Foundations of Mindfulness: Springer, 1-29.

Stone, D. 2011. Cultivating financial mindfulness: A dual-process theory. In Consumer Knowledge and Financial Decisions: Springer, 15-27.

Sutcliffe, K. M., T. J. Vogus, and E. Dane. 2016. Mindfulness in organizations: A cross-level review. Annual Review of Organizational Psychology and Organizational Behavior 3:55-81.

Sweeney, B., and B. Pierce. 2006. Good hours, bad hours and auditors' defence mechanisms in audit firms. Accounting, Auditing and Accountability Journal 19 (6); 858-892.

Sweller, J. 2011. Cognitive load theory. In Psychology of learning and motivation: Elsevier, 37-76.

Thatcher, J. B., R. T. Wright, H. Sun, T. J. Zagenczyk, and R. Klein. 2018. Mindfulness in information technology use: Definitions, distinctions, and a new measure. MIS quarterly 42 (3):831-847.

Thompson, L., V. H. Medvec, V. Seiden, and S. Kopelman. 2001. Poker face, smiley face, and rant 'n'rave: Myths and realities about emotion in negotiation. Blackwell handbook of social psychology: Group processes:139-163. 
Tillman, R., and H. N. Pontell. 1992. Is justice "collar-blind"?: Punishing Medicaid provider fraud. Criminology 30 (4).

Tomlinson, E. C., and J. Greenberg. 2007. 17 Understanding and deterring employee theft with organizational justice. Research companion to the dysfunctional workplace: Management challenges and symptoms:285.

Totterdell, P., M. S. Hershcovis, K. Niven, T. C. Reich, and C. Stride. 2012. Can employees be emotionally drained by witnessing unpleasant interactions between coworkers? A diary study of induced emotion regulation. Work and Stress 26 (2):112-129.

Townsley, M., and D. J. Birks. 2008. Building better crime simulations: systematic replication and the introduction of incremental complexity. Journal of Experimental Criminology 4 (3):309-333.

Treviño, L. K. 1992. Moral reasoning and business ethics: Implications for research, education, and management. Journal of Business Ethics 11 (5-6):445-459.

Trincas, R., E. Bilotta, and F. Mancini. 2016. Specific beliefs about emotions are associated with different emotion-regulation strategies. Psychology 7 (13):1682.

Trotman, K. T., and W. F. Wright. 2012. Triangulation of audit evidence in fraud risk assessments. Accounting, Organizations and Society 37 (1):41-53.

Troy, A. S., A. J. Shallcross, and I. B. Mauss. 2013. A person-by-situation approach to emotion regulation: Cognitive reappraisal can either help or hurt, depending on the context. Psychological science 24 (12):2505-2514.

Turillo, C. J., R. Folger, J. J. Lavelle, E. E. Umphress, and J. O. Gee. 2002. Is virtue its own reward? Self-sacrificial decisions for the sake of fairness. Organizational Behavior and Human Decision Processes 89 (1):839-865.

Unsworth, N., and G. J. Spillers. 2010. Working memory capacity: Attention control, secondary memory, or both? A direct test of the dual-component model. Journal of Memory and Language. $62(4): 392-406$

Van den Bos, K., and E. A. Lind. 2002. Uncertainty management by means of fairness judgments. In Advances in experimental social psychology: Elsevier, 1-60.

van Prooijen, J.-W., and J. Lam. 2007. Retributive justice and social categorizations: the perceived fairness of punishment depends on intergroup status. European Journal of Social Psychology 37 (6):1244-1255.

Vetter, A. 2020. 4 Ways CPAs Can Manage Their Stress: Accountants Who Invest in a Sound Mind and Body Can Reap Dividends at Work. Journal of Accountancy 229 (1):22. 
Vinten, G., E. A. Payne, and R. J. Ramsay. 2005. Fraud risk assessments and auditors' professional skepticism. Managerial Auditing Journal 20(3): 321-330.

Waldron, V. R., and K. J. Krone. 1991. The experience and expression of emotion in the workplace: A study of a corrections organization. Management Communication Quarterly 4 (3):287-309.

Webster Jr, M., and J. E. Driskell Jr. 1978. Status generalization: A review and some new data. American Sociological Review, 220-236.

Weisburd, D., E. Waring, and S. Wheeler. 1990. Class, status and the punishment of white-collar criminals. Law and Social Inquiry 15 (2):223 - 243.

Weiss, H. M., and R. Cropanzano. 1996. Affective events theory: A theoretical discussion of the structure, causes and consequences of affective experiences at work. Research in organizational behavior: An annual series of analytical essays and critical reviews, Vol.18.

Wheeler, S., D. Weisburd, E. Waring, and N. Bode. 1987. White collar crimes and criminals. American Criminal Law Review. 25:331.

Wheeler, S., D. Weisburd, E. Waring, and N. Bode. 1988. White collar crimes and criminals. American Criminal Law Review 258:331 - 357.

Wiggins, J. A., F. Dill, and R. D. Schwartz. 1965. On" Status Liability". Sociometry: 197-209.

Wilkins, J. 2014. The use of cognitive reappraisal and humour as coping strategies for bullied nurses. International Journal of Nursing Practice 20 (3):283-292.

Wolfgang, M. E., R. M. Figlio, P. E. Tracy, and S. I. Singer. 1985. The national survey of crime severity. Washington, DC: US Government Printing Office.

Wong, E., F. Tschan, L. Messerli, and N. K. Semmer. 2013. Expressing and amplifying positive emotions facilitate goal attainment in workplace interactions. Frontiers in psychology 4:188.

YouTube. Mindfulness 2020 Available from https://www.youtube.com/results?search_query=mindfulness. Accessed May 27, 2021.

Zaki, J., and W. C. Williams. 2013. Interpersonal emotion regulation. Emotion 13 (5):803.

Zlomke, K. R., and K. S. Hahn. 2010. Cognitive emotion regulation strategies: Gender differences and associations to worry. Personality and individual differences 48 (4):408-413.48 (4):408-413. 